\title{
SMARTER \\ IMAGING MANAGEMENT \\ OPERATIONS MANAGEMENT \\ FOR RADIOLOGY
}

Jasper van Sambeek 


\section{SMARTER IMAGING MANAGEMENT}

OPERATIONS MANAGEMENT FOR RADIOLOGY

Jasper van Sambeek

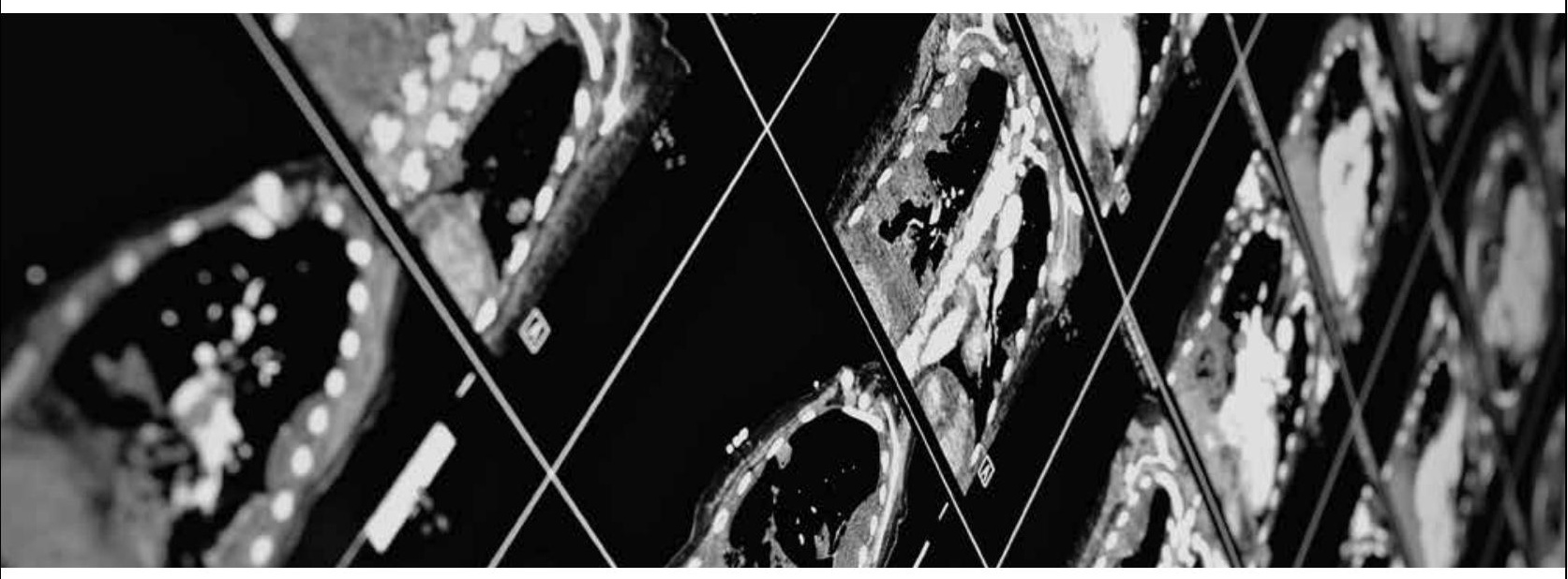




\section{Graduation Committee}

Chairman \& secretary: Prof. dr. T.A.J. Toonen

University of Twente, Enschede, the Netherlands

Promotors:

Prof. dr. ir. J.J. Krabbendam

University of Twente, Enschede, the Netherlands Prof. dr. ir. E.W. Hans

University of Twente, Enschede, the Netherlands

Members:

Prof. dr. W. van Harten

University of Twente, Enschede, the Netherlands

Prof. dr. W.H.M. Zijm

University of Twente, Enschede, the Netherlands

Prof. dr. A. Fitzgerald

Griffith University, Australia

Prof. dr. M.S. Lavieri

University of Michigan, USA

M.E. Pijl, MD, Ph.D.

Rijnstate Hospital, Arnhem, the Netherlands

Ph.D. thesis, University of Twente, Enschede, the Netherlands

Printed by: Ipskamp Printing, Enschede, the Netherlands

Design and layout: Helmi Scheepers

Editing: Colleen Higgins

Copyright (C) 2018, Jasper van Sambeek, Amsterdam, the Netherlands

All rights reserved. No part of this publication may be reproduced without

the prior written permission of the author.

ISBN: 978-94-028-1013-4

SMARTER IMAGING MANAGEMENT

OPERATIONS MANAGEMENT FOR RADIOLOGY

\section{Proefschrift}

ter verkrijging van de graad van doctor aan de Universiteit Twente, op gezag van de rector magnificus,

Prof. dr. T.T.M. Palstra volgens besluit van het College voor Promoties

in het openbaar te verdedigen op vrijdag 4 mei 2018 om 16:45 uur

door

Jasper Rudolf Carolus van Sambeek

geboren op 26 juni 1980 te Eindhoven, Nederland 
Dit proefschrift is goedgekeurd door de promotoren:

Prof. dr. ir. J.J. Krabbendam

Prof. dr. ir. E.W. Hans 


\section{VOORWOORD}

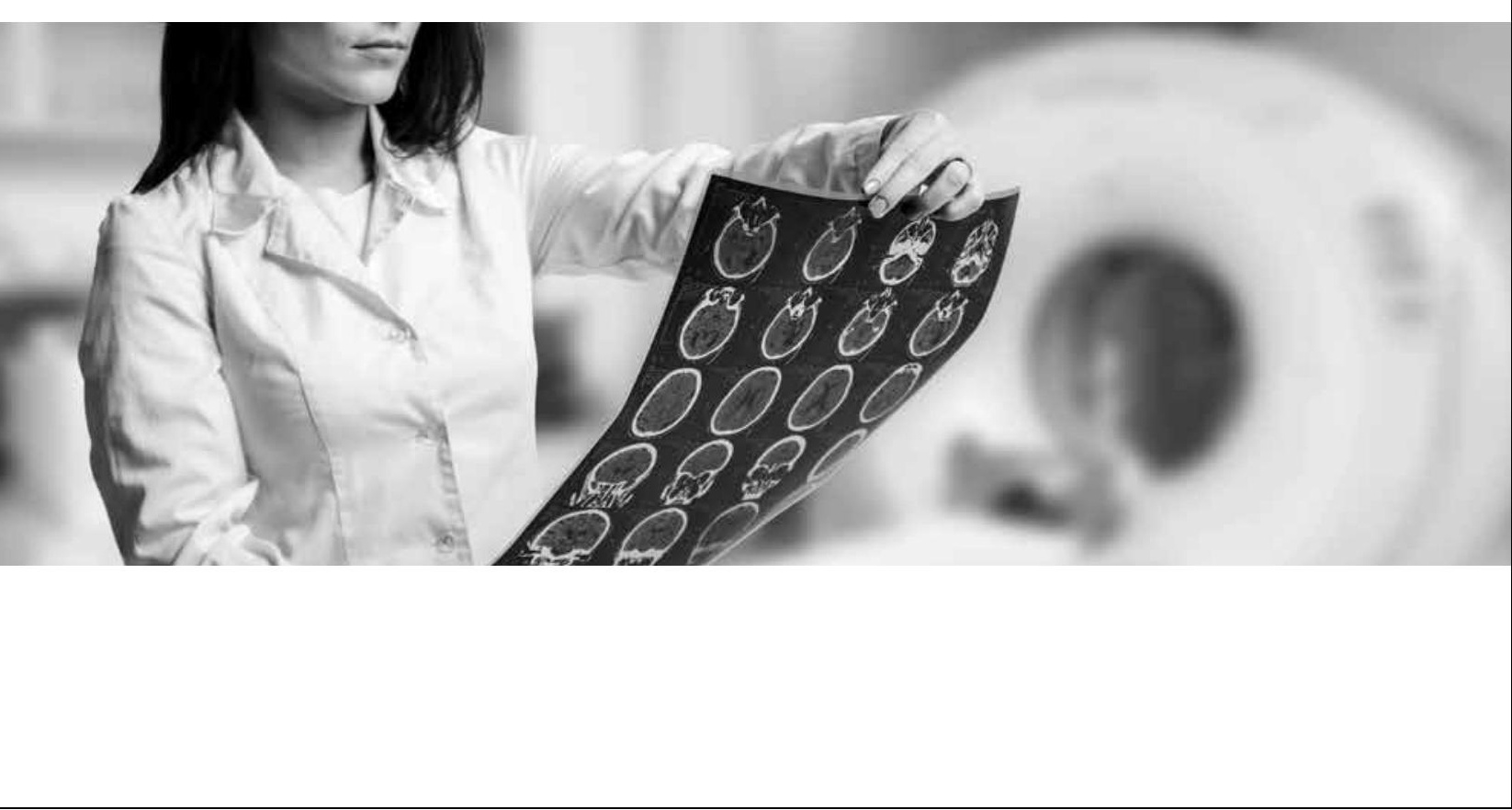


Dertien jaar werken aan een proefschrift. Dan weet je niet van ophouden, toch? Toch bestempelen veel mensen in mijn omgeving mij niet als een typische wetenschapper. Ikzelf ook niet. Maar wel zijn er best wat redenen waarom ik met een goed gevoel terugkijk op mijn keuze om te gaan promoveren:

- Het is leuk om mensen te verrassen. Dat heb ik twee keer gedaan: bij mijn start en onlangs toen ik besloot de boel weer op te pakken.

- Ik heb veel interessante mensen mogen ontmoeten: begeleiders, mede-onderzoekers, stagiaires, zorgprofessionals, managers etc.

- Je leert er veel van, zoals hoe een ziekenhuis werkt, de juiste vragen stellen, methodieken om te analyseren en oplossingen bedenken.

- Het is gaaf om te merken dat je iets bijdraagt. Aan de wetenschap, maar vooral aan de zorg!

Graag maak ik van de gelegenheid gebruik om enkele overtuigingen te delen die ik heb gevormd tijdens deze periode. Als ik mensen vertel waar ik mij mee bezig houd is de meest gehoorde reactie: oh daar valt een heleboel te verbeteren. Dat begrijp ik niet helemaal: er gaan zoveel dingen goed! Wij hebben in Nederland één van de beste zorgstelsels ter wereld. Onze zorgprofessionals behoren tot de hoogst opgeleiden van allemaal. Laten wij dit in eerste instantie koesteren. En beseffen dat er geen complexere organisaties zijn dan ziekenhuizen. Natuurlijk gaat daar wel eens iets mis . Wanneer je dit bespeurt, help het ziekenhuis dan te verbeteren. Dat was mijn motto.

Operations Management (OM) - in Jip en Janneke taal zou je kunnen zeggen 'bedrijfsprocessen verbeteren' - wordt vaak eenzijdig benaderd. Meestal staat efficiency (= vooral in het belang van het management) centraal en soms effectiviteit (= van in het belang van de klant/patiënt). Zelden staat medewerkerstevredenheid centraal bij OM. In mijn optiek zou dat juist een startpunt kunnen zijn. Medewerker blij ${ }^{1}$ betekent klant/patiënt blij en dat betekent management blij.

Een voorname schakel om succesvol te verbeteren is voor mij het leggen van verbinding. In mijn onderzoek hebben we verbinding gelegd tussen de medische wereld en OM, maar ook tussen allerlei verschillende mensen: patienten, laboranten, verpleegkundigen, baliemedewerkers, planners, artsen, managers, ICT'ers en onderzoekers. In mijn werk voor Sleutelnet staat verbinding leggen in de zorg ook centraal. En steeds maar weer blijkt hoe mooi het is om synergie te creëren. Dit geldt ook voor buiten de lijntjes kleuren, net even iets anders doen dan het geijkte. Rijnstate deed dit met CT op inloop en dat dit een rake innovatie is, is één van de belangrijke conclusies in dit proefschrift.

Bedanken in een voorwoord vind ik afgezaagd, maar is eigenlijk is ook wel terecht. Ik heb veel aan jullie gehad de afgelopen jaren en niet in het minste heel veel plezier met jullie gehad. Daarom in het kort dank aan (mensen van) UT, AMC, Rijnstate, Berenschot, Sleutelnet, stagiaires, de MBA, Geldropse vrienden, Grootsch, Cnødde, de Boskamp, buurtjes van de Nieuwendammerdijk, familie, Erwin, Koos en natuurlijk Hanka.

Tot slot: wetenschap is mooi. Dit is het slim beantwoorden van vragen. Maar vooral het stellen van slimme vragen. De praktijk is ook bijzonder mooi. Dat is slim bijdragen. En je afvragen hoe je slim kunt bijdragen. En het mooist is misschien nog wel het verbinden van die wetenschap met die praktijk, helemaal in de zorg. Ik ben dankbaar dat ik juist daar mijn steentje aan heb mogen bijdragen. En hopelijk mag ik dat nog een hele poos!

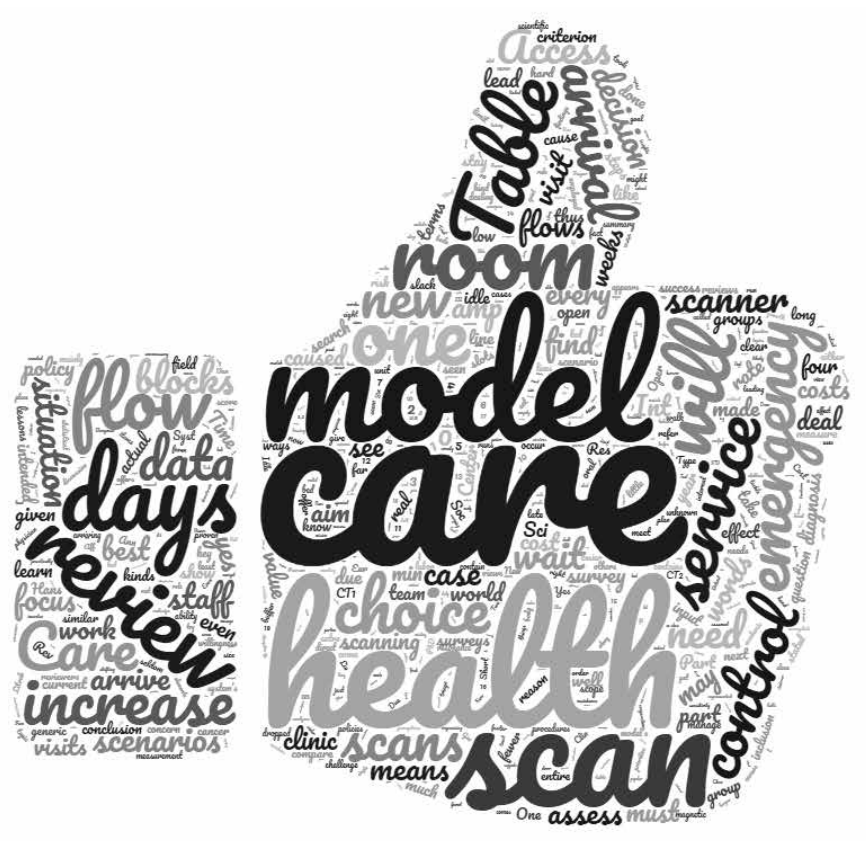




\section{TABLE OF CONTENTS}

CHAPTER 1

Introduction

CHAPTER 2

Models as instruments for optimizing hospital processes:

a systematic review

CHAPTER 3

Applying the variety reduction principle to management

of ancillary services

CHAPTER 4

Reducing MRI access times by tackling the appointment-scheduling strategy

CHAPTER 5

Patient views on walk-in computed tomography facilities

CHAPTER 6

The feasibility of walk-in computed tomography facilities

CHAPTER 7

Walk-in- versus appointment-based computed tomography in practice: Impact on patient satisfaction, efficiency, and workflow

CHAPTER 8

Discussion

Bibliography

147

Samenvatting in het Nederlands

167

About the author 
SUMMARY

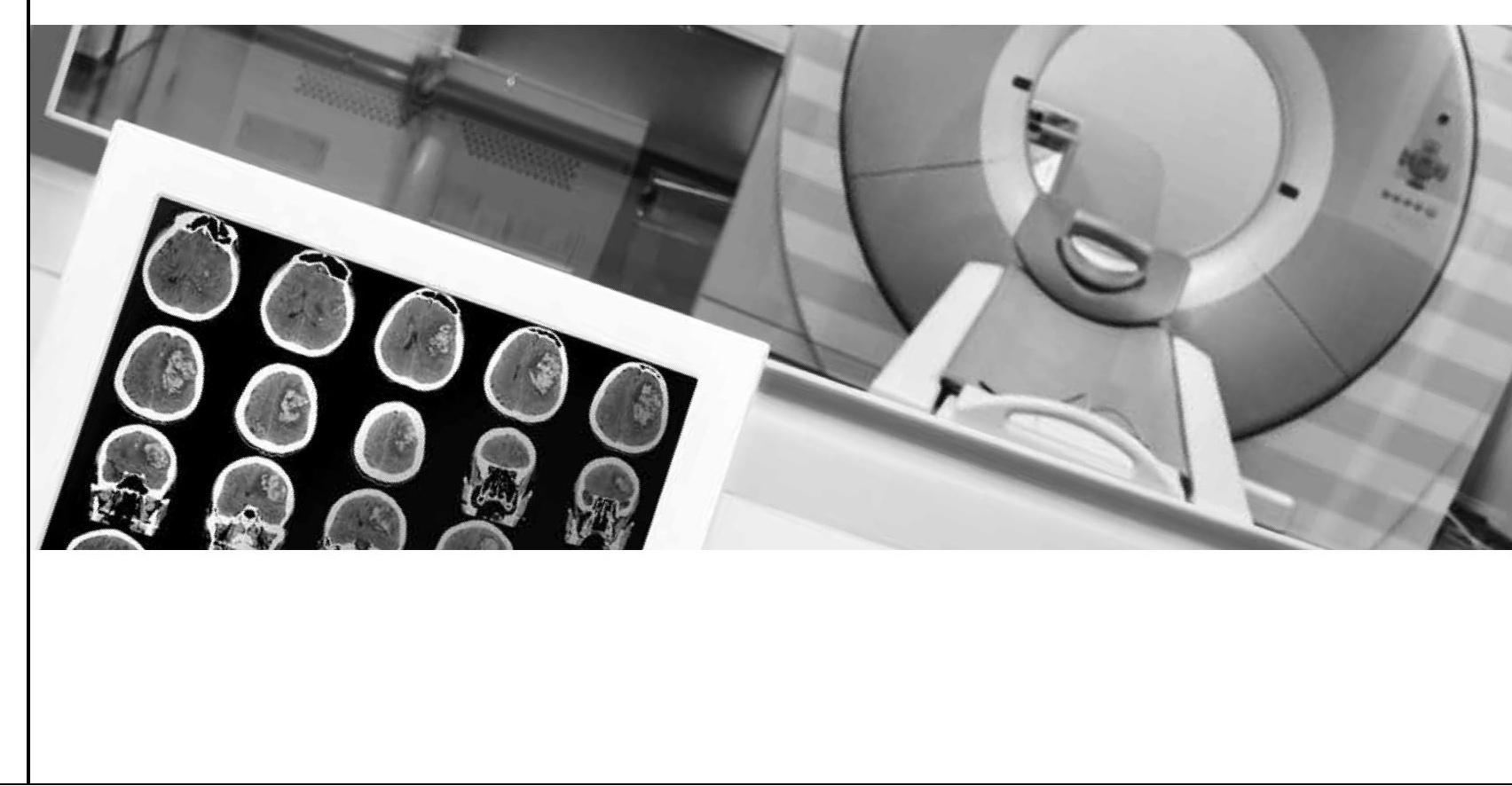


Since pressure on efficiency is rising, hospital processes are becoming increasingly complex, and patients and other stakeholders are becoming more demanding, hospitals need to reassess the value they offer their stakeholders. This dissertation focusses on improving service levels, together with efficient deployment of resources, and provides tools to optimize hospital processes. We choose to tackle one hospital resource that is used by a large portion of all patient flows and which forms a major bottleneck: the imaging department. Imaging resources appear to be one of the biggest bottlenecks in hospitals, because patients are increasingly requiring imaging exams and patients usually have to wait longer than desirable for an appointment. Moreover, since imaging resources are costly, they must be utilized efficiently. Therefore, hospitals would greatly benefit from smarter imaging management.

Our approach to perform smarter imaging management is the discipline of Operations Management (OM): the analysis, design, planning, and control of all of the steps necessary to provide imaging. Specifically, we focused on the tactical planning level of radiology services, involving patient routing, access policy, and determining the appointment scheduling strategy. The main research question is how can we find, implement, and evaluate Operations Management solutions to improve the operational performance of imaging processes in hospitals from a multi-stakeholder perspective?

We used various methods to answer our research question. First, we performed a systematic review of literature. Second, we performed case studies in the main bottleneck modalities: computer tomography (CT) and magnetic resonance imaging (MRI). Parallel, we performed a patient preference study, which gave us insights in what patients want to be improved. This led to a simulation study about the most promising OM solution: walk-in CT. Afterwards, we performed an evaluation study in a hospital that had worked several years with this solution.

We used a combination of methods that together come closer to 'evidence based' than most health OM studies, using computer simulation and process improvement in practice. Moreover, we determined the success of the improvements by involving both management, professionals, and patients. We performed our case and patient preferences studies within two Dutch hospitals: Academic Medical Center (AMC) in Amsterdam and Rijnstate in Arnhem.
Chapter 2 has the objective to find decision-making models for the design and control of processes regarding patient flows, considering various problem types, and to find out how usable these models are for managerial decision making. A systematic review of the literature was carried out. Literature from three databases was selected based on inclusion and exclusion criteria and the results were analyzed. Sixty-eight articles were selected. Of these, 31 contained computer simulation models, 10 contained descriptive models, and 27 contained analytical models. The review showed that descriptive models are only applied to process design problems, and that analytical and computer simulation models are applied to all types of problems to approximately the same extent. Only a few models have been validated in practice, and it seems that most models are not used for their intended purpose: to support management in decision making. The comparability of the relevant databases appears to be limited, and there is an insufficient number of suitable keywords and $\mathrm{MeSH}$ headings, which makes searching systematically within the broad field of health care management relatively hard to accomplish. The findings give managers insight into the characteristics of various types of decisionsupport models and into the kinds of situations in which they are used. Our literature study in 2009 was the first time literature on various kinds of models for supporting managerial decision making in hospitals was systematically collected and assessed. This thesis contains this study as well as an update covering the period 2009-2017.

Chapter 3: As central diagnostic facilities, CT scans appear to be bottlenecks in many patient-care processes. An important cause of relatively lowcapacity utilization is variability in the time needed for the scanning process. By reducing this variability, we managed to simultaneously reduce access times from 21 days to 5 days and increase the utilization rate from $44 \%$ to $51 \%$ in the CT-department of Academic Medical Center, Amsterdam, the Netherlands. Our strategy is applicable in every appointment-based hospital facility with variation in the length of time of the process. It allows simultaneously reducing costs and improving service for the patient.

Chapter 4: High access times for magnetic resonance imaging (MRI) facilities have a negative impact on quality of care and patient service. Since these resources are both scarce and expensive, utilizing the capacity is the most economical way of reducing these access times. In our experience in Dutch hospitals, patient appointments are not scheduled efficiently. Consequently, 
the most promising way of reducing access times is to optimize the scheduling strategy. The objective of this study was to reduce MRI access times by optimizing the scheduling strategy and by implementing this strategy in practice in a university hospital in the Netherlands. The scheduling process was analyzed to define the improvement potentials and to simulate the process. Computer simulation was used to copy the process and experiment with scheduling strategies in theory. Promising scenarios were defined and run in the simulation model. Based on the simulation results, a new scheduling strategy was designed and implemented. The simulation experiments showed that block reduction leads to a maximum decrease in access time of $93 \%$. Implementing a scheduling strategy with a practically applicable minimum number of blocks resulted in an actual decrease from 36, 22, 28, 9, and 9 to 7 , $2,10,3$, and 1 calendar day(s) respectively, depending on the patient group. This study proved that modeling the scheduling process can contribute to optimizing the scheduling strategy, which can lead to a reduction in access times for imaging facilities such as MRI scanners.

Chapter 5: Although innovations in health care access systems are intended to increase patient centeredness, this seldom implies that patient preferences have been examined. Walk-in access to computed tomography (CT) seems promising to satisfy patients, but this has never been verified. This study examines to what extent a walk-in system for the CT facility matches patient preferences. We used the analytic hierarchy process (AHP) on 106 patients to assess the patients' perspective about the performance indicators access time, waiting time, one stop shopping, and autonomy of choice. We let the patients prioritize and assess various performance level combinations. The patients prioritized these indicators with the respective values of $0.224,0.188,0.432$ and 0.157 . Six access system designs proved to be acceptable and relevant, whereof the most preferred appeared to be the walk-in scenarios. This led to the conclusion that from the patients' perspective, a walk-in system is a better access system for $\mathrm{CT}$ scan facilities than an appointment system. This study also demonstrated that AHP is a valuable technique for investigating patient preferences concerning access to a hospital facility.

Chapter 6: In hospitals, it is easier for patients to limit the number of hospital visits in walk-in systems than in appointment systems. Especially for imaging services, walk-in facilities may greatly contribute to both the quality of health care and the level of service. Although computed tomography (CT) facilities often have high access times, walk-in systems are seldom used. The objective of this study was to explore how a walk-in system would affect the performance of the CT modality. We conducted a case study in the Academic Medical Center (AMC), a university hospital in Amsterdam, the Netherlands. Extensive data on the CT process were gathered and analyzed. Performance indicators were defined and measured. Computer simulation was used to prospectively evaluate walk-in interventions. The model was validated and a sensitivity analysis was performed. Scenarios were defined and run in the simulation model. Walk-in visits are not possible for all patients, since some scans require professionals from different hospital departments to be present for part of the process, and this needs to be scheduled. Therefore, we focused on finding an ideal combination of walk-ins and appointments. With this walk-in intervention, a large number of the CT patients will be able to reduce the number of hospital visits, and these patients will be able to choose when they have their scan. Computer simulation showed that the average access time decreases from 3 days to 1 day, and that the average waiting time increases from 12 to 20 minutes for walk-ins. Average overtime increases by 15 minutes for walk-ins. In addition, it appears to be possible to scan $10 \%$ more patients in a walk-in system, and requires less effort to plan. This study shows that a walk-in system for a CT facility can contribute to both service level and efficiency. A combination walk-in/appointment system provides the best solution. We demonstrated that this reduces the number of hospital visits, eliminate access times, serve more patients, require less planning, and give patients autonomy in determining when to visit the facility.

Chapter 7: Long access time to computed tomography (CT) facilities is seen as a substantial problem in many hospitals. "Walk-in" is an intervention that eliminates access times, since it gives patients direct access without an appointment. The Rijnstate hospital (Arnhem, The Netherlands) implemented walk-in CT in 2010, which offered the opportunity to study the positive and negative effects of walk-in CT in practice and how these effects are balanced. Employee interviews $(\mathrm{N}=10)$, patient surveys $(\mathrm{N}=535)$ and a data analysis using data from the Electronic Patient Record (EPR) of 129.148 patients between October 2008 and March 2017 were conducted. All stakeholders stated that the system improved with the introduction of walk-in. The interviews also resulted in main performance indicators: access time, waiting time, one-stopshop, autonomy of choice, productivity and employee satisfaction. The patient survey divulged the maximum acceptable waiting time: $79 \%$ of patients stated 
this to be 15-30 minutes or more. When asked which performance indicator is most important, 'one stop shop' was mentioned by 134 patients over access time, waiting time and autonomy of choice (ranged from 79 to 88). The data analysis showed a doubling in production, while CT capacity hardly increased. The percentage of outpatients that had to wait 30 minutes or less has decreased from $85,2 \%$ in 2009 to $59,5 \%$ in 2016 , but the absolute number of outpatients with these waiting times increased from 5.146 to 7.681 . Overtime production regarding outpatients has decreased over the years. Walk-in CT performs better regarding the main performance indicators than a full appointment system. The reasons are that it almost nullifies CT access time, enhances one-stop-shop for patients. Walk-in also improves satisfaction of patients, referring physicians as well as the entire radiology staff, technicians and doctors alike. Furthermore, all results suggest that productivity can be higher with walk-in than with only appointments.

Chapter 8 elucidates successively the lessons learned about OM in hospitals and the walk-in system, our conclusions, relevance of the studies and our recommendations. Besides volume, variety and visibility, particularly variability is an important factor when OM is applied in hospitals. Various types of variability occur, such as in arrival distribution, in patient journeys, in resource capacity, in process times and in patient types. When variability occurs, buffers - such as extra capacity or extra time - are deployed or arise. But too many buffers are undesirable, because they are inefficient or cause bad service. So, before using buffers, one should try to eliminate variability. The high degree of variability in hospital care processes is caused in part by the inherent complexity of these processes, but the degree of variability caused by humans - artificial variability - is highly underestimated. In particular this artificial variability gives leads to process improvements. Our main OM lesson for hospital managers is to learn to deal with variability. This encompasses more frequent and thorough analysis of process data, improved forecasting, efforts to reduce variability (e.g. through standardization), and efficient deployment of flexibility/buffers to be able to handle any remaining variability.

Our following lessons concern the applicability of OM in hospitals. Since OM originates from industry, we focused on better understanding the differences between the hospital sector and industry. We found that the main differences between the two sectors that influence the application of $O M$ are: 1) care processes have higher variability, 2) hospitals experience higher cus- tomer dependence, 3) there are more stakeholders, 4) in healthcare the consumer usually not the direct payer, 5) processes are often difficult to schedule (since care pathways are sometimes hard to predict), 6) hospitals have more social responsibility, 7) healthcare has more regulation by government and 8 ) in healthcare the definition of quality and costs are often imprecise. Besides these differences in system characteristics, the applicability of OM in hospitals is also dependent on the way the people involved think, what we have metaphorically referred to as differences between the medical world and the OM world. We found that the main differences between these two worlds relate to: 1) research method, 2) focus, 3) type of change, 4) willingness to take risks and 5) leading coalition. We stress that making more impact with OM in hospitals requires a better understanding of these differences and a decrease of the distances.

We learned that the success of both walk-in and appointment systems depend on the characteristics of the system and the way the system is adapted and managed. Walk-in is more promising when: 1) patients evenly walk in, 2) walk-ins are predictable, 3) many scans fit in a day, 4) scan times vary highly, 5) scan times are unpredictable, 6) post-processing is short, 7) capacity is flexible, 8) patients do not tend to arrive on time, 9) patients require specific preparation not too often and 10 ) patients do not mind waiting in the waiting room.

Our key message is that there is need for smarter imaging processes and OM can greatly contribute to this. Disruptive OM changes like walk-in have been understudied, but have been proven - both analytically and empirically to greatly improve performance. Successfully assessing and applying new OM concepts for smarter imaging necessitates 1) focus on dealing with variability, 2) understanding of both $O M$ and the hospital context, and 3) the willingness to change disruptively. Mathematical modeling and computer simulation are effective tools to prospectively assess new policies, thereby providing evidence in support of disruptive change, and help convincing involved staff and clinicians. 


\section{CHAPTER 1}

Introduction

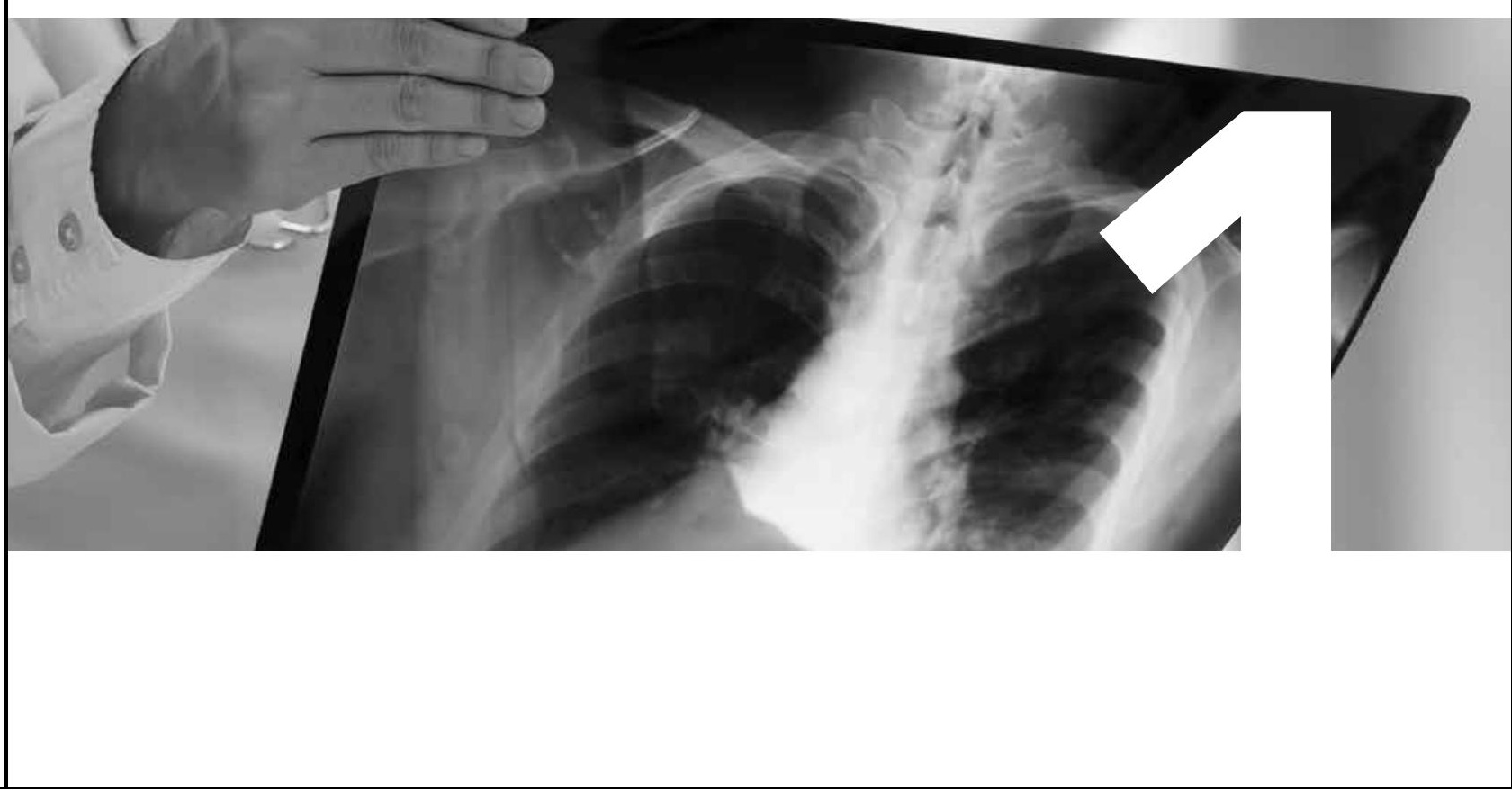




\subsection{Prologue}

Hospital managers today are facing three main, and growing, challenges. Pressure on efficiency is rising ${ }^{1,2}$, hospitals are becoming increasingly complex, and patients and other stakeholders are becoming more demanding ${ }^{3-7}$. The pressure on efficiency is largely caused by rising costs ${ }^{8-11}$, especially for advanced facilities like imaging, and tightening of the labor market. Complexity is increasing in many ways. Simple care is shifting to primary care ${ }^{12}$, and technology (such as imaging), as well as the flow of patients through the hospital, are becoming more and more complex. Increased complexity in patient flow is caused mainly by the increase in hospital resources (professionals and materials) that are needed to exam and treat one patient. This is due to superspecialization and the fact that more and more patients have comorbidities due to the aging of the population ${ }^{5,13-17}$.

Demand is changing in a number of ways. Patients are becoming more demanding because they are better informed and because the traditional doctorpatient relationship is becoming more equal ${ }^{18,19}$. In many countries, market forces are increasing, which leads to more power for patients, financiers, referring doctors and patients, and more competition between hospitals. Also, the tighter labor market makes it more important to meet employee demands.

These growing challenges have consequences. Hospitals need to reassess the value they offer their stakeholders, such as to patients, general practitioners, financiers, and to employees and at the same time they need to reassess their deployment of resources. Assessing value can be about quality of care, about quality of labor, about quantity of care, and increasingly about service levels. Our focus is improving service levels, such as easy access to health services, together with efficient deployment of resources. We chose a focus on service levels, because the changing demand requires better service ${ }^{20}$ and improving service often goes hand-in hand with increase of efficiency ${ }^{21}$. To meet efficiency requirements, the service they provide must be in balance with their limited resources. Hospital managers thus need to optimize hospital processes to better utilize resources. In other words, they need to improve their operational performance. Given the growing complexity of these processes, supportive tools are required that managers can use to accomplish this. This dissertation aims to make a valuable contribution to providing hospital managers with the tools they need to optimize hospital processes so that they can meet these challenges.

A popular method for improving operational performance in hospitals, has been clinical pathways - or care pathways - in recent decades. Coffey et al. ${ }^{22}$,
Allen ${ }^{23}$ and Hunter et al. ${ }^{24}$ defined clinical pathways as a multidisciplinary care management tool that provides the optimal sequencing and timing of interventions by physicians, nurses and other staff for a particular diagnosis or procedure or for patients with similar characteristics. This method is used to standardize care pathways to improve quality of care, but besides clinical pathways are also used for optimizing hospital processes to improve patient flow $^{25}$. The main contribution of the clinical pathway framework is the reduction of variation in the care process of similar patients ${ }^{26}$. When it is used for operational performance causes, it has similarities with the 'focused factory' principle ${ }^{27}$. This is a method from manufacturing, were a production line is set apart to be able to optimize the flow of this specific line. Clinical pathways have advantages and disadvantages ${ }^{28}$. The disadvantage of clinical pathways is that they have a weak evidence base ${ }^{24}$, optimize the flow of specific patient groups one by one and can be costly ${ }^{27}$. Consequently, optimizing all patient flows with clinical pathways takes a considerable amount of time and energy. Moreover, this method is easier applied in factories than in hospitals because of the large presence of variety and variability in hospital processes. Variety is reflected, for example, by many different patients, hospital resources and patient flows. Variability is reflected by many uncertainties, such as patient arrivals, diagnosis results, throughput times, and resources required. Our approach is not to use clinical pathways, but instead to tackle one hospital resource that is used by a large portion of all patient flows and which forms a major bottleneck. If such a resource can be better utilized, operational performance can be greatly improved.

\subsection{We need "smarter imaging management"}

Imaging resources appear to be one of the biggest bottlenecks in hospitals, because more and more patients are requiring imaging exams ${ }^{29}$ and patients usually have to wait longer than desirable for an appointment ${ }^{30-35}$. Many other resources are depending on the operational performance of imaging resources and at the same time imaging resources are very expensive. Therefore, they appear to be one of the hospital resources that would greatly benefit from better service and utilization ${ }^{31-33,36-39}$. In many hospitals, imaging resources form a bottleneck for many patient flows. The length of time between a request for imaging and the exam is referred to as access time. For example, access times for magnetic resonance imaging (MRI) and computed tomography (CT) can be days or weeks, and sometimes even months ${ }^{30,40,41}$ Since imaging facilities are expensive, increasing capacity is undesirable. 
Therefore, we need to focus more on improving the operational performance of imaging facilities, which leads to both increasing service level and reducing costs ${ }^{\mathbf{4 2}, 43}$. We call this "smarter imaging management."

Another factor is that integral capacity management is gaining importance in hospitals. This is the planning and control of the total hospital capacity, which takes the relationship between the interacting resources into account ${ }^{44}$. This requires more flexibility in supporting facilities such as imaging. The shorter the access time and the less often a CT or MRI scanner is fully scheduled, the more flexible these modalities can be.

Imaging is growing ever more complex ${ }^{45}$. The following is a summary of some of these complexities:

- Technology continues to develop, resulting in more advanced scanners ${ }^{8}$.

-Digitization is increasing ${ }^{46}$, resulting in increasing demand for radiologists and X-ray technicians to be knowledgeable about information technology (IT).

-Radiology is becoming more and more specialized, requiring professionals to be more knowledgeable.

-The number of radiology modalities is increasing ${ }^{29}$, resulting in a need for a wider knowledge base.

- Clients (patients, referring physicians, and financers) are becoming more demanding $3,47,48$.

- Competition (caused by customer demand, the free market, and private diagnostic centers) is increasing 49,50 .

- The labor market is becoming more complicated (including a growing shortage of X-ray technicians).

These growing complexities make imaging management more complicated. This results in a desire to find methods or tools that can help to approach imaging management in a smarter way, which is a central principle of this dissertation. To perform smarter imaging management, an effective discipline to apply is operations management $(\mathrm{OM})^{\mathbf{5 1}, 52}$. This is the core professional field we selected for this dissertation.

\subsection{Operations Management}

OM involves managing the resources and processes that produce and deliver goods and services ${ }^{53}$. Health operations managers are responsible for managing two interacting sets of issues:
- Resources - what type of materials, information, people (as customers or staff), technology, buildings and so on, are appropriate to best fulfil the organization' objectives.

- Processes - how resources are organized to best create the required mix of products and services.

Or, to put it more succinctly, do we have the right resources and are we using them appropriately?

Another way to explain it is that $O M$ is the analysis, design, planning, and control of all of the steps necessary to provide a service for a client. In other words, OM is concerned with identifying the needs of clients, and designing and delivering services to meet their needs in the most effective and efficient manner ${ }^{54}$.

OM is typically divided into process design and process control - or 'planning and control'. Process design is the activity of determining the physical form, shape, and composition of products, services, and processes. Planning and control is concerned with operating the resources and ensuring availability of materials and other variable resources in order to supply the goods and services which fulfil customers' demands ${ }^{55}$. Slack describes a third area within OM: process improvement. This study uses process improvement to tackle process design and process control, but tackling the process improvement function it is not within the scope of this study.

When organizational problems are solved with OM, we call them OM problems. A way to differentiate OM problems is to divide them into process design problems, process control problems, and capacity problems. We will return to the first two problems in our case studies in this dissertation. Capacity problems imply determining the dimensioning and allocation of capacity; and are only taken into account in our literature review and are not included in our case studies. Because imaging resources are very expensive, we focus on better utilization instead of increasing capacity. Capacity problems concern long-term decisions (for example, the number of CT scanners). The scope of our case studies is limited to medium-term decisions, and the capacity is considered as a known fact.

Four characteristics of demand, sometimes called the 'Four Vs', have a significant effect on how processes need to be managed: volume, variety, variation and visibility ${ }^{\mathbf{5}}$. Visibility indicates how much of the value added by the operation is 'experienced' directly by customers, or how much it is 'exposed' to its customers. The easiest to manage are operations with high volume, low variety, low variability and low visibility. 
Process control - or planning - is a broad managerial field, and can be further explained by distinguishing between the strategic, the tactical, and the operational planning levels. Hulshof et al. ${ }^{56}$ introduced a very usable framework to identify, break down, and classify decisions to be made in the managerial field of health care process control (see Figure 1). This helps us to understand the type of problem we are facing in the health care setting. With this understanding, we can target our literature searches for possible indications of the positive or negative effects of an OM intervention. This framework is usable, because the planning levels and health care processes differ from a logistic - or OM - perspective. In other words, the system characteristics are different, so other OM solutions will work. For example, imaging resources are expensive and their capacity cannot increase incrementally. Ambulatory care services in general are not emergent, can be planned, are relatively short and patients arrive and afterwards leave.

\section{FIGURE 1 / Proces control framework ${ }^{56}$}

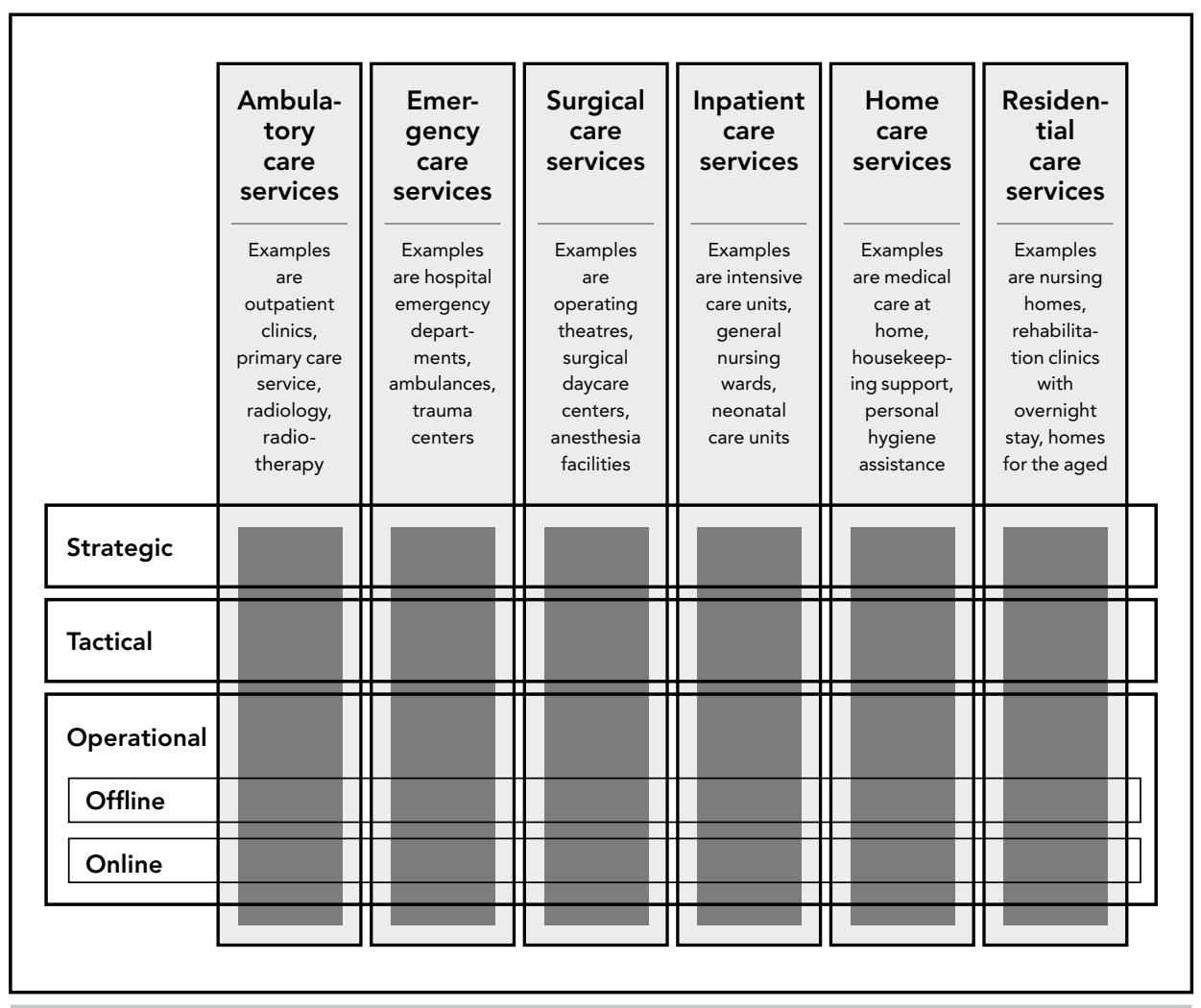

Strategic planning addresses structural decision-making. This involves defining the organization's mission and the decision-making to translate this mission into the design, dimensioning, and development of the health care delivery process. Tactical planning translates strategic planning decisions into guidelines that facilitate operational planning decisions. While strategic planning addresses structural decision-making, tactical planning addresses the organization of the operations/execution of the health care delivery process (i.e., the "what, where, how, when, and who"). Operational planning (both "offline" and "online") involves the short-term decision-making related to the execution of the health care delivery process. Following the tactical blueprints, execution plans are designed at the individual patient level and the individual resource level. When the goal is reducing access times, strategic planning decisions generally require more capacity and consequently increase costs, while operational planning is too short-term to be able to considerably influence the access times. Therefore, process control interventions that aim to reduce access time usually focus on the tactical planning level.

Radiology services are ambulatory care services, and the OM interventions we evaluate in this dissertation can be placed at the tactical level for these services. There are many areas of OM decision-making in this field, such as patient routing, capacity allocation, temporary capacity change, admission control, appointment scheduling, staff shift scheduling, and access policy. The interventions in this dissertation concern patient routing, access policy interventions, and appointment scheduling. But how do we know whether these interventions will work within the imaging context? Can we find evidence for this?

\subsection{Evidence for smarter imaging management}

In our studies we aim on an evidence based method. An increasingly popular scientific method applied in medicine for finding evidence is evidencebased medicine (EBM). This approach to medical practice is intended to optimize decision-making by emphasizing the use of evidence from well-designed and well-conducted research. Although all medicine based on science has some degree of empirical support, EBM goes further, classifying evidence by its epistemological strength, and requiring that only the strongest types (coming from meta-analyses, systematic reviews, and randomized controlled trials) can yield strong recommendations; weaker types (such as from case-control studies) can yield only weak recommendations ${ }^{57}$. According to the EBM theory, only an analytical study can answer questions about such things as how, when, or why the characteristics came into being. ${ }^{19}$ In medicine, it is often 
possible to control the variables that are not being studied reasonably well. From the perspective of finding interventions for smarter imaging management, we would like to see evidence-based management. In business management, it is practically impossible to control the variables, because organizations are very complex and many variables are constantly shifting. Although opinions about whether evidence-based management is possible vary widely ${ }^{\mathbf{5 8}}$, we found a method that comes close. On the one hand, we used computer simulation to calculate consequences of possible interventions and on the other hand we implemented the interventions in practice and evaluated them. This adds value to literature, because the scientific literature on OM in health care is based almost exclusively on theory, and more theory proven in practice is desirable ${ }^{59}$. A limited number of OM interventions in literature can be found on process improvements that have been proven in practice. This dissertation aims to change this.

\subsection{Who determines what is successful?}

We identified the need for smarter imaging management and the methods to find successful OM interventions for imaging. In addition to OM tools that provide us with theoretically "smart" interventions, we aimed to implement these in practice to demonstrate the positive effects of the interventions. But how can we assess the success of an intervention? Who determines the performance indicators? And who weighs them? In this dissertation, these indicators are determined not only by hospital management and physicians, but we also asked patients about what they view as relevant.

It has been increasingly acknowledged that non-medical issues are of great importance to patients, and that patient satisfaction can be used as an indicator for the quality of health care ${ }^{60}$. Hospitals are shifting to more patientcentered care: patients' views and perceived priorities are being used to help improve the quality of services ${ }^{61,62}$. To gather opinions among a representative group of patients, surveys are a good method for reaching enough patients ${ }^{63-65}$. We used patient surveys to help determine the effectiveness of our imaging interventions.

\subsection{Objective}

The objective of the research presented in this dissertation was to improve the operational performance of imaging processes in hospitals using $\mathrm{OM}$ methods. To accomplish our goal, we formulated the following research questions:

\section{The main research question:}

How can we find, implement, and evaluate operations management solutions to improve the operational performance of imaging processes in hospitals from a multi-stakeholder perspective?

\section{The sub-questions were:}

1. What can we learn from the literature about how management models can contribute to optimizing the performance of hospital departments? (Chapter 2)

2. What kind of $O M$ solutions contribute to optimizing the performance of imaging departments? (Chapters 3, 4, and 6)

3. Which imaging department performance indicators do patients value most? (Chapters 5 and 7 )

4. How can the performance of imaging departments be improved when OM solutions are implemented in practice? (Chapters 3, 4, and 7)

5. What can we learn from applying $O M$ in imaging departments and what can OM learn from our studies? (Chapter 8)

\subsection{Research setting}

\subsubsection{Radiology department}

The radiology department serves as one of the main supporting facilities for providing diagnostics. Radiology is a specialty that uses medical imaging to diagnose and treat diseases that can be seen inside the body. A variety of imaging techniques (such as X-ray radiography, ultrasound, CT, nuclear medicine, including positron emission tomography (PET), and MRI) are used to diagnose or treat diseases. Interventional radiology is the performance of medical procedures with the guidance of imaging technologies. The acquisition of medical images is usually carried out by the radiographer, often known as an X-ray technician. Depending on the location, the diagnostic radiologist, or reporting radiographer, then interprets or "reads" the images and produces a report of their findings and impression or diagnosis. This report is then transmitted to the clinician who requested the imaging, either routinely or emergently. Imaging exams are stored digitally in the picture archiving and communication system (PACS), where they can be viewed by all members of the health care team within the same health system, and compared with future imaging exams. ${ }^{2}$ 
Hospital services are becoming increasingly dependent on radiology, particularly on the more complex modalities such as CT and MRI. This is caused by the rapid developments in technology and the opportunities this leads to. It is thus not surprising that the demand for CTs and MRIs is increasing year after year. Being a supporting facility implies that many hospital departments rely on the radiology department, and when it does not function optimally, there are negative consequences for many patients and referring clinicians. These factors, along with the growing pressure on costs, make smarter imaging management more and more necessary.

\subsubsection{Academic Medical Center and Rijnstate}

The radiology department at the Academic Medical Center (AMC) in Amsterdam, the Netherlands, was our main research setting (Chapters 3, 4, 5, and 6). Being a university hospital, the three principal tasks of the AMC are patient care, research, and education. The focus of patient care in the AMC is tertiary referral care and is associated with special diagnostic procedures and treatment that are often expensive and complex. The service area for this tertiary referral care covers the entire country. The AMC also serves as a general hospital for the population of the multicultural urban area in and around southeastern Amsterdam. The hospital has 1,002 beds and over 7,000 employees; there are approximately 317,000 outpatient consultations and 53,000 admissions (both day care and clinical) every year (2016). ${ }^{3}$

Rijnstate, a large training hospital in the Arnhem region of the Netherlands, was the research setting for Chapter 7. The hospital has 809 beds and over 4,200 employees. There are approximately 516,000 outpatient consultations and 64,000 admissions (both day care and clinical) every year (2016). ${ }^{3}$

Although the research in this dissertation was inspired by and tested on case studies in the AMC and Rijnstate, these methods were generically formulated and are thus also applicable in other hospitals.

\subsection{Dissertation outline}

This dissertation consists of four parts. Part I (Chapter 2) is a systematic review of literature with a wider scope than the rest of the dissertation. We aimed to explore the field of the optimization of patient flows within hospital departments in general, making use of modeling. The wider scope provided us with lessons we could apply within our department of interest, the radiology department.
Part II (Chapters 3 and 4) presents various imaging case studies for improving operational performance. We introduced various practical OM inter ventions to deal with common problems in imaging situations. We analyzed the interventions not only theoretically, but also implemented and evaluated them in practice.

Part III (Chapters 5, 6, and 7) focuses on one innovative but controversia intervention: a walk-in system for the $\mathrm{CT}$ modality. We studied the consequences of this intervention from the perspective of various stakeholders using computer simulation, patient preference studies, and evaluation of ex perience in practice.

The dissertation concludes with Part IV (Chapter 8), with a wrap-up of the findings and a discussion.

With the exception of Chapter 7, which we conducted in 2016 and 2017, all chapters originate from studies performed between 2006 and 2010. Since a great deal of literature appeared following this period, we conducted new literature research to evaluate the extent to which overlapping studies had been conducted that could make our own studies less relevant. Therefore, Chapters 2 through 6 begin with a "Literature update" section.

\section{The outline is as follows:}

1. Introduction

Part I 2. Models as instruments for optimizing hospital processes: a systematic review

Part II 3. Applying the variety reduction principle to management of ancillary services

4. Reducing MRI access times by tackling the appointmentscheduling strategy

Part III 5. Patient views of walk-in computed tomography facilities 6. The feasibility of walk-in CT

7. Walk-in $\mathrm{CT}$ in practice

Part IV 8. Discussion 


\section{CHAPTER 2}

Models as instruments for optimizing hospital processes:

a systematic review

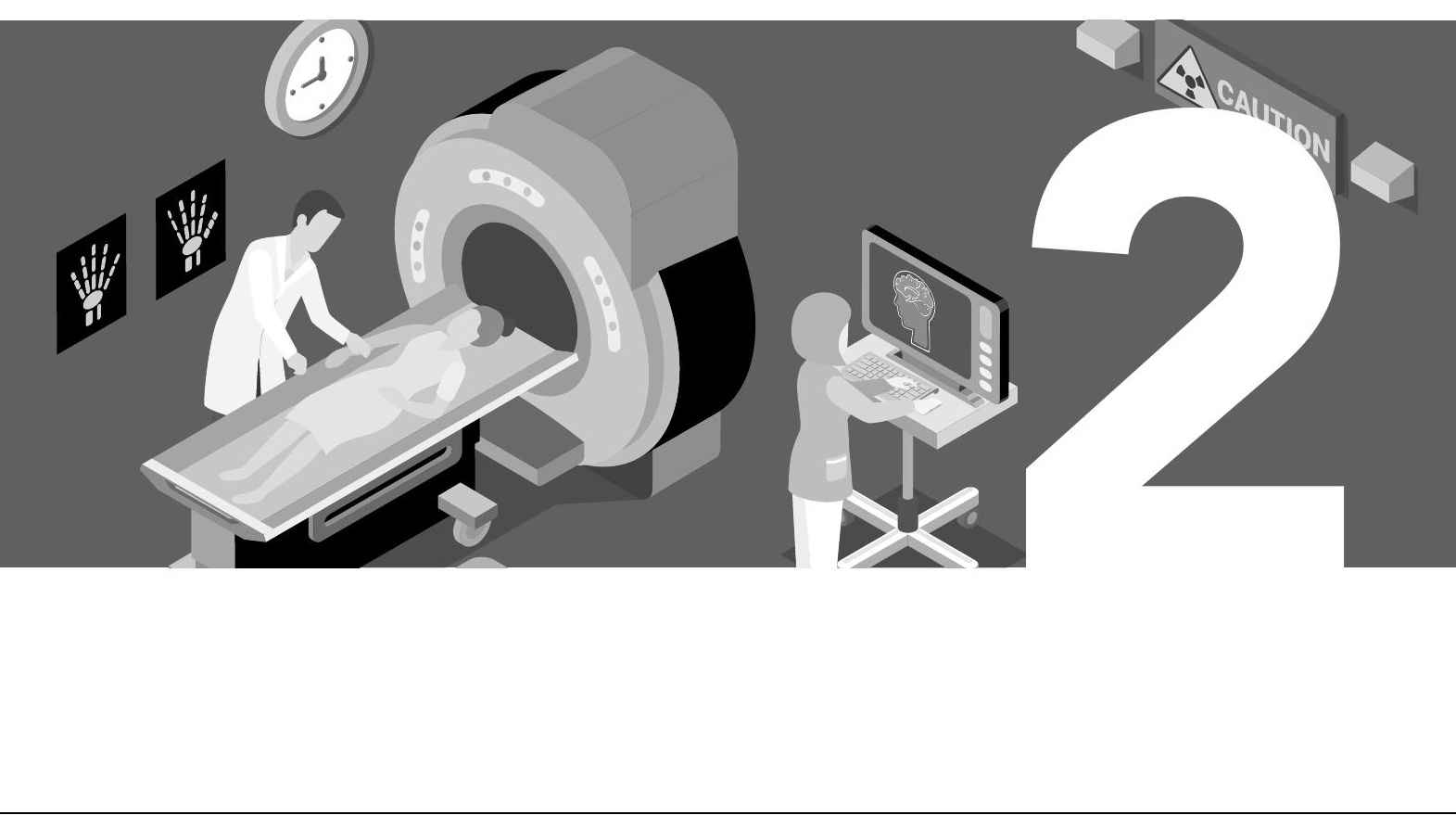




\section{LITERATURE UPDATE FOR CHAPTER 2}

The first aim of this chapter was to search for literature on models for the design and control of processes regarding patient flows within hospital departments. The second aim was to search for a relationship between the type of problems and the type of models. The third aim was to examine the models' usability for managerial decision-making. Because this systematic literature review was conducted in 2008 , it is likely that in the meantime new systematic literature reviews have been published that overlap with our review. In this section, we compare similar systematic reviews published since 2008 with our own to determine the extent to which our conclusions are still valid and reassess our contribution to the literature. Table 1 (page 26) shows to which extent these new reviews match our inclusion criteria.

Borgman (2017) ${ }^{66}$ searched in Chapter 2 of his Ph.D. dissertation for papers that use OR/MS methods to model and quantitatively assess patient related processes that take place within a hospital setting. Just like our study, he mainly focused on individual departments, but he limited his search to nonelective departments. He confirmed our conclusion that very few studies report about implementation of their outcomes.

Brailsford et al. (2009) ${ }^{67}$ searched for modelling in healthcare in general. Since their scope was far wider than process improvement and patient flow, their review resulted in more model types than ours, such as statistical analysis and statistical modeling. Our search strategy was more aimed with specific inclusion and exclusion criteria, using very specific free text words and keywords per criterion. Contrary to our problem-model approach, they analyzed the broader relation between the function, such as patient behavior and risk management, and the method. They confirm our conclusion that few studies report evidence of implementation.

Cardoen et al. (2010) ${ }^{68}$ provide a review of research on operating room planning and scheduling. They evaluate the literature on multiple fields that are related to either the problem setting (e.g. performance measures or patient classes) or the technical features (e.g. solution technique or uncertainty incorporation).
Elder et al. (2015) ${ }^{69}$ demonstrated three key strategies to improve patient flow through the emergency department. They concluded that advanced practice nursing roles, physician-assisted triage, and medical assessment units could influence the emergency department flow. These strategies decreased length of stay and did not increase wait rates (in the emergency department). They are still adhering to the Institute of Medicine's quality-of-care indicators.

Günal \& Pidd (2010) ${ }^{70}$ looked at discrete event simulation for performance modeling in health care. They found that most of the studies were unit-specific and facility-specific, and that discrete event simulation models were being used to support better operational decision-making and planning.

Jack \& Powers (2008) ${ }^{71}$ wrote a review about demand management, capacity management, and performance in health care services. They describe demand management as being used to search for causes of demand uncertainty with the intention of eliminating these causes and matching demand and the available capacity. They suggest that when demand management and capacity management strategies are engaged effectively, this should result in an increase in the overall performance of the health care organizations. They primarily provided a synthesis of the research conducted between 1986 and 2006 on demand management, capacity management, and performance, and described a detailed research agenda for future research.

Johnston et al. (2009) ${ }^{72}$ used discrete event simulation together with a visual display of results to attempt to reduce patient flow in hospital radiology departments. They found that simulation software was useful because it demonstrates the relationship between process change and improved efficiency among staff members. This was because it provided room for discussion and also allowed for the modeling of patient frequencies, the varying durations of hospital procedures, staffing constraints, and patient movements.

Kortbeek (2012) ${ }^{73}$ provides, in the second chapter of his Ph.D. dissertation, a structured overview of the typical decisions to be made in resource capacity planning and control in healthcare, and a review of the relevant OR/MS literature for each planning decision. A taxonomy is formulated to identify and position planning and control decisions. This taxonomy is the starting point to obtain a complete specification of planning decisions, and to gain understanding of the interrelations between various planning decisions. 
Marynissen \& Demeulemeester $(2016)^{74}$ also focused on process improvement and patient flow, but had a narrower focus, delineating to integrated hospital scheduling problems, where patients need to sequentially visit multiple resource types.

Mielczarek \& Uzialko-Mydlikowska (2010) ${ }^{75}$ also examined computer simulation in the health care sector. They specifically looked at three methods: discrete event simulation, Monte Carlo simulation, and continuous simulation represented by the system dynamics. They found that most research focused on analyzing the performance of health care systems. Their analysis showed that discrete event simulation is the commonly preferred method.

Mohiuddin et al. (2017) ${ }^{76}$ focused on patient flow in emergency departments by using computer simulation methods. They concluded that it is safe and efficient to use computer simulation to pre-test the influence of changes on care delivery in the emergency department before implementation takes place.

Oredsson et al. (2011) ${ }^{77}$ wrote a systematic review about interventions to improve patient flow in emergency departments. The interventions were triage-related and were divided into the following groups: streaming, fasttrack, team triage, point-of-care testing, and nurse-requested X-ray. Their main conclusion was that introducing fast-track and team triage will both lead to shorter waiting times, shorter length of stay, and fewer patients leaving without being seen. For the other interventions (streaming patients into different tracks, point-of-care testing, and nurse-requested X-ray), there was little evidence that they will lead to a shorter waiting time and a shorter length of stay.

Rezaei-Hachesu et al. (2017) ${ }^{78}$ focused on discrete event simulation in emergency departments. They used a 10-step model for simulation and planning to analyze problems and choose best-case scenarios. Their results demonstrated the usefulness of simulation methods in emergency departments (and other areas of health care).

Sobolev et al. (2011) ${ }^{79}$ reviewed the literature on ways to simulate patient flow in surgical care and their serviceability for policy analysis related to the delivery of this type of care. They found that $75 \%$ of the studies included used discrete event models. Furthermore, they found a great deal of diversity in the presentation of assumptions (91\%), system requirements (88\%), input and output data (91\%), and results of simulation-based policy analysis.

The review of Thor et al. (2007) (20 $^{80 c u s e d ~ o n ~ s t a t i s t i c a l ~ p r o c e s s ~ c o n t r o l ~ i n ~}$ health care quality improvement. They concluded that it is a versatile tool that can help stakeholders to manage patient care in health care and to improve patients' health.

Vanberkel et al. (2009) ${ }^{\mathbf{8 1}}$, similar as Marynissen \& Demeulemeester (2016), focus on a holistic approach to modelling patient flows, being the flow through multiple hospital departments.

In our review, we aimed on models that improve the performance of patient flow in hospital departments, based on specific inclusion criteria. Besides, we searched for certain models (simulation, analytical, and descriptive) and finding links with different kinds of problems. The new reviews had a different aim and did not link problem types with a suggested model. This indicates that our review is still unique. Our third aim - to assess the publications to see whether the results of the models had been applied - was not repeated within the new reviews. This leads us to conclude that there is no reason to suppose that our statement about the lack of information on the decision taken based on the models' outcomes is no longer valid.

Ideally, we would repeat our process of systematically searching the databases for new published studies that match our inclusion criteria. Unfortunately, we did not have the resources to conduct such an extensive systematic search and analysis. 


\section{Inclusion criteria /}

\section{Author}

Borgman (2017) 66

Brailsford et al. (2009) ${ }^{67}$

Cardoen et al. (2010)68

Elder et al. (2015) 69

Günal \& Pidd (2010)70

Jack \& Powers (2008) 7

Johnston et al. (2009) 72

Kortbeek (2012) ${ }^{73}$ meester $(2016)^{74}$

Mielczarek \& Uzialko-

Mydlikowska (2010) ${ }^{75}$

Mohiuddinet al. (2017) 76

Oredsson et al. (2011)77

Rezaei-Hachesu et al. $(2017)^{78}$

Sobolev et al. (2011) ${ }^{79}$

Thor et al. (2007) 80

Vanberkel et al. (2009) ${ }^{81}$

\section{Title}

Urgent care planning and scheduling in hospitals: a literature review

An analysis of the academic literature on simulation and modelling in health care

Operating room planning and scheduling: A literature review

Systematic review of three key strategies designed to improve patient flow through the emergency department Discrete event simulation for performance modelling in health care: a review of the literature

A review and synthesis of demand management, capacity management and performance in health-care services

Modelling radiology department operation using discrete event simulation

Structured review of the state of the art in operations research

\section{Literature review on integrated hospital scheduling} problems

Application of computer simulation modelling in the health care sector: a survey

Patient flow within UK emergency departments: a systematic review of the use of computer simulation modelling methods

A systematic review of triage-related interventions to improve patient flow in emergency departments

A step-by-step framework on discrete events simulation in emergency department: a systematic review

\section{Systematic review of the use of computer simulation} modelling of patient flow in surgical care

Application of statistical process control in health care improvement: systematic review

A survey of health care models that encompass multiple departments

\section{Central theme of the review}

Non-elective care planning and control within hospitals

To analyze the relative frequency of use of a range of operational research modelling approaches in health care

Overview on operating room planning and scheduling

Three key strategies to promote patient throughput

Discrete event simulation for hospital performance modelling

Demand management, capacity management and performance research in health care

Reduce patient flow in a radiology department

Overview of decisions to be made in resource capacity planning and control in healthcare and the relevant OR/MS literature for each planning decision

Integrated hospital scheduling problems

Computer simulation models (DES, MC and SD) to support decision-making in health care

The usefulness of computer simulation for analyzing patient flow of the emergency department

Multiple interventions to improve patient flow in emergency departments

Ten steps for simulation and planning for both analyzing problems and choosing best-case scenarios

Computer simulation to analyze changes in the delivery of surgical care

Statistical process control in health care quality improvement

Review of quantitative health care models to illustrate the extent to which they encompass multiple hospital departments 


\section{ABSTRACT}

Purpose: To find decision-making models for the design and control of processes regarding patient flows, considering various problem types, and to find out how usable these models are for managerial decision making.

Design/methodology/approach: A systematic review of the literature was carried out. Relevant literature from three databases was selected based on inclusion and exclusion criteria and the results were analyzed.

Findings: Sixty-eight articles were selected. Of these, 31 contained computer simulation models, 10 contained descriptive models, and 27 contained analytical models. The review showed that descriptive models are only applied to process design problems, and that analytical and computer simulation models are applied to all types of problems to approximately the same extent. Only a few models have been validated in practice, and it seems that most models are not used for their intended purpose: to support management in decision making.

Research limitations/implications: The comparability of the relevant databases appears to be limited and there is an insufficient number of suitable keywords and $\mathrm{MeSH}$ headings, which makes searching systematically within the broad field of health care management relatively hard to accomplish.

Practical implications: The findings give managers insight into the characteristics of various types of decision-support models and into the kinds of situations in which they are used.

Originality/value: This is the first time literature on various kinds of models for supporting managerial decision making in hospitals has been systematically collected and assessed.

\subsection{Introduction}

\section{"Man is a tool-using animal ... Without tools he is nothing,} with tools he is all." - Thomas Carlyle

The hospital's identity as a health community is slowly being transposed to that of an enterprise. Hospitals are getting bigger, are using relatively higher numbers of non-medical employees, their customers are becoming more critical, and they are operating in an increasingly competitive climate. Average patient stay has been reduced considerably and the number of outpatients versus inpatients is always changing, resulting in less intensive patient-caregiver relationships. The traditional conflicting pressures of maximizing the quality of patient care versus ensuring organizational survival have become especially acute due to recent economic pressures ${ }^{\mathbf{8 2}}$. These developments have resulted in more complex and businesslike organizations, which has been accompanied by more challenges to be dealt with. The complexity of the system causes ambiguity in terms of how an individual's work should be performed and how the work of many individuals should be successfully coordinated into an integrated whole ${ }^{83}$. This new situation for hospitals requires increased professionalism of hospital management to allow them to make the right decisions.

One of the most significant issues management has to deal with is the use of a hospital's limited resources in relation to an increasing demand for quality, quantity, and desired service level. An effective way of meeting this demand while at the same time reducing or restricting costs is to optimize the system's logistics. Effectively managing the system's logistics - which consists of arrivals, activities, and resources - involves the same problems many hospital managers have to deal with. Traditional clinical research methods are barely adequate when it comes to dealing with the main problems with regard to managing the systems in a hospital. Randomized controlled trials and controlled experiments cannot be carried out adequately because of too many dependent variables. Moreover, these methods are too risky and expensive, and are consequently generally unsuitable for these situations. Therefore, there is an increasing need for tools that can predict the consequences of different alternative scenarios. In complex situations, decision makers can use managerial models that predict the results of a scenario. A model helps to understand a system's behavior without actually changing the system.

There have been various studies about managerial models designed for the hospital setting. Usually they describe or compare specific types of models, such as simulation models and Markov chain models ${ }^{\mathbf{8 4}, 85}$. Furthermore, they usually describe modeling techniques, not models that have been practically applied in hospitals. Systematic reviews of the literature in this field are particularly scarce. Reviews generally deal with a specific range of models such as computer simulation models ${ }^{86-88}$. This study focuses on various kinds of decision-support models and is thus not limited to a specific range of models. In addition, rather than focusing on the entire hospital, it only deals with processes within specific hospital departments. First of all, the complexity of the hospital organization and the number of different kinds of processes make it extremely hard to generate a straightforward solution to the main challenge for the entire hospital. Designing a model at this level would be very abstract 
and result in information with limited value. Second, very often it is not necessary to focus on the entire hospital. According to the theory of constraints, attacking "bottleneck" processes or departments is the fastest and most effective way of streamlining flows through an organization ${ }^{89}$.

The primary objective of this study was to search for literature on models for the design and control of processes concerning patient flows within departments in a hospital. These models must be able to provide insight into different scenarios and to consider them with the aim of optimizing the performance of these departments. The secondary objective was to find out if there is any relationship between the type of problems and the types of models used. The third objective was to find out how usable these models are for managerial decision making. Therefore, this study also reflects on the applicability of the results of the models and the extent to which the models are generic.

\subsection{Theoretical background}

The first concern was to set out clear definitions. Apart from a formulation for a model, types of models and problems have to be defined to find out which models are used for which problems.

\subsubsection{Problem types}

There are many ways to classify problem types. We have chosen a classification that best fits our primary objective, based on two theoretical frameworks. In Slack's framework ${ }^{55}$, operations management problems are classified into topics of design, planning and control, and improvement. According to our objectives, although all problems relevant to this review are related to improvement, the improvement always concerns the process design or the planning and control in hospitals. Therefore, the topic of improvement does not occur in the classification in this review. According to the framework for hospital planning and control90, planning and control can take on different forms. The framework distinguishes four hierarchical levels: strategic, tactical, operational offline, and operational online, which are described respectively as "capacity dimensioning," "allocation," "scheduling," and "control." In our classification, the capacity problems correspond with "capacity dimensioning," and scheduling problems contain both "allocation" and "scheduling." The relevant scheduling problems in this context do not contain the level "control," since we are concerned with patient flows and not patients who are already in the hospital. The managerial decisions relevant to this study occur "before the action," not during the action (online). In the literature, scheduling problems often deal with rostering: assigning human resources to shifts. These kinds of problems do not belong to our definition of scheduling problems, since they do not directly deal with patient flows either.

In summary, the classification employed for problem types is:

- Capacity problems: what kind and what amount of resources to attract;

- Process design problems: which process steps to make use of and in what order;

- Scheduling problems: at what moment to allocate which resources to which patients.

\subsubsection{What is a model?}

A model is a broad concept containing many potential and employed explanations. A standard definition of a model is an artificially created system that represents reality. A system is a compilation of elements that are related, so that no elements are isolated from the remaining ${ }^{91}$. Law ${ }^{92}$ defines a model as "a set of assumptions about how a system works, to try to gain some understanding of how the system behaves". The most significant aspect of this formulation is the latter part. The models we looked for give insight into the consequences of possible managerial decisions (scenarios) with regard to setting up or changing a system and therefore insight into its behavior. De Leeuw ${ }^{91}$ adds the notion that the way a model is built depends on the aim of use, which means that many possible models can be used for a given system. According to our objectives, the definition employed in this review is therefore a representation of a real system that gives insight into the system's behavior, with interfaces with reality corresponding with the aim of use.

The traditional model types are the physical model and the descriptive model. Descriptive models give insight into a system's behavior by describing relationships between aspects of the system. Physical models imitate real shapes and sometimes movements of a system. Applications of physical models still occur in civil engineering and building development, but not as a tool for hospital managers; therefore, these are irrelevant for this study. Later modeling development brought us mathematical models. They represent a system in terms of logical and quantitative relationships that are then manipulated and changed to see how the system reacts. Mathematical models can be divided into analytical models, which are able to provide precise information on questions of interest, and simulation models, which estimate a system's true characteristics. The pre-assumption is that different model types perform best depending on the type of problem. 
In summary:

1. Descriptive models: Models that visually or textually represent a solution. A descriptive model is flexible and often easy to understand and use; however, these models lack quantitative, accurate insight into system behavior.

2. Analytical models: Models that can calculate output measures of interest for fictive scenarios. The advantage is that they are exact and quantitative, but it is usually difficult to interpret their results. In complex processes, they often ignore too many factors to be able to compare their quantitative results with reality.

3. Computer simulation models: Models that use computer software programs to simulate variations of the real process accelerated, and afterwards show output measures. Computer simulation models are the most accurate model types, because they calculate over time and often take variability into account. The disadvantages are the cost and development time needed.

\subsection{Methods}

\subsubsection{Search strategy}

We selected three different databases. The medical database Medline contains articles from 1950 through 2006, the medical database Embase contains articles from 1980 through 2006, and the management science database Business Source Elite (BSE) contains articles from 1985 through 2006. For our search of the databases, we formulated inclusion and exclusion criteria (listed in Table 2).

We searched the Medical Subject Headings (MeSH) database to find useful $\mathrm{MeSH}$ headings for every inclusion criterion. Several MeSH headings were found per criterion. Using these headings, a number of titles and abstracts were retrieved for each heading and evaluated for relevance. If a relevant abstract was found, the other MeSH headings in this abstract were also evaluated for relevance. All the MeSH headings found were entered in the keyword (subject headings) database of Embase to find the corresponding keywords (subject headings). Because not all of the $\mathrm{MeSH}$ headings had corresponding subject headings, the results of the subject headings were also evaluated for relevance. From the relevant abstracts, we derived free-text words for each criterion to increase the specificity of our search strategy.

In $\mathrm{BSE}$, the $\mathrm{MeSH}$ and subject headings were used to find corresponding BSE keywords in the same way we found the corresponding subject headings.

\section{TABLE 2 / Inclusion and exclusion criteria}

Inclusion Criteria

- Articles containing a model that deals with the design and/or control of a process.

- Articles with models concerning patient flows that can be applied to departments within a hospital. Articles may concentrate on optimizing the performance of either an entire department or a function or process within a department.

- Articles using simulation-based descriptive, or analytical models. We looked both for models that tell us how to arrive at the optimal situation as well as models that directly suggest a specific design.

- Articles containing models that directly aim to improve the performance of the process. Performance is defined as product quality, customer service, flexibility, timeliness, reliability, safety, and quality of work.

Exclusion Criteria

- Articles using models that aim to optimize more than one department at a time.

- Articles not published in peerreviewed journals or published as a full paper in conference proceedings.

- Articles concerning models that support medical considerations.

- Articles with models primarily concerned with implementing organizational change.

- Articles suggesting models that primarily forecast or predict demand or length of stay.

- Articles containing models that primarily demonstrate relationships.

- Articles concerning software and/or hardware and information technology (IT) with no direct effect on patient flows.

- Articles suggesting models that describe an organizational structure.

Because BSE is not a medical database, this resulted in slightly different keywords and free-text words. The keywords and free-text words are listed in the appendices.

To meet all the criteria, the articles needed to contain at least one keyword or free-text word per criterion. After performing our search with the selected keywords and free-text words, articles were then selected based on the title 
and abstract. Two reviewers independently evaluated titles and abstracts to select articles for the review. Through discussion, the two reviewers jointly determined which articles would be useful for the review in their full-text versions. This was done based on the inclusion and exclusion criteria. If they disagreed, a third reviewer was consulted. To evaluate the full text, full publications of all selected abstracts were obtained (in electronic or printed form) for the two reviewers. The results of the evaluations were compared and the differences in opinions were resolved through discussion. When the final list of the included articles was completed, the references of these articles were evaluated for relevance. Seemingly relevant papers from the references were obtained and evaluated in the same way as the other papers.

The authors developed a classification table for structuring the literature. Using the classification table (Table 3), the two reviewers independently collected data to reach the review objectives. To make sure there were no differences in how the reviewers defined the terms, the definitions were cleared beforehand (Table 3). The results of the two reviewers were compared and the differences in opinions were resolved through discussion.

\subsection{Results}

\subsubsection{Overview}

The flow chart of the review is shown in Figure 2. With the search for keywords, we found a total of 27 relevant MeSH headings in Medline, 21 relevant subject headings in Embase and 11 relevant keywords in BSE. The keywords and free-text words are sorted by criteria in the appendices. The search strategy that the article must contain at least one of the keywords or free-text words per criterion resulted in a total of 609 articles. All the abstracts of these articles were read by two reviewers, who selected 128 articles for further evaluation. Of these articles, one was in German, one in Czech, and one in Swedish. Because the full texts could not be obtained, 10 articles were excluded from the review. The 118 articles were evaluated by the reviewers, who selected 64 articles that met the inclusion and exclusion criteria ${ }^{93-155}$.

Most articles were excluded because they modeled more than one department or were not related to patient flows. The references of the selected articles were evaluated to look for more relevant articles. This resulted in four additional articles relevant to the review ${ }^{156-159}$.

\section{TABLE 3 / Classification table}

\begin{tabular}{|c|c|c|}
\hline Item & Definition & Categories \\
\hline Type of model & $\begin{array}{l}\text { What type of model is } \\
\text { described in the article? }\end{array}$ & $\begin{array}{l}\text { - Computer simulation } \\
\text { - Descriptive } \\
\text { - Analytical }\end{array}$ \\
\hline Type of problem & $\begin{array}{l}\text { What type of problem is } \\
\text { described in the article? }\end{array}$ & $\begin{array}{l}\text { - Capacity problem } \\
\text { - Process design problem } \\
\text { - Scheduling problem }\end{array}$ \\
\hline $\begin{array}{l}\text { Kind of department } \\
\text { it can be applied to }\end{array}$ & $\begin{array}{l}\text { To what kind of department } \\
\text { can the model be applied? }\end{array}$ & $\begin{array}{l}\text { - Imaging diagnostics } \\
\text { - Inpatient } \\
\text { - Outpatient } \\
\text { - Operation room } \\
\text { - Laboratory } \\
\text { - Intensive care } \\
\text { - Radiotherapy } \\
\text { - Emergency room }\end{array}$ \\
\hline Study objective & $\begin{array}{l}\text { What is the objective of the } \\
\text { study (not of the model)? }\end{array}$ & $\begin{array}{l}\text { - Designing a model } \\
\text { - Comparing models } \\
\text { - Using a model } \\
\text { - Assessing/proposing a } \\
\text { model }\end{array}$ \\
\hline $\begin{array}{l}\text { Outcome measures } \\
1 \text { and } 2\end{array}$ & $\begin{array}{l}\text { Outcome measures are the } \\
\text { measures used to assess the } \\
\text { results of the model. One or } \\
\text { two outcome measures were } \\
\text { defined per article. }\end{array}$ & $\begin{array}{l}\text { - \# of appointments } \\
\text { - \# of patients } \\
\text { - Access-denial probability } \\
\text { - Access times } \\
\text { - Cost } \\
\text { - Length of stay } \\
\text { - Needed capacity } \\
\text { - Overtime } \\
\text { - Patient experiences } \\
\text { - Quality of care } \\
\text { - Random performance } \\
\text { indicators } \\
\text { - Throughput time } \\
\text { - Utilization } \\
\text { - Waiting times } \\
\text { - Workload }\end{array}$ \\
\hline $\begin{array}{l}\text { Validated in } \\
\text { practice }\end{array}$ & $\begin{array}{l}\text { An article has been validated in } \\
\text { practice when the results of the } \\
\text { model have been applied in } \\
\text { the hospital (not when only the } \\
\text { model has been validated). }\end{array}$ & $\begin{array}{l}\text { - Yes } \\
\text { - No }\end{array}$ \\
\hline Generic & $\begin{array}{l}\text { An article is generic when the } \\
\text { model can be used in another } \\
\text { hospital and/or department. }\end{array}$ & $\begin{array}{l}\text { - Yes } \\
\text { - No }\end{array}$ \\
\hline
\end{tabular}




\section{FIGURE 2 / Flow chart of the systematic review}

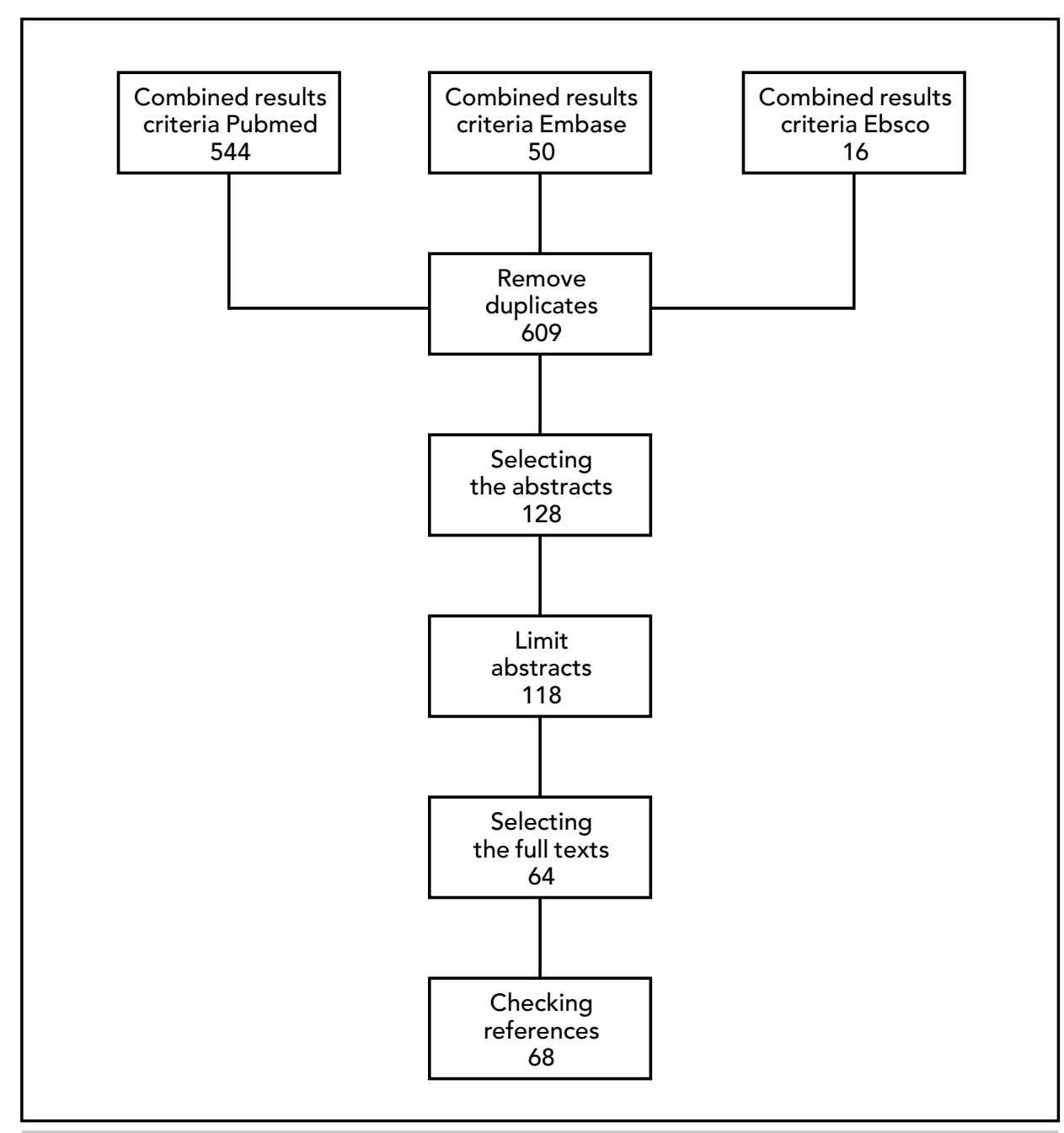

\subsubsection{Data collection}

From the selected studies, we collected the data summarized in Table 4

As illustrated in Table 4, only $15 \%$ of the studies contained descriptive models. Analytical (40\%) and computer simulation (46\%) models were clearly used more frequently. Half of the studies (51\%) examined a process design problem, while scheduling problems and capacity problems represent $34 \%$ and $15 \%$ respectively. Most of the models can be applied in the emergency room (21\%), operating room (24\%), and outpatient (21\%) departments.

\section{TABLE 4 / Collected data}

\begin{tabular}{|c|c|c|c|c|c|}
\hline Type of Model & $\#$ & $\%$ & Type of Problem & $\#$ & $\%$ \\
\hline Computer simulation & 31 & 46 & Capacity problem & 10 & 15 \\
\hline Descriptive & 10 & 15 & Process design & 35 & 51 \\
\hline Analytical & 27 & 40 & Scheduling & 23 & 34 \\
\hline Kind of Department & $\#$ & $\%$ & Objective of Study & $\#$ & $\%$ \\
\hline Imaging diagnostics & 2 & 2.9 & Designing a model & 51 & 75 \\
\hline Inpatient & 13 & 19 & Comparing models & 8 & 12 \\
\hline Outpatient & 14 & 21 & Using a model & 4 & 5.9 \\
\hline Operating room & 16 & 24 & Critiquing/proposing & 5 & 7.4 \\
\hline Laboratory & 2 & 2.9 & a model & & \\
\hline Intensive care & 6 & 8.8 & & & \\
\hline Radiotherapy & 1 & 1.5 & & & \\
\hline Emergency room & 14 & 21 & & & \\
\hline Outcome Measures & $\#$ & $\%$ & Validated in Practice & $\#$ & $\%$ \\
\hline Utilization & 25 & 22 & Yes & 17 & 25 \\
\hline Waiting times & 17 & 15 & No & 51 & 75 \\
\hline Needed capacity & 15 & 13 & & & \\
\hline Cost & 14 & 12 & Generic & \# & $\%$ \\
\hline Throughput time & 12 & 11 & & & \\
\hline \# of patients & 8 & 7 & Yes & 33 & 49 \\
\hline Other & 23 & 20 & No & 35 & 51 \\
\hline
\end{tabular}

The objective of most of the studies (75\%) was to design a model. Only $25 \%$ of the studies contained models that have been validated in practice. Half of the studies are generic. At $22 \%$, utilization is the most frequently used outcome measure, while other relevant outcome measures are cost, needed capacity, throughput time, and waiting times. 


\section{FIGURE 3 / Number of articles per type of model per year}

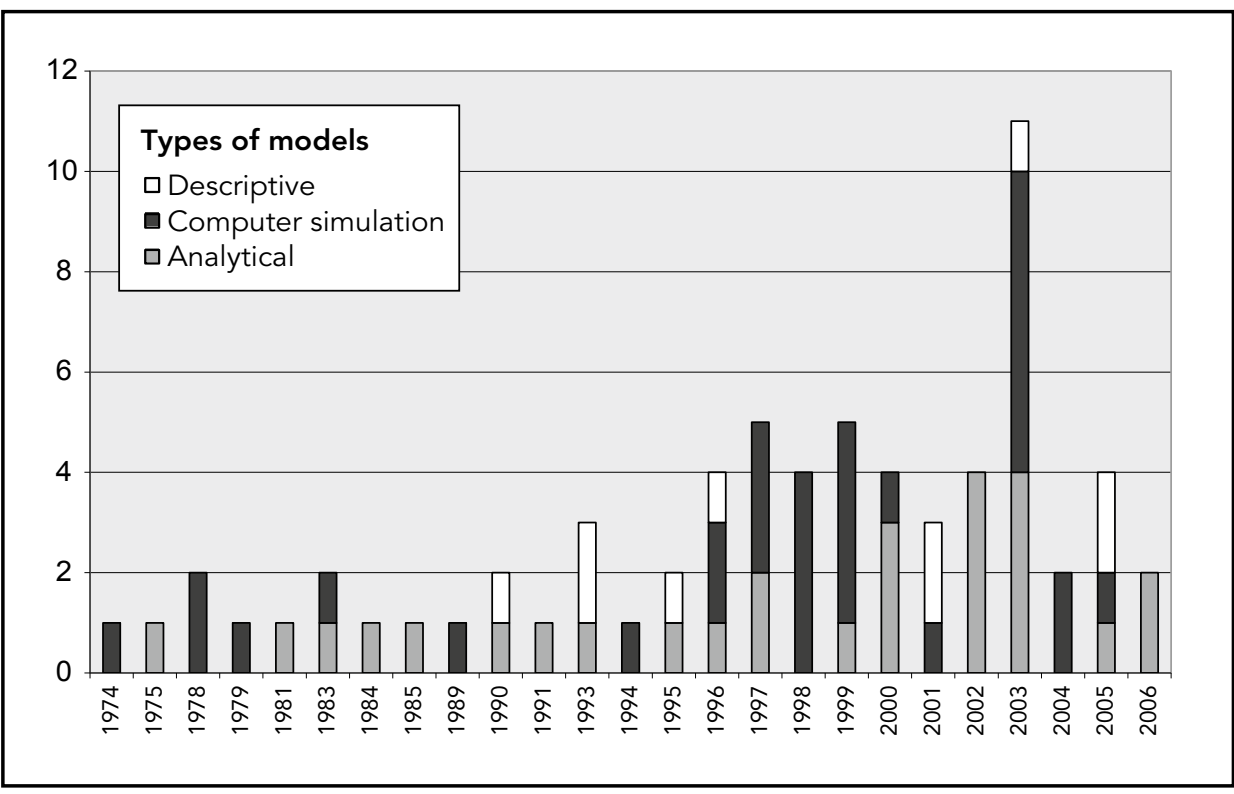

FIGURE 4 / Relationship between type of problem and type of model

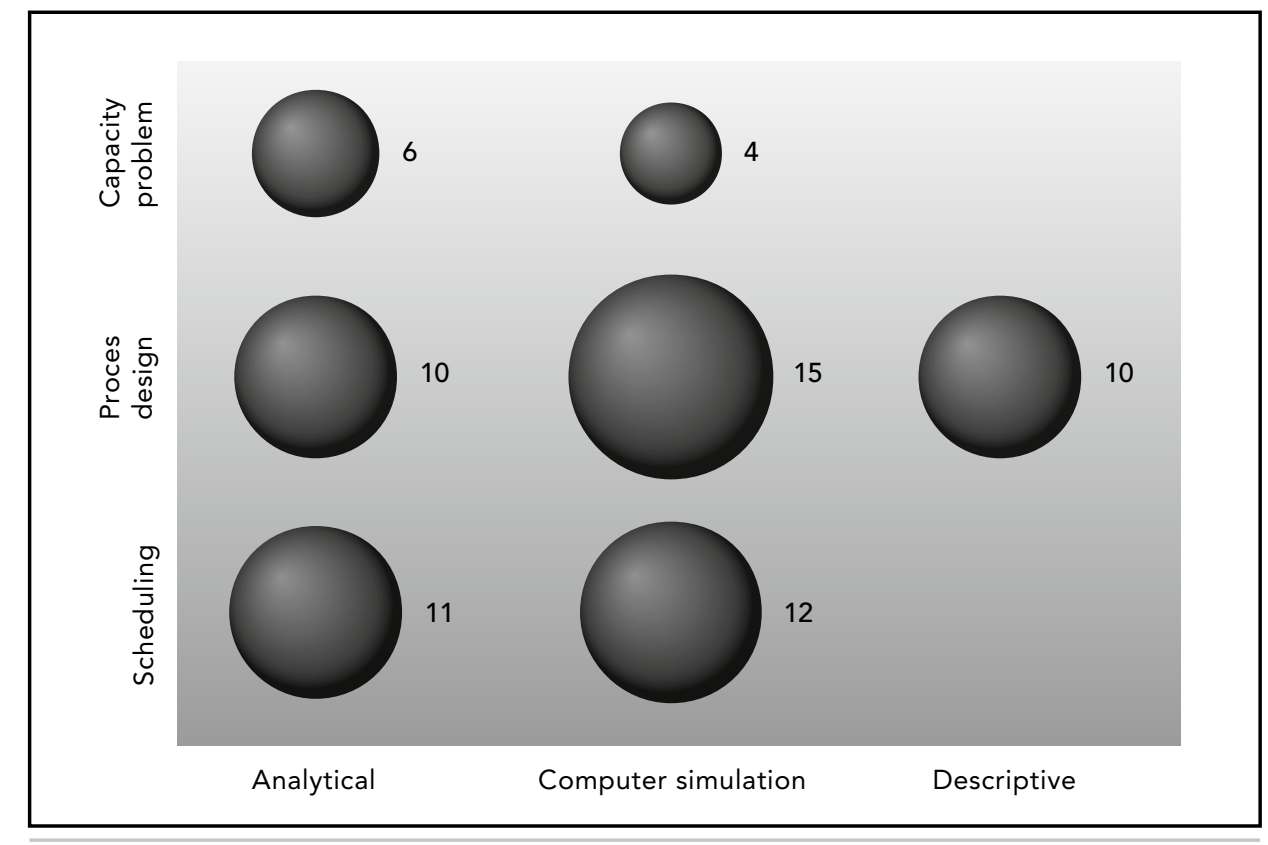

Figure 3 shows the number of articles published per year on the different types of model. This graph indicates that more articles on the subject are being published over the years, with a peak in 2003, especially on computer simulation models.

\subsubsection{Type of problem and model}

Figure 4 illustrates the relationship between the type of problem and the model. Descriptive models are only used for process design problems. The figure shows that capacity problems and scheduling problems have a similar relationship to the model types. The only difference is that capacity problems are evaluated slightly more often using analytical models, and scheduling

TABLE 5 / Relationship between problem type and other categories

\begin{tabular}{|c|c|c|c|c|c|c|c|c|}
\hline & & \multicolumn{7}{|c|}{ Problem Type } \\
\hline & & \multicolumn{2}{|c|}{$\begin{array}{l}\text { Capacity } \\
\text { problem }\end{array}$} & \multicolumn{2}{|c|}{$\begin{array}{c}\text { Process } \\
\text { design }\end{array}$} & \multicolumn{2}{|c|}{ Scheduling } & \multirow[b]{2}{*}{ Tota } \\
\hline & & $\#$ & $\%$ & $\#$ & $\%$ & \# & $\%$ & \\
\hline \multirow[t]{8}{*}{ Department } & Emergency room & 1 & $7 \%$ & 11 & $79 \%$ & 2 & $14 \%$ & 14 \\
\hline & Imaging diagnostics & & $0 \%$ & 1 & $50 \%$ & 1 & $50 \%$ & 2 \\
\hline & Inpatient & 3 & $23 \%$ & 8 & $62 \%$ & 2 & $15 \%$ & 13 \\
\hline & Intensive care & 3 & $50 \%$ & 2 & $33 \%$ & 1 & $17 \%$ & 6 \\
\hline & Laboratory & & $0 \%$ & 2 & $100 \%$ & & $0 \%$ & 2 \\
\hline & Operation room & 3 & $19 \%$ & 3 & $19 \%$ & 10 & $63 \%$ & 16 \\
\hline & Outpatient & & $0 \%$ & 7 & $50 \%$ & 7 & $50 \%$ & 14 \\
\hline & Radiotherapy & & $0 \%$ & 1 & $100 \%$ & & $0 \%$ & 1 \\
\hline \multirow[t]{2}{*}{ Generic } & No & 4 & $11 \%$ & 17 & $49 \%$ & 14 & $40 \%$ & 35 \\
\hline & Yes & 6 & $18 \%$ & 18 & $55 \%$ & 9 & $27 \%$ & 33 \\
\hline \multirow[t]{2}{*}{ Validated } & No & 10 & $20 \%$ & 21 & $41 \%$ & 20 & $39 \%$ & 51 \\
\hline & Yes & & $0 \%$ & 14 & $82 \%$ & 3 & $18 \%$ & 17 \\
\hline Outcome & Utilization & 2 & $8 \%$ & 10 & $40 \%$ & 13 & $52 \%$ & 25 \\
\hline \multirow[t]{6}{*}{ measure } & Waiting times & & $0 \%$ & 9 & $53 \%$ & 8 & $47 \%$ & 17 \\
\hline & Needed capacity & 8 & $53 \%$ & 5 & $33 \%$ & 2 & $13 \%$ & 15 \\
\hline & Cost & 2 & $14 \%$ & 6 & $43 \%$ & 6 & $43 \%$ & 14 \\
\hline & Throughput time & & $0 \%$ & 9 & $75 \%$ & 3 & $25 \%$ & 12 \\
\hline & \# of patients & 1 & $13 \%$ & 6 & $75 \%$ & 1 & $13 \%$ & 8 \\
\hline & Other & 3 & $13 \%$ & 15 & $63 \%$ & 6 & $25 \%$ & 24 \\
\hline
\end{tabular}


problems are evaluated more often using computer simulation models. Although process design problems are evaluated using all types of models, simulation models are used most often.

\subsubsection{Types of problems in relation to the other categories}

Table 5 (page 39) shows the relationships between the problem type and the other categories. In the operating room, scheduling problems are examined most often (63\%). Although process design problems occur in every department, this happens most frequently in the emergency room (79\%) and inpatient (62\%) departments.

\section{TABLE 6 / Relationship between model type and other categories}

\begin{tabular}{|c|c|c|c|c|c|c|c|c|}
\hline & & \multicolumn{7}{|c|}{ Model Type } \\
\hline & & \multicolumn{2}{|c|}{ Analytical } & \multicolumn{2}{|c|}{$\begin{array}{l}\text { Computer } \\
\text { simulation }\end{array}$} & \multicolumn{2}{|c|}{ Descriptive } & \multirow[b]{2}{*}{ Total } \\
\hline & & \# & $\%$ & \# & $\%$ & \# & $\%$ & \\
\hline \multirow[t]{8}{*}{ Department } & Emergency room & 4 & $29 \%$ & 6 & $43 \%$ & 4 & $29 \%$ & 14 \\
\hline & Imaging diagnostics & 1 & $50 \%$ & & $0 \%$ & 1 & $50 \%$ & 2 \\
\hline & Inpatient & 8 & $62 \%$ & 3 & $23 \%$ & 2 & $15 \%$ & 13 \\
\hline & Intensive care & 1 & $17 \%$ & 4 & $67 \%$ & 1 & $17 \%$ & 6 \\
\hline & Laboratory & & $0 \%$ & 1 & $50 \%$ & 1 & $50 \%$ & 2 \\
\hline & Operation room & 8 & $50 \%$ & 8 & $50 \%$ & & $0 \%$ & 16 \\
\hline & Outpatient & 4 & $29 \%$ & 9 & $64 \%$ & 1 & $7 \%$ & 14 \\
\hline & Radiotherapy & 1 & $100 \%$ & & & & & 1 \\
\hline \multirow[t]{2}{*}{ Generic } & No & 4 & $11 \%$ & 31 & $89 \%$ & & $0 \%$ & 35 \\
\hline & Yes & 23 & $70 \%$ & & $0 \%$ & 10 & $30 \%$ & 33 \\
\hline \multirow[t]{2}{*}{ Validated } & No & 22 & $43 \%$ & 27 & $53 \%$ & 2 & $4 \%$ & 51 \\
\hline & Yes & 5 & $29 \%$ & 4 & $24 \%$ & 8 & $47 \%$ & 17 \\
\hline Outcome & Utilization & 12 & $48 \%$ & 12 & $48 \%$ & 1 & $4 \%$ & 25 \\
\hline \multirow[t]{6}{*}{ measure } & Waiting times & 7 & $41 \%$ & 10 & $59 \%$ & & $0 \%$ & 17 \\
\hline & Needed capacity & 6 & $40 \%$ & 8 & $53 \%$ & 1 & $7 \%$ & 15 \\
\hline & Cost & 7 & $50 \%$ & 4 & $29 \%$ & 3 & $21 \%$ & 14 \\
\hline & Throughput time & 2 & $17 \%$ & 9 & $75 \%$ & 1 & $8 \%$ & 12 \\
\hline & \# of patients & 5 & $63 \%$ & 3 & $38 \%$ & & $0 \%$ & 8 \\
\hline & Other & 9 & $38 \%$ & 5 & $21 \%$ & 10 & $42 \%$ & 24 \\
\hline
\end{tabular}

\subsubsection{Types of models in relation to the other categories}

Table 6 shows the relationships between the model type and the other categories. What stands out in this table is that descriptive models are always generic, while computer simulation models are never generic. Analytical models are usually generic. What is also striking in Table 6 is that analytical and computer simulation models have seldom been validated in practice, while most of the descriptive models have been validated.

\subsection{Discussion}

Few systematic reviews have been applied to the specialty of health care management ${ }^{160}$. This is remarkable, since the systematic review is a widely used and highly accepted research technique in health care. In systematic reviews, the aim is usually to collect all relevant research about one specific topic in order to assess the "real truth" among the often numerous contradictions. When the topic concerns a causal relationship that is the basis for an optimal treatment or diagnostic method, it often is possible to find such real truth. In management research, though, this is more complicated due to the many elements and relationships within the managed system, and the large differences between specific situations. Moreover, this study made clear that, on the topic of health care management, the search itself is also more complicated. Despite having well-outlined and clearly defined inclusion and exclusion criteria, the subject appeared to be a very broad one. Literature was found in journals about general management, operational research, operations management, health management, and various hospital departments such as anesthesiology, radiology, intensive care, surgery, and emergency care. This shows the significance of consulting various databases when searching for health care management topics. Unfortunately, the comparability of the databases is limited, especially between management databases and medical databases. Moreover, the supply of MeSH headings or keywords in management databases corresponds poorly with the aim of systematically searching for health care management literature, and the management $\mathrm{MeSH}$ headings or keywords in health care databases have not been sufficiently developed. As a result, searching for articles about optimization of hospital processes is a timeconsuming activity, and contains the risk that even though a systematic procedure for reviewing is used, this may not turn up all of the relevant literature.

Our goal was to search for descriptive, analytical, and computer simulation models and to find relationships between types of problems and model types, as capacity problems, process design problems, and scheduling problems. 
Descriptive models, analytical models, and computer simulation models are often used to tackle the problems. It was assumed that due to the increasing professionalism in hospitals, advanced models such as computer simulation models would be used more frequently as time went on. Although the review showed an increase in the number of models, over time it did not show a development from descriptive models towards more and more computer simulation models. It is possible that the relative use of simulation models did actually increase when compared to less advanced models because of less reporting, since often simulation models may not be seen as scientifically relevant.

The results of this review showed some characteristics of the particular types of models. First, descriptive models are often generic and have usually been validated in practice, are used in different kinds of hospital departments, and use a range of outcome measures. Second, although most analytical models are generic, they have not usually been validated in practice. Analytical models are used most often in the operating room and inpatient departments. The main outcome measures are utilization, waiting times, and needed capacity. Third, computer simulation models are never generic and have usually not been validated in practice. They are used mainly in emergency rooms, operating rooms, and outpatient departments. The main outcome measures are utilization, waiting times, needed capacity, and throughput time.

It is useful for managers to know which type of model to choose for a given situation. All relevant models within this review are aimed at tackling managerial problems that can be classified into one of three types of problems: capacity problems, process design problems, and scheduling problems. The most obvious relationship between model type and problem type is that descriptive models were found only for process design problems. Capacity problems and scheduling problems were tackled using both analytical and computer simulation models to approximately the same extent. Process design problems - the problem encountered most often - were tackled by computer simulation models to a somewhat greater extent than by the other two model types. Furthermore, no significant relationships could be distinguished. No article mentioned the required expertise, the time needed, and the cost of the model. This information is obviously relevant with regard to the choice of a model. In fact, in all relevant studies, the reasoning for the choice of model type was absent. It presumes that choosing for a specific type of model is, for the most part, based on the available expertise and resources.
A managerial model is defined as a representation of a real system that gives insight into the system's behavior, with interfaces with reality corresponding with the aim of use. The aim of use is to help the manager confronted with a problem solve the problem by providing insight into the consequences of different scenarios. Based on this insight, management can then decide to change aspects of the organization (or not) and in what way. It is striking that the overwhelming majority of the papers did not mention what decision the managers took based on the model's outcomes. In other words, it was not possible to find evidence that the models are being used in the way they were intended to be used. This leads to the assumption that the means often becomes the end - that is, building the model becomes more important than using it. A probable explanation for this is that the models presented in peerreviewed literature were built mainly by researchers who intended them to be used for scientific reasons rather than for practical applications. Because we only searched scientific databases, this could be a bias of our review. We are very aware of the fact that a vast number of effective models are being used by managers, and that these have not been published. We would suggest that researchers pay more attention to basing the similarities on the aim of a model it is often possible to make a model simpler, and more effective.

\subsection{Practical implications}

This review provided insight into the appropriateness of different model types in various situations. Although no article gave background on why a model type was chosen, it was possible to extract shared characteristics per model type from the articles. This insight can provide support for managers in choosing a model type for their specific problems. To choose a model, explicit criteria have to be defined. This, in combination with characteristics per model type, determines the final choice. Table 7 summarizes the most important characteristics per model type. 


\section{TABLE 7 / Model type characteristics}

\begin{tabular}{lccc}
\hline Type of Model & Descriptive & Analytical & Computer Simulation \\
\hline Cost & + & + & - \\
Time to develop & + & + & - \\
Generic & + & $+/-$ & - \\
Variability & - & - & + \\
Dependability & - & $+/-$ & + \\
Face validity & + & - & + \\
Validity & $+/-$ & - & + \\
Theoretical optimum & - & + & - \\
Sensibility to input value & + & - & $+/-$ \\
\hline
\end{tabular}

A plus means that the model type scores well for this criteria. The selection criteria are explained as follows:

- Cost: Some models are typically more expensive to develop or procure than others because of the advanced software or expertise required.

- Time to develop: The time span between the choice of a model and the moment the model can be used.

- Generic: The extent to which a model can be used for situations other than the one it was designed for.

- Variability: The extent to which variability can be taken into account.

- Dependability: The extent to which the model's results are representative for the real situation.

- Face validity: The extent to which stakeholders' recognition of the real situation in the model supports their trust in the model.

- Validity: The extent to which the model represents the real situation.

- Sensibility for input value: The extent to which inaccuracy of the model's input values influence the model's results.

Figure 4 (page 38) can be explained in part when these characteristics are linked to the three problem types. Because exact numbers are required, the main criterion for scheduling and capacity problems is usually dependability. Analytical and computer simulation models score well for this criterion and indeed, no descriptive models were found that tackle these problems. The review showed that other characteristics are highly dependent on a specific situation, not on the global problem type. For instance, aspects such as culture, available financial or human capacity, influence of stakeholders, specific pro- cesses, a deadline, and the level of detail of the present information can greatly influence a model's desired characteristics. Therefore, Table 7 can help every manager who is considering using a model to support a decision that concerns optimizing patient flows in a specific situation.

\subsection{Conclusion}

Models for the design and control of processes concerning patient flows within departments in a hospital are frequently applied to managerial problems in hospitals. Although our review resulted in a promising amount of papers, few reported the consequences of implementing the model's results, and this was especially true for analytical models and computer simulation models. This makes it hard or even impossible to evaluate the usability of the models. Furthermore, we could find no clear relationship between a problem type or situation and the most effective model type. Which model is most appropriate depends on many parallel factors. In general, descriptive models are most appropriate when the model has to be generic, and qualitative and computer simulation models are most appropriate when situations are complex with a high degree of variability, and when the results must be specific and quantitative.

We propose introducing more specific MeSH headings and keywords to improve the tractability of health care management studies. Although we suc ceeded in finding interesting relationships and characteristics per model type when confronted with a general type of problem, we cannot conclude by putting forward the most appropriate model. This depends on too many elements in addition to the problem type. Up to now, research overviews within the field of health care management have almost exclusively been performed by random searches. We argue that, in the context of health care management, a systematic review is an effective technique for getting a reliable overview of research on a subject. 


\section{APPENDIX 1: KEYWORDS}

\begin{tabular}{|c|c|c|c|}
\hline Criteria & $\begin{array}{l}\text { PubMed MeSH } \\
\text { Headings }\end{array}$ & $\begin{array}{l}\text { Embase } \\
\text { Subject }\end{array}$ & $\begin{array}{l}\text { Business Source } \\
\text { Elite }\end{array}$ \\
\hline $\begin{array}{l}\text { 1. Design/ } \\
\text { control model }\end{array}$ & $\begin{array}{l}\text { - Personnel Staffing and } \\
\text { Scheduling } \\
\text { - Decision Support } \\
\text { Techniques } \\
\text { - Health care rationing } \\
\text { - Hospital planning } \\
\text { - Health resources } \\
\text { - Workload } \\
\text { - Systems analysis } \\
\text { - Planning techniques } \\
\text { - Forecasting } \\
\text { - Appointments and } \\
\text { schedules }\end{array}$ & $\begin{array}{l}\text { - Hospital Planning } \\
\text { - Patient Scheduling } \\
\text { - Health Care Financing } \\
\text { - Resource manage- } \\
\text { ment } \\
\text { - Process design } \\
\text { - Process control }\end{array}$ & $\begin{array}{l}\text { - Scheduling } \\
\text { - Planning } \\
\text { - Medical care } \\
\text { - Cost shifting } \\
\text { - Decision support } \\
\text { systems }\end{array}$ \\
\hline $\begin{array}{l}\text { 2. Supporting } \\
\text { department }\end{array}$ & $\begin{array}{l}\text { - Hospital Departments } \\
\text { - Hospital Units }\end{array}$ & - Hospital Department & - Hospitals \\
\hline 3. Kind of model & $\begin{array}{l}\text { - Models, Statistical } \\
\text { - Models, Organiza- } \\
\text { tional } \\
\text { - Models, Theoretical } \\
\text { - Systems Theory } \\
\text { - Computer Simulation }\end{array}$ & $\begin{array}{l}\text { - Experimental Model } \\
\text { - Theoretical Model } \\
\text { - Computer Model } \\
\text { - Statistical Model } \\
\text { - Stochastic Model } \\
\text { - Process Model } \\
\text { - Computer Simulation }\end{array}$ & $\begin{array}{l}\text { - Models \& model } \\
\text { making } \\
\text { - Mathematical } \\
\text { models }\end{array}$ \\
\hline $\begin{array}{l}\text { 4. Performance } \\
\text { improvement }\end{array}$ & $\begin{array}{l}\text { - Efficiency, Organiza- } \\
\text { tional } \\
\text { - Time management } \\
\text { - Length of Stay } \\
\text { - Bed Occupancy } \\
\text { - Hospitals/utilization } \\
\text { - Patient Admission } \\
\text { - Organizational } \\
\text { innovation } \\
\text { - Time factors } \\
\text { - Quality of health care } \\
\text { - Waiting lists }\end{array}$ & $\begin{array}{l}\text { - Time Management } \\
\text { - Productivity } \\
\text { - Health Care Quality } \\
\text { - Job Performance } \\
\text { - Hospital Utilization } \\
\text { - Hospital Admission } \\
\text { - "Length of Stay" }\end{array}$ & $\begin{array}{l}\text { - Time manage- } \\
\text { ment } \\
\text { - Mathematical } \\
\text { optimization } \\
\text { - Waiting period } \\
\text { - Health facilities } \\
\text { - Utilization }\end{array}$ \\
\hline
\end{tabular}

\section{APPENDIX 2: FREE-TEXT WORDS}

\section{Free-text words: Embase and PubMed}

- Criterion 1: patient process, process of the patient flow, patient flow process, design of the process, process design, design of the patient process, process management, management of the process, management of the patient process, manage the process, manage the patient process, managing the process, managing the patient process, process control, control of the process, control of the patient process, operations management, organization of the process, organization of the patient process, organizing the process, organizing the patient process, organization of the process, organization of the patient process, organizing the process, organizing the patient process, organization of the process, organization of the patient process, organizational design, organization of the process, organization of the patient process, organizing the process, organizing the patient process, organization of the process, organization of the patient process, organizing the process, organizing the patient process, organization of the process, organization of the patient process, organizational design

- Criterion 2: department, hospital division

- Criterion 3: model, framework

- Criterion 4: optimization of resources, resource optimization, resource utilization, utilization of resources, process optimization, optimization of the process, optimizing the process, process improvement, improvement of the process, improving the process, improving the patient process, optimizing the patient process, improving performance, performance improvement, capacity utilization, utilization of capacity, optimisation of resources, resource optimisation, process optimisation, optimisation of the process, optimising the process, optimising the patient process, resource utilization, utilization of resources, capacity utilization, utilization of capacity

\section{Free-text words: Business Source Elite}

- Criterion 1: process, design, control, operations management

- Criterion 2: hospital

- Criterion 3: model, method, framework, too

- Criterion 4: optimization of resources, resource optimization, resource utilization, utilization of resources, process optimization, optimization of the process, optimizing the process, process improvement, improvement of the process, improving the process, improving the patient process, patient flow, 


\section{CHAPTER 3}

Applying the variety reduction principle to management of ancillary services

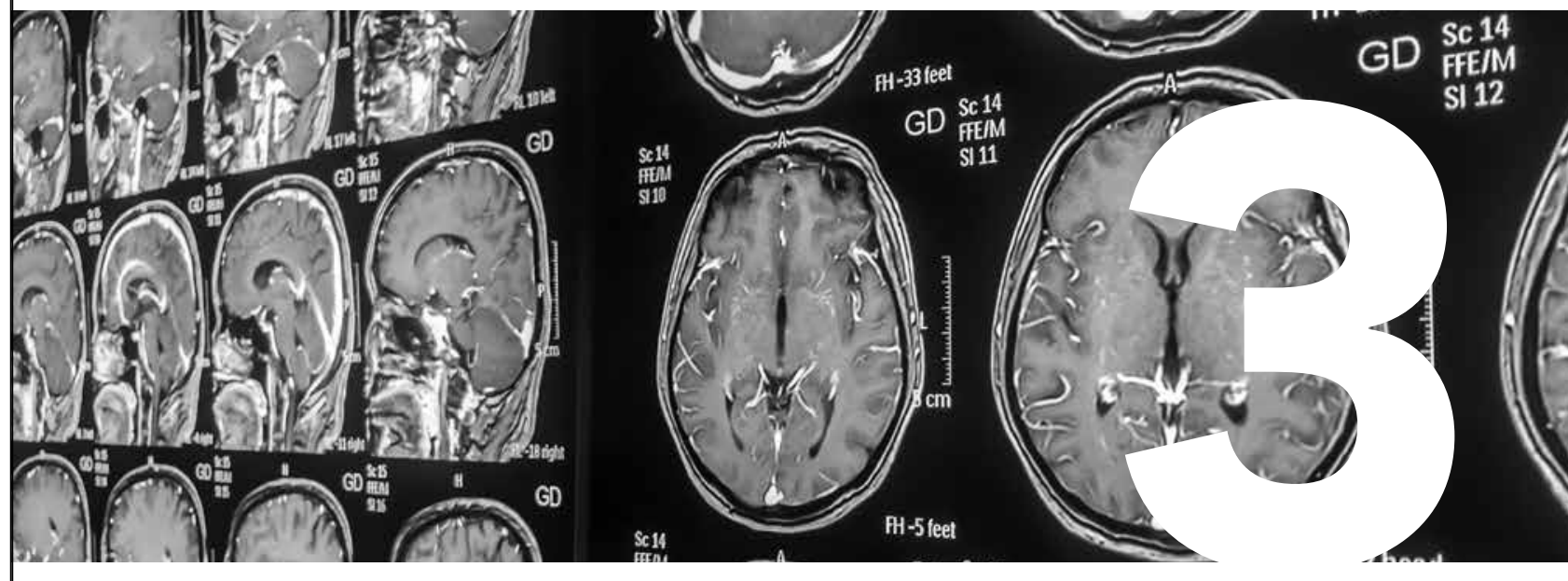




\section{LITERATURE UPDATE FOR CHAPTER 3}

In the study presented in this chapter, we developed a process design intervention that we then applied to the CT scan facilities. What we contributed to the literature was, on the one hand, the insight into the influence of variability on the process performance of these facilities, and on the other, that we demonstrated this in practice. Our study was published in 2007, and what follows here is an overview of the literature related to our study that was published after our own.

Several studies focused on improving the operational performance of the CT scanning process. Boland et al. (2008) ${ }^{161}$ identified several strategies and tactics that can be used to enhance CT capacity. One of the interventions they proposed is the same intervention we introduced in our publication and which was implemented in the Academic Medical Center (AMC). Grant et al. (2012) (33 $^{4}$ also proposed several strategies to improve operational performance and reduce imaging costs. Jin et al. (2011) 162 used computer simulation to analyze several predefined scenarios with a varying number of CT scanners and CT locations to identify the optimal patient flow management strategy. Karstoft (2011) used "lean management" to improve the performance of the CT scanning process. ${ }^{163} \mathrm{Hu}$ et al. (2010) ${ }^{164}$ used informatics and benchmarks to improve productivity and reduce the cost of the imaging services. Boland and Duszak (2014) ${ }^{165}$ used the concept of the imaging value chain, and suggested several interventions to optimize modality operations. None of the results of these studies demonstrated that their suggested interventions would work in practice.

We found a related discrete event computer simulation study using OM in nuclear medicine, and using a multi-stakeholder perspective. ${ }^{166}$ This study aimed at finding the optimal balance between waiting time, cycle time, and patients' preferred appointment times and equipment utilization, human resource utilization, and patient throughput from the hospital management's perspective. Our main conclusion - to move as many activities as possible out of the CT scanner room - is also stated by Reinus et al. (2000) ${ }^{167}$ The difference between their study and ours is that while they used mathematical scheduling to predict the improvement, we implemented it in practice to demonstrate this.

Several years after our study was published, Tokur et al. (2012) ${ }^{168}$ also arrived at the same solution of placing intravenous (IV) catheters outside of the scanner room. Unfortunately, they did not measure the effect of the imple- mentation accurately. Falsini et al. (2010) ${ }^{169}$ introduced a flexible heuristic procedure for real-time appointment scheduling in a diagnostic imaging center using set-up time minimization. Like many studies, they focused on better scheduling, while we redesigned and changed the process. Taner et al. (2012) ${ }^{170}$ conducted a six-sigma study and found two major disturbing process steps in their imaging process: malfunction of the system and improper positioning of patients. According to our study, they tackled the process steps with the highest level of disturbance, and implemented the improvements. In their case, this was not a process redesign, but rather incremental changes, like training of staff.

We conclude that the new literature supplements our conclusions.

\section{ABSTRACT}

As central diagnostic facilities, CT scans appear to be bottlenecks in many patient-care processes. An important cause of relatively low-capacity utilization is variability in the time needed for the scanning process. By reducing this variability, we managed to simultaneously reduce access times from 21 days to 5 days and increase the utilization rate from $44 \%$ to $51 \%$ at the Academic Medical Center, Amsterdam, the Netherlands. Our strategy is applicable in every appointment-based hospital facility with variation in the length of time of the process. It allows to simultaneously reduce costs and improve service for the patient.

\subsection{Introduction}

Although seemingly contradictory, improving patient service and restricting healthcare expenditures are the concern of every health care organization. Porter ${ }^{171}$ suggests that although both are possible in theory, most authors focus only on improving hospital productivity ${ }^{172-174}$. While research focused on both service improvement and cost reduction in health care is scarce, we show this combination is possible.

Suboptimally organized diagnostic resources are the bottleneck in many patient flows, therefore hampering optimization of patient services and savings on costs ${ }^{175,176}$. Contrary to other central facilities such as the operating room and outpatient department, there is little literature about optimization of diagnostic departments. This study describes a case study concerning redesign of a Computer Tomography scan (CT scan) department in the 
Academic Medical Center in Amsterdam, one of the leading academic hospitals in the Netherlands. Both managers of hospital departments and researchers may profit from our approach and findings.

An effective way of cost reduction in a capital-intensive process such as the CT scan is to increase the utilization level. Optimizing the utilization of central facilities is entirely relevant, because increasing the capacity is only possible in very large steps and is extremely costly. Several studies have focused on increasing resource utilization, including beds ${ }^{177,178}$, operating theatres ${ }^{102,179-181}$, emergency departments ${ }^{97}$ and hospital resources in general ${ }^{172,182}$. Causes of inefficient utilization and delays pointed out by previous studies are: interdependent resources ${ }^{183}$, the "snowball effect" (patients deliberately arriving late because of experiencing delays in the past), complex interrelationships within an organization, waiting for other hospital facilities ${ }^{184}$, and an exaggerated perception of uncertainty in health care environments ${ }^{\mathbf{1 8 5}}$. However, there is little in the literature about diagnostic resource utilization.

High access times cause both bad experienced patient service and unnecessary costs ${ }^{175,176}$. We define access time as the time between the doctor's statement that some kind of facility is necessary for a patient, and the moment this patient is actually making use of this facility. Just like utilization research, studies that concentrate on the reduction of access times generally do not focus on diagnostic facilities ${ }^{174,184,186}$

According to queuing principles ${ }^{187}$, although capacity utilization and access time reduction are conflicting objectives, hospitals want to optimize both. Relatively few papers focus directly on both the increase in the utilization of hospital resources and the reduction of access time, perhaps because of the apparent contradiction. Therefore, our research fills a gap in the current literature by analyzing the possibility of optimizing both values simultaneously, and by aiming for a diagnostic facility.

The main objective of our study was to practice Porter's theory of combining service improvement and cost reduction for a diagnostic department. We chose the CT scan as an example of a central facility for the following reasons: its access time was far too high, it forms an essential part of many clinical pathways, the demand for scans is continuously increasing, and it is an expensive device. We have tried to make the CT scan less of a bottleneck by reducing its access time, which contributes to patient service and indirectly to cost reduction, and improve productivity by increasing its utilization. Therefore we formulated the following research question: Can we decrease access time for the CT scan and simultaneously increase its utilization level?

\subsection{Theoretical Framework}

Productivity in health care is strongly affected by the inherent variability of arrival and service times ${ }^{\mathbf{1 8 8}}$. Variability is, therefore, a primary factor of interest in controlling hospital capacity $100,185,189,190$. Concerning the CT scan process, we distinguish two kinds of variability: arrival variability and flow time variability. Arrival time variability is the randomness of demand for the CT scan. Flow time variability is the level of variation of real process time.

To reduce the effects of arrival time variability, the AMC uses an appointment-based system for the CT scan. A standard lead-time per appointment is quoted for this, which includes a flow time and planned slack. We refer to the flow time as the actual time a patient is in the process, and the slack time functions as a buffer against variations in the flow time. All appointments are planned in succession, which implies that the maximum amount of appointments per time interval is the total time the capacity is available, divided by the lead-time.

The slack time is quoted based on the desired service level, in other words, on the wait in the waiting room. This service level is thus determined by the

\section{FIGURE 5 / Variability concept}

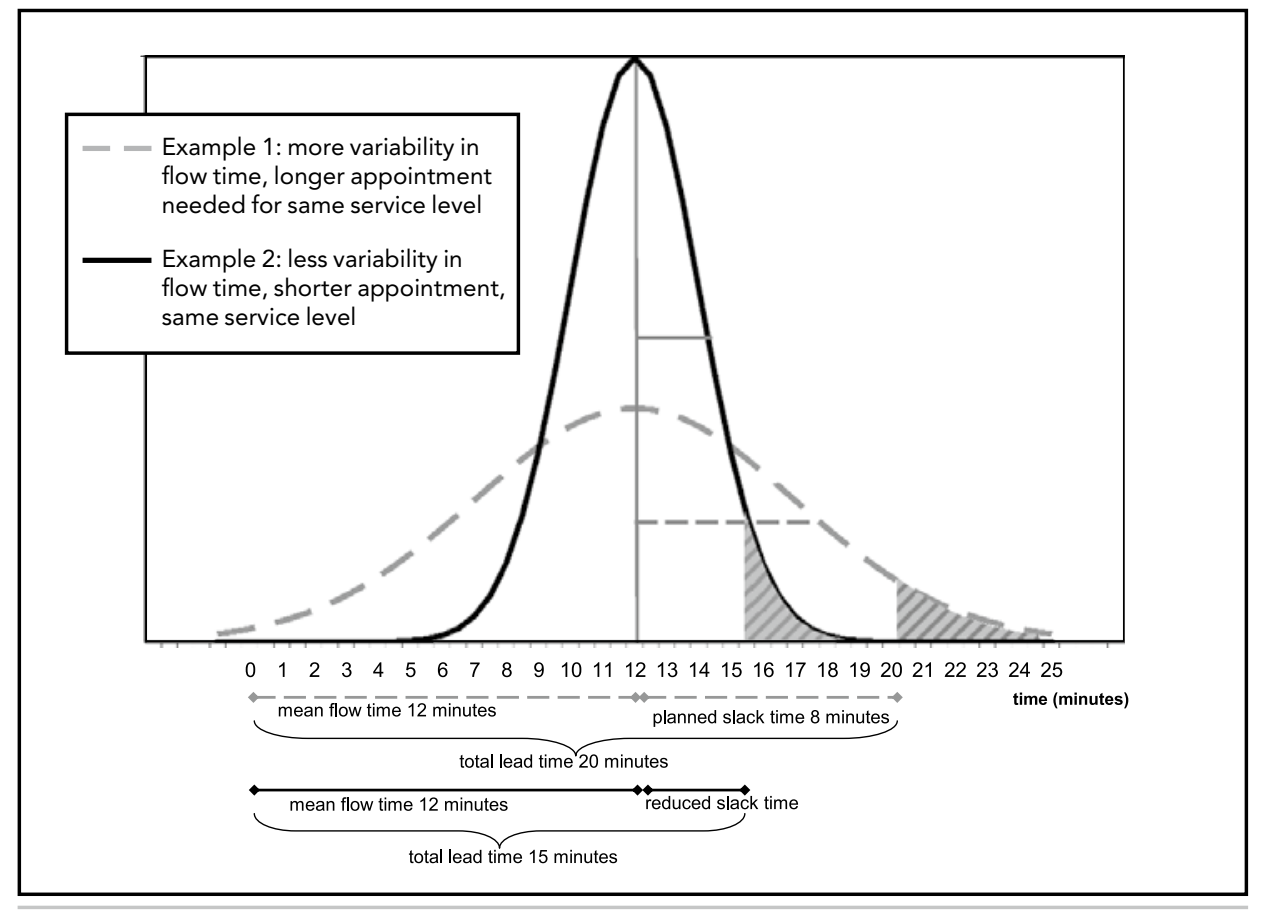


probability that the actual flow time does not exceed the lead-time. This probability depends on the mean flow time, the variability of the flow time, and the amount of the planned slack ${ }^{191}$, see Figure 5 . The higher this probability, the shorter the mean waiting time of patients in the waiting room. It is essential to understand that a loss of capacity is effectuated every time the flow time is shorter than the lead-time. Moreover, expanding the lead-time leads to increased access times, because then fewer appointments can be scheduled per time interval. This makes clear that shortening lead-times both increases resource utilization and reduces access times. However, the question remains as to how this can be achieved while maintaining the average waiting time in the waiting room. The answer: by reducing the variability in flow time, which is exactly what this research aims to do.

\subsection{Methods}

The AMC radiology department has three CT scans, including a dedicated one for the Emergency Department. This project focused on the other two CT scans. Since a randomized controlled study was not feasible, the project used a time-series design with several measurement periods as the second-best approach for obtaining the empirical data ${ }^{192}$ (Shojania \& Grimshaw, 2005). The project consisted of three phases (see Figure 6):

Phase 1: A qualitative and quantitative analysis of current processes; identification of bottlenecks; selection of interventions with the greatest expected reduction of variability in flow time.

\section{FIGURE 6 / Phases in project}

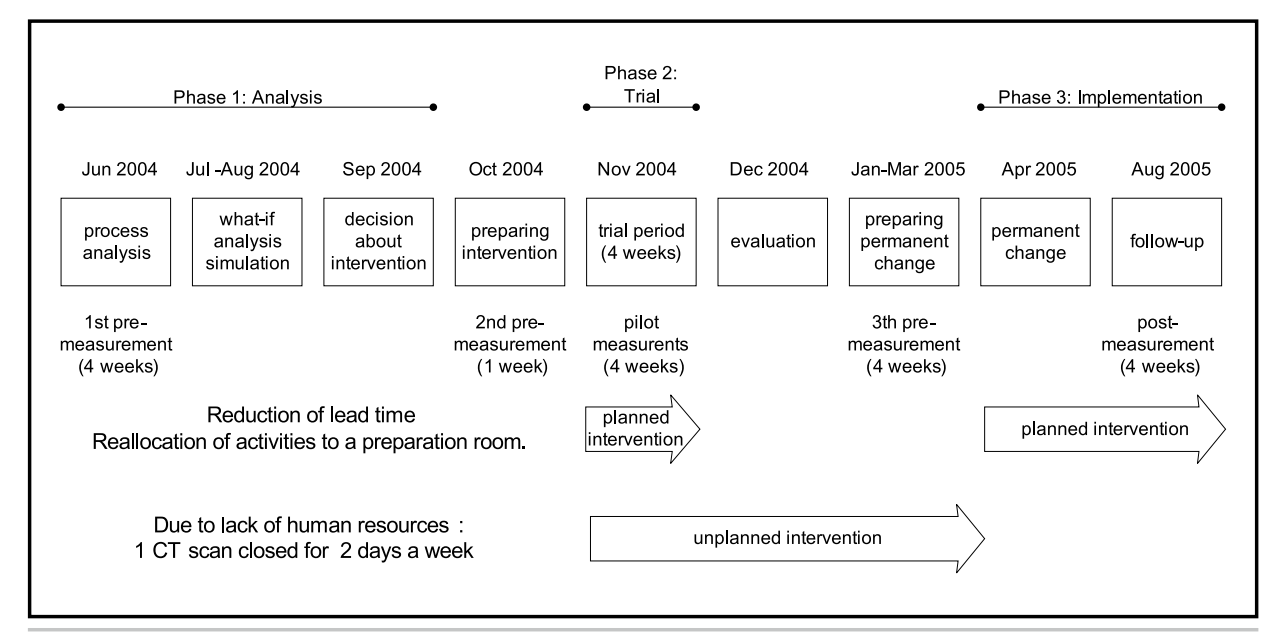

Phase 2: Trial period for proposed changes, accompanied by measurements. In the evaluation of the trial, results were compared with the expectations that emerged from the analyses.

Phase 3: Preparation for permanent changes, implementation, and quantified evaluation of effects, with a post-measurement period.

\subsubsection{Phase 1: Analysis}

The process analysis consisted of a qualitative process mapping of the processes related to making appointments and the working processes in the scanning rooms. Data were gathered by observation on working days and by interviews with radiology assistants, administrative staff, and management. Bottlenecks were analyzed using fishbone diagrams. Parameters for which quantitative data are gathered in this phase are listed in Box 1 (page 56).

Retrospective access time was measured from January 2004 through August 2005. Using our planning system (XCare, McKesson), we calculated the access time for all patients that were referred for a CT-scan, and averaged that for each date. For the utilization and prospective access time, we used two pre-measurement periods, the first in June 2004 and the second in October 2004. We used the measurement results from the first period as input for brainstorming sessions on improvements.

We did not perform a quantitative measurement of the variability in flow times. Due to the enormous variation in types of scans, it was hard to get reliable results. Instead, we gained insight into the most variable parts of the whole scanning process by observation, and by relying on the radiology assistants' expertise.

Based on the process analysis, possible interventions for reducing variability were found by brainstorming with the working group members. The most promising and most feasible opportunity appeared to be to reallocate the insertion of intravenous access lines to a preparation room. The time needed for this activity was very hard to predict and needed a lot of slack in the lead-time for appointments. Because of the wish to minimize the risk of running behind schedule time, the variability in this activity caused the lead-time to be much longer than the average flow time. By removing it from the CT room, lead-time could be reduced by 5 minutes.

\subsubsection{Phase 2: Trial intervention}

In phase 2, we implemented the changes for a 4-week period. Each day, one of the four radiology assistants was assigned to insert intravenous access 
- Utilization of CT-rooms: distribution of time spent to several pre-defined categories of activities (during opening hours): The activities were categorized by the following five activities: preparation of patient, scanning, finishing, room empty due to waiting for new patient (room and radiology assistants are is ready for next patient, but the next scheduled patient has not arrived yet), room empty for other reasons (f.e. cleaning). We applied a work-sampling in which at random time intervals, with an average of 1 minute, the situation in the room was recorded. We measured several times within one week during four hour periods. The preparation starts when the patient enters the room and consists of removing metal materials, inserting intravenous access lines and informing patients about the procedures. In the scanning time, we include positioning of the patient on the equipment and performing the scan. Scanning time ends with the patient leaving the equipment. Finishing ends when the patient has left the room and the scan software is ready with calculation and saving the CT data. We see the scanning time as the primary utilization aim of the capacity. Beside, preparation and finishing is inevitable, but should be kept as short as possible. Room empty time has to be reduced as far as possible.

- Access time (prospective): time between request for a CT scan and the appointment (in working days). Different time frames were allocated to outpatients and to inpatients. Furthermore, the CT scans differed in the type of scans that could be made, so for each scan a distinct access time was measured. During 4 weeks, we measured the third possible appointment (CBO, 2005) two times a week by searching in the planning system for possible time slots for 3 categories of patients: inpatient body-scans (CT2), outpatient bodyscans (CT2) and outpatient neurological scans (CT1). For neurological scans (CT1) for inpatients, no access time existed.

- Access time (retrospective): time between request for a CT scan and the appointment (in working days). For all patients we calculated the number of working days between referral and scanning-date. For each date between January 1, 2004 and August 31, 2005, we calculated the average access time for all appointments arranged on that day. We skipped the measurements from the analysis when more than 50 days passed between these dates. We expected these exceptional long delays not to express access times but to be chosen for medical reasons or by patient preferences.

Prospective measured access time was our preferred parameter, but we could get only two measurement points each week. For this reason we supplement measurements with retrospective analyses of all patient access times. lines. We measured the same variables as during the first phase (see Box 1 : Measurements). In addition to these measurements, we assessed the experiences of the radiology assistants.

Unfortunately, along with our planned intervention, an unplanned change took place. Due to a lack of radiologists, the department had to close down one of the two scans for 1.5 days each week. They chose to close down CT1.

\subsubsection{Phase 3: Implementation and further improvements}

In phase 3, preparations were made for permanent changes. With the start of the new working methods in April 2005, the radiologist shortage problem was solved and the work schedule returned to normal.

Radiology assistants experienced some inconveniences with the new working processes during the trial period. From their point of view, they did not have enough time for their patients because one assistant inserts the intravenous access line and another helps the patient in the scanning room. We modified working processes slightly based on the observations of the radiology assistants. Instead of assigning a radiology assistant to patient preparation, a doctor's assistant performed this task for both CT scans. Moreover, due to the intensified day programs, there was less time to adapt to disturbances such as late patient arrivals and lost or unclear request forms. So, in the next phase we tried to remove these kinds of disturbances as much as possible. We changed the referra procedure so that a Radiologist assesses the request form on the day of referra with the result that all referrals were clear and no forms are missing at the ap pointment days. Furthermore, we ask patients to show up ten minutes before appointment time. Again, we measured the figures mentioned in Box 1: Measurements; we measured prospective access time from March 2005 through September 2005. The utilization measurement was performed in September 2005.

\subsection{Results}

\subsubsection{Phase 1: Analysis}

Flowcharts and fishbone diagrams (not presented here) were composed, and the following data were gathered:

Utilization of scan capacity: During opening hours, $44 \%$ of the time was used for positioning the patient and performing the scans. An additional $21 \%$ was used for preparation (11\%) and finishing up (10\%). From the process observation, we learned that the time needed for preparation activities had the highest variability. Furthermore, the CT room was empty $35 \%$ of the time 


\section{FIGURE 7 / Utilization of CT capacity}

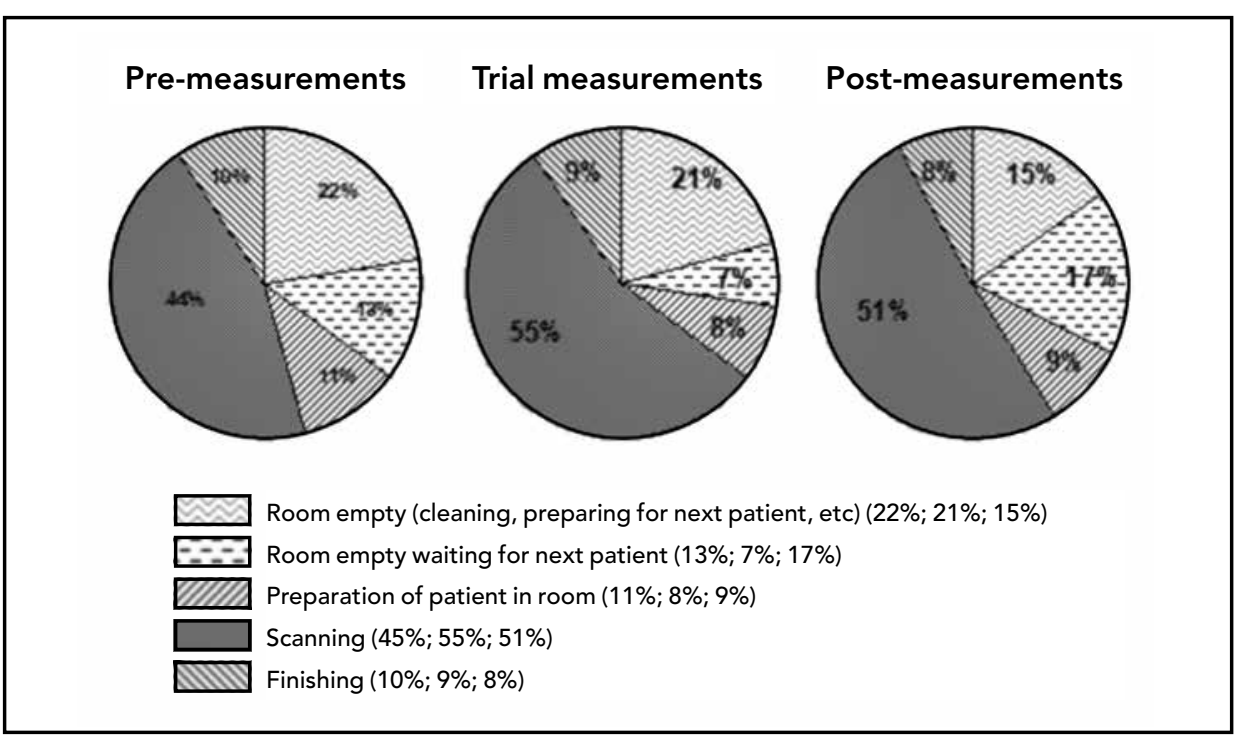

due to cleaning and preparing for the next patient, or waiting for a patient who had not yet arrived (see Figure 7). The waiting for next patient $(11 \%)$ is due to the planned slack.

Access time (prospective): The third possible appointment appeared to be different for the various patient groups. For outpatients, the access time was 6 working days for neurological scans (CT1) and 16 working days for body scans (CT2). For inpatients, the access time was shorter: 4 days for planned body scans. Neurological scans for this patient group were to a large extent accomplished during the time slots reserved for same-day service.

Access time (retrospective): Figure 8 shows the average access time for three 3-month periods. It appeared that access time decreased from 15.4 days (sd 3.4) for CT1 and 14.7 (sd 3.9) in the first quarter of the year to 11.4 (CT1, sd 3.2) and 12.9 (CT2, sd 3.2) in the third quarter. So when interpreting the intervention results we have to take this decrease into account.

\subsubsection{Phase 2: Trial intervention}

Utilization: Percentage of scanning time increased to $55 \%$ (before $44 \%$ ); preparation and finishing up took $17 \%$ (before $21 \%$ ), and room-empty time $28 \%(35 \%)$. As can be seen in Figure 3: Utilization of CT capacity the waiting time until the arrival of the next patient decreased from $13 \%$ to $7 \%$. Although

\section{FIGURE 8 / Access times (retrospective)}

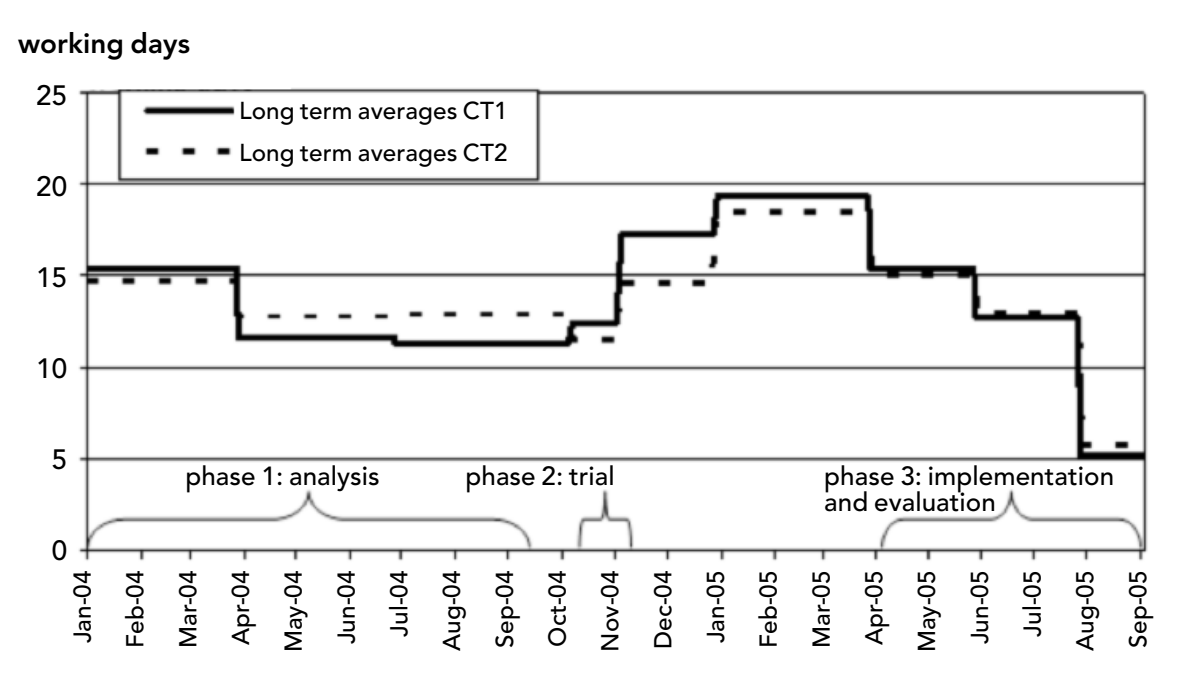

less time per patient was used, the increase in the number of patients led to a relative increase in preparation activities. However, the time necessary for preparation in the scanning room became more predictable and less variable.

Access time (prospective): For outpatients, the third possible appointment was on average 11 working days for neurological scans (CT1) and 13 working days for body scans (CT2). For inpatients, the access time remained about 3 days for planned body scans.

Access time (retrospective): Figure 4: Access times (retrospective) shows that the access time for CT1 increased to almost 12.4 days (sd 2.2) and that there was a slight decrease in access time for CT2, to 11.5 days (sd 2.5). No significant reduction in access time was found for the combination of planned and unplanned interventions.

\section{Results of Phase 3: Implementation and further improvements}

Utilization: Percentage of scanning time was $51 \%$ (before $44 \%$ ); preparation and finishing took $17 \%$ (before $21 \%$ ) and room-empty time $32 \%$ (before 35\%) (see Figure 3: Utilization of CT capacity and Table 2).

Access time (prospective): Measurements for third appointments even increased to 32 working days for outpatients in March 2005, due to the closing of CT capacity during this period. After the intervention, access time de- 
creased to less than 5 working days for all patients in August 2005. In September 2005, we reached an access time of 1 day for all patient categories.

Access time (retrospective): Due to the reduction in capacity, access times have risen to 19.3 working days (CT1, sd 4.7) and 18.5 working days (CT2, sd 3.4) for outpatients in January through March 2005. Figure 4: Access times (retrospective) shows that access times decreased from the start of the intervention. There was some time needed to reduce the backlog. In July through September 2005, access time was decreased to 5.2 working days (CT1, sd = 2.9) and 5.8 working days (CT2, sd 3.0). Compared with each of the previous measurement periods, this was a significant reduction $(p<0.001)$. Until now, access times have remained less than 5 working days.

A summary of the results can be found in Table 8 .

\subsection{Discussion}

This paper demonstrates the possibility of reducing access time and increasing the utilization of an appointment-based diagnostic hospital facility. This is therefore a good example of an application of Porter's theory that cost reduction and productivity improvement can be attained together. By doing away with the part of the process that contributed most to flow time variability, we were able to reduce the lead-time of the process (productivity improvement) without increasing waiting times in the waiting room. The intervention resulted in a decrease of access time from 21 days to less than 5 days, and an increase of the utilization rate from $44 \%$ to $51 \%$. This contributed directly to patient service and indirectly to cost reduction.

From the comparison of utilization between pre- and post-measurements (see Figure 3: Utilization of CT capacity), it appeared that no substantial improvements were found. The time the scanning room was empty due to waiting for the next patient increased from $13 \%$ to $17 \%$. However, we encountered that during the final work sampling measurement, there was some waiting time for the next patient due to open spaces in the schedule. This could also explain the relatively low utilization of the scan capacity compared with the measurements during the trial period (Figure 3: Utilization of CT capacity). These open spaces indicate that the department has the opportunity to deal with fluctuations in demand for CT-scans without increasing access times in a busier period.

Positive consequences of the results are better service for patients (because of smoother and shorter flows through the hospital) and a higher level of hospital productivity. In addition, it breaks the vicious circle of CT scan access
TABLE 8 / Summary of the results

\begin{tabular}{|c|c|c|c|}
\hline \multicolumn{2}{|c|}{ Pre-measurements } & \multirow{2}{*}{$\begin{array}{l}\text { Trial period } \\
55 \% \\
(53 \%-57 \%)\end{array}$} & \multirow{2}{*}{$\begin{array}{c}\text { Post-measurements } \\
51 \% \\
(48 \%-54 \%)\end{array}$} \\
\hline $\begin{array}{l}\text { Utilization: scanning time } \\
\text { ( } 95 \% \text { confidence interval) }\end{array}$ & $\begin{array}{l}44 \% \\
(41 \%-47 \%)\end{array}$ & & \\
\hline $\begin{array}{l}\text { Room empty } \\
\text { ( } 95 \% \text { confidence interval) }\end{array}$ & $\begin{array}{l}35 \% \\
(32 \%-38 \%)\end{array}$ & $\begin{array}{l}28 \% \\
(26 \%-30 \%)\end{array}$ & $\begin{array}{l}32 \% \\
(29 \%-35 \%)\end{array}$ \\
\hline $\begin{array}{l}\text { Access time for CT1 } \\
\text { retrospective, in working days. } \\
\text { (standard deviation; p-value } \\
\text { compared with pre-measure- } \\
\text { ments) }\end{array}$ & $\begin{array}{l}11.4 \\
\text { (sd 3.2) }\end{array}$ & $\begin{array}{l}12.4 \\
\text { (sd 2.2; NS) }\end{array}$ & $\begin{array}{l}5.2 \\
(\text { sd 2.9; } p<0,001)\end{array}$ \\
\hline $\begin{array}{l}\text { Access time for } \mathrm{CT} 2 \\
\text { retrospective, in working days. } \\
\text { ( } \mathrm{p} \text {-value compared with } \\
\text { pre-measurements) }\end{array}$ & $\begin{array}{l}12.9 \\
(s d 3.2)\end{array}$ & $\begin{array}{l}11.5 \\
\text { (sd 2.5; NS) }\end{array}$ & $\begin{array}{l}5.8 \\
(\text { sd 3.0; } p<0,001)\end{array}$ \\
\hline
\end{tabular}

1. We measured 15 half-days and obtained a $95 \%$ confidence interval that the error is less than $2 \%$.

2. We present this item apart, because it is valid to all stakeholders and otherwise we would have to repeat it in every row of the table.

time that a higher level of urgent demand arises when access time increases (short-term demand becomes urgent demand), which caused an even larger increase in access time.

It is important to note that in our experience, such interventions may cause resistance. One probable cause of resistance to the optimization of the CT scan process is its decentralized command. In a process that is a part of many patient flows, it is important that the decision-maker has an overview of the overall process. In a decentralized controlled structure, this is generally not the case and the department's interests frequently conflict with the hospital's interests. The interests most important to the CT scan personnel are the quality of the work and finishing the daily program on time - not reducing access time. Furthermore, traditionally, physicians are focused on individual patients, which can conflict with the interests of entire patient groups. 
A possible consequence of reducing access time for a CT scan is an increase in demand. Due to the previous lengthy access time for a CT scan, physicians sometimes decided to administer the second-best imaging procedure, or to apply for a CT scan in another hospital. The quality of care improves by performing CT scans when indicated for diagnosis and by doing this in the hospital familiar to the patient. Another indication for possible increase in demand is that an earlier study has shown the positive relationship between health care resources and health care utilization caused by supplier-induced demand ("A built bed is a filled bed") ${ }^{193}$.

Studying the possibilities for coping with increasing demand will be valuable, and it will be useful to do further research on managing variability in order to increase productivity. We are planning to investigate the effects of doing away with the appointment-based system and increasing the flexibility of supply. We expect that simulation is an instrument we can use to predict the consequences different scenarios will have for adjusting capacity on demand.

\subsection{Practical implications}

Our strategy can work in every hospital process, if the system meets two conditions: first, it applies to appointment-based systems and second, there must be variation in the actual appointment duration. An appointment-based system with variation should contain planned slack, because hospital departments only allow a limited waiting time for the patient. The amount of planned slack should increase with the appointment duration variability and with the allowed waiting-time. Eliminating slack by reducing variation seems obvious, but, as Shojania and Grimshaw ${ }^{192}$ state, an active approach is needed to apply this kind of evidence in practice. However, as Clancy and Cronin ${ }^{194}$ argue, in every situation the implementation of a 'best practice' has to be customized to the local situation. Therefore, a first essential step in decreasing variability is to find out what the parts of the specific process with the highest variability are. Disturbances must be taken into account as 'parts of the process', because often their average time span is considerable and the variability high. The most obvious methods to find possibilities for variability reduction are observation of the process, measurements of time and brainstorming with practitioners in the process.

Next to our application to parallelize activities, managers can also apply other strategies to reduce the effect of process steps with high variability. Single Minute Exchange of Die (SMED) is a principle used in manufacturing industry and has been very successful in both increasing quality and reducing costs ${ }^{195}$. SMED is applied to reduce setup time and improve productivity, enabling smaller batch sizes to be produced whilst reducing lead-time. The approach is to separate setup time into "internal" and "external" activities. An internal activity is one that can only be done with the machine stopped; an external activity is anything that can be done before or after the set up withou stopping the machine. Profit could be achieved by: 1) maximizing external activities, 2) converting internal activities to external where possible, and 3) engineering or streamlining all remaining internal activities. Our principle resembles the SMED approach in figuring out if activities with high flow time variation can be executed 'off line'. In our context, the insertion of intravenous access lines is an example of a former internal activity converted into an external activity. Difference is that we do not focus on setup times and batch sizes. We suggest the possibility for hospital managers to apply one of two other SMED strategies to reduce the lead-time of a process.

In all cases, active involvement of both key persons from the department and logistic experts in these analyses is essential ${ }^{196,197}$. Just like every organizational change applying the variety reduction principle can bring along problems. To avoid these, Horton ${ }^{198}$ suggests a culture change of leadership and a staff mantra that says: 'What is the barrier, and how do we eliminate it?'. According to Horton, improving flow is not about building more beds or hiring more staff, but about developing and improving processes to decrease variability and smooth flow.

So far for the contradiction of improving patient service and restricting healthcare expenditures! 


\section{CHAPTER 4}

Reducing MRI access times by tackling the appointmentscheduling strategy

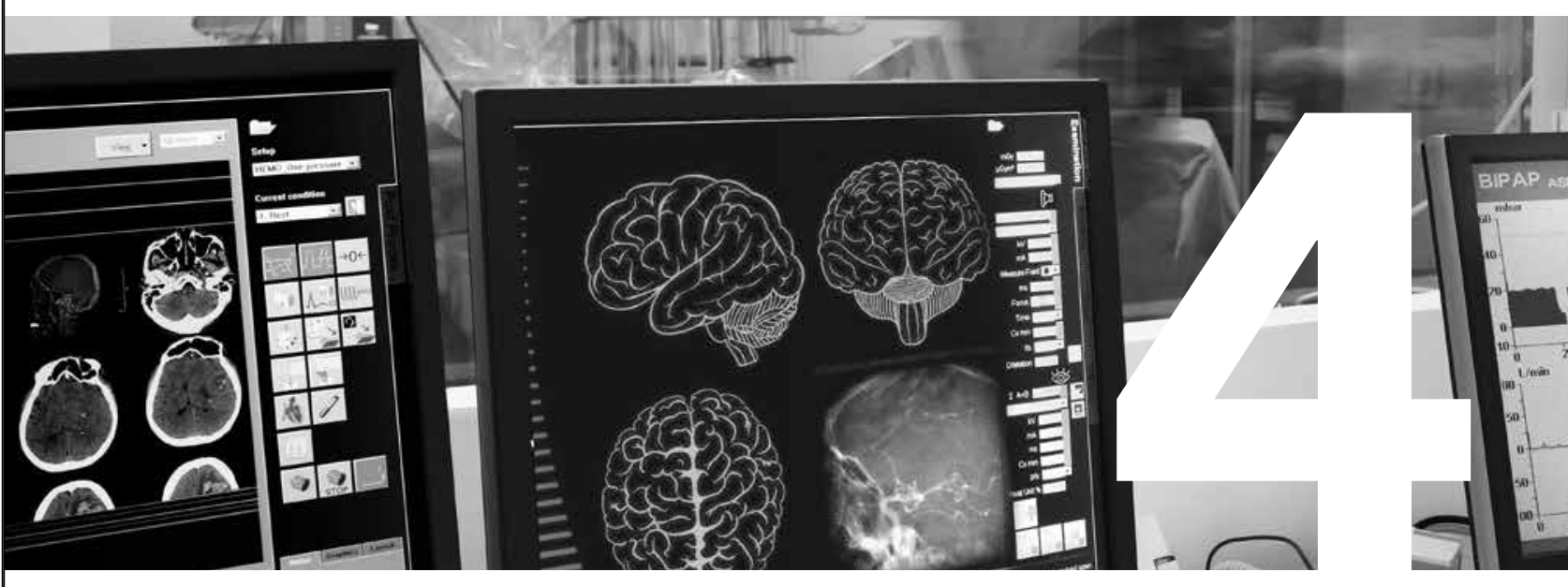




\section{LITERATURE UPDATE FOR CHAPTER 4}

The aim of the study described in this chapter was to reduce access times by developing a new scheduling strategy with computer simulation and to implement this strategy in practice. This contributed to the literature because we showed that the combination of theoretical scheduling methods, computer simulation, and implementation in practice results in a substantial reduction in access times. Between the time our study was conducted (2011) and the writing of this literature update (2017), related studies have been published in the literature.

New scheduling strategies are still being developed. Several studies have been conducted on appointment scheduling for MRI facilities, which will be discussed here. Tokur et al. (2012) ${ }^{168}$ stated that MRI access time could be improved by moving preparatory activities out of the scanner room and by increasing the scheduling strategy. They suggest basing the schedule on one of the three expected total MRI processing times. Bhattacharjee and Kumar Ray (2016) ${ }^{199}$ stated that classification of patients could lead to a better appointment system and assess it with discrete event simulation, just as we did.

They based their classification on certain sequencing and appointment rules. So, these two studies also looked at reducing MRI access times by changing the appointment blocks.

Wessman et al. (2014) 200 introduced methods for reducing barriers in the MRI process to improve the turnaround times, and successfully implemented this in practice. By using "lean" methods and multiple plan-do-check-act cycles, they came up with process improvements including protocol turnaround time, schedule standardization, schedule intervals, examination timing, service standards, and scheduling redesign. As in our own study, they aimed for a reduction in scheduling variability, but rather than reducing the number of appointment block categories, they set the MRI scheduling intervals to a standard time slot.

There was one study about appointment scheduling for radiology departments in general. Huang and Marcak (2013) ${ }^{201}$ found that reclassification of patient groups can improve patient access to care in radiology departments. Certain patient characteristics, such as gender, part of the body being scanned, etc., can influence the length of the procedure time. Huang and Marcak (2013) used an algorithm to place specific time groups into the best time slots in the scheduling system. In this way, patient access times were reduced, as well as costs.
Zacharias and Armony (2016) 202 argued in favor of controlling the demand for health care by looking at two things: the panel size (the size of the patient population that receives care from the practice on a regular basis) and appointment availability (the number of available appointment slots per day). They argued that an open access policy ("meeting today's demand today") is the best option if you want to account for the two types of delays: appointment delay and clinical delay.

Furthermore, Liu and Ziya (2014) ${ }^{203}$ found that a clinic's "walk-in probability" has no effect on the optimal panel size. The optimal panel size is achieved when the clinic is balanced: in other words, when there are no extreme patient waiting times and no system idle times. If the panel size is optimal, the system cannot be overloaded. Liu and Ziya (2014) also showed that if overbooking is an option, a higher walk-in probability would lead to higher overbooking levels and to larger panel sizes.

Our article 204 used discrete event simulation to investigate whether our proposed way of reducing MRI access times was working. Discrete event simulation is a promising tool for investigating improvements in operational efficiency and in reducing costs. ${ }^{205-207}$ Aeenparast et al. (2013) argued that, based on a discrete event simulation, the best way to decrease waiting times is to change physicians' working times and patients' admission times in a way that ensures they are at the hospital at the same time (so that physicians do not arrive late and patients do not arrive early) ${ }^{205}$. Lee et al. (2013) ${ }^{208}$ looked at appointment scheduling for outpatient clinics by using a discrete event simulation in a different way. They compared two scheduling methods: open access and overbooking. In general, they argued that overbooking will lead to better outcomes than an open access system. It would seem that this conclusion cannot simply be applied to the MRI context, since the main variables (such as the proportion of patients desiring same-day appointments and idle time costs) are different.

We analyzed the current waiting times for MRI scans in hospitals in the Netherlands. It is striking to observe that the waiting time in the Academic Medical Center (AMC) in Amsterdam is 33 days. ${ }^{209}$ This is much longer than expected, since they use the block reduction method, which should reduce it to less than 14 days. We conclude that the new literature supplements our conclusions. 


\section{ABSTRACT}

Background: High access times for magnetic resonance imaging (MRI) facilities have a negative impact on quality of care and patient service. Since these resources are both scarce and expensive, utilizing the capacity is the most economical way of reducing these access times. As a rule, patient appointments are not scheduled efficiently. Consequently, the most promising way of reducing access times is to optimize the scheduling strategy. The objective of this study was to reduce MRI access times by optimizing the scheduling strategy and by implementing this strategy in practice in a university hospital in the Netherlands.

Assessment of problems: The scheduling process was analyzed to define the improvement potentials and to simulate the process. Computer simulation was used to copy the process and experiment with scheduling strategies in theory. Promising scenarios were defined and run in the simulation model. Based on the simulation results, a new scheduling strategy was designed and implemented.

Results of assessment: The simulation experiments showed that block reduction leads to a maximum decrease in access time of $93 \%$.

Strategies for change Implementing a scheduling strategy with a practically applicable minimum number of blocks resulted in an actual decrease from 36 , $22,28,9$, and 9 to $7,2,10,3$, and 1 calendar days respectively, depending on the patient group.

Lessons and messages: This study proved that modelling the scheduling process can contribute to optimizing the scheduling strategy, which can lead to a reduction in access times for imaging facilities such as MRI scanners.

\subsection{Background}

Minimizing patients' throughput times in hospitals is a hot topic in health care. Central facilities such as diagnostic imaging departments often have a large impact on patients' throughput times. ${ }^{210}$ One of the major bottlenecks in many hospitals is magnetic resonance imaging (MRI). For this reason, access times for MRI facilities is one of the main performance indicators for radiology departments. ${ }^{211}$ Because these facilities are a very expensive resource, capacity is deliberately limited, which results in high access times. To reduce undesirable access times, one possibility would be to increase the MRI capacity. Another, more economical, way would be to better utilize the available capacity.
Because an MRI facility is an appointment-based resource, the scheduling strategy applied greatly affects its utilization. Inappropriate scheduling is common in hospitals, ${ }^{116}$ and is often the result of scheduling strategies that have developed over time. Partial adjustments to the strategy are usually based on medical reasons, with too little concern for the systems' performance indicators such as access times and utilization rate. More attention should be paid to improving MRI appointment scheduling. Because real-time experimentation can have a significant negative impact on patients and costs, modelling is an appropriate technique for testing promising scheduling improvements. Although others have shown that modelling scheduling strategies can support the optimization of the scheduling process in radiology departments ${ }^{167,212,213}$ they often did not take into account the different scheduling times for different protocols.

The MRI scanning facility in a university hospital has to deal with many types of and high degrees of variability in the process. The most frequently used modelling techniques (such as analytical models) do not take this variability into account. In contrast, discrete event simulation is more appropriate, because it is a modelling technique that will give very specific quantitative results in situations where variability is important. ${ }^{116,159,214}$ Although discrete event simulation has been applied within radiology modalities ${ }^{215}$, so far it has not been used for complex appointment systems like those in MRI facilities.

The aim of this study was to reduce MRI access times to fewer than 14 days by optimizing the scheduling strategy and implementing this strategy in practice. The objectives of this study were:

- to undertake process analysis of the MRI scan scheduling process;

- to apply computer simulation to test strategies to measure the impact on access times;

- to implement the solution in a "real world" context, and

- to measure the impact of the solution on access times.

The study was carried out in the Academic Medical Center (AMC) in Amsterdam, a university hospital in the Netherlands. Every year, 12,000 patients visit this hospital's radiology department for MRI scans. All MRI outpatients have scheduled appointments. Inpatients were excluded from the scope of this study because they are not scheduled, but called when there is an opening. When the study started, MRI access times ranged from 16 days to 36 days, depending on the scanner and the patient category. 


\subsection{Assessment of problems}

The problem was approached by putting together a project team that included radiology management, a specialized laboratory worker, the head of planning staff, a radiologist, and researchers who are experts in scheduling and patient logistics. The first step was to analyze the scheduling process.

Scheduling took place manually by assessing MRI requests according to patient category, urgency level, required scanner, and scan duration. Appointments were scheduled in a specific block type in the master schedule (see Figure 9). For instance, a non-urgent hand scan was scheduled in a "skeletal" block. When an appointment could not be scheduled in the patient category block within the requested urgency period, another block type could be used.

\section{FIGURE 9 / Master schedule before intervention}

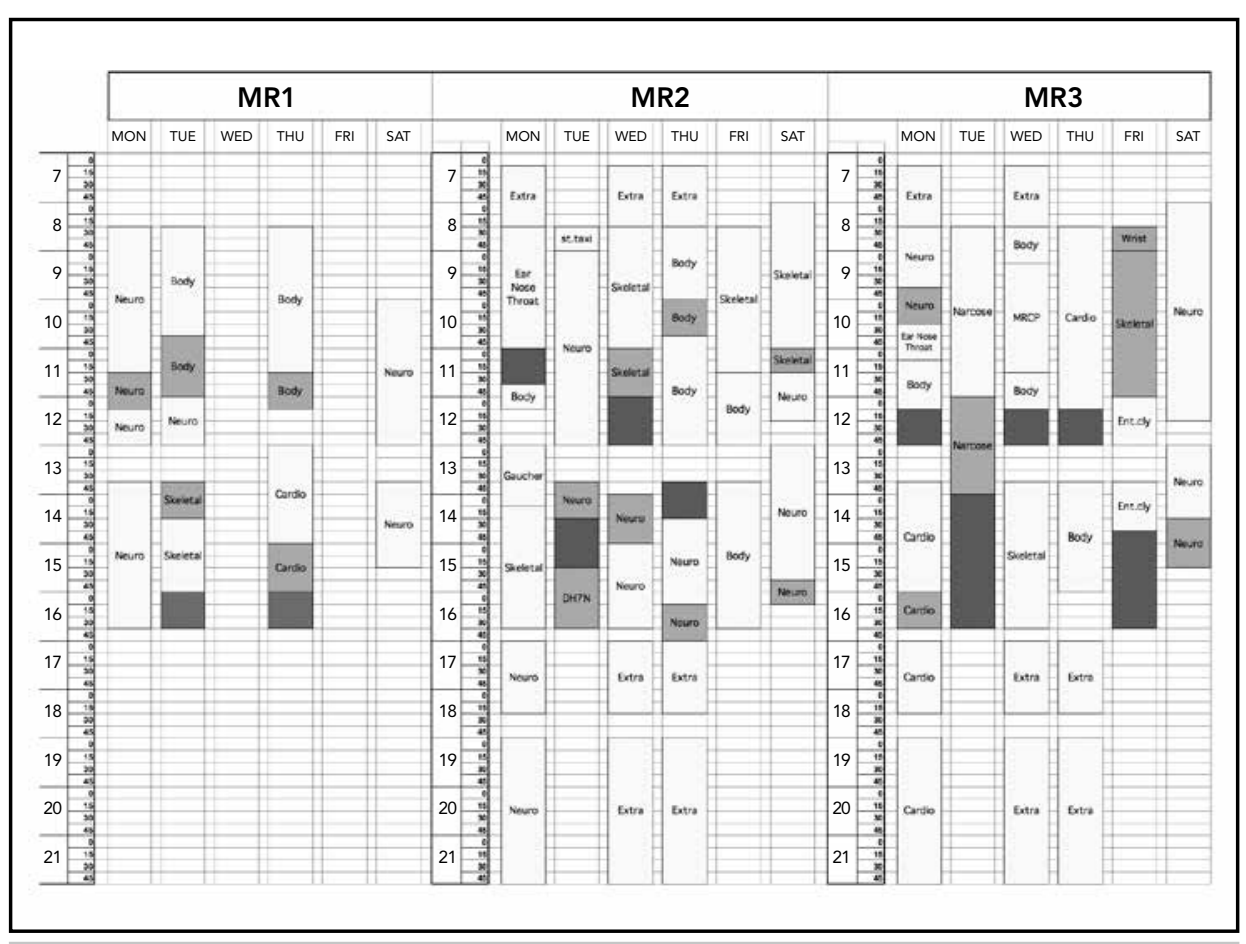

To determine access time, six patient groups were differentiated. This was necessary because there was less availability for some groups than for others, which resulted in different access times. The patient groups were based on whether a radiologist needed to be present during the scan, and on the scan- ner required. Because a radiologist was not present all day, and because some patients had to be scanned on the most advanced scanner, access times for the various patient groups were usually different.

Access time was measured weekly using a prospective schedule check. To do this, the planning system was searched for potential time slots, and the first day with a possibility for scheduling two appointments of a given category was selected. By searching for two successive possibilities, the measurements were not influenced by accidental gaps in the schedule (caused by things such as late cancellations)

The following are the most important bottlenecks that emerged from the process analysis:

- The high average access times for all patients resulted in a large number of semi-urgent requests. If all patients could be scanned within two weeks, it would be unnecessary to categorize as semi-urgent those patients who have to be helped within two or three weeks.

- The complexity of the scheduling strategy was caused mainly by the large number of blocks (78 per week).

- Of all appointments, $15 \%$ were scheduled outside of their block type due to the large number of blocks.

The problem analysis led to the assumption that significantly reducing the number of blocks per week would be the scheduling adjustment most likely to achieve the objective. Since this would be a major change (especially for the influential radiologists), it was desirable to have as much information as possible about the expected change. Therefore, the project team decided to simulate the process by modelling it.

Due to the complexity of the planning strategy, we selected computer simulation to approach this problem ${ }^{92}$, and used MedModel software. We used data from the planning system in the AMC (X/Care, McKesson). These data included all registered appointments from 1 January 2006 to 31 October 2006.

The simulation run was for a period of one year, excluding a four-month start-up period. After building the model, we validated it using actual access times and utilization rates (extracted from X/Care). The accepted deviation between the actual situation and simulation was $10 \%$.

\subsection{Results of assessment}

After designing the model and validating the present situation, we defined several interventions to study their effect on access times. Since there were so many blocks, reducing the number of blocks seemed likely to have the biggest 
impact. The primary goal of the computer simulation was to analyze and demonstrate the impact of block reduction, and four scenarios were simulated to analyze this:

1. Present situation: 15 different patient categories, 2 urgency levels (semiurgent and non-urgent);

2. Six different patient categories, 2 urgency levels;

3. One patient category, 2 urgency levels;

4. One patient category, 1 urgency level (which meant that all patients could be scheduled in any slot during the week).

Table 9 compares the present situation to the relative reduction in access times that resulted from the simulation model.

\section{TABLE 9 / Simulation results}

\begin{tabular}{lllll}
\hline Scenario & $\mathbf{1}$ & $\mathbf{2}$ & $\mathbf{3}$ & $\mathbf{4}$ \\
\hline Master schedule & $\begin{array}{l}15 \text { categories } \\
2 \text { urgency } \\
\text { levels }\end{array}$ & $\begin{array}{l}\text { 6 categories } \\
2 \text { urgency } \\
\text { levels }\end{array}$ & $\begin{array}{l}1 \text { category } \\
2 \text { urgency } \\
\text { levels }\end{array}$ & $\begin{array}{l}1 \text { category } \\
\text { equal } \\
\text { urgency }\end{array}$ \\
\hline $\begin{array}{l}\text { Reduction in average } \\
\text { access time }\end{array}$ & $0 \%$ & $43 \%$ & $66 \%$ & $93 \%$ \\
\hline
\end{tabular}

The total capacity per week is equal in every scenario. In scenarios 1 to 3 (that have both semi-urgent and non-urgent blocks), the proportion of semiurgent to non-urgent is equal. Table 1 clearly illustrates that the number of blocks greatly influences the expected access time for an average patient: the lower the number of blocks, the lower the access time.

\subsection{Strategy for change}

\subsubsection{Description of the new scheduling strategy}

The simulation results convinced all stakeholders within the department that it was necessary to reduce the number of blocks. A choice for the strategy to implement resulted from the discussions that followed the presentations of the model's outcomes. This strategy aimed for the absolute minimum number of block types, keeping only the most essential ones. A new master schedule was proposed and implemented, and contained four different patient categories: "regular," "stereotactic," "cardiology," and "anesthesia." Two categories (cardiology, anesthesia) were retained because a medical team from outside the radiology department had to be present during these scans. One category (stereotactic) was retained because patients had to be scanned right before brain surgery, and it was essential to have a fixed time during the week. All other patient categories were grouped into a new block (regular). Fewer semiurgent blocks were required when access times dropped below two weeks. Initially, the urgent and semi-urgent hours per week remained the same as in the old master schedule. Figure 10 shows the new master schedule (an empty block represents the new category (regular)).

\section{FIGURE 10 / Master schedule after intervention}

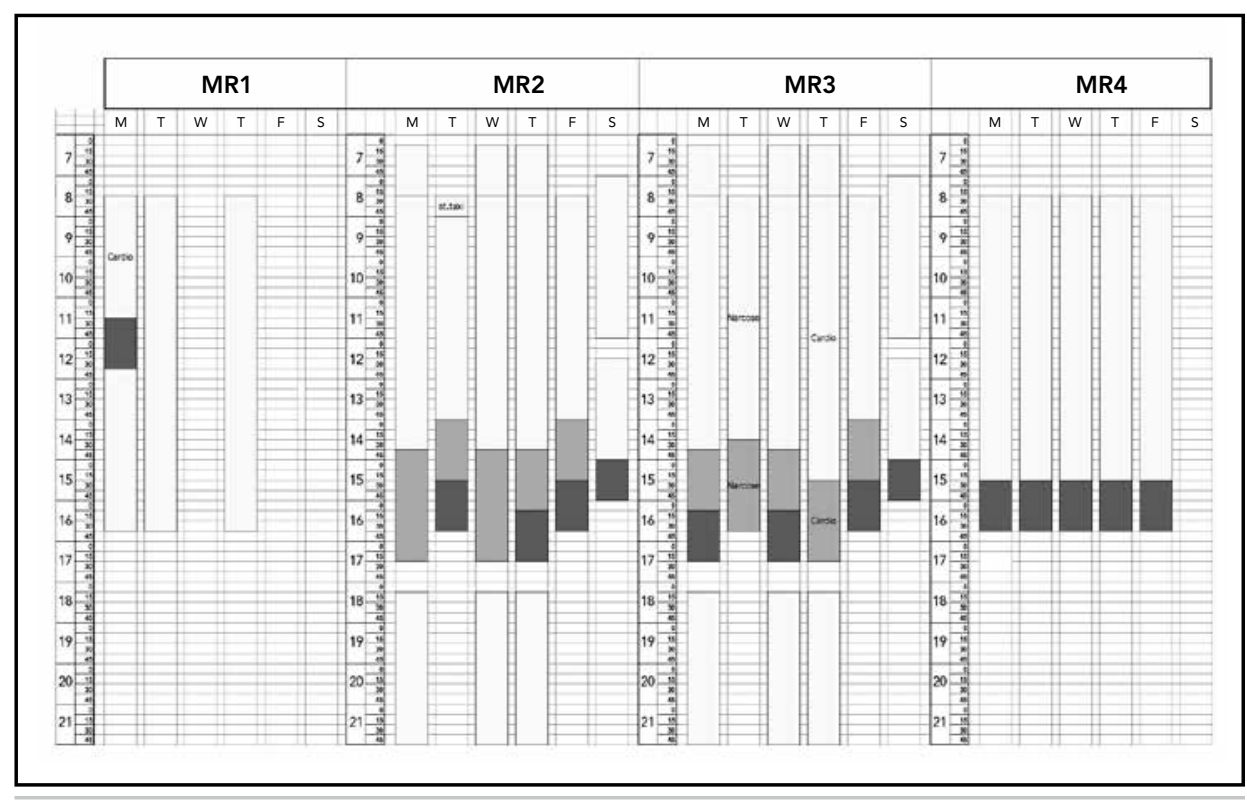

The new scheduling strategy was implemented on 1 January 2008. This meant that patients who were scheduled for an appointment on 1 January or later were scheduled in the new roster. For a period of three months, the project team evaluated the new situation both quantitatively and qualitatively: access times were measured prospectively every week until week 20 , and again during week 36 . This was performed in the same way as explained in the process assessment. The qualitative evaluation consisted of weekly meetings 
during which experiences and complaints from the work floor were discussed, and improvement measures were assigned to project members.

\subsubsection{Evaluation of the new scheduling strategy}

Figure 11 presents a comparison between the weekly access times in 2008 and the average 2007 access times for the six patient groups. All access times were measured prospectively and are expressed in calendar days.

\section{FIGURE 11 / Development of access times after intervention for} the six patient groups

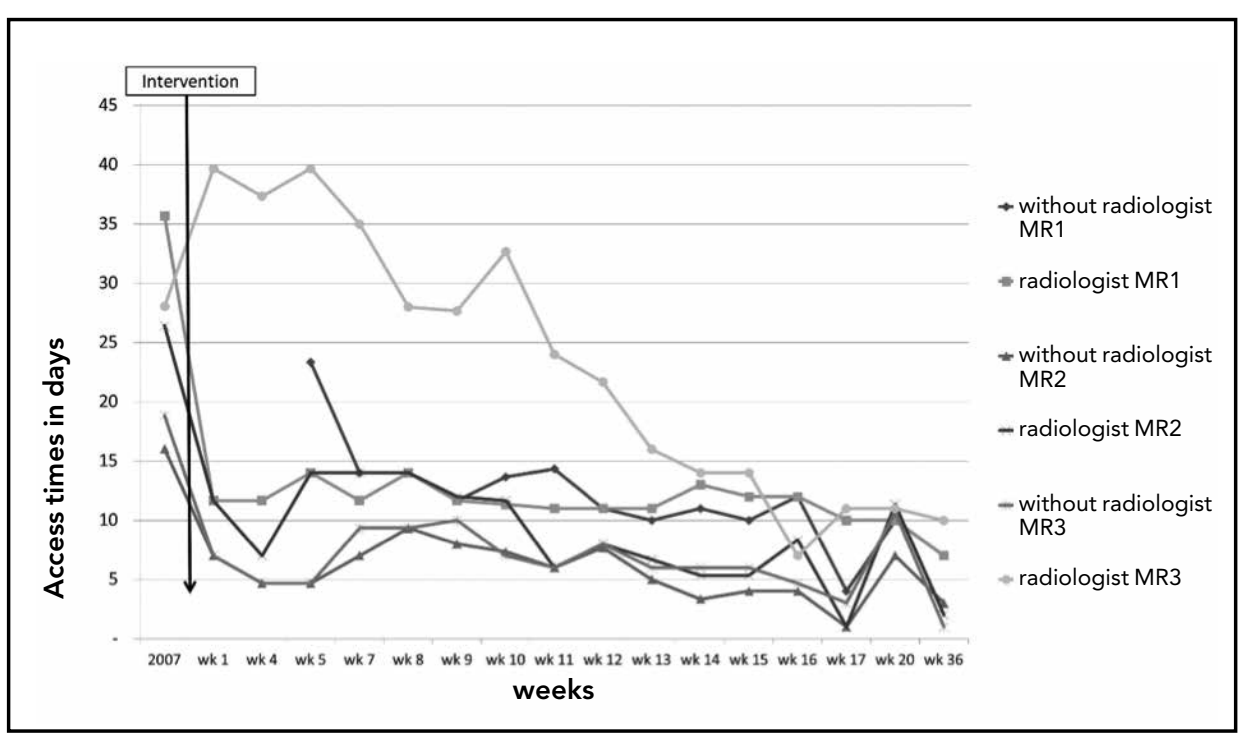

The figure clearly shows better results in 2008 than before the new scheduling strategy was implemented. In September of 2008, access times for the "radiologist" categories dropped from 36, 22, and 28 days in 2007 to 7, 2, and 10 days respectively. Access times for less critical patient groups "without radiologist" dropped from 9 and 9 days to 3 and 1 days. During the autumn of 2008, all access times were well below the two-week performance target.

Right from the start, the increased scheduling flexibility resulted in low access times for MR1 and MR2, and for the early and late time slots of MR3 (without radiologist). At the beginning of the new scheduling period, the "MR3 radiologist" patient group lagged behind the other categories: for $M R 3$, a radiologist had to be scheduled for many scans, which resulted in re- stricted availability. Encouraging examination of whether a radiologist was truly necessary proved to have a positive impact on the access time for this category. Within the first 15 weeks, this access time gradually dropped to an acceptable number of days. This can be explained by an increase in the number of scans per week. The scanning production per month increased somewhat, resulting in an increase in the scheduled utilization rate, which went from $70 \%$ in 2007 to $80 \%$ in 2008

The category "MR1 without radiologist" came into being in week 5, because until then a radiologist had been present for all MR1 scans (no early or evening blocks). The sudden drop in access times for most patient groups was caused by a timely change to the master schedule for 2008. Months before 2008 began, the planning department was already scheduling appointments they could no longer fit into 2007 in the new 2008 master schedule. During the evaluation period, no significant changes in overtime or cancellations were reported.

\subsection{Lessons and messages}

After implementing the new scheduling strategy, access times for all relevant patient categories dropped to an acceptable level of fewer than 14 days This study showed that modelling the scheduling process can contribute to optimizing the scheduling strategy, which can lead to a reduction in access times for imaging facilities such as MRI scanners.

Scheduling techniques and modelling have increasingly proved to be valuable in hospital environments. Computer simulation appeared to have various strengths within the context of this study. First, it was possible to consider various interesting scenarios for evaluation. Second, unpredictable variables such as patient cancellations could be taken into account, which provided results with a high confidence level. Third, because it was possible to satisfactorily visualize the consequences of scenarios, stakeholders relied on the results. The most important added value of the simulation model in this study appeared to be the persuasive power of computer simulation. Although the radiologists in particular were very skeptical about block integration, they were convinced by the numbers that resulted from the simulation.

There were differences between the simulation results and the actual results after implementation. This was caused by the difference between the experimental master schedules in the simulation model and the actual master schedule after implementation. It was only after seeing the results and becoming convinced that the radiologists started to discuss and develop a realistic 
master schedule with a minimum number of blocks. Many factors were taken into account, such as the number, dispersal, and appropriate time intervals of urgent blocks, non-regular blocks, and spaces that met the requirements.

When the department learned to work in this new way and the improved performance became apparent, all stakeholders accepted and supported the new scheduling strategy. Over time, minor changes in the roster have been established because of external factors such as the changing availability of cardiologists. However, this has not led to more blocks. The study confirmed that history-based scheduling can be far from optimal, especially within highly political environments such as hospitals. Using scheduling methods from operations management and simulation modelling contribute greatly to radiology performance.

\section{GLOSSARY}

- Access time: The time between the MRI referral and the appointment (in calendar days).

- Patient category: A classification for group appointments based on the type of scan.

- Urgency level: The extent to which an appointment must be scheduled quickly for medical reasons. There are two urgency levels relevant to scheduling: semi-urgent and non-urgent.

- Block type: A classification of time intervals within the weekly master schedule reserved for a specific patient category or a specific urgency level.

- Block: A specific time interval on a given day and MRI scanner within the weekly master schedule reserved for the patients defined in its block type.

- Patient group: A classification for determining access times based on whether a radiologist needed to be present during the scan, and the type of MRI scanner required.

\section{CHAPTER 5}

\section{Patient views on walk-in computed tomography facilities}

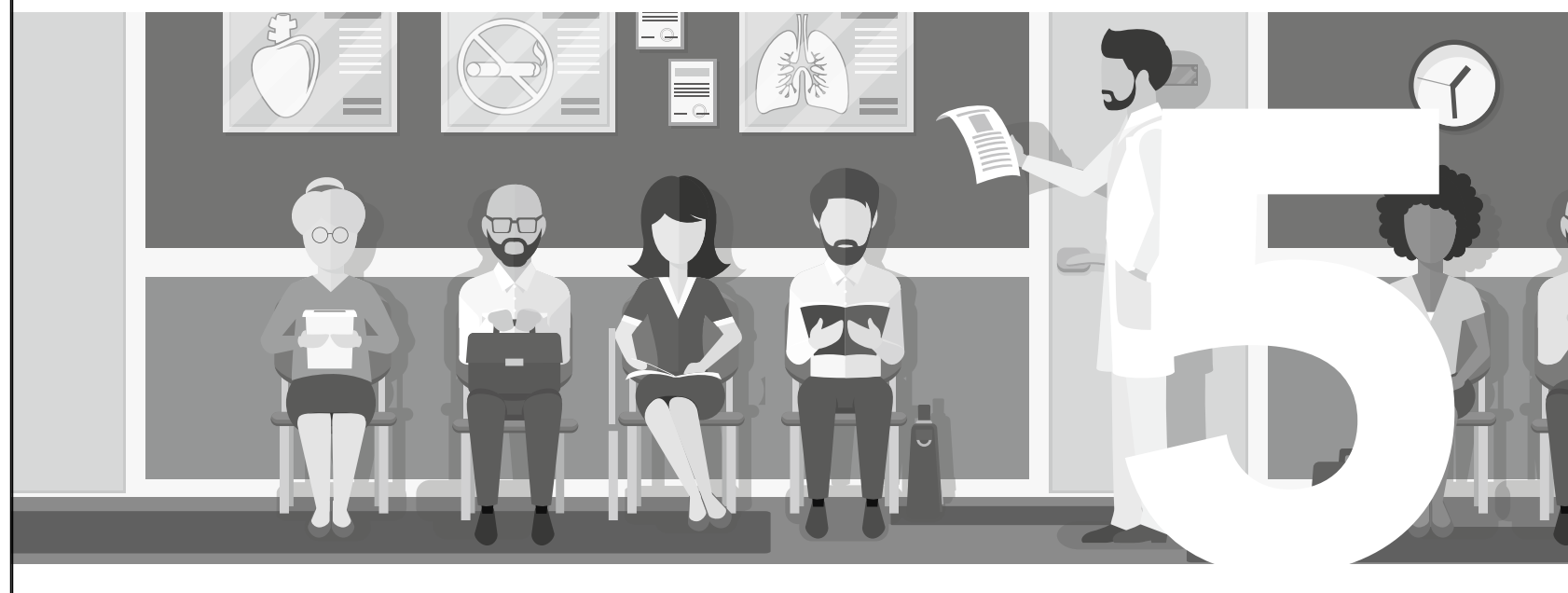




\section{LITERATURE UPDATE FOR CHAPTER 5}

The study presented in this chapter investigated patient preferences concerning walk-in CT facilities. As far as we were aware, patient experiences with walk-in versus appointment systems had not yet been studied, especially not by surveying a substantial number of patients. In the period between conducting our study (2009) and publishing this dissertation (2017), several related studies have appeared in the literature, and are elucidated in this section. Over the past eight years, improvements in health care have remained focused on patient centeredness. ${ }^{216-219}$ The Picker Institute (1993) ${ }^{220}$ concluded that one of the eight principles for patient-centered care is access to care, including limiting the waiting time for this access.

The focus continues to be on the goals of increasing the quality of and efficiency in health care ${ }^{221-223}$. Some of these goals could be achieved by introducing walk-in systems, and these systems appear to be promising. ${ }^{224}$ Kortbeek (2012) ${ }^{73}$ showed the advantages of combining a walk-in with an appointment system: this provides a higher level of accessibility and gives patients more freedom to choose the date and time of their hospital visit.

Some studies have taken patient preferences into account concerning the choice of the access system. For example, scheduling studies elicit patients' preferred time slots. ${ }^{225,226}$ An important advantage of a walk-in system is that it introduces the concept of "one-stop shopping." One-stop shopping implies that a patient can have multiple consultations on a single day, thus reducing the number of hospital visits. ${ }^{73}$ In most studies that have focused on this concept, assumptions have been made to optimize the access system rather than asking patients about their preferences. An advantage of the one-stop shopping concept is that patients can receive their diagnosis on the same day. However, a disadvantage could be that the examination slots are not always filled, resulting in lower utilization. ${ }^{227}$

Studies have shown that patients greatly value one-stop shopping. ${ }^{\mathbf{3 , 2 2 8}}$ Furthermore, patients value the ability to get an appointment within two weeks after their referral. Also, seeing the same physician for every consult is considered important. ${ }^{\text {225,228-231 }}$ Moreover, patients prefer shorter appointment delays, greater ability to choose their own appointment time, and shorter waiting times. ${ }^{\mathbf{2 2 5 , 2 2 9}}$ In Albada and Triemstra's study (2009), ${ }^{\mathbf{2 3 0}} \mathbf{4 1 \%}$ of patients indicated they considered a walk-in system to be important. Also, when they use a walk-in system, they are willing to wait longer. ${ }^{228}$
Saaty's analytic hierarchy process (AHP) is a technique for multi-criteria decision analysis (MCDA). ${ }^{232}$ This technique remains valuable when studying patient preferences. ${ }^{233,234}$ With MDCA, decision-making is based on certain criteria, and the focus is on which criteria are important. ${ }^{235}$ Although this still seems to be an appropriate way to rank performance criteria, this was not the case for the objective and the context within which we applied it.

In the years following our study, not much has been written about walk-in facilities in health care. Most studies investigated appointment systems in general, and did not specifically examine walk-in systems. ${ }^{236-238}$ In particular, little research has been done that investigated patient preferences for walk-in facilities. In conclusion, we can state that patient preferences concerning walkin facilities have not been studied in the same way that we did.

\section{ABSTRACT}

Although innovations in health care access systems are intended to increase patient centeredness, this seldom implies that patient preferences have been examined. Walk-in access to computed tomography (CT) seems promising to satisfy patients, but this has never been verified. This study examines to what extent a walk-in system for the CT facility matches patient preferences. We used the analytic hierarchy process (AHP) on 106 patients to assess the patients' perspective about the performance indicators access time, waiting time, one stop shopping, and autonomy of choice. We let the patients prioritize and assess various performance level combinations. The patients prioritized these indicators with the respective values of $0.224,0.188,0.432$ and 0.157 . Six access system designs proved to be acceptable and relevant, whereof the most preferred appeared to be the walk-in scenarios. This led to the conclusion that from the patients' perspective, a walk-in system is a better access system for CT scan facilities than an appointment system. This study also demonstrated that AHP is a valuable technique for investigating patient preferences concerning access to a hospital facility.

\subsection{Background}

Although health care providers around the world are continuously improving their services, too often patients are not consulted about what they actually want. Over the last decade, the focus of improvements has been increasingly patient-centered, alongside the existing goals of increasing quality and effi- 
ciency ${ }^{239-243}$. Improving patients' access to health care facilities is a growing trend intended to meet all three goals ${ }^{244-246}$. This approach is patientcentered, as it takes not only medical and financial aspects into account, but also service aspects such as waiting times. In theory, the walk-in system is one of the most patient-centered solutions for access systems. This system allows patients to arrive at a facility without an appointment. While walk-ins are usually only permitted in emergency situations ${ }^{247}$, what we are concerned with here are walk-in services motivated by patient centeredness. Little is known about the success of these walk-in facilities ${ }^{248}$. Furthermore, with the exception of primary and emergency care, literature about walk-in health care facilities is scarce 249-251. $^{24}$.

Although innovations in health care access systems are intended to increase patient centeredness, this seldom implies that patient preferences have been examined. Most of these innovations are motivated by health care providers' assumptions that patients will benefit from them. However, more and more, patients carefully consider their choices before deciding which hospital to visit, and as a consequence, patients are having a greater and greater effect on competition. For this reason, it would seem to be increasingly necessary to consult patients before introducing innovations to access systems.

Facilities where patient access is particularly relevant include short-term low-level care facilities visited by many patients every day. Primary care, outpatient, and radiology facilities all have these characteristics, but of these, access to radiology facilities is the one least often studied. This is surprising, especially since these facilities are scarce, and often struggle with high access times to appointments. A second reason for focusing on radiology is that although patients' views on access systems have been studied, as far as we know this has not been done for radiology facilities ${ }^{252-256}$. Apart from the patients' wishes concerning walk-in facilities, expected patient behavior is also relevant to hospital managers who are considering walk-in systems for their facilities. This is particularly the case for predictions about arrival times and their distribution and how this influences the practical suitability of a walk-in system, since arrival peaks have a negative impact on waiting times in the waiting room and the utilization of facilities.

Our study contributes to the existing literature by examining patients' views on access to radiology departments and their behavioral intentions, which results in valuable input for the design of truly patient-centered innovations. This leads to our research question: To what extent does a walk-in system for radiology facilities match patient preferences?

\subsubsection{Differences between appointment and walk-in systems}

Radiology facilities differ substantially in terms of cost, scarcity, and percentage of seriously injured or ill patients. To maximize homogeneity in the patient sample, we selected one radiology facility. We chose the computed tomography (CT) scan based on the facility's scarcity and the resulting frequently high access times, which meant there was potential for considerable improvement if patients were allowed to arrive at the moment of their choice. Patient preferences were elicited for both the walk-in system and the appointment system currently in use. In several studies $254,257-259$, waiting time in the waiting room appears to be an important indicator for patient access to health care facilities. Two other relevant factors for patients are access times in days to their hospital visits, and convenient appointment times ${ }^{260-263}$. Furthermore, the goal of reducing the number of hospital visits by enabling "one-stop shopping" is receiving more and more attention ${ }^{264-266}$. Based on this, we identified four performance indicators that can differ between the two systems, which are presented in Table 10.

\section{TABLE 10 / Classification table}

\begin{tabular}{llll}
\hline & Description & Appointment system & Walk-in system \\
\hline $\begin{array}{l}\text { Access } \\
\text { time }\end{array}$ & $\begin{array}{l}\text { The time a patient } \\
\text { has to wait } \\
\text { between a CT } \\
\text { referral and the } \\
\text { scan (in days). }\end{array}$ & $\begin{array}{l}\text { The difference between } \\
\text { referral and appoint- } \\
\text { ment time is the access } \\
\text { time, which is often } \\
\text { several days or weeks. }\end{array}$ & $\begin{array}{l}\text { There is no access time, } \\
\text { because patients may } \\
\text { arrive at the moment of } \\
\text { their choice. }\end{array}$ \\
$\begin{array}{llll}\text { Waiting } \\
\text { time }\end{array}$ & $\begin{array}{l}\text { The time a patient } \\
\text { has to wait } \\
\text { between arrival } \\
\text { and the actual } \\
\text { scan (in minutes). }\end{array}$ & $\begin{array}{l}\text { In theory, waiting time is } \\
\text { limited because appoint- } \\
\text { ments are scheduled and } \\
\text { spread out over the day. }\end{array}$ & $\begin{array}{l}\text { The waiting time varies } \\
\text { throughout the day, } \\
\text { although we would } \\
\text { expect to see peaks and } \\
\text { lulls in patient arrivals. }\end{array}$ \\
$\begin{array}{l}\text { One-stop } \\
\text { shopping }\end{array}$ & $\begin{array}{l}\text { The possibility of } \\
\text { having the CT } \\
\text { scan directly } \\
\text { following an } \\
\text { outpatient visit. }\end{array}$ & $\begin{array}{l}\text { Only possible with the } \\
\text { use of a complex } \\
\text { scheduling system that } \\
\text { encompasses two } \\
\text { departments. }\end{array}$ & $\begin{array}{l}\text { Always possible based } \\
\text { on the access system, } \\
\text { though there may be } \\
\text { medical restrictions for } \\
\text { one-stop shopping. }\end{array}$ \\
$\begin{array}{l}\text { Autonomy } \\
\text { of choice }\end{array}$ & $\begin{array}{l}\text { The patient may } \\
\text { choose the } \\
\text { moment for the } \\
\text { CT scan. }\end{array}$ & $\begin{array}{l}\text { Only possible when } \\
\text { scheduling is applied in } \\
\text { dialogue with the } \\
\text { patient. }\end{array}$ & \begin{tabular}{l} 
Always possible. \\
\hline
\end{tabular} \\
\hline
\end{tabular}


The table clearly shows that walk-in systems are promising in terms of access time. A substantial number of patients may experience longer waiting times in walk-in systems. This depends on the precise system characteristics (such as the patient arrival pattern and average time and variability of the scans), but for CT scans we assume that the overall waiting times will be longer for walk-in systems than for appointment systems. Differences in one-stop shopping and autonomy of choice for the two systems depends on how the department is organized. While there will be no difference for some departments, and for others a walk-in system will be more appropriate, an appointment system will certainly never be more suitable for these criteria.

To support the choice for an optimal design of an access system in radiology, this study aims to 1) elicit patient preferences for alternative access systems, and 2) forecast patient arrival patterns if a walk-in system were to be introduced. The latter aim contributes to the ability to predict the logistical consequences of walk-ins, such as lull periods, overtime, and waiting requirements.

\subsection{Methods}

Saaty's analytic hierarchy process (AHP) is a technique to support multicriteria decision analysis that has been shown to be valuable in supporting patient preferences ${ }^{\mathbf{2 3 3}, \mathbf{2 3 4}}$. This technique supports patients in choosing between alternatives, and provides analytic support for evaluating a finite number of decision alternatives with a finite number of performance indicators. AHP offers the possibility of weighting only the performance indicators of access systems, providing the opportunity to evaluate an endless number of access scenarios regarding their performance on these criteria. The AHP structures a decision into a hierarchy of criteria, subcriteria, and alternatives. Using pairwise comparisons of two (sub)criteria or alternatives, it generates consistency ratios and weighting factors to prioritize the criteria and alternatives. The consistency ratio indicates how far the pairwise judgments deviate from a purely random set of pairwise comparisons. Sensitivity analysis can be used to test the robustness of the priorities. These priorities support the handling of multiple trade-offs between the various performance indicators, and quantify the degree to which certain scenarios are preferable to alternatives.

Access systems may impact patients in various ways. The AHP is a userfriendly technique that quantifies the various impacts that need to be calculated to comprehensively evaluate patient preferences for access systems. Because various access system designs can be employed, AHP provides more possibilities than other methods with limited alternatives. In this way, it is possible to gain insight into priorities and bandwidths. We applied the AHP in prioritizing four performance indicators for theoretical access systems. These criteria are short access time, short waiting time, one-stop shopping, and autonomy in choice of moment. These criteria are divided into subcriteria, in this case, different levels of performance. Alternative access system scenarios are evaluated on their performance levels, and are created by combining specific performance levels for all criteria. The following is an example of an access system scenario: The patient has a CT scan on a different day than their appointment in the outpatient department, this day is chosen by the hospital, the access time is 4 days, and the patient has to wait in the waiting room for 15 to 30 minutes. The criteria, the corresponding performance levels, and the alternatives are presented in Figure 12.

\section{FIGURE 12 / Overview of criteria and performance levels}

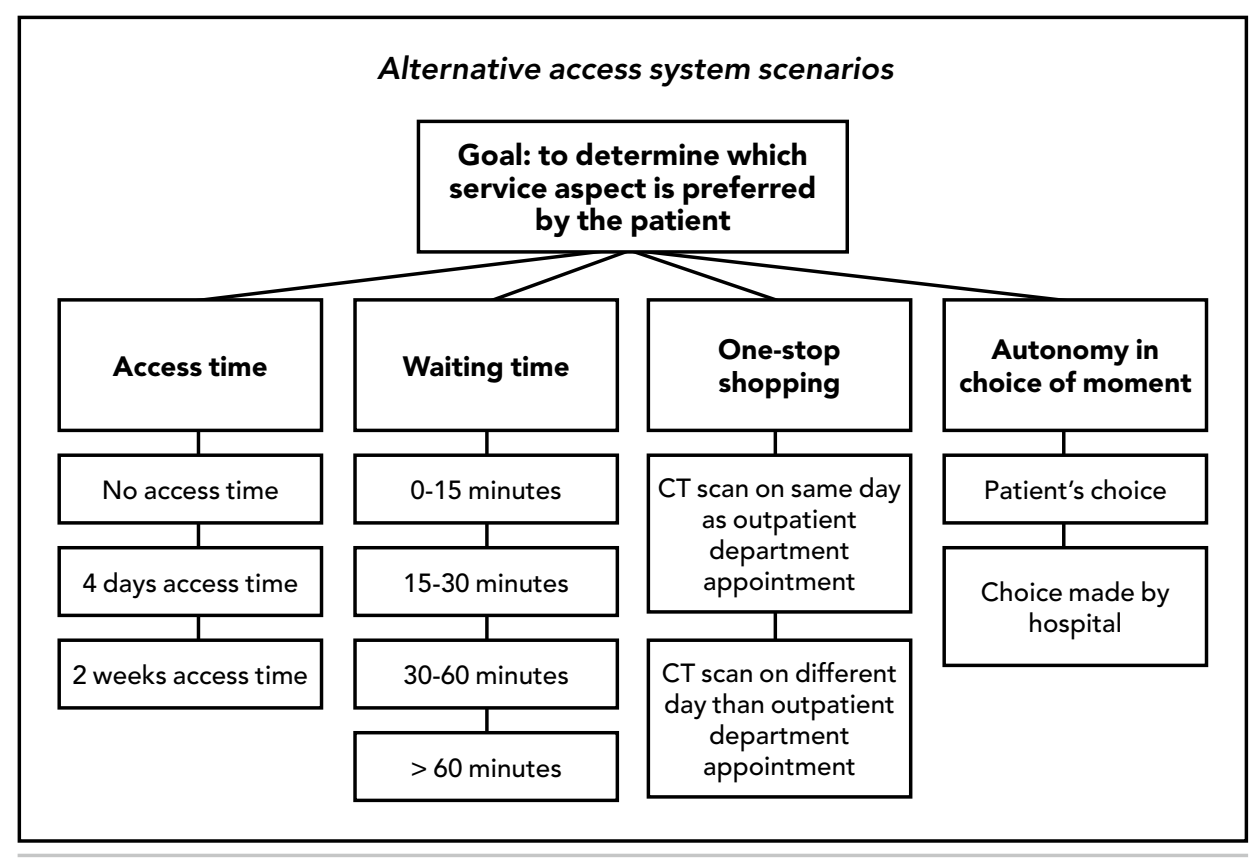

The performance levels were selected based on the only possibilities (concerning one-stop shopping and autonomy of choice), experiences with access times in the Academic Medical Center (AMC) in Amsterdam, the Netherlands, and literature on waiting times in walk-in systems $37,254,255,267,268$. 


\subsubsection{Data collection}

Data were collected in 2009 from a group of 106 outpatients from various clinical departments who were waiting for a CT scan in the AMC. Exclusion criteria were being physically or mentally unable to respond to the questionnaire and not being able to speak Dutch fluently. The response rate was $86 \%$ after exclusion. Data were collected by means of a questionnaire. The main part of this questionnaire consisted of pairwise comparisons defined in line with the validated procedures of the AHP. Accordingly, the importance of performance indicators and subsequently the preferences for the performance levels were compared pairwise. In addition, the questionnaire included questions about patient characteristics, the patient's preferred day and time for a CT scan, acceptable performance ranges for access and waiting times, and information that could persuade the patient to arrive on another day or time.

The questionnaire also contained questions about their preferred time to arrive at the hospital for a CT scan, in the case they arrive from outside the hospital. We compared these results with the expected arrival pattern for patients arriving from the outpatient department, based on the outpatient schedules of the ten main referring outpatient departments. We conducted this arrival pattern from the data (January 2008 - December 2008) from the appointment system (X-care).

\subsubsection{Prioritization of criteria and performance levels}

The patients compared the importance of the criteria. In these comparisons, the most important criterion was assigned a score between 1 and 9, of which 1 represented "equally important" and 9 represented "extremely important." The following is an example of a pairwise comparison of the importance of two main criteria:

Which criterion is more important regarding access to the CT scan, and to what degree?

\begin{tabular}{|c|c|c|}
\hline $\begin{array}{l}\text { Short access } \\
\text { time (days } \\
\text { between }\end{array}$ & 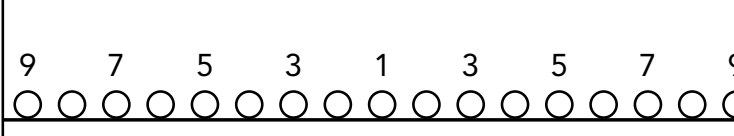 & $\begin{array}{l}\text { Short waiting } \\
\text { time (minutes } \\
\text { waiting in }\end{array}$ \\
\hline $\begin{array}{l}\text { outpatient } \\
\text { visit and } \\
\text { CT scan) }\end{array}$ & & $\begin{array}{c}\text { the CT scan } \\
\text { waiting room) }\end{array}$ \\
\hline
\end{tabular}

The performance levels for each criterion were subsequently compared in the same way. In this case, the comparison focused on which outcome leve was preferred for the criterion and to what degree. For the comparisons between outcome levels, the 9-point scale ranges from indifference to extreme preference. The geometric mean of individuals' pairwise comparisons repre sents the group score.

The AHP software uses an eigenvector method approach to calculate the consistency of the pairwise comparisons and the weighting factors. These weighting factors represent the importance of the performance indicators and the patient preferences for the performance levels. This eigenvector method can be interpreted as being a simple averaging process by which the weighting factors are the average of all possible ways of comparing the importance of the performance indicators or the preference for the performance levels. Accordingly, weighting factors were calculated for the performance indicators and the performance levels. The performance of an access system scenario is the weighted average of the weighting factors of every performance level being fulfilled. See Saaty ${ }^{\mathbf{2 3 2}}$ for a more in-depth explanation of this mathematical approach. The software illustrates these weights by means of graphs.

\subsubsection{Performance of the alternative designs for access systems}

Multiple designs for access systems were created by making realistic combinations of performance levels. The overall patient preference for each access system design was evaluated by aggregating the weighted performance scores of these designs on access time, waiting time, possibility for one-stop shopping, and autonomy of choice for patients. For access system designs to be acceptable, they needed to be preferred over the outcomes of the current appointment system.

\subsubsection{Patient behavior in walk-in systems}

A complicating factor is that when a walk-in system is introduced, waiting times can rise because of possible peak periods. To explore this hypothetical consequence, we included some questions about patients' preferred arrival times and their willingness to adapt their arrival times if they are informed about such peak periods. Two situations can occur in terms of patient arrivals. In the first situation, the patient utilizes the one-stop shopping option and arrives for the CT scan just after his or her outpatient visit. In the second situation, the patient chooses to have the scan at a moment that suits them better, and arrives from outside of the hospital (for example, from home or work). 
Since the first situation depends on the outpatient schedule, we used data analysis to generate this arrival pattern based on the scheduled outpatient consultations over the course of one year, and also the likelihood that a physician would refer a patient for a CT scan and the expected time it would take the patient to walk from the outpatient department to the radiology department. For the second situation, we included several questions in our questionnaire concerning preferred arrival times during the week. We added some questions concerning patients' willingness to avoid peak hours if they were informed about how to do this. To be able to predict a patient's arrival in a walkin system, we examined when patients are referred for CT scans, considering many patients would then immediately walk to the CT scan facility.

\section{TABLE 11 / Respondents' characteristics}

\begin{tabular}{l|c|c|c}
\hline Patient characteristics $(\mathbf{n}=106)$ & Percentage & Average & $\begin{array}{c}\text { Standard } \\
\text { deviation }\end{array}$ \\
\hline Gender and year of birth & $51 \%$ & & \\
\hline male & $49 \%$ & & \\
\hline female & & 1956 & 19 \\
\hline year of birth & & & \\
\hline Educational level & $26 \%$ & & \\
\hline low & $32 \%$ & & \\
intermediate & $38 \%$ & & \\
\hline high & & & \\
\hline Employment status & $25 \%$ & & \\
\hline Full-time job & $8 \%$ & & \\
\hline Part-time job & $49 \%$ & & \\
\hline Retired or unemployed & $6 \%$ & & \\
\hline Student & & & \\
\hline Domestic situation & $41 \%$ & & \\
\hline Partner, no children & $22 \%$ & & \\
\hline Partner, with children & $5 \%$ & & \\
\hline Single, with children & $19 \%$ & & \\
\hline Single, no children & & & \\
\hline Transportation and travel time & $76 \%$ & & \\
\hline Own transportation & $12 \%$ & & \\
\hline Public transport & $4 \%$ & & \\
\hline Combination & & 43 minutes & 29 \\
\hline Travel time & & & \\
\hline \hline
\end{tabular}

\subsection{Results}

\subsubsection{Patient characteristics}

The patient characteristics of the 106 respondents who completed the questionnaire about their preferences for the access system scenarios can be found in Table 11. The patient characteristics reveal a relatively low level of employment. A higher employment level could intensify patient preferences for one-stop shopping and autonomy of choice.

\subsubsection{Priorities}

The patients weighted the performance indicators and performance levels of the access systems. The weighting factors for these criteria and levels can be found in Figure 13

\section{FIGURE 13 / Weighting factors of the performance indicators and}

\section{performance levels}

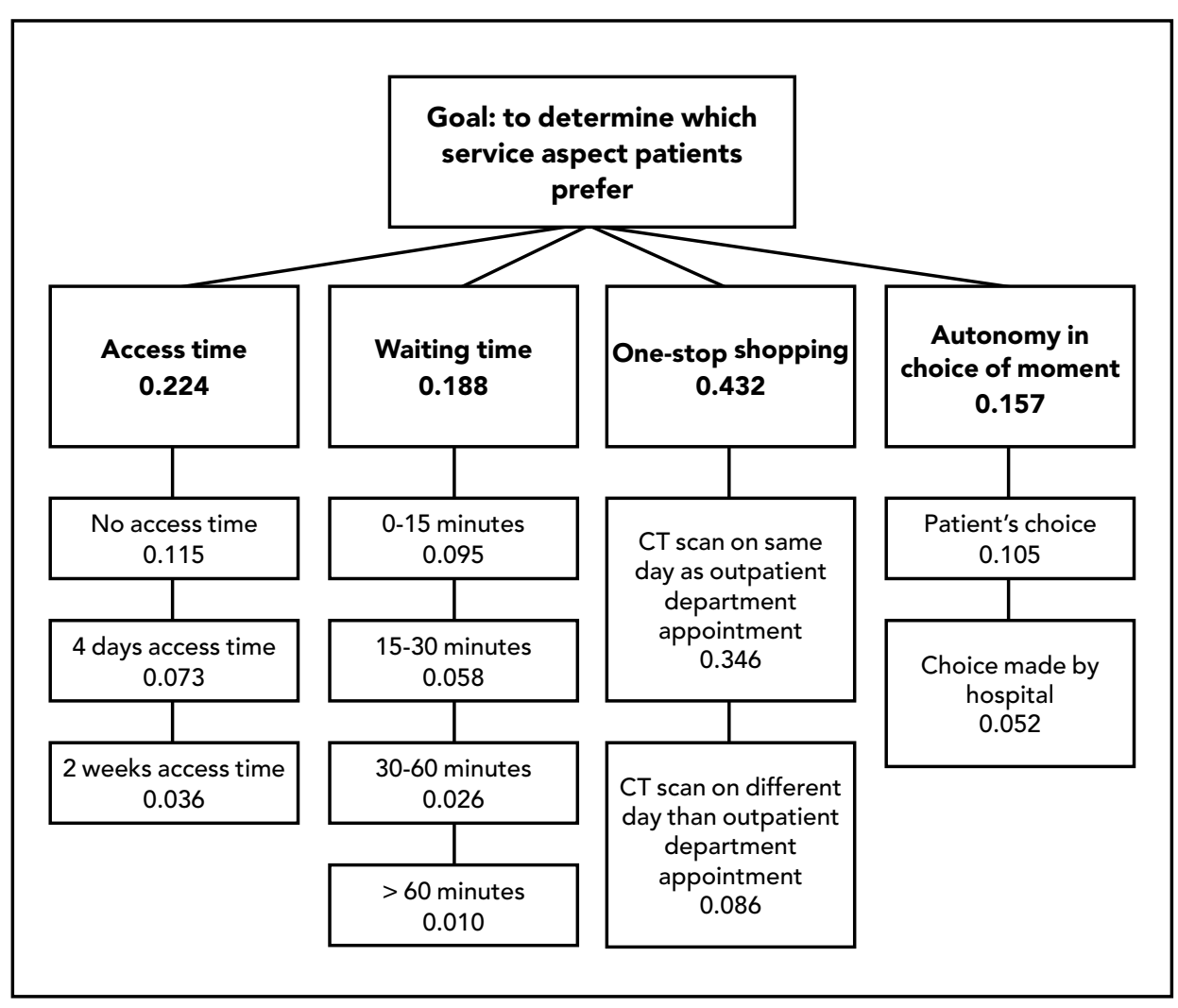


The sum of the weighting factors of the performance levels indicates the priority of the higher-level performance criterion. The patients rated the possibility for one-stop shopping to be most important, followed by short access time, short waiting time, and, least important, autonomy in choosing the moment for the CT scan. The inconsistency in the pairwise comparisons made by the group are all acceptable (Consistency ratio $<=0.10$ ), except for the inconsistency in comparisons between the performance levels of waiting times (Inconsistency ratio $=0.17$ ). This inconsistency is higher than the acceptable maximal inconsistency ratio of 0.10269 . The weighting factors for the performance levels show that what contributes most to a preference for an access system scenario is the ability to have the CT scan on the same day as the appointment in the outpatient department. Access time and waiting time are the second and third most important performance scores for access systems respectively.

These weighting factors can be used to evaluate entire access system designs. The overall performance of an access system design is the sum of the weights of the corresponding performance levels. The overall performance reflects patient preferences for the alternative access systems.

Patients indicated that the maximum acceptable waiting time is $12.4 \mathrm{~min}$ utes; however, if there is no access time, patients are willing to wait a maximum of 23.2 minutes. Patients indicated that the maximum acceptable access time is 11.4 days. Regarding their arrival time, $55 \%$ of the patients indicated they would adjust this if they were informed about busy periods.

\subsubsection{Preferences for access system designs}

The performance of access system scenarios is presented in Table 12. Performance of access system scenarios. Considering that we analyzed 3, 4, 2, and 2 performance levels for access time, waiting time, one-stop shopping, and autonomy of choice respectively, there were 48 access system designs possible in theory $(3 \times 4 \times 2 \times 2=48)$. We did not take into account those designs that were unacceptable to patients or those that were not relevant in a practical sense. The patients indicated that all designs with more than 0 days of access time and more than 15 minutes of waiting time were unacceptable. In addition, when the access time was 0 days (as is the case for walk-in systems), more than 30 minutes of waiting time was unacceptable, as were designs with 14 days of access time. Designs with 0 days of access time and no autonomy of choice were not considered to be relevant, because if a patient can arrive and be served immediately, there is always autonomy of choice. In the same way, designs with 0 days of access time and no one-stop shopping option were not considered to be relevant, because patients would have no reason to leave and come back for their CT scan after their first hospital visit. Six access system designs proved to be acceptable and relevant. The designs are listed in order of decreasing preference. The final performance score is the sum of the performance level priorities met by the access system scenario.

\section{TABLE 12 / Performance of access system scenarios}

\begin{tabular}{cccccc}
\hline Design & $\begin{array}{c}\text { Access } \\
\text { time }\end{array}$ & $\begin{array}{c}\text { Waiting } \\
\text { time }\end{array}$ & $\begin{array}{c}\text { One-stop } \\
\text { shopping }\end{array}$ & $\begin{array}{c}\text { Patient's } \\
\text { choice }\end{array}$ & $\begin{array}{c}\text { Final } \\
\text { score }\end{array}$ \\
\hline 1 & 0 days & $0-15 \mathrm{~min}$. & yes & yes & 0.661 \\
2 & 0 days & $15-30 \mathrm{~min}$. & yes & yes & 0.624 \\
3 & 4 days & $0-15 \mathrm{~min}$. & yes & yes & 0.619 \\
4 & 0 days & $0-15 \mathrm{~min}$. & yes & no & 0.608 \\
5 & 2 weeks & $0-15 \mathrm{~min}$. & yes & yes & 0.582 \\
6 & 0 days & $15-30 \mathrm{~min}$. & yes & no & 0.571 \\
7 & 4 days & $0-15 \mathrm{~min}$. & yes & no & 0.566 \\
8 & 2 weeks & $0-15 \mathrm{~min}$. & yes & no & 0.529 \\
9 & 0 days & $0-15 \mathrm{~min}$. & no & yes & 0.401 \\
10 & 0 days & $15-30 \mathrm{~min}$. & no & yes & 0.364 \\
11 & 4 days & $0-15 \mathrm{~min}$. & no & yes & 0.359 \\
12 & 0 days & $0-15 \mathrm{~min}$. & no & no & 0.348 \\
13 & 2 weeks & $0-15 \mathrm{~min}$. & no & yes & 0.322 \\
14 & 0 days & $15-30 \mathrm{~min}$. & no & no & 0.311 \\
15 & 4 days & $0-15 \mathrm{~min}$. & no & no & 0.306 \\
16 & 2 weeks & $0-15 \mathrm{~min}$. & no & no & 0.269 \\
\hline \hline
\end{tabular}

Overall, patients prefer a design with no access time: the walk-in system. The best-case scenario would be a walk-in system with 0 to 15 minutes of waiting time. The worst-case scenario would be an appointment system in which patients have an access time, no one-stop shopping option, and no autonomy of choice. A viable improvement to the appointment system would be to let patients decide on their moment of choice, but only if the waiting time does not exceed 15 minutes. However, this improved appointment system is still not preferred over the walk-in system scenarios. An analysis of all designs that are possible in theory showed that patients prefer a walk-in system even if this means they would have to wait an hour for their CT scan. Overall, the scenario analysis shows that patients prefer walk-in systems over standard appointment 
systems. If a walk-in system is introduced, when patients arrive at the hospital is relevant, mainly because peaks and lulls have consequences for the utilization of resources and for waiting times. The following section presents our findings on predicted arrival times for patients.

\subsubsection{Patient behavior}

The predicted arrival rate for patients arriving from the outpatient department is shown in Figure 14.

\section{FIGURE 14 / Predicted arrival rate for walk-in patients}

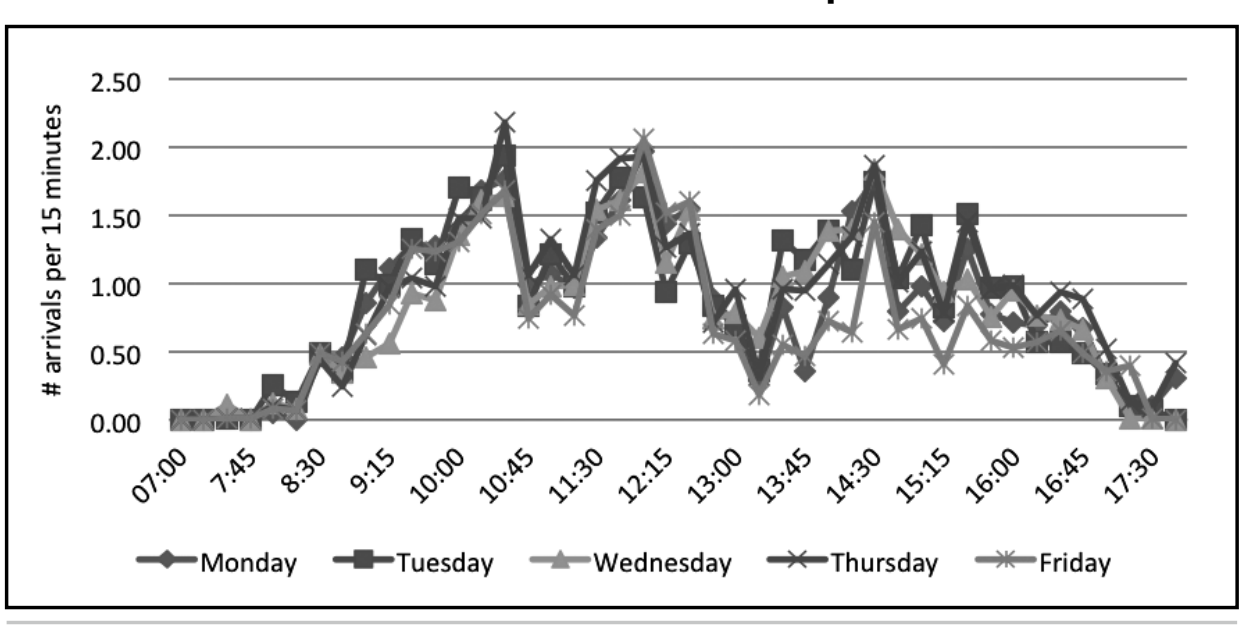

It appears there are few differences between weekdays, with only Fridays being slightly quieter. The pattern shows some peak periods and lull periods. The results from the questionnaire for patients arriving from outside the hospital were similar. With regard to differences, they preferred Monday, Tuesday, and Wednesday over Thursday, Friday, and Saturday. Monday, Tuesday, and Wednesday were chosen respectively 65,64 , and 69 times as preferred days, and Thursday, Friday, and Saturday respectively 31, 28, and 6 times. Most respondents (87 respondents) selected 11:00-13:00 as their preferred time for having a CT scan, followed by 9:00-11:00 (73 respondents); 13:00-15:00 and 7:00-9:00 were selected by respectively 45 and 40 respondents. Time slots later in the afternoon were not as popular: 15:00-17:00 was selected 16 times, and 17:00-19:00 and 19:00-21:00 were both selected only once. Of the respondents, $54 \%$ would like to know about busy periods so they can decide to come at another moment.

\subsection{Discussion}

From the patients' perspective, a walk-in system is a better access system for CT scan facilities than an appointment system. This is based on the questionnaire results, which imply that patients prefer the advantages of a walk-in system over the advantages that appointments can be expected to offer. Namely, patients prioritize the one-stop shopping performance indicator as being most valuable, followed by short access times. To patients, it is important to minimize the number of hospital visits, and if they need to come back, they want to do so as soon as possible. Next, patients want to limit the waiting time in the waiting room, and least important is the possibility of choosing the moment for the hospital visit.

Since one-stop shopping is a priority, arrivals to the radiology department will depend on the outpatient consultations, as these are the main departments that refer patients. Outpatient departments typically deal with peak periods. Since the preferred arrival times of patients who arrive independent of outpatient consultations correspond with outpatient peaks, fluctuations in patient arrivals must be expected when a walk-in system is implemented. This results in daily peaks and lulls, entailing the risk of temporarily long waiting times and lulls. However, walk-in patients are willing to accept longer waiting times than patients arriving for appointments. Another nuance is that most patients can be persuaded to arrive at quiet moments by informing them about busy moments. In short, we are convinced that the possible negative consequences of a walk-in system resulting from peak periods are outweighed by the advantages that are more important to patients.

The study was performed in a university hospital characterized by patients with relatively complex needs who, on average, have more travel time than patients in general hospitals. If this study had been performed in a general hospital the results might have been different, such as the high priority given to one-stop shopping. The fact that the patients we surveyed were restricted to one hospital might have also affected the priorities. It is possible that the relatively low access time in the AMC radiology department at the moment patients completed the questionnaire meant that patients were less concerned about access times than they would have been if they had been waiting for their appointment for weeks. In conclusion, since one factor tends more towards a walk-in system, and the other less so, these factors will largely balance each other out and will not lead to an adaptation of the conclusion for general hospitals. We find it highly probable that, for all hospital types, a walk-in system is better suited to patient preferences than an appointment system. 
If patients prefer a walk-in system, does this mean that this is the best way to organize radiology facilities? Given that we focused solely on one of the stakeholders, this study does not provide the answer to this question. Additional stakeholder analysis is needed to be able to answer this question. Walkin systems have some serious logistical and operational consequences. Even if it is possible to influence patients' arrival behavior, we still expect there will be more peak and lull periods than in an appointment system. Since resource utilization for walk-in systems is unknown, given a fixed number of resources, no predications can be made as to whether the same number of patients can be served as in an appointment system. Therefore, it is not known what the consequences will be in terms of efficiency if a walk-in system were to be introduced for the CT scan. The average and maximum waiting times for a walk-in system are also unknown. Furthermore, this requires increased flexibility from radiology personnel, because they will need to prioritize patients and manage a possibly fuller waiting room. Employee preferences could potentially become an issue. There are also some practical implications, such as when hospital policy requires medical information to be obtained or a referral to be approval by a radiologist before a patient can be served.

This study demonstrated that AHP is a valuable technique for investigating patient preferences concerning access to a hospital facility. Because we employed various access system designs, AHP provided us with more possibilities than other methods with limited alternatives. In this way, we gained insight into priorities and bandwidths. AHP can be more widely employed as a decision support technique for management.

Since the system and patient characteristics of the CT scan are comparable to many other hospital facilities, it is probable that our conclusions will be valid for other facilities as well. Many facilities are visited after a referral from the outpatient department, such as the laboratory, outpatient operation room, preoperative anesthesia assessment, and many radiology modalities. This study will hopefully remove some of the hesitation hospital managers may have regarding walk-in systems.

\section{CHAPTER 6}

\section{The feasibility of walk-in computed tomography facilities}

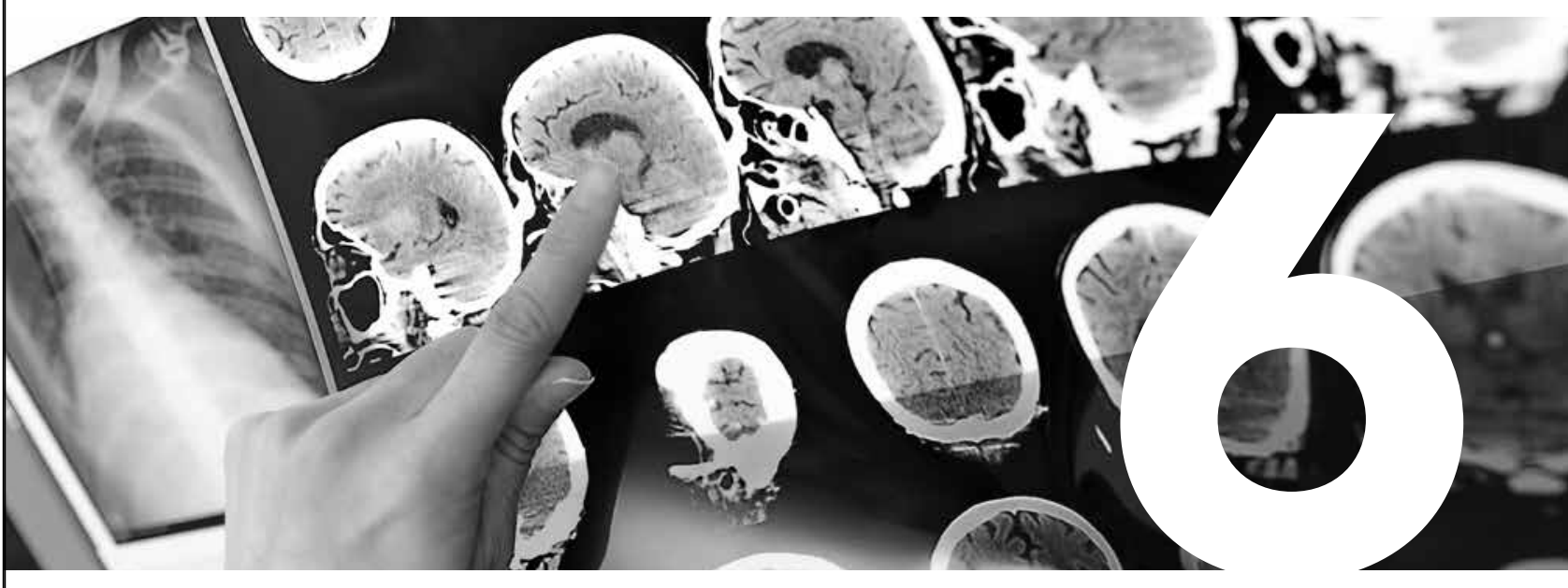




\section{LITERATURE UPDATE FOR CHAPTER 6}

The aim of the study presented in this chapter was to explore how a walk-in system would affect the operational performance of the CT modality. Our study contributes to the existing literature because we have theoretically proven that the advantages of a CT walk-in facility are greater than the advantages of an appointment system for CT scans. Furthermore, using computer simulation, we demonstrated how this could best be implemented.

What follows here is an overview of related studies published in the literature after our study in the Academic Medical Center (AMC) (2009). Various new studies support our conclusions that an appointment system causes unnecessary access times, and the planning consumes time and money. ${ }^{\mathbf{2 2 7}, \mathbf{2 7 0 , 2 7 1}}$ An advantage of the walk-in system is that it reduces access times and can increase utilization because it eliminates slack times for appointments. ${ }^{\mathbf{2 2 7 , 2 7 0 , 2 7 1}}$ Furthermore, it offers patients the opportunity to choose the day and time for their CT scans, and means that a portion of the patients will have to visit the hospital less frequently. ${ }^{\mathbf{2 2 7}, 270}$ However, the walk-in system also has some drawbacks. Some people need preparatory activities before their scan, so a walk-in system would not be appropriate for them. Moreover, demand can be highly variable in walk-in systems, and this can result in long waiting times and low utilization. ${ }^{227,270,272}$

An important factor for the success of a walk-in system is to manage the variability of patient arrivals. In this chapter, we explain that the predicted arrival times are about the same from Monday through Friday (with the exception of some minor variations on Friday). Peak hours are around 10:30 a.m., 12:00 p.m., and 2:30 p.m., which has also been shown by Braaksma et al. ${ }^{227}$ Our simulation study would appear to have had an impact on practice, because the AMC recently (in 2016) started using a walk-in system for their CT scan facilities. ${ }^{209}$

Kortbeek et al. (2014) 272 developed a scheduling strategy in which appointments are scheduled at times when the predicted number of walk-in patients is low. This system would seem to be a good match for the system characteristics of the AMC. ${ }^{272,273}$ Furthermore, Smid (2013) ${ }^{270}$ showed that this combined system results in a decrease in the number of no-shows. Braaksma (2015) ${ }^{227}$ also studied the combined system, and concluded that for CT scans it achieves its goals of quality, efficiency, and patient service. The best way to combine walk-ins and appointments is to employ appointment schedule optimization. ${ }^{227}$
There are also authors who looked at a combined system in a different way: by basing the number of walk-in patients on the no-show rate. Zhao et al. $(2013)^{274}$ looked at no-shows and cancellations as an explanation for the indirect waiting time. As a result, they argued that the best system is to overbook appointments every day because each population group has a certain probability of not showing up. ${ }^{275-278} \mathrm{Cao}$ (2014) concluded that this strategy can increase clinic profits. ${ }^{279}$

Wiesche et al. (2016) ${ }^{280}$ took patient preferences into account to investigate how many appointments a hospital has to offer each day with a combined system. They looked at three different scheduling strategies: patient structure (in which urgent patients are treated first), and intraday and interday scheduling. They concluded that having two appointment blocks - one in the morning and one in the afternoon - works best. ${ }^{280}$ Furthermore, it is also possible to adapt these blocks to patient arrival rates. ${ }^{281}$ The appointments are spread throughout the day in a way that evenly distributes the workload over the day, which results in the same waiting times for scheduled patients in both the morning and afternoon. ${ }^{281}$ The "Dome rule" could be used to create a planning constant based on factors that influence the no-shows, walk-in patients, etc. ${ }^{282}$ The Dome rule means that one patient is scheduled at a time, whereby appointment intervals first increase, and then decrease at the end of the session. ${ }^{199,282}$

Another way to look at the combined system is to combine an open access system with appointments. As discussed in the previous chapter, an open ac cess system means "meeting today's demand today." 283 In an open access system, appointments are scheduled for the same day, which is different than a walk-in system, in which no appointments are scheduled. This system can result in less waiting time for patients and less idle time and overtime for doctors, compared with a traditional appointment system. ${ }^{284}$

We found no published studies on implemented walk-in systems for CT scan facilities. As far as we know, Rijnstate is the only hospital in the Netherlands that has extensive experience with walk-in CT facilities (see Chapter 7). The AMC (the university hospital where the studies presented in Chapters 2 through 6 were conducted) only introduced walk-in CT facilities in 2016. In the early 2000s, the former TweeSteden hospital in Tilburg introduced walk-in CT facilities, but that was temporary.

We conclude that this new literature supplements our own conclusions. A combined system of walk-ins and appointments still seems to be the best option. Nonetheless, the new literature also suggests that basing the combined 
system on no-shows by overbooking the appointment slots every day is promising. Furthermore, the Dome rule and the open access system have been shown to offer possibilities for a combined system.

\section{ABSTRACT}

Background In hospitals, it is easier for patients to limit the number of hospital visits in walk-in systems than in appointment systems. Especially for imaging services, walk-in facilities may greatly contribute to both the quality of health care and the level of service. Although computed tomography (CT) facilities often have high access times, walk-in systems are seldom used. The objective of this study was to explore how a walk-in system would affect the performance of the CT modality.

Methods: We conducted a case study in the Academic Medical Center (AMC), a university hospital in Amsterdam, the Netherlands. Extensive data on the CT process were gathered and analyzed. Performance indicators were defined and measured. Computer simulation was used to prospectively evaluate walk-in interventions. The model was validated and a sensitivity analysis was performed. Scenarios were defined and run in the simulation model.

Results: Walk-in visits are not possible for all patients, since some scans require professionals from different hospital departments to be present for part of the process, and this needs to be scheduled. Therefore, we focused on finding an ideal combination of walk-ins and appointments. With this walk-in intervention, a large number of the CT patients will be able to reduce the number of hospital visits, and these patients will be able to choose when they have their scan. Computer simulation showed that the average access time decreases from 3 days to 1 day, and that the average waiting time increases from 12 to 20 minutes for walk-ins. Average overtime increases by 15 minutes for walk-ins. In addition, it appears to be possible to scan $10 \%$ more patients in a walk-in system, and requires less effort to plan.

Conclusion: This study shows that a walk-in system for a CT facility can contribute to both service level and efficiency. A combination walk-in/appointment system provides the best solution. We demonstrated that this reduces the number of hospital visits, eliminate access times, serve more patients, require less planning, and give patients autonomy in determining when to visit the facility.

\subsection{Introduction}

Diagnostic imaging facilities are essential to many care pathways. Because diagnostic services are shared resources, these facilities often appear to create bottlenecks for patients. Particularly in the radiology department, there is an increasing demand for rapid access to diagnostic examinations. However, access times are frequently long, and there may be several weeks between a referral and the patient's appointment ${ }^{30}$. Since access time to imaging facilities delays treatment, deterioration of the patient's health is a serious risk. As such, reducing access time for diagnostic imaging offers great potential.

This study focused on the computed tomography (CT) department in the Academic Medical Center (AMC), a university hospital in Amsterdam, the Netherlands with 1,000 beds. An earlier study to reduce variability and optimize the logistical processes for the AMC's CT scanners resulted in a significant decrease in access times, from 21 to fewer than 5 days on average ${ }^{\mathbf{2 8 5}}$ (Chapter 3). To further improve quality of care and the level of service by reducing or eliminating access times, the CT department is considering introducing a walk-in service so that patients can visit at a moment of their choice without an appointment.

Diagnostic imaging facilities traditionally provide appointment-based services. This is done to balance the workload and thus manage waiting times and utilization. However, the disadvantages of an appointment system are that patients need to revisit the hospital, and access times can be long. A study on patient preferences in the AMC among the CT patient population ${ }^{286}$ (Chapter 5) showed that patients prefer the advantages of walk-in systems over those of appointment systems. Patients indicated that a one-stop-shopping option and a short access time are more important than a short waiting time in the waiting room. In addition, patients are willing to wait longer when they walk in than when they have an appointment ${ }^{37,228}$.

An alternative to an appointment system is a walk-in system in which patients can visit a radiology facility at the moment of their choice. This allows for one-stop shopping, which reduces the number of hospital visits and also access time to the facility. Walk-in systems are rarely used in CT facilities, and as a result, the logistical effects of introducing the walk-in concept to these facilities are largely unknown. CT has some system characteristics that can lead to some doubts about the feasibility of walk-in. Because of the inherent uncertainty regarding arrival times of walk-in patients (both peak hours and peak days), waiting time and utilization are harder to control. However, some patients cannot arrive on a walk-in basis because they require preparation activi- 
ties before their scan or because a clinician from another department has to be present, which means that it may be neither desirable nor realistic to completely abandon appointments. We hypothesize that by combining the appointment and walk-in systems, it is possible to combine the best of both worlds. Although the effects of walk-in health care services have been studied $^{\mathbf{2 8 7}, \mathbf{2 8 8}}$, as far as we know this has not been done for CT facilities.

The objective of this study was to explore how walk-in services would affect the performance of the CT modality. To do this, we used computer simulation to analyze different degrees of walk-in services in a case study in the AMC. The AMC serves patients from all over the Netherlands, and this increases the advantages of one-stop shopping.

\subsection{Methods}

To assess the logistical implications of the introduction of a walk-in system in the CT modalities, we designed a computer simulation model. Computer simulation is a tool used for managerial purposes to prospectively assess the consequences of various alternative interventions without actually changing the system ${ }^{289}$. Modeling, and especially computer simulation, has proven to be a valuable method for assessing such effects in health care settings ${ }^{290,291}$. Computer simulation is highly suited to our problem setting for a number of reasons. First, experimenting with a walk-in system in practice carries the risk of creating undesirable effects for patients. Second, field experimentation makes it difficult to control all the variables, can increase the resistance of stakeholders, takes more time, and offers less statistical reliability. Finally, compared to other modeling techniques, simulation provides a high degree of flexibility for incorporating the impact of inherent uncertainties (in patient arrivals, service times, etc.) within the CT process, for incorporating the detailed patient routing and time-dependent character, and for evaluating multiple performance measures. The simulation study was performed following Law and Kelton's 10-step methodology ${ }^{289}$ :

\subsubsection{Formulate the problem and plan the study}

Based on interviews with the stakeholders, we defined our objectives, formulated measurable performance indicators, and defined the scope of the study. Performance indicators from the perspective of patients were based on the patient preferences study ${ }^{\mathbf{2 8 6}}$ performance indicators from the perspective of the hospital were extracted from interviews with radiology management.

\subsubsection{Analyze the context and define a model}

The present situation was surveyed by process mapping, data gathering, assessing the current scores on the formulated performance indicators, interviewing management, radiologists, and laboratory staff, and observing the CT scanning and scheduling process. We extracted historical data on CT requests from the X/Care scheduling software (McKesson). In cooperation with laboratory staff, we performed time measurements to gather information with respect to process times and patients' arrival times for their appointments. We consulted experts to determine which patient types would be eligible for walk-in services. To evaluate walk-in interventions, we generated a predicted arrival pattern for walk-in patients, since a walk-in system had not yet been implemented and therefore no real data was available. This estimated arrival pattern was based on the referring outpatient departments' consultation schedules. To predict the arrival pattern, we evaluated the clinic agendas of the eight most-referring specialties to determine the amount of consultation hours, which together account for $81.6 \%$ of all outpatients $C T$ scan requests. The pattern for the predicted number of CT patients per 15-minute period was generated by multiplying the number of patients seen by each specialty by the probability that a patient would be referred for a CT scan by that specialty. Data was extracted from the appointment scheduling software X/Care over an one year period (2008). Based on the patient preferences study we conducted among CT patients in the $\mathrm{AMC}^{286}$ (Chapter 5), we determined the fraction of patients who chose to visit the $\mathrm{CT}$ facility directly after their referral. We assumed a transfer time of 20 minutes between the outpatient clinic and the radiology department. Subsequently, we designed the conceptual model, which consisted of a description of the model objective, input parameters, content, output parameters, and assumptions and simplifications (See Appen$\operatorname{dix} 1)$.

\subsubsection{Validate the data}

Laboratory staff and planners who are highly familiar with the operations of the CT system were consulted to validate and verify the process map and data analysis.

\subsubsection{Construct and verify a computer program}

Based on the process map, the simulation model was programmed in MedModel, a discrete-event computer simulation software tool from ProModel that is specially designed to model health care situations. The process steps 
and all logical rules from reality were digitally simulated in the model. Input data such as patient arrivals, process times, and probabilities of certain events were imported. Verification was performed by debugging during and after programming.

\subsubsection{Make pilot runs}

To make validation possible, pilot runs were made that simulated the current situation. To obtain a $95 \%$ confidence interval for the performance indicators, we determined the initial conditions for the simulation runs, the length of the warm-up period, the length of the simulation runs, and the number of independent simulation runs (replications).

\subsubsection{Validate the model}

To validate the simulation model, the scores on the performance indicators for the present scenario were compared with the measurements in practice.

\subsubsection{Conduct design experiments}

Various interventions were formulated that employed various combinations of the appointment and walk-in systems.

\subsubsection{Make production runs}

Simulation runs were done to obtain performance data on the system designs of interest.

\subsubsection{Analyze the output data}

The output data were analyzed to compare the interventions and formulate conclusions. Then, to test the main assumptions, sensitivity analyses were performed by determining the effect of small changes in various input parameters on system performance.

\subsubsection{Document, present, and implement the results}

The results were documented and presented to the radiology department management. A walk-in CT facility has now been introduced at the $A M C$, but its implementation is beyond the scope of this chapter.

\subsection{Results}

The results section is structured as follows: first, the process analysis and performance indicators (steps 1-3) are presented; second, the simulation model (steps 4-6); third, the design of the interventions (step 7); and fourth, the numerical results of the simulated interventions (steps 8-10).

\subsubsection{CT scheduling and scanning process}

The AMC has three CT scanners. Two are situated in the radiology department, and one is dedicated to the emergency department. Currently, all outpatients are scanned on one of the two modalities in the radiology depart ment, while all emergency patients are scanned in the emergency department. Inpatients are scanned in either the radiology or the emergency department. The scope of this study is limited to the two CT scanners in the radiology department.

At the time of this study, a CT scan required a request for an appointment, which was a paper form that was usually filled out by a medical specialist. These requests came from inpatient or outpatient clinics, or sometimes from other hospitals or general practitioners outside the hospital. Each request was assessed by a radiologist prior to scheduling the appointment to check the ap plications for accuracy, or to refer the patient to another diagnostic facility. After assessment, the appointment was scheduled by the planning department.

Figure 15 shows the $\mathrm{CT}$ imaging process during the appointment. First, the patient registers upon arrival. After registration, the patient's eligibility is de-

\section{FIGURE 15 / CT imaging process}

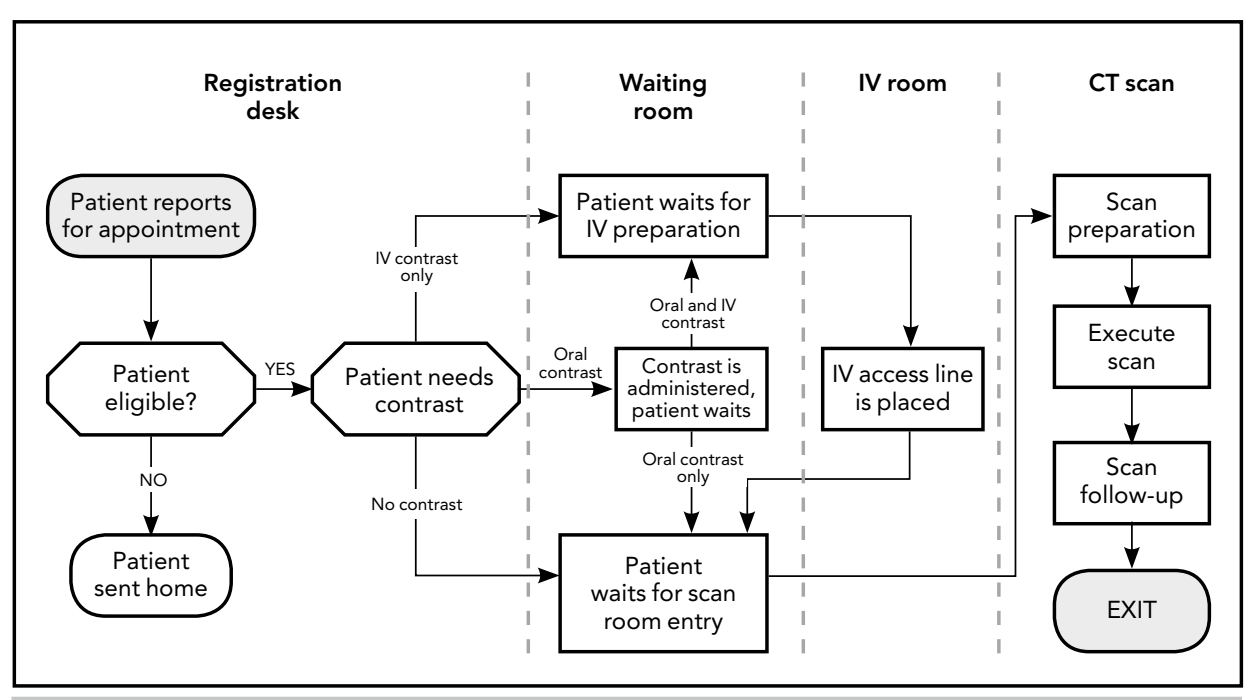


termined. Eligibility depends on whether the patient is in a fasting state (if required), whether it is known if a patient is allergic to the contrast (if relevant), and, in some cases, whether creatinine levels are known. If the patient is eligible, he or she can be scanned. Patients often require oral and/or intravenous (IV) contrast. Depending on the type of oral contrast, patients are required to start drinking the contrast 30 or 60 minutes prior to the execution of the scan. IV contrast requires the placement of an access line, which is done in the IV room. If both oral and IV contrasts are required, the IV access line is placed while the patient is drinking the oral contrast. Inpatients generally arrive at the CT facility prepared, which means that oral contrast or an IV access line was administered on the ward. As such, inpatients who enter the waiting room are ready for their CT scan. Scan preparation includes removing clothing (by the patient), positioning the patient, and administering the IV contrast. Scan follow-up is the process that includes the patient leaving the room after the scan has been completed.

The radiology department employs a planning team for all imaging facilities; this team is responsible for the scheduling of appointments. X/Care electronic scheduling software (McKesson) is used throughout the entire hospital. In the schedule for the CT scanners, several appointment blocks are reserved for a specific patient group or specialty. Some appointment blocks are there for historical reasons, for example, because at some point an outpatient department claimed some of the limited capacity. When an appointment is scheduled, patient type, urgency, type of examination and future outpatient clinic appointments are taken into account.

The appointment schedule contains appointment blocks that represent the capacity assigned to each examination type. The blocks are classified as follows:

\section{Outpatients}

1.1. For patients who need long preparation times (if oral contrast is administered, patients need to be in a fasting state)

1.2. For patients who prefer an appointment

2. Examinations that require anesthesia

3. Cardiac examinations

4. Inpatients

5. Colonography examinations

6. Orthopedic examinations

7. Patients who do not require IV contrast
Some imaging-related factors are relevant to the choice for walk-in visits or appointments. First, appointments have different durations, varying from 15 to 45 minutes. Second, preparation may be necessary, such as drinking oral contrast or placing the IV access line so that intravenous contrast can be administered. In addition, patients are required to be in a fasting state for some scans. While some examinations can be done on either CT scanner, others are restricted to the newest one.

\subsubsection{Performance indicators}

We formulated eight performance indicators to assess the CT process. We will first introduce the four patient indicators extracted from the patient preferences study ${ }^{\mathbf{2 8 6}}$, and present them in the order of priority assigned to them by patients These patient priorities are in line with earlier research on outpatient clinics ${ }^{259}$ :

- One-stop shopping: The ability to combine more than one procedure or consultation on a single day, which minimizes the number of hospital visits.

- Access time (in days): The number of days between a doctor's request for imaging and the moment the patient actually has the scan ${ }^{\mathbf{2 8 6}}$.

- Waiting time (in minutes): The time a patient has to wait in the waiting room ${ }^{286}$; only involuntary waiting time is included. Voluntary waiting time is the time a patient arrives before his appointment time.

- Autonomy of choice: The autonomy to determine when to visit the hospital for a scan.

The following four hospital performance indicators were selected based on their relevance according to hospital management, and the expected differences between appointment and walk-in systems based on the literature:

- Schedulers required: Staff members are required to schedule appoint-

ments.

- Overtime (in minutes): The time used to scan patients after regular opening hours. Negative overtime implies that the last patient was scanned before closing time.

- Utilization: The time the CT scan rooms are occupied during regular opening hours divided by the total time the CT scanners are available. Calibration time is included in utilization, as this is perceived as being compulsory. Maintenance time, downtime, closures due to staff shortages, changeover time, and other planning inefficiencies are all excluded 
from utilization, as this is considered to be time when capacity was available.

- Number of postponements: Scans are postponed if equipment breaks down or patients are late. Another reason for postponements is when patients leave the clinic because they are unwilling to wait for their scan.

\subsubsection{Design and validation of the simulation model}

For the simulation model, we used the process descriptions to accurately simulate both the patient and the information flow, see Figure 16. We formulated input parameters for the simulation model; an overview of these parameters can be found in Appendix 1.

\section{FIGURE 16 / Screenshot of the simulation model}

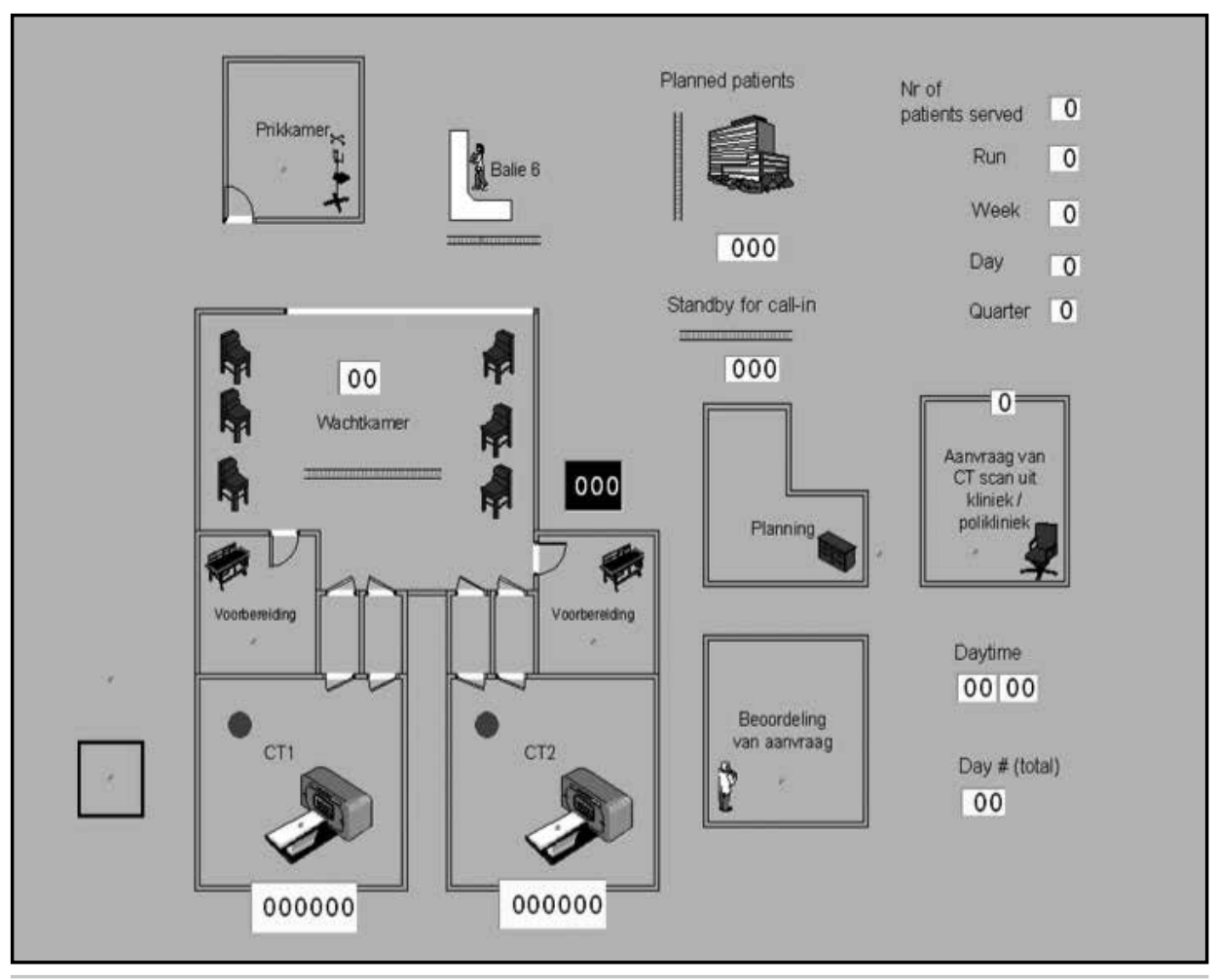

The predicted arrival rate is shown in Figure 17. Based upon our patient preference study ${ }^{\mathbf{2 8 6}}$, we assumed that patients faced with an expected waiting time of longer than 1.5 hours would prefer to make an appointment.

\section{FIGURE 17 / Predicted arrival rate for walk-in patients}

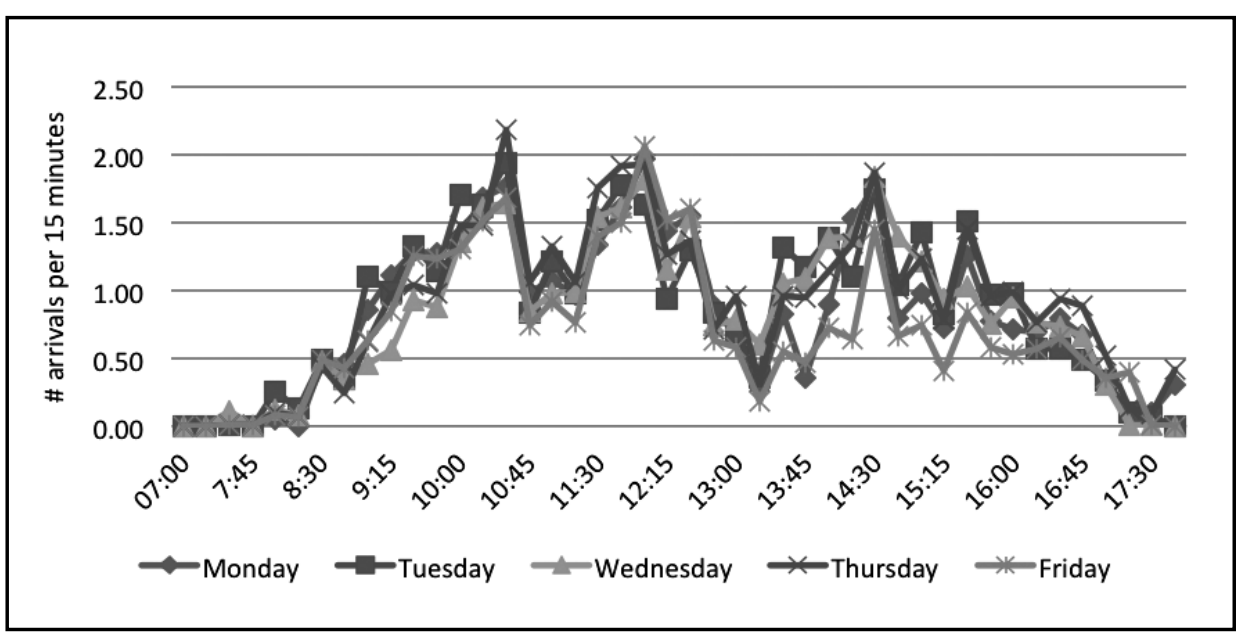

Validation of the simulation model was performed at two levels, first at the level of the planning process and then at the level of the imaging process. To validate the planning process, we used prospective access times determined by the third available appointment slot. This focusses on the future possible appointment slots at a given moment. Validation based on retrospective access times - afterwards determining the difference between referral day and imaging day - was not possible because, in practice, many appointments were deliberately scheduled later than was actually possible, based on the patient's preference. To test for significant difference in access times between current practice and the simulation model, we performed an independent t-test for equality of means. The $95 \%$ confidence interval of the difference includes zero, which indicates we could identify no significant difference between access times in practice and in the model. We thus considered the planning process in the simulation model to have been validated.

To validate the imaging process, we used waiting time to validate our model against current practice. An independent sample t-test was used to compare the sample from practice (2-week measurement with $\mathrm{N}=386$ ) with the simulation model sample ( 1 run of 1 year with $N=10,910$ ) of waiting time. The $95 \%$ confidence interval includes zero, and so we rejected the hypothesis that the two samples were significantly different. We thus considered the imaging process in the simulation model to have been validated. 


\subsubsection{Interventions}

We evaluated the following interventions:

i0) Current situation: All patients have scheduled appointments.

i1) Walk-in system: All patients arrive as walk-ins

i2) Combination walk-in/appointment system: For this intervention, we designed a schedule with blocks of appointments during quiet periods intended exclusively for patients not eligible for walk-in visits. These appointment blocks were intended for three patient types: patients who require a multidisciplinary medical team during imaging (cardiac patients and those coming for a colonography or an examination requiring anesthesia), patients who require preparation (oral contrast) and who need to be in a fasting state for their scan, and patients who prefer to have an appointment. These can be both inpatients and outpatients. The number of patients who prefer an appointment was based on the patient preferences study ${ }^{286}$

i3) Combination + call-in inpatients: The same as i2, except that inpatients are called in prospectively during periods with short waiting times.

Chapter 4 demonstrated that separate appointment blocks for each patient type has a negative effect on access time ${ }^{204}$. If a walk-in system is introduced, this inefficiency will be avoided implicitly. According to hospital management, i1 is an intervention that cannot be implemented in practice. However, it does serve as a reference point for interventions i2 and i3.

\subsubsection{Simulation: Numerical results}

The results per intervention are presented in Table 13. We distinguish inpatients and outpatients for access time and waiting time because these indicators cost more for inpatients than for outpatients, because inpatients use nursing departments, and because they are usually in worse condition.

Table 13 shows that in i 2 and i 3 , approximately half of the patients are required to, or choose to, have an appointment. All interventions except i0 offer a one-stop shopping option. As expected, the average access time is significantly lower in a walk-in system than in i0. Waiting time increases with the introduction of a walk-in system. Fortunately, patients are willing to wait longer when they walk $\mathrm{in}^{37}$. In interventions with a combination walk-in/appointment system (i2 and i3), the average waiting time is lower than the patients' maximum acceptable waiting time of 23 minutes for a walk-in situation ${ }^{\mathbf{2 8 6}}$. Autonomy in determining when to visit the hospital is offered in all interventions except i0.
TABLE 13 / Simulation results per intervention

\begin{tabular}{|c|c|c|c|c|c|}
\hline & & i0 & i1 & i2 & i3 \\
\hline & & $\begin{array}{l}\text { Appoint- } \\
\text { ments } \\
\text { (current } \\
\text { system) }\end{array}$ & Walk-ins & $\begin{array}{l}\text { Combina- } \\
\text { tion }\end{array}$ & $\begin{array}{c}\text { Combina- } \\
\text { tion }+ \\
\text { call-in }\end{array}$ \\
\hline \multirow{9}{*}{$\begin{array}{l}\text { Patient } \\
\text { indicators }\end{array}$} & Planned patients & $100.0 \%$ & $0.0 \%$ & $47.8 \%$ & $55.5 \%$ \\
\hline & One-stop shopping & no & yes & yes & yes \\
\hline & Autonomy of choice & no & yes & yes & yes \\
\hline & $\begin{array}{l}\text { Access time, outpatients } \\
\text { (in days) }\end{array}$ & 3.1 & 0.0 & 1.0 & 1.1 \\
\hline & Access time, inpatients (in days) & 2.4 & 0.0 & 0.8 & 0.0 \\
\hline & $\begin{array}{l}\text { Waiting time, walk-in } \\
\text { outpatients (in minutes) }\end{array}$ & - & 33.4 & 34.8 & 35.4 \\
\hline & $\begin{array}{l}\text { Waiting time, outpatients with } \\
\text { appointments (in minutes) }\end{array}$ & 11.0 & - & 6.6 & 8.0 \\
\hline & $\begin{array}{l}\text { Waiting time, walk-in inpatients } \\
\text { (in minutes) }\end{array}$ & - & 27.4 & 28.7 & 14.6 \\
\hline & $\begin{array}{l}\text { Waiting time, inpatients with } \\
\text { appointments (in minutes) }\end{array}$ & 12.2 & - & 6.0 & 0.0 \\
\hline \multirow{4}{*}{$\begin{array}{l}\text { Hospital } \\
\text { indicators }\end{array}$} & Planning team required & yes & no & partly & partly \\
\hline & Average overtime (in minutes) & -17.4 & 14.1 & -2.3 & -2.7 \\
\hline & Utilization & $52 \%$ & $53 \%$ & $53 \%$ & $53 \%$ \\
\hline & Postponements & $0 \%$ & $0 \%$ & $6 \%$ & $4 \%$ \\
\hline
\end{tabular}

i0 requires a planning team, and i 1 does not. i2 and i3 require a planning team with half of the resources of i0. There is more overtime when walk-ins are allowed, but, on average, there is no overtime for $\mathrm{i} 2$ and $\mathrm{i} 3$. Utilization is slightly higher when walk-ins are included in the system. Postponements do not occur in the present situation, since they can be referred to the CT scanner in the emergency department. With walk-ins, $4.3 \%$ of the visits are postponed.

For the sensitivity analyses, we selected input parameters that directly affect waiting time:

- Maximum acceptable waiting time: the maximum amount of time

patients are willing to wait when deciding whether to get in line or go

home

- Patient changing time: the setup time necessary for each patient; 
- Request assessment time: the average time a radiologist needs to review a request:

- Transfer time: the average time between calling in inpatients and their actual arrival.

The changeover time between two patients was found to vary considerably. Since patient changeover time is a parameter the department can control to some degree, this should be studied when implementing a walk-in system.

\subsection{Conclusion}

We conclude that CT facilities that provide a walk-in option for patients is a better choice than purely appointment-based CT facilities. First, from the patients' perspective, this offers the one-stop shopping option, reduced average access times, and autonomy of choice in terms of when to visit the hospital. Although average waiting times increase in a walk-in system, walk-in patients are willing to wait longer, and so this increased waiting time will generally be considered to be acceptable. Second, the hospital also benefits from a walk-in option because efficiency increases. This is indicated by slightly higher utilization, and less planning is required. A drawback of this option is that some walk-in patients will still have to revisit the hospital, but we would argue that this is subordinate to the aforementioned advantages.

A $100 \%$ walk-in system is not optimal, because some patients require a multidisciplinary medical team to be present during preparation for their CT scan or during imaging. Moreover, offering patients the choice between walking in or making an appointment is more patient-friendly. This led to our conclusion that, for CT facilities, a combination walk-in/appointment system is best.

This study assessed three interventions concerning the proportion of walkin versus appointment-based CT scans. The intervention $\mathrm{i} 3$ showed the best results for both patients and the hospital. In this intervention, fixed appointment blocks were scheduled during quiet periods for patients who required a multidisciplinary medical team during imaging, patients who needed preparation time, and patients who preferred to make an appointment. In addition, inpatients were called in during periods when waiting times were expected to be short so that patient arrivals were more evenly distributed.

\subsection{Discussion}

There are various reasons why appointment systems are commonly used for CT scanning resources. First, patient inflow is distributed evenly so that lengthy lull periods and disproportional waiting times are limited. Second, physicians often prefer predictability, and some scans require preparation or for patients to be in a fasting state. Third, hospital managers cannot get an overview of the effects of alternatives, and experimenting can be risky for patients. However, this study has demonstrated that there is a better solution: combining an appointment system with a walk-in system. Such a system combines the best of both worlds, both for patients and for the hospital. For patients, this would include faster service with greater choice, and for the hospital, greater efficiency.

In the combination walk-in/appointment system, underutilization during periods of low demand is diminished by planning appointments or calling in inpatients. Moreover, when a walk-in system is implemented, no-shows and cancellations are virtually nonexistent. Finally, in the combined system, efficiency increases because slack time per scan is required only during appointment blocks to deal with the variability of the scanning duration ${ }^{285}$.

There are some effects to consider when introducing a walk-in option to a CT facility. In our interventions, we assumed that, in the waiting room, patients with appointments had priority over walk-in patients. As a result, some patients might see others arriving later than they did, but being served before them. This situation requires clear patient communication. More flexibility will be required from radiologists, because every patient may be different, and from laboratory staff, because of closing times will vary. Furthermore, we recommend that waiting rooms should be well-managed and supported by information technology. Finally, as in all interventions that lead to reduced access time, an increase in referrals could be expected ${ }^{259}$.

We investigated the effects of a $10 \%$ increase in demand for the walk-in intervention. While this resulted in an even greater increase in utilization, patient advantages decreased, particularly waiting times. Further optimization is pos sible, especially by determining the optimal proportion of appointments and the optimal appointment block positions within the weekly schedule $\mathrm{e}^{204}$

The method we used - discrete event computer simulation - proved valuable. Although it is labor intensive, it provides representative quantitative results and contributes to convincing the leading coalition: physicians.

We expect our intervention to benefit the CT facilities in the AMC and in other hospitals, and also other hospital facilities now working with appointment systems (especially for systems with high variability in service time). Furthermore, university hospitals will benefit even more, because patients have longer travel times, and one-stop shopping provides a greater advantage. 


\section{CHAPTER 7}

Walk-in versus appointment-based computed tomography in practice: Impact on patient satisfaction, efficiency, and workflow 


\section{ABSTRACT}

Background/Objective: Long access time to computed tomography (CT) facilities is seen as a substantial problem in many hospitals. Walk-in is an intervention that eliminates access times, since it gives patients direct access without an appointment. The Rijnstate hospital (Arnhem, The Netherlands) implemented walk-in CT in 2010, which offered the opportunity to study the positive and negative effects of walk-in CT in practice and how these effects are balanced.

Methods: Employee interviews $(N=10)$, patient surveys $(N=535)$ and a data analysis using data from the Electronic Patient Record (EPR) of 129,148 patients between October 2008 and March 2017 were conducted.

Results: All stakeholders stated that the system improved with the introduction of walk-in. The interviews also resulted in main performance indicators: access time, waiting time, one-stop-shop, autonomy of choice, productivity and employee satisfaction. The patient survey divulged the maximum acceptable waiting time: $79 \%$ of patients stated this to be $15-30$ minutes or more. When asked which performance indicator is most important, 'one stop shop' was mentioned by 134 patients over access time, waiting time and autonomy of choice (ranged from 79 to 88). The data analysis showed a doubling in production, while CT capacity hardly increased. The percentage of outpatients that had to wait 30 minutes or less has decreased from $85.2 \%$ in 2009 to $59.5 \%$ in 2016 , but the absolute number of outpatients with these waiting times increased from 5.146 to 7.681 . Overtime production regarding outpatients has decreased over the years.

Conclusions: Walk-in CT performs better regarding the main performance indicators than a full appointment system. The reasons are that it almost nullifies CT access time and enhances one-stop-shop for patients. Walk-in also improves satisfaction of patients, referring physicians as well as the entire radiology staff, technicians and doctors alike. Furthermore, all results suggest that productivity can be higher with walk-in than with only appointments.

\subsection{Introduction}

Wait times for health care is a major problem in many countries. ${ }^{292}$ One of the main causes for these lengthy waits is access time, which is defined as the time a patient has to wait until his or her appointment. ${ }^{292,293} \mathrm{~A}$ long access time is obviously inconvenient for patients, since this unnecessarily lengthens the care pathway and thereby postpones recovery. Long access times to radio- logy, which includes computed tomography (CT) facilities, are a considerable problem in many hospitals. ${ }^{40} \mathrm{An}$ important reason for this is that a large number of patients who require a CT scan either have or are suspected of having cancer, and it is becoming increasingly clear that being in a state of uncertainty has a negative impact on these patients' well-being. ${ }^{33,38,39,294}$ In the Netherlands, for example, patients often have to wait weeks for the first appointment slot. 295

Many types of interventions have been implemented in radiology departments to improve access times. ${ }^{296}$ The intervention that has resulted in the greatest improvement is to provide patients with direct access to the facilities without an appointment, thus eliminating access time. This is referred to as a walk-in system, and is being used more and more frequently for radiology procedures like X-ray exams and ultrasound. Of potentially even greater interest would be to introduce a walk-in system for the CT facilities, because of the long access times there. However, many hospital managers and radiologists seem to view walk-in CT facilities as undesirable. Their main concern is that allowing patients to walk in would lead to unacceptable waiting times in the waiting room and lower productivity, caused by the unpredictable distribution of patient arrivals. Another concern is that full waiting rooms would lead to regular overtime, which would be undesirable for radiology employees. These concerns are based on assumptions, though, and the advantages that these walk-in facilities could offer are promising.

In addition to eliminating access time, walk-in CT facilities offer patients 'one-stop shopping' and the ability to choose their own time of arrival. With one-stop shopping, a CT scan can be performed on the same day as other hospital visits, such as an outpatient consultation. This eliminates the need for an additional hospital visit when it becomes clear during the first consultation that a CT scan is necessary, and means that the patient can have the scan immediately. In some cases, it might save even more than one hospital visit, as when the CT report will be ready the same day and the referring physician at the outpatient clinic can see the patient again after their scan. These advantages may be more important to patients than the anticipated disadvantage of longer waiting times in the waiting room. Modeling has shown that walk-in systems seem to provide considerable advantages in a number of other hospital departments, $\mathbf{2 7 1 , 2 7 7 , 2 8 3 , 2 9 7}$ and several studies from the literature have con-

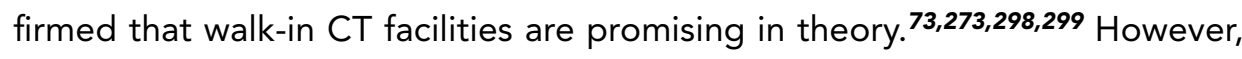
we could find no evidence in the literature that was based on the implementation of walk-in CT facilities in practice. 
The Dutch Rijnstate hospital has been working with walk-in CT facilities since 2010, and this offered us the opportunity to study its effects using real data and actual experience. Because the implementation of the walk-in CT facilities was completed some years back, it was possible to study the effects in a steady state in which all teething problems had already been dealt with. Our main research question was the following: What are the positive and negative effects of Rijnstate's walk-in CT system for stakeholders, and is this walk-in system more appropriate than an appointment system?

\subsection{Methods}

Rijnstate is a large teaching hospital the east of The Netherlands with 16 radiologists, 8 radiology residents, and 3 doctors of nuclear medicine. The hospital has three CT scanners at two locations. Until 2009, Rijnstate worked with an appointment system. In January 2010, they introduced a walk-in system for all outpatients and emergency patients. This is not a $100 \%$ walk-in system, however, because inpatients and outpatients who require special preparation (for example, kidney-preserving hydration therapy) are still given an appointment. Furthermore, cardiac studies, virtual colonoscopy, and biopsy procedures are planned. All other patients (including those being scanned using an oral and/or intravenous contrast agent) have access to the walk-in system. The system meets Dutch and European quality requirements and patient safety standards.

A stakeholder approach was chosen for this study, because the change from an appointment to a walk-in system had an impact on many stakeholders, and having the trust of the relevant stakeholders is considered to be an important factor in hospitals. ${ }^{300}$ The following stakeholders were considered: patients, referring physicians, hospital management, radiologists, $\mathrm{X}$-ray technicians, and the front office employees (who do the planning and staff the reception desk). These stakeholders were selected based on their influence on or interest in the choice of CT access system. This study focused on assessing the walk-in concept for the $\mathrm{CT}$ modality by evaluating the application in practice.

To assess the effects of the walk-in CT system, we conducted interviews with employees, patient surveys, and a data analysis of electronic patient records (EPR). The approaches of the interviews, surveys, and data analysis are explained in the following sections. The researchers determined these approaches in cooperation with the lead radiologist and the radiology manager.

\subsubsection{Part I - Interviews}

Between November 22 and November 30, 2016, we interviewed 10 hospital employees who represented the employee stakeholders ( 2 referring physicians, 2 radiologists, 2 CT technicians, 2 front office employees, and 2 managers). Inclusion criteria were extensive experience with both walk-in and appointment CT systems. We interviewed both supporters and critics of the walk-in system. The focus of the interviews was on items of interest for the interviewee, relevant performance indicators, patients' reactions, personal and colleagues' perceptions, and lessons learned. We selected these topics based on what we found during our literature research on what is known about performance indicators and what is still unknown, so we could ask the appropriate questions. In this way, we aimed to include all the possible ways the walk-in system could have affected these stakeholders. The interviews were compiled into a report and summarized, and, together with the lead radiologist and radiology manager, conclusions were subsequently drawn.

\subsubsection{Part II - Patient surveys}

We used a questionnaire to study patient preferences. In addition to achieving our study objective, the questionnaire was also intended to measure patient satisfaction. To be able to compare this with the results from earlier questionnaires, we used questions similar to those we had used in the past, and added four questions pertaining to the study objective. The questionnaire consisted of 14 closed-ended questions. We formulated the four new questions based on what we did and did not know from the literature. The questionnaire is presented in Appendix B. Inclusion criteria were that the patient had a CT scan in December 2016 or January 2017 and was present in the CT waiting room during office hours. There were 535 respondents, with an average age of 62 (standard deviation 13.9). The exact response rate is unknown, but during this period, all patients were asked to complete the questionnaire when they arrived at the reception desk and the majority of them returned it. We used descriptive statistics to analyze the results.

\subsubsection{Part III - EPR data analysis}

From the literature ${ }^{301-303}$, we learned that EPR data analysis could be used to study the performance indicators of the various stakeholders (patients, employees, and hospital managers). The main topics for analysis were productivity and throughput times. Productivity was analyzed by comparing production rates and capacity over time, and throughput times were extracted from the 
patient journey, which was made possible by recorded snapshots of 'journey milestones' such as registration time and call-up time. Moreover, we could get a picture of the improvement potential by analyzing fluctuations in patient arrival times over the analyzed period of 8 years.

We collected the raw input data for the EPR data analysis from the EPR EZIS (Chipsoft, Amsterdam, The Netherlands). We processed this input data with Pentaho Kettle (Orlando, FL, USA) to make it usable for visualizations, which we generated in Tableau 10.1 (Seattle, WA, USA). Table 14 presents the variables we used. We selected these variables based on the potential to extract positive or negative performance indicators before and after the implementation of the walk-in system. The data used for the analysis included 129,148 patients seen and 143,068 scans performed between October 1, 2008 and March 31,2017 . We chose this period so we could analyze an extensive period before and after the introduction of the walk-in system. We conducted the data analysis by generating a variety of tables and diagrams in Tableau, which provided us with information about throughput times, productivity, and arrivals from various time periods. Several Rijnstate employees (including radiology management and radiologists) validated the output data.

Door-to-door time - time from registration at the department until report approval - differs between the appointment and walk-in system, since the moment of registration in the appointment system resembles the moment the patient arrives at the department for their appointment (excluding access time). In the walk-in system the moment of registration is equal to the first contact of a patient with the radiology department and includes waiting time. As a consequence, the door-to-door time within the appointment system is difficult to compare with the door to door time within the walk-in system, since the first, unfortunately, excludes the access time and the latter is the total patient throughput time. It was not possible to include the access time for the appointment system door-to-door time.

\subsection{Results}

\subsubsection{Part I - Interviews}

A major topic in the interviews was what is important for the interviewee about the performance of the CT modality and which access policy suits this better. Hereby, we were able to extract various items of interests from the perspective of the different employee stakeholders in terms of the access policy.

\section{TABLE 14 / EPR data analysis variables}

\begin{tabular}{|c|c|c|}
\hline Attribute & Description & Value \\
\hline \multicolumn{3}{|l|}{ Data obtained } \\
\hline Patient ID & $\begin{array}{l}\text { Unique number for each referral, per } \\
\text { patient }\end{array}$ & Integer \\
\hline Scan ID & Unique number for each scan conducted & Integer \\
\hline Patient type & Corresponding patient type & $\begin{array}{l}\text { Emergency; } \\
\text { Clinical; Outpatient }\end{array}$ \\
\hline Specialty & Specialty of the referring physician & String \\
\hline Description & Type of scan the patient underwent & String \\
\hline Registration time & $\begin{array}{l}\text { Time when patient registered at the } \\
\text { radiology department desk }\end{array}$ & Date and time \\
\hline Call-up time & $\begin{array}{l}\text { Time when patient was asked to enter the } \\
\mathrm{CT} \text { room }\end{array}$ & Date and time \\
\hline Departure time & $\begin{array}{l}\text { Time when patient left the } \mathrm{CT} \text { room and } \\
\text { radiology department }\end{array}$ & Date and time \\
\hline Wrap-up time & Time when radiologist approved the report & Date and time \\
\hline Appointment time & Time of appointment, if present & Date and time \\
\hline Location & $\begin{array}{l}\text { Location of the hospital where the patient } \\
\text { underwent the scan }\end{array}$ & Arnhem; Zevenaar \\
\hline $\begin{array}{l}\text { Scan protocol } \\
\text { information }\end{array}$ & $\begin{array}{l}\text { Extra information regarding the protocol } \\
\text { that corresponds to the type of scan }\end{array}$ & $\begin{array}{l}\text { With contrast; } \\
\text { Without contrast }\end{array}$ \\
\hline \multicolumn{3}{|l|}{ Variables calculated } \\
\hline Waiting time & [Call-up time]-[Registration time] & Minutes \\
\hline Scan time & [Departure time]-[Call-up time] & Minutes \\
\hline Door-to-door time & [Wrap-up time]-[Registration time] & Minutes \\
\hline
\end{tabular}

We translated these items of interest into a limited set of performance indicators that favor these specific items of interest. This made it clear that some indicators are of interest to a single stakeholder, and others to multiple stakeholders. The interview reports helped us to score the performance indicators for the two systems. Because the interview questions had no quantitative element, they did not show how the employees prioritized the performance indicators. The interviews provided us with new information, which can help other hospitals that are considering introducing walk-in CT facilities and which we 


\begin{tabular}{|c|c|c|c|c|}
\hline \multicolumn{3}{|c|}{ TABLE 15 / Summary of interview results } & \multirow{2}{*}{ 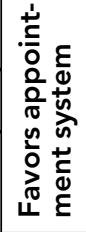 } & \multirow{2}{*}{ 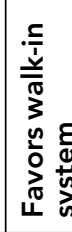 } \\
\hline Stakeholders & Items of interest & $\begin{array}{l}\text { Performance } \\
\text { indicator }\end{array}$ & & \\
\hline All stakeholders* & Satisfied patients & All & & + \\
\hline \multirow{4}{*}{$\begin{array}{l}\text { Patients } \\
\text { (according to } \\
\text { staff) }\end{array}$} & $\begin{array}{l}\text { Short period of uncertainty } \\
\text { regarding diagnosis }\end{array}$ & Access time & & + \\
\hline & $\begin{array}{l}\text { Short wait in waiting room (more } \\
\text { acceptable in walk-in system) }\end{array}$ & Waiting time & + & \\
\hline & Fewer hospital visits & One-stop shopping & & + \\
\hline & $\begin{array}{l}\text { Have scan at moment of their } \\
\text { choice }\end{array}$ & Autonomy of choice & & + \\
\hline Referring & Quick diagnosis & Access time & & + \\
\hline \multirow{2}{*}{ physicians } & Follow-up phase easy to plan & Access time & & + \\
\hline & No second-best examinations & Access time & & + \\
\hline \multirow[t]{4}{*}{ Radiologists } & Workload & Employee satisfaction & $=$ & $=$ \\
\hline & Productivity & Productivity & & + \\
\hline & $\begin{array}{l}\text { Approve report at moment of } \\
\text { their choice }\end{array}$ & Employee satisfaction & + & \\
\hline & $\begin{array}{l}\text { Service provided to referring } \\
\text { physicians }\end{array}$ & Employee satisfaction & & + \\
\hline X-ray technicians & Workload & Employee satisfaction & $=$ & $=$ \\
\hline $\begin{array}{l}\text { Front office } \\
\text { (planning and } \\
\text { reception desk) }\end{array}$ & Workload & Employee satisfaction & $=$ & $=$ \\
\hline \multirow[t]{5}{*}{$\begin{array}{l}\text { Hospital } \\
\text { management }\end{array}$} & Service provided to patients & $\begin{array}{l}\text { Access time, waiting } \\
\text { time }\end{array}$ & & + \\
\hline & Productivity & Productivity & & + \\
\hline & Employee satisfaction & Employee satisfaction & $=$ & $=$ \\
\hline & $\begin{array}{l}\text { Fewer staff members required } \\
\text { for scheduling }\end{array}$ & Productivity & & + \\
\hline & Competitive market advantage & Access time & & + \\
\hline
\end{tabular}

* We present this item apart, because it is valid to all stakeholders and otherwise we would have to repeat it in every row of the table. elucidate in the discussion. Table 15 presents a summary of the results from the employee interviews on items of interest, performance indicators, and their scores for both systems.

All stakeholders indicated increased satisfaction since the introduction of the walk-in system, due largely to their contact with patients who expressed their satisfaction with this system. In addition, the employee interviews contained explanations for this increase in patient satisfaction (for example, a shorter period of uncertainty about the diagnosis and a minimum of hospital visits). The referring physicians stated that, thanks to the elimination of access time, the walk-in system made it possible to get a diagnosis more quickly so they could start treating their patients, outpatient departments needed fewer resources for follow-up planning, and there were fewer 'second-best' examinations (conventional radiology). The radiologists mentioned that, for the walk-in system to be totally successful, the scan reports must be approved immediately, which means they have to be more flexible. But they gave more weight to the advantages the walk-in system provides them with in terms of better service to their patients and to the referring physicians, and greater productivity. Both front office employees and X-ray technicians said their workload has changed, but not necessarily in a negative sense. Their workload is now greater during peak periods, but is roughly the same overall. The performance indicators for radiology management's items of interest favor a walk-in system.

\subsubsection{Part II - Patient surveys}

The three most relevant results from the patient surveys concerned maximum acceptable waiting time, their behavior if waiting time becomes unac ceptably long and how they score the performance indicators. These results are presented visually in Figure 18

Approximately $79 \%(100 \%-20.8 \%)$ of patients indicated that a waiting time of a maximum of $15-30$ minutes is acceptable. Around $21 \%$ wanted the waiting time to be less than 15 minutes. Approximately $29 \%(15.2 \%+8.4 \%+$ $5.3 \%$ ) of the patients found a waiting time of $30-45$ minutes or more to be acceptable, and around $14 \%(8.4 \%+5.3 \%)$ found even longer waits to be acceptable.

If patients found the waiting time to be unacceptably high, the majority indicated they would not leave the waiting room. This means they would choose to continue to wait, because the disadvantages of leaving are greater (such as having to come back for another hospital visit). 


\section{FIGURE 18 / Patient survey results}

Maximum acceptable waiting time $(\mathrm{N}=395)$

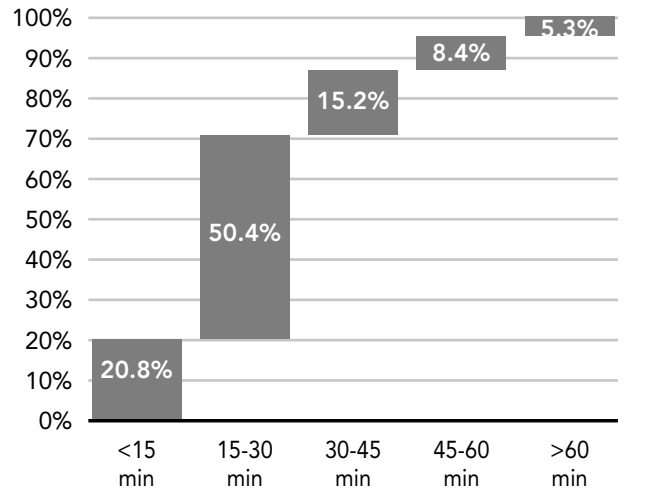

Valuation 'very important' $(\mathrm{N}=361)$

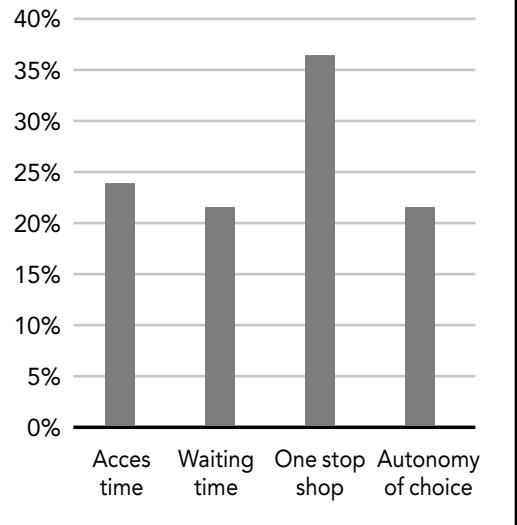

What would you do if
the waiting time was
unacceptably high?
$\begin{aligned} & \text { (N= 389) }\end{aligned}$

Of the patients who took part in the survey, 68.3\% indicated their actual waiting time had been within the range they considered acceptable. One-stop shopping was chosen by 134 patients as the most important performance indicator in the CT facility's access policy. Short access time, waiting time in the waiting room, and autonomy of choice for the time of the scan all scored within a range of $\mathrm{N}=79$ to 88 .

\subsubsection{Part III - EPR data analysis}

First we analyzed the productivity, defined as the number of scans executed within given capacity. An important factor that contributes to the productivity is the occupancy rate, defined as the number of minutes that patients have spent in the CT room divided by the total opening hours of the scanners times the number of scanners. So the indicator productivity is measured in number of scans and the indicator occupancy rate is a percentage. Besides occupancy rate, there can also be other factors that influence productivity, such as the speed of a scanner: the same scan takes longer in an old scanner than in a new scanner. In the last seven years, production in the CT department has shown a steady increase in both the total number of minutes spent in the CT room (bars) and the total number of scans (line), as shown in Figure 19.

\section{FIGURE 19 / Production data}

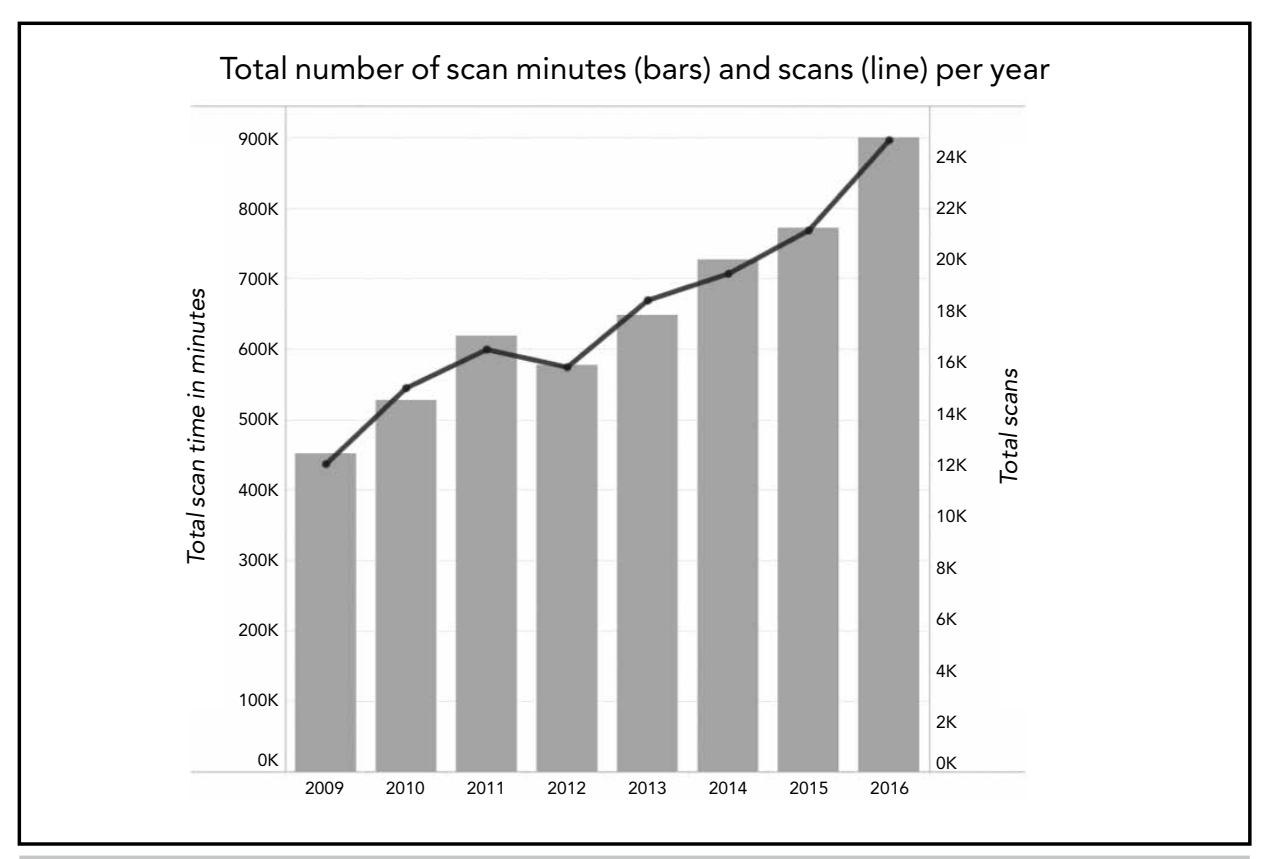

Although both decreased slightly in 2012, comparing the results from 2009 with those from 2016 shows a significant difference in minutes spent in the CT room, which doubled from 451,584 in 2009 to 899,579 in 2016. The total number of scans also doubled, going from 11,279 in 2009 to 22,466 patients in 2016. This increase in production should be seen within the context of almost no increase in capacity. The number of scanners remained the same, and the only changes during these years were a slight increase in the number of CT technicians, and the installation of a faster scanner in 2015. This faster scanner is partly an explanation of the increase of the productivity. A faster scanner could cause more idle time - thus lower occupancy rate -, because extra setup times and limited demand. However, we saw an increase in the number of scan minutes instead of a decrease. Since the number of scan minutes doubled and 
the capacity hardly increased, there must be another cause of the increased occupancy rate and thus of the increased productivity. Since occupancy rate doubled and there have not been main changes next to the new scanner and the introduction of the walk-in system, it is probable that walk-in is the main cause of the increase of productivity.

Ideally, we had compared the productivity before walk-in and after. Unfortunately, this was not well comparable, because not only the access system changed but also the speed of a scanner and the number of CT technicians in peak hours. In other words, the capacity changed but the exact change over time is not possible to determine because it is built by several variables. We know the capacity increased only a fraction, because the number of scanners

\section{TABLE 16 / Portions within given waiting times}

\begin{tabular}{|c|c|c|c|c|c|}
\hline & & $0 \min \leq$ & $15 \min \leq$ & $30 \min \leq$ & $60 \min \leq$ \\
\hline \multirow[t]{6}{*}{ Emergency } & \multirow[t]{2}{*}{2009} & $92,5 \%$ & $96,9 \%$ & $98,5 \%$ & $99,5 \%$ \\
\hline & & 2.147 & 2.249 & 2.287 & 2.310 \\
\hline & \multirow{2}{*}{2012} & $95,1 \%$ & $97,8 \%$ & $98,9 \%$ & $99,7 \%$ \\
\hline & & 3.073 & 3.162 & 3.197 & 3.222 \\
\hline & \multirow[t]{2}{*}{2016} & $94,0 \%$ & $97,9 \%$ & $99,1 \%$ & $99,7 \%$ \\
\hline & & 4.523 & 4.711 & 4.771 & 4.799 \\
\hline \multirow{6}{*}{ Inpatient } & \multirow{2}{*}{2009} & $59,5 \%$ & $88,0 \%$ & $96,0 \%$ & $98,7 \%$ \\
\hline & & 1.736 & 2.566 & 2.798 & 2.879 \\
\hline & \multirow[t]{2}{*}{2012} & $55,6 \%$ & $87,4 \%$ & $95,7 \%$ & $99,1 \%$ \\
\hline & & 1.596 & 2.511 & 2.749 & 2.845 \\
\hline & \multirow[t]{2}{*}{2016} & $44,3 \%$ & $82,6 \%$ & $94,5 \%$ & $99,5 \%$ \\
\hline & & 2.068 & 3.858 & 4.415 & 4.646 \\
\hline \multirow{6}{*}{ Outpatient } & \multirow{2}{*}{2009} & $28,8 \%$ & $68,9 \%$ & $85,2 \%$ & $92,7 \%$ \\
\hline & & 1.740 & 4.158 & 5.146 & 5.597 \\
\hline & \multirow{2}{*}{2012} & $27,7 \%$ & $62,4 \%$ & $77,7 \%$ & $90,2 \%$ \\
\hline & & 2.212 & 4.981 & 6.201 & 7.199 \\
\hline & \multirow[t]{2}{*}{2016} & $14,7 \%$ & $43,3 \%$ & $59,5 \%$ & $78,0 \%$ \\
\hline & & 1.897 & 5.594 & 7.681 & 10.070 \\
\hline \multirow{6}{*}{ All patients } & \multirow[t]{2}{*}{2009} & $49,9 \%$ & $79,6 \%$ & $90,7 \%$ & $95,7 \%$ \\
\hline & & 5.623 & 8.973 & 10.231 & 10.786 \\
\hline & \multirow{2}{*}{2012} & $48,8 \%$ & $75,6 \%$ & $86,2 \%$ & $94,2 \%$ \\
\hline & & 6.881 & 10.654 & 12.147 & 13.266 \\
\hline & \multirow[t]{2}{*}{2016} & $37,9 \%$ & $63,2 \%$ & $75,3 \%$ & $87,1 \%$ \\
\hline & & 8.488 & 14.163 & 16.867 & 19.515 \\
\hline
\end{tabular}

and opening hours are the main building blocks for the capacity. Therefore, the opinion of the involved employees that walk-in made possible the doubling of the production for the bigger part, can be reasoned.

In Table 16 we show the number and percentage of patients who waited fewer minutes than the number of minutes shown for the years 2009, 2012 and 2016. This overview is relevant because showing only average waiting times could imply that, when variability is high, the waiting time is much longer than shown for a substantial number of patients.

Table 16 can be explained as follows. Three types of patients are distinguished, because their access policy differs. Emergency patients are given priority, so their waiting time is obviously shorter. Inpatients have scheduled appointments, so their waiting time might also be shorter. So, the biggest challenge is to ensure acceptable waiting times for outpatients. The first column ( 0 min $\leq)$ means patients have no waiting time at all, and can go straight through when they arrive. In $2009,92.5 \%$ of all emergency patients and $28.8 \%$ of all outpatients did not have to wait for their scans, while $98.5 \%$ of all emergency patients, $96.0 \%$ of all inpatients and $85.2 \%$ of all outpatients had to wait 30 minutes or less. In $2016,99.1 \%$ of all emergency patients, $94.5 \%$ of all inpatients and $59.5 \%$ of all outpatients had to wait 30 minutes or less. The $30-\mathrm{min}$ ute limit is relevant because the patient surveys showed that the majority of patients indicated this limit is acceptable. Although the percentage of outpatients who waited less than half an hour decreased by more than $25 \%$ (from $85.2 \%$ to $59.5 \%$ ), we found that the total number of outpatients who had their CT scan within half an hour increased by approximately 2,500 (from 5,146 to 7,681 ) in this period, which is an increase of almost $50 \%$. This can be explained by the increase in production.

Table 17 presents the average waiting times for all patients during office hours. While in 2009 the average waiting time peaked between 9:00 and 11:00, the peak has now shifted to between 10:00 and 13:00, with the highest averages between 12:00 and 13:00. We see many time slots with relatively low waiting times, and some with high waiting times.

With regard to overtime, the total number of outpatients (per year) called in for a CT scan between 17:00 and 19:00 dropped from 33 patients in 2009 to 26 patients in 2016. The total number of patients called in between 17:00 and 19:00 more than doubled, largely caused by the rise of emergency ward patients. But these emergency patients typically arrive at unexpected moments and do not disrupt regular office hours. This means that the relevant numbers for assessing the walk-in system are the outpatient delays. 
TABLE 17 / Average waiting times per weekday

\begin{tabular}{l|l|c|c|c|c|c|c|c|c|c|c|c}
\hline & & $07: 00$ & $08: 00$ & $09: 00$ & $10: 00$ & $11: 00$ & $12: 00$ & $13: 00$ & $14: 00$ & $15: 00$ & $16: 00$ & $17: 00$ \\
& $07: 59$ & $08: 59$ & $09: 59$ & $10: 59$ & $11: 59$ & $12: 59$ & $13: 59$ & $14: 59$ & $15: 59$ & $16: 59$ & $17: 59$ \\
\hline $\mathbf{2 0 0 9}$ & Mon & 9,7 & 12,1 & 19,2 & 22,3 & 17,1 & 13,8 & 16,2 & 20,1 & 18,1 & 10,0 & 1,5 \\
access & Tues & 9,3 & 12,6 & 21,8 & 21,8 & 15,6 & 10,5 & 13,9 & 17,5 & 18,3 & 9,4 & 3,6 \\
time = & Wedn & 7,8 & 10,3 & 15,2 & 20,1 & 14,9 & 12,1 & 12,9 & 16,5 & 16,4 & 6,4 & 9,1 \\
$\mathbf{4}$ weeks & Thurs & 5,6 & 9,6 & 19,9 & 19,9 & 14,5 & 14,3 & 15,0 & 16,8 & 14,8 & 11,5 & 1,8 \\
& Fri & 9,6 & 11,4 & 16,1 & 19,1 & 14,8 & 12,8 & 13,5 & 13,8 & 14,1 & 12,5 & 6,0 \\
\hline $\mathbf{2 0 1 2}$ & Mon & 6,3 & 9,3 & 12,7 & 19,4 & 20,0 & 27,2 & 22,4 & 18,5 & 17,1 & 10,8 & 0,3 \\
access & Tues & 8,4 & 7,6 & 12,4 & 20,9 & 22,4 & 23,9 & 18,0 & 17,2 & 12,4 & 9,8 & 2,2 \\
time = & Wedn & 4,7 & 8,3 & 12,5 & 18,8 & 18,3 & 21,6 & 15,9 & 15,0 & 16,4 & 8,7 & 1,9 \\
$\mathbf{0}$ & Thurs & 1,0 & 8,2 & 13,0 & 21,3 & 22,7 & 27,6 & 21,1 & 18,7 & 15,0 & 7,8 & 4,4 \\
& Fri & 4,1 & 8,5 & 10,5 & 22,9 & 20,3 & 23,3 & 20,7 & 18,2 & 19,8 & 10,2 & 2,9 \\
\hline $\mathbf{2 0 1 6}$ & Mon & 4,2 & 12,4 & 22,1 & 30,3 & 30,7 & 39,5 & 37,2 & 26,7 & 29,5 & 24,6 & 3,1 \\
access & Tues & 2,7 & 10,0 & 20,9 & 25,3 & 29,8 & 34,4 & 28,1 & 24,5 & 28,1 & 21,4 & 4,7 \\
time $=$ & Wedn & 5,0 & 11,9 & 21,1 & 31,2 & 30,7 & 32,5 & 29,4 & 24,1 & 25,2 & 21,3 & 2,7 \\
$\mathbf{0}$ & Thurs & 6,1 & 10,3 & 20,9 & 30,4 & 32,3 & 41,5 & 30,1 & 25,9 & 27,4 & 21,3 & 5,2 \\
& Friday & 5,8 & 12,1 & 18,8 & 31,6 & 34,1 & 37,5 & 30,9 & 28,1 & 28,4 & 14,6 & 4,2 \\
\hline
\end{tabular}

The average door-to-door time decreased considerably in the years we studied. For example, the results of the average door-to-door time as observed in the third quartile dropped from 18.9 hours in 2009 , to 8.1 hours in 2012, to 5.2 hours in 2016. As mentioned, for the appointment system in 2009 this is excluding the access time.

The combined results of the three data collection methods show that the walk-in system eliminates access time, and that this is highly valued by all stakeholders. Improvements in terms of higher productivity and more patient and employee satisfaction also point toward a walk-in system. All three methods show that, although waiting times in the waiting room can be longer in a walk-in system during peak periods, the overall waiting times appear to be acceptable if production does not increase much further without increasing capacity.

\subsection{Discussion}

Our study provided us with performance indicators for the CT modality's access policy from the perspective of the relevant stakeholders. We know a great deal from the literature about operations management in radiology and access policies in health care, but little is known about walk-in CT facilities within this precise context. The interviews provided us with the employee performance indicators, and the surveys with the patient performance indicators. Furthermore, we were able to use all of these indicators to score the access policies of both the walk-in and the appointment system, and so reach a conclusion as to which policy is best for the CT modality.

We conclude that a walk-in CT system (with a limited number of appointments for certain types of examinations) functions better than one that is en tirely appointment-based, primarily because it virtually eliminates CT access time, enhances the one-stop shopping policy for patients, and increases satisfaction among patients and referring physicians, as well among the radiology staff, technicians and doctors alike. Furthermore, all of the results suggest that productivity can be greater in a walk-in system than in one that is entirely appointment-based. Management should closely monitor waiting time, produc tivity, and production versus capacity, and make adjustments when necessary.

Although increasing quality of care was not the objective of the walk-in intervention, literature indicates that reducing access times to diagnostic facilities positively contributes to patients' wellbeing. Severe cases, such as cancer patients, can benefit from quick diagnosis ${ }^{31,33,34}$.

In our study, we encountered only one substantial disadvantage of walk-in $\mathrm{CT}$ facilities, which was longer waiting times in the waiting room during specific periods. In our survey, $79 \%$ of patients indicated that a waiting time of up to 30 minutes was acceptable, and in $2016,75 \%$ of patients had their examination start within 30 minutes. Moreover, waiting in a walk-in system is considered to be less annoying than if patients expect to have their scan at a specific appointment time, ${ }^{37,298,304}$ and so patients at Rijnstate are willing to wait longer in the waiting room. The increasing use of CT scans brings with it the risk that waiting times in the waiting room will become unacceptably high if capacity remains unchanged. Therefore, we encourage hospitals that are considering introducing walk-in CT facilities to closely monitor waiting times from the perspective of patient satisfaction and local standards, especially since we know from the literature ${ }^{187}$ that when utilization reaches $100 \%$, waiting times will increase exponentially.

Walk-in CT is particularly advantageous if the door-to-door time is minimal and predictable, so that the referring departments can plan the patient's next visit when ordering the $\mathrm{CT}$. This means the $\mathrm{CT}$ technicians need to handle the post-processing quickly, and the radiologist needs to read the study, write and approve a report quickly. This is often possible before the end of the day of the scan, and sometimes the day after, which decreases the duration of the diag- 
nostic process, and subsequently the amount of time the patient has to wait for the examination results. When patients would like to use the one-stop shopping option, the radiologist can give these specific patients priority to guarantee that they receive their authorization on time. This makes it possible to start treatment earlier and might also be less costly, at least for the patient (fewer travel costs, peer support). Other methods - such as open-access scheduling - can also make one-stop shopping possible, but their complexity means that more effort must be expended to produce fewer results.

The walk-in system in Rijnstate can be further improved by influencing patient arrival times and thereby reducing peak loads. This should be done in conjunction with the referring departments, for example, by making changes to the outpatient schedules. Rijnstate is working on this, but since it is hard to change the operations in all referring outpatient departments, there is still potential for improvement.

A limitation of this study is that after the radiology management introduced a walk-in system to the $\mathrm{CT}$ facilities, they also implemented other improvements, so the increase in productivity cannot be attributed solely to the walkin system. In the past eight years, management has installed a faster scanner, changed intravenous contrast administration from a single- to a multi-patient system, changed the location where patients are prepared for their scan so that this now happens outside of the scanner room, adapted the scanning protocol to current guidelines, and brought in an extra X-ray technician. While we could not determine the impact of each of these changes independently, the stakeholders feel it is likely that the walk-in system is the main reason productivity has increased.

We expect that our conclusions will also apply to CT facilities in other hospitals. With regard to equipment, the only condition is that there should be more than one scanner. If there is only one scanner, and this scanner fails, this will result in an unacceptable situation. Transitioning from an appointment to a walk-in system forms a major hurdle. Commitment to the walk-in CT facilities should be hospital-wide, meaning that all radiologists and referring physicians have to cooperate so that the change can be implemented all at once. Moreover, the introduction of a walk-in system requires radiologists and other staff members to be adaptable and flexible. This calls for careful preparation that involves all stakeholders, and after its introduction there will need to be a period devoted to fine-tuning the system. Communication is key in this process, because it will feel unnatural to most radiology staff members, and will also drastically change the way they work.
Radiology management designed the walk-in concept in cooperation with the four main referring departments: neurology, pulmonary medicine, otolaryngology, and internal medicine. We would suggest that other hospitals allow referring physicians to support the change. The primary reason for this close cooperation is that it is mainly these physicians who determine the arrival pattern of patients, and they can contribute greatly to managing the expectations of patients. From the moment the walk-in system was introduced, Rijnstate no longer scheduled any outpatients, with the exception of specific patient categories. During the initial period following its introduction, we noticed a slight increase in referrals. We observed that, in the former appointment system, access time formed a barrier for some physicians when it came to ordering CT examinations, and they would sometimes choose for a suboptimal diagnosis.

To make use of the walk-in CT facilities, patients have to meet certain preconditions, which are the absence of contrast-induced nephropathy conditions (determined beforehand) and the absence of dietary restrictions prior to their CT examination. The transition to a walk-in system must be accompanied by measures that ease this transition, such as expectation management, providing information to patients on current waiting times, influencing patient arrival times, encouraging staff to be more flexible, and selecting 'smart' appointment times. Another important measure is to have a separate preparation room for placing IV access lines.

Studies in the literature were usually restricted to the introduction of an operations management $(\mathrm{OM})$ solution, possibly with a calculation of the consequences. ${ }^{305}$ We verified the effectiveness of walk-in CT facilities in practice, which is the best evidence that a walk-in system can work within this context.

Our study offers a process intervention that can be implemented by all hospitals with more than one CT scanner. This intervention greatly increases the modalities' performance, not only from the perspective of patients, but also from the perspective of all staff members and the hospital. This study provides sufficient evidence that walk-in CT facilities work in practice. A purely theoretical underpinning for impactful process interventions is usually not enough, particularly within a complex setting such as a hospital and with professionals.

We suggest further research to determine to what extent our conclusions are valid in other hospitals. In addition, it would be valuable to study the suitability of walk-in systems in other radiology modalities and in other hospital departments. 


\section{CHAPTER 8}

Discussion

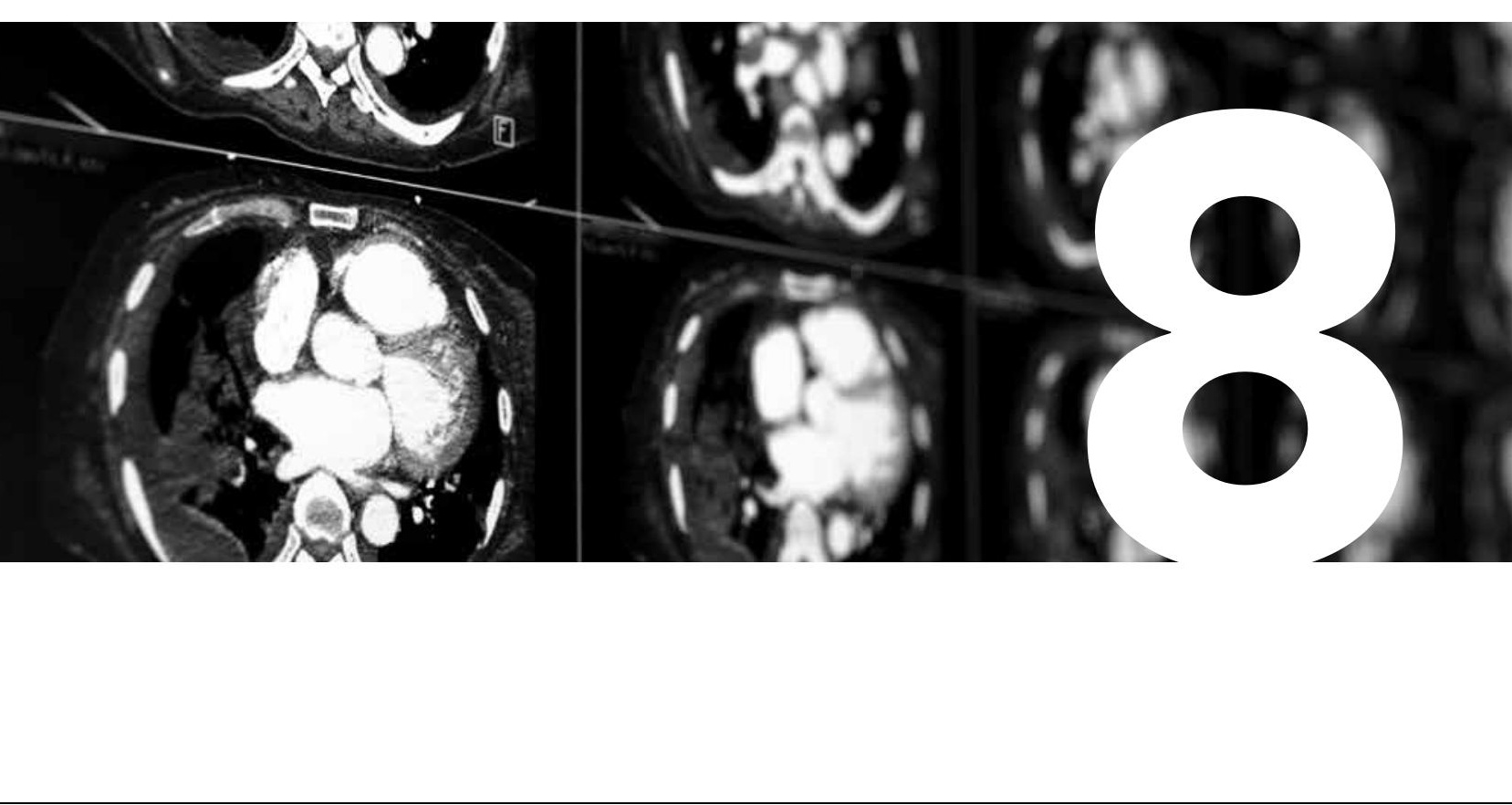


In this final chapter, we will first elucidate the lessons we learned about operations management (OM) in hospitals. We have divided these lessons into three parts: a) Volume, variety, and visibility, b) Variability, and c) The special nature of $\mathrm{OM}$ in hospitals. Second, we share the lessons we learned about the walk-in system, the main subject of Chapters 5, 6, and 7. Third, we present our conclusions, and fourth, we discuss the social and scientific relevance of our study, points for consideration, and recommendations for further research and recommendations for hospitals.

\subsection{Lessons learned about OM in hospitals}

\subsubsection{Volume, variety, and visibility}

In Chapter 1, we introduced Slacks' four characteristics of demand: volume, variety, variation, and visibility. ${ }^{53}$ These characteristics have a considerable effect on how processes need to be managed. The third characteristic appears to have played a particularly important role in our studies, and is elucidated under subheading $\mathrm{b}$. We use the word variability rather than variation because we want to emphasize the ability to vary. The extent of the variability is a characteristic of a number of entities which fits more properly with process analysis, while variation indicates a comparison between entities. "If there's great variability in a population, there's a lot of variation between the individuals of that population." The other characteristics are described briefly in the following paragraphs in terms of how they influence the way radiology processes need to be managed.

A high volume of products or services means a high degree of repeatability, which makes a high degree of specialization both feasible and economical. In other words, it makes the processes easier to manage because they are better understood. For imaging, this means it would be helpful to aim for a high number of similar exams. Hospital managers should therefore learn to limit exceptions, because every exception leads to a low-volume event.

Producing a high variety of products and services implies a wide range of different activities. This by necessity also involves a wide range of skills and technology that is sufficiently general-purpose to cope with the range of activities, and sufficiently flexible to change between activities. So, minimizing variety makes managing the process easier and more efficient. In Chapter 4 we saw that reducing the variety of scheduling blocks largely improved the performance of the magnetic resonance imaging (MRI) modality.
Visibility indicates how much of the operation's added value is "experienced" directly by customers or how much it is "exposed" to its customers. Generally, processes that directly involve customers (such as scans) will have higher visibility than those that involve materials and information (such as assessing an exam). In low-visibility operations, the time lag between a customer request and the response might be measured in days rather than the nearly immediate response expected from high-visibility ones. This lag allows the activities to be performed at a time convenient to the operation (for example, making pooling possible), thus achieving higher utilization. In health care, it is usually impossible to adapt the visibility of a process, but what managers can do is efficiently design the processes that are less visible. A well-known OM concept that responds to this, organizes the front office and the back office differently with different resources.

Variability is the process characteristic we encountered most in the studies contained in this dissertation, and is elucidated under the next subheading.

\subsubsection{Variability: the key OM problem in hospitals}

Variability means that a system is subject to constant change. Processes are generally easier to manage when they only have to cope with constant demand. Then resources can be geared to a level that is just capable of meeting demand. All activities can be planned in advance. By contrast, when demand is changing all the time, resources will have to be adjusted over time. Moreover, when demand is unpredictable, extra resources will have to be designed into the process to provide a buffer that can absorb unexpected demand. Buffers, such as extra capacity or extra time, are measures to control the complex system. Hospitals are a spawning ground for variability and therefore contain many buffers. But too many buffers are undesirable, because they are inefficient or cause bad service. So, before using buffers, one should try to eliminate variability. The challenge is to reduce variability when possible, and deal with it when necessary. Therefore, we make a distinction between natural variability and artificial variability. ${ }^{189,306}$ Natural variability has an external source of uncertainty, for example the flow time of the insertion of intravenous access lines (see Chapter 3). Artificial variability concerns variation that is created by planning and control, for example through block allocation of capacity (see Chapter 4). Since this (planned) variety is often not managed on a tactical level throughout care pathways, it is often perceived as variability on the operational level. The high degree of variability in hospital care processes is caused in part by the inherent complexity of these processes, but the degree of variabil- 
ity caused by humans - artificial variability - is highly underestimated. All studies in this dissertation contain elements that address the challenge of reducing artificial variability and anticipating natural variability. Figure 20 presents some examples of the variability we encountered in our studies.

\section{FIGURE 20 / Types of variability in hospitals}

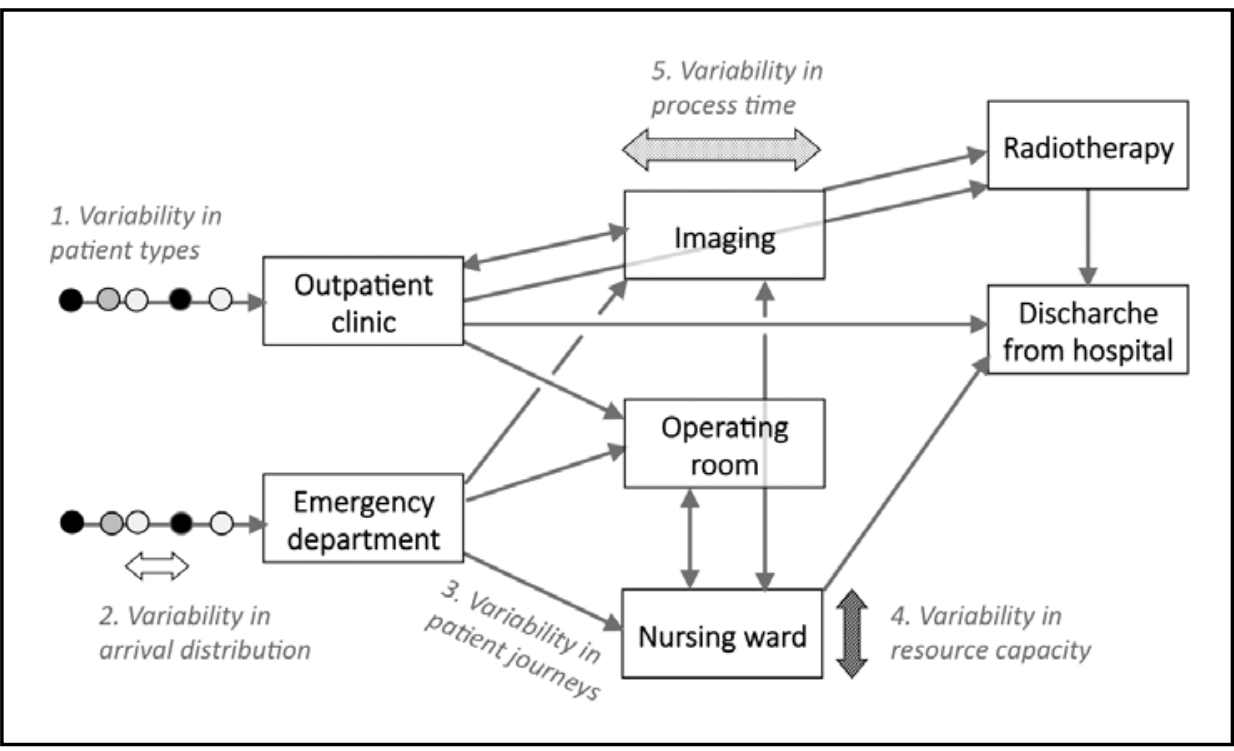

In Figure 20, various types of patients (1) arrive to a hospital, but the arrival distribution (2) is not exactly known on forehand. Many different patient journeys (3) are possible. Every process step (the blocks that illustrate departments, such as the outpatient clinic and the emergency department) has some capacity, but the quantity of this capacity (4) differs over time, for example because of employees' absence. Moreover, the duration of a process step (5) is uncertain.

Most variability is both artificial and natural. For example, we have seen that the predictability of patient arrival times is often controlled by an appointment system. But even then, many patients arrive late. Patient lateness can be limited by using text message reminders or a penalty clause (artificial variability), but it will be impossible to eliminate patient lateness entirely (natural variability).

Artificial variabilities in processes are usually introduced gradually and unintentionally, and lead to suboptimal processes and undesirable results. Therefore, processes must be evaluated regularly. Chapter 3 contains a clear example of how reducing variability can improve performance. To deal with variability, process design and process control must create space so that the variability can be absorbed. This space within a process is known as a buffer Buffers are typically expressed by negative effects, such as higher costs or longer waiting times. ${ }^{307}$ Although buffers are necessary when processes have to deal with some kind of variability, their use should be limited. The fewer the buffers, the more the efficiency and/or flow of the process will be increased, which is why variability should be minimized.

Variability can be absorbed by three types of buffers: capacity, time, and inventory. One of the most undesirable buffer expressions in hospitals are waiting patients (time buffer), either outside the hospital or in waiting rooms (which also requires an inventory buffer). These are two kinds of time buffers we refer to the first time buffer as "access time" and the second as "waiting time". Table 18 presents some examples of variabilities in imaging along with possibilities for buffering them.

\section{TABLE 18 / Examples of variabilities and buffers}

\begin{tabular}{ll}
\hline Examples of variability & Buffers \\
\hline $\begin{array}{l}\text { Holiday period during rostering, leading } \\
\text { to lower employee capacity }\end{array}$ & Higher access times (time) \\
$\begin{array}{l}\text { Unpredictable exam duration } \\
\text { (capacity) }\end{array}$ & Overtime by an x-ray technician \\
$\begin{array}{l}\text { Uncertainty about number of patients } \\
\text { in the waiting room }\end{array}$ & $\begin{array}{l}\text { Large number of chairs in waiting } \\
\text { room (inventory) }\end{array}$ \\
No continuous flow of patient arrivals & Waiting in the waiting room (time) \\
\hline
\end{tabular}

The main OM lesson for hospital managers is to learn to deal with variability. There are five ways to do this:

1. Eliminate: For example, in Chapters 6 and 7, we eliminated "no-show variability" (because there are no no-shows in a walk-in system).

2. Reduce: In Chapter 3, we reduced the variability of the scan time.

3. Choose the right form: In Chapters 6 and 7, we saw that although patient arrival variability increased after introducing a walk-in system, we eliminated "no-show variability." 
4. Buffer in the right way: Chapters 6 and 7 show that implementing a walk-in system resulted in the elimination of access time and (possibly) an increase in waiting time.

5. Follow variability with flexibility: Chapters 6 and 7 show that the flexibility that is introduced with a walk-in system can lead to striking improvements in performance. Increasing the flexibility of a process - such as a walk-in system - is even more valuable when the following processes are highly dependent on this process.

\subsubsection{The special nature of OM in hospitals}

$\mathrm{OM}$ is a discipline that origins from industry, where it has had large successes. The question is whether it can be copied to the health care sector. Criticasters stress that hospitals are very complex organizations, and applying OM on hospitals is very hard. OM advocates believe this is a good reason to use OM, because OM can help simplifying. There is less OM experience in service organizations than in industry, but this is changing. A good example is the aviation sector, where OM is very successfully applied. This section comments on the applicability of OM in hospitals. To determine this, it is important to understand the differences between the hospital sector and industry. Furthermore, the success of OM is highly dependent on the acceptation of people involved, so understanding both worlds - in other words the way people in these sectors think - is especially important.

When conducting our OM studies, we found that hospital employees were largely unfamiliar with our OM approach. ${ }^{308}$ Although more and more hospitals actively focus on OM to improve their effectivity and efficiency, OM is unknown and of no great concern to most employees. As in every industry, it is challenging to effectively engage employees in OM improvements and motivate them to support these improvements. However, our studies showed us there are various reasons why this challenge is even greater in hospitals. We use two comparisons to explain this. First, we compare hospital characteristics with industry characteristics, and second, we compare the medical world with the OM world.

The first comparison, hospital versus industry characteristics, is concerned with the characteristics of the different systems. There are great differences between the hospital sector and industry when it comes to the use of OM concepts. OM originated in industry, and is a professional area within the field of business administration. For some 20 years, hospital managers in the Netherlands have been using OM to improve the performance of their processes.
They are discovering that the inherent characteristics of hospitals and healthcare processes make that $\mathrm{OM}$ concepts that were successful in industry cannot be simply copied to healthcare. Here we explain the main differences in the system characteristics that influence the application of OM:

1. High variability: Due to many uncertainties, variabilities tend to occur more often and to a higher degree in hospitals than in an average industrial organization. This is caused by the complexity of and interference by the many different patient flows and resources required. Overall service depends on many diverse resources. In the previous section, we presented some examples of variabilities.

2. High customer dependence: In hospitals, the customer is not just part of the process - his or her health or life depends on it. In addition, there is an information asymmetry between the patient and the physician that reinforces this dependence. Moreover, emotions play a significant role on the part of both customers and professionals.

3. Hospitals are faced with more stakeholders than almost any other organization: patients, professionals, managers, insurance companies, governments, and supervisory bodies, as well as partners in the chain, patient advocates, unions, the media, banks, suppliers, and so forth. All these stakeholders have their own interests and ways of influencing hospital management. A particularly interesting explanation of stakeholders in hospitals was explored by Glouberman and Mintzberg, ${ }^{309,310}$ who distinguished four additional coalitions with opposing interests: the clinical coalition (doctors and nurses), the insiders coalition (nurses and managers), the containment coalition (managers and trustees), and the status coalition (trustees and doctors).

4. The consumer is usually not the direct payer. This results in a certain degree of indifference on the part of patients towards the cost of their treatment. In other words, although all patients demand the best possible health care services, the cost of this care is of little importance to a patient who is ill.

5. The production process in industries is usually predictable and can largely be scheduled. Health care is by definition customized service, and only the specific treatment that maximizes a patient's health will be offered. Therefore, many patient flows are more difficult to schedule in advance.

6. Social responsibility: Although enterprises in commercial industries are increasingly acting in a socially responsible way, hospital managers need to take this factor much more into account. Every health care delivery must com- 
ply with the three Es of health care: equity, effectiveness, and efficiency. ${ }^{\mathbf{3 1 1}}$ From a macro-economic perspective, one should also add the fourth E: economy.

7. Hospitals are heavily regulated by government and politics. This explains the high dependability on policies and changes to them, and hospital leaders' intensive focus on these policies. ${ }^{312}$

8. The definition of quality and costs is imprecise. ${ }^{308}$ We want to maximize quality of care, but patient outcomes are hard to measure. Maximizing quality is also quite ambiguous. Do you maximize the quality of the outcome for a particular episode of care? Or do you try to maximize the patient's quality of life? And we want to minimize costs. But costs to whom? The hospital? The government? The patient? The doctor? And do we want to minimize the cost per hospital visit (minimize care and length of stay) or do we want to minimize the overall annual cost?

The second comparison, the medical world versus the OM world, is concerned with the way the people involved think. This study distinguished between two separate "worlds": the medical world and the OM world. The differences between these worlds must be taken into account when OM is applied in a hospital. It is not strange that there are differences. Medical education does not focus on OM, and until some years ago there was little incentive to apply $\mathrm{OM}$ in hospitals. We use five dimensions to explain the differences between the two worlds, and these are shown in Table 19. The comparison is not the result of in-depth research, but rather an impression we gained from our studies. With our comparison, we attempt to explain the misunderstandings that occur between OM experts and hospital employees, and by doing so, potentially help to reduce these misunderstandings.

An important insight of our studies is that - despite the differences with industry - we can successfully apply OM in a hospital. As hospitals become increasingly familiar with OM, the distance between these two worlds is decreasing. To meet the challenges hospital managers are facing, we would stress the need to accelerate this decrease. People who work with OM in hospitals must learn to understand the medical world, and physicians should learn to understand the OM world. This could start by teaching professionals from both worlds about the five dimensions. The next section describes the lessons we learned during the intervention we focused on in Chapters 5, 6, and 7: the walk-in system.

\section{TABLE 19 / Medical world versus OM world}

\begin{tabular}{|c|c|c|c|}
\hline Dimension & Medical world & OM world & Complication \\
\hline $\begin{array}{l}\text { Research } \\
\text { method }\end{array}$ & $\begin{array}{l}\text { Empirical } \\
\text { research }\end{array}$ & $\begin{array}{l}\text { Design } \\
\text { research }\end{array}$ & $\begin{array}{l}\text { Medical insights are usually highly empiri- } \\
\text { cally underpinned. This is the way physicians } \\
\text { are used to being convinced in favor of a } \\
\text { medical intervention. An OM intervention } \\
\text { is much harder to underpin quantitatively. } \\
\text { This makes it harder to convince people in } \\
\text { hospitals to implement an OM intervention. }\end{array}$ \\
\hline Focus & $\begin{array}{l}\text { The individual } \\
\text { patient }\end{array}$ & The process & $\begin{array}{l}\text { The medical interest is straightforward: } \\
\text { the health of the patient. OM focuses on } \\
\text { the process, what means there are always } \\
\text { different interests, such as quality, cost, and } \\
\text { employee satisfaction. Chapter } 7 \text { elaborated } \\
\text { on some relevant interests in the computed } \\
\text { tomography (CT) modality. }\end{array}$ \\
\hline Type of change & Incremental & Disruptive & $\begin{array}{l}\text { This is about changing "how we do things." } \\
\text { Successful organizational changes moti- } \\
\text { vated by OM are often disruptive. } \\
\text { In general, physicians do not suddenly } \\
\text { change the way they treat patients. }\end{array}$ \\
\hline $\begin{array}{l}\text { Willingness to } \\
\text { take risks }\end{array}$ & Unacceptable & Acceptable & $\begin{array}{l}\text { Because of the high number of variables, the } \\
\text { consequences of an organizational change } \\
\text { motivated by OM are always uncertain to } \\
\text { some degree. This implies that it is impos- } \\
\text { sible to fully avoid taking risks when } \\
\text { applying OM. Taking risks in medicine can } \\
\text { be deadly, and therefore physicians are } \\
\text { highly averse to taking risks. As a conse- } \\
\text { quence, doctors tend to approach organiza- } \\
\text { tional changes in an evidence-based } \\
\text { manner. }\end{array}$ \\
\hline $\begin{array}{l}\text { Leading } \\
\text { coalition }{ }^{313}\end{array}$ & Physicians & Managers & $\begin{array}{l}\text { Outside hospitals, OM decisions are } \\
\text { normally made by managers, who are often } \\
\text { trained or experienced in this discipline. In } \\
\text { hospitals, physicians - who have no OM } \\
\text { training or experience - often have the } \\
\text { power to greatly influence important } \\
\text { organizational decisions. }\end{array}$ \\
\hline
\end{tabular}




\subsection{Lessons learned from the walk-in system intervention}

The studies described in Chapters 5, 6, and 7 all focus on applying the walkin concept to the CT modality. We found this concept to be an interesting one for the CT context, and also learned more general concepts about the walk-in system that can provide valuable insights when considering the walk-in concept for other situations. These lessons are explained in this section.

\subsubsection{Walk-in versus appointment system}

The success of both walk-in and appointment systems depend on the characteristics of the system and the way the system is adapted and managed. There are challenges and opportunities inherent in both systems. ${ }^{237}$ In this section, we approach the walk-in system theoretically to analyze the circumstances under which the advantages of a walk-in system would be able to dominate the disadvantages. In other words, when would the risks of full waiting rooms and high idle times be too great to consider a walk-in system, given current capacity and demand? This is largely defined by mathematical laws known from factory physics. ${ }^{187}$ The following are the main logistic system characteristics that influence the success of walk-in systems in hospitals:

- Variety in patient arrivals (varying volumes): The more even the distribution (about the same every hour), the better it is for a walk-in system. This is because it is more difficult to adjust capacity on demand when there is a high degree of fluctuation.

- Variability in patient arrivals (unpredictable volumes): The more predictable the distribution (about the same every Monday morning), the better it is for a walk-in system. Unpredictable demand makes it even more difficult to adjust capacity.

- Ratio of average scan time to the daily capacity (long or short processing times): The more scans that can be fit into a day, the better it is for a walk-in system. This is because it is easier to compensate for variety and variability in arrival distribution.

- Variety in scan times (longer and shorter scans): The more variety there is in scan times, the more attractive a walk-in system becomes. This is because high scan time variety makes scheduling more complicated.

- Variability in scan time (unpredictable scan times): The greater the variability of scan times, the more attractive a walk-in system becomes. This is because the actual scan time often differs from the appointment time.

- Duration of the post-processing, reading, and reporting process: The shorter this process can be, the greater the advantages of a walk-in system will be. This is because a main advantage of a walk-in system is a short "door-todoor time", but this is partly dependent on the duration of post-processing

- Flexibility in capacity: When peak periods can be dealt with by temporarily increasing capacity, this benefits a walk-in system.

The extent to which patients tend to arrive late for appointments, do not show up at all, or cancel at short notice: The more this occurs, the more attractive a walk-in system becomes.

- The frequency with which patients require specific preparation: The less that is required in terms of preparation, the better it is for a walk-in system. One reason is that a major advantage of a walk-in system is that patients can have a scan immediately following an outpatient consultation this advantage diminishes when preparation is required. (Patients are sometimes required to arrive in a fasting state or to be examined for a diagnosis.)

- The more willing patients are to wait in the waiting room, the more suitable a walk-in system will be.

The fluid nature of these logistic system characteristics makes it complicated to determine whether the characteristics for a given system indicate a walk in system. Another complicating factor is that the weight of these characteristics is unknown: which logistic system characteristics have the greatest influence? The challenge is to determine whether the logistic system characteristics and the extent to which they can be influenced is more beneficial to a walk-in or an appointment system. The following subheadings describe the two main risks that opponents of walk-in systems warn about - high idle times and long waiting times - in relation to the above logistic system characteristics.

\subsubsection{Idle time}

Idle time is almost always taken into account as a performance criterion when applying $\mathrm{OM}$ in hospitals. We will clarify the risk of idle time here. We define productivity as the total scan time achieved over a period of time in relation to capacity (which consists of scanners, opening hours, and radiology employees, including support staff). In this given situation, idle time has a negative effect on productivity. Productivity is affected when a walk-in system is introduced. Most people presume that unpredictable arrivals with inevitable idle moments will cause a decrease in productivity, but this is not necessarily true. There are also factors that have a positive impact on productivity. The following three factors influence idle time when a walk-in system is introduced: 
- Idle time during quiet moments when no patients are arriving increases;

- Idle time due to last-minute cancellations, no-shows, and waiting for latecomers decreases;

- Idle time due to waiting for the next patient to arrive when the previous patient is finished earlier than scheduled decreases.

The relationship between these factors is illustrated in Figure 21.

\section{FIGURE 21 / Idle times in walk-in and appointment system}
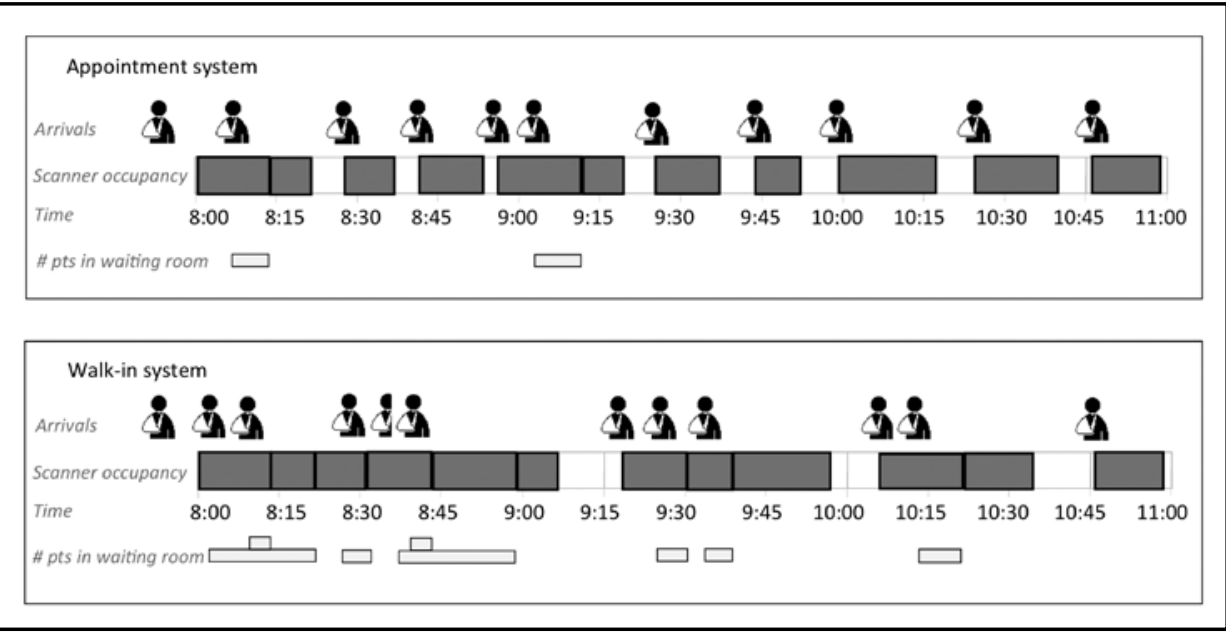

This relationship between the idle time factors can be explained as follows. In an appointment system, the appointment time slot must be longer than the average scan time to compensate for fluctuations in scan time and latecomers. If there was no margin, the waiting times and overtime at the end of the day would become unacceptable. In a walk-in system, to compensate for quiet arrival moments and limit waiting times during peak periods, the opening hours per scanner must be longer than the average scan time multiplied by the average number of patients per scan day. In other words, the appointment system requires a margin for every appointment, and the walk-in system requires a margin per scan day. The main idle time question is whether the sum of the traditional margins per appointment is larger than the margin per scan day for the walk-in system. Figure 21 shows many short gaps between the scans in the appointment system, and some longer gaps in the walk-in system. The system characteristics and the way the system is managed determines whether the sum of the numerous short gaps is larger than the sum of the few longer gaps.

\subsubsection{Waiting time}

Patient preference studies show that patients assess waiting time differently in different situations. ${ }^{37,314}$ In an appointment system, we distinguish between waiting time before the appointment time (which we refer to as "voluntary waiting time" for the patient, or vwt) and waiting time after the appointment time (which we refer to as "involuntary waiting time" for the patient, or iwt). In a walk-in system, there is one type of waiting time, which we refer to as "walkin waiting time," or wwt. However, as with both vwt and iwt, patients assess this in different ways.

We learned that, for the same length of waiting time, patients assess iwt as the most annoying and vwt as the least annoying. Therefore, if we examine the negative impact, we can conclude the following:

\section{vwt $<$ wwt $<$ iwt}

We have to take this into account when waiting times in the waiting room increase after introducing a walk-in system. The waiting times in the new situation are significantly less of a disadvantage than the same duration of iwt in the old situation.

This means that when we assess the performance indicator waiting time, we need to take the type of waiting time into account when we start to compare the results. To choose the best system design, it is desirable to be able to make trade-offs between these waiting times and idle time. Although extensive research has been done to determine the relative cost of patient waiting time versus system idle time, ${ }^{315}$ we found no studies that distinguished between, and quantified, the different types of waiting time.

Another factor is that patients usually assess waiting time differently when they know that the alternative will be a long access time. For example, when patients are offered an appointment in four weeks, many of them will accept a waiting time of an hour when they are also offered a walk-in and can be served the same day. When a hospital chooses to start offering only walk-ins, how patients assess a specific waiting time (for example, a wait of one hour) can change over time. When the alternative that includes an access time is no longer offered, patients quickly forget that the waiting time is in contrast to an access time. As a result, patients may assess the one-hour waiting time as more annoying than when they were aware of the alternative. 


\subsubsection{Walk-in is disruptive}

Walk-in is a radical organizational change and can be expressed as a disruptive innovation. Traditional organizations - such as hospitals - are generally hardly able to adopt disruptive innovations. ${ }^{316}$ The fact that almost no hospital followed Rijnstate's walk-in success and the big skepticism the walk-in concept met in the beginning, are indications that walk-in CT meets Christensen's innovators dilemma. ${ }^{316}$ This dilemma explains how successful organizations lose their position by improving the things they already do. What can we learn from this? In Christensen's applications of his dilemma on the health care sector, ${ }^{317}$ he argues for the healthcare industry to open its doors to market forces. He means being open to disruptive technologies and business models that may threaten the status quo but will ultimately raise the quality of health care for everyone.317 With walk-in CT we showed an example of a disruptive business model, driven by the market force of more need for low access times.

\subsection{Conclusions}

We designed, calculated, implemented, and evaluated new OM solutions in hospital imaging departments. This led to improvements to service, access, and quality of care. Moreover, our solutions and lessons learned can inspire other departments and hospitals to use OM to improve their performance.

Smarter imaging management is, above all, about dealing with variability. When a manager succeeds in this, he or she gains better control of the processes. OM provides valuable tools for dealing with the many types of variabilities in imaging processes. Although there are substantial differences between hospitals and industry, our studies showed that OM can contribute to better performance in imaging management.

One particularly interesting intervention based on OM theory is the walk-in system. Especially in capital-intensive imaging modalities such as the CT modality, the walk-in concept is seldom applied. We demonstrated that a walk-in system, combined with appointments for specific patient groups, provides better operational performance than an appointment system alone. The main performance gains are the elimination of access times, the possibility for onestop shopping, and the likelihood of an increase in productivity.

In contrary to the vast majority of OM studies in hospitals, we not only demonstrated the value of OM theoretically, but also applied our solutions in practice. In doing so, we encountered new challenges that did not emerge from our theoretical studies, and learned how to deal with OM changes.
Furthermore, because our evidence has been validated in practice, it is stronger than most studies. Therefore, the key message of this dissertation is as follows:

There is need for smarter imaging processes and OM can greatly contribute to this. Disruptive OM changes like walk-in have been understudied, but have been proven - both analytically and empirically to greatly improve performance. Successfully assessing and applying new OM concepts for smarter imaging necessitates 1) focus on dealing with variability, 2) understanding of both $O M$ and the hospital context, and 3 ) the willingness to change disruptively.

\subsection{Discussion}

There is a large gap between science and practice when it comes to OM in hospitals. Most scientific OM studies for hospitals were not conducted in hospitals, and so were not applied in practice. ${ }^{305}$ And most applied OM interventions have not been scientifically underpinned. This is a wasted opportunity on two fronts. First, OM studies thus remain theoretical exercises, and the outcomes are not utilized. Second, since the leading coalition in hospitals - the doctors - is very sensitive to scientific arguments, a strong theoretical foundation helps to build support among those who will be required to work with the OM intervention.

We would stress that OM should be used more often and more effectively in hospitals, precisely because hospitals are very complex organizations, OM tools will contribute to gaining better control over processes and variabilities, and, therefore, to better operational performance. We offer some suggestions on how to apply OM in hospitals more effectively. First, process optimization in hospitals is almost always implemented gradually. This means we see many small interventions, but few radical changes, such as the introduction of a walkin system. For example, Rijnstate successfully introduced a walk-in CT, and the second hospital followed eight years later. Hospital managers and physicians consider experimenting with radical changes to be risky because this can influence patients' health. In medical environments, people are used to examining evidence before making decisions about radical changes. We would suggest that computer simulation can both provide a type of evidence, and make it pos- 
sible to experiment while taking virtually no risks. And maybe we just need to be bolder when it comes to experimenting with OM improvements in hospitals.

Our second suggestion is to learn more from peers. Although Rijnstate's success with a walk-in CT is widely known, in all these years no other hospital has visited Rijnstate to learn from their experience. In the four years I worked at the Academic Medical Center (AMC) in Amsterdam and as a management consultant in various hospitals, I rarely heard of meetings with other hospitals to learn from their OM approach, even though their patients and resources were very similar.

Another factor is that OM in hospitals is often based on incorrect assumptions about what stakeholders prefer or how processes behave. For example, by asking patients and radiology employees about their main preferences, we learned a great deal about how successful the intended OM interventions would be. The behavior of a process after an intervention is usually difficult to predict. For example, computer simulation taught us that waiting times would remain acceptable after introducing a walk-in CT. This was the opposite of what people expected. Thus, our third suggestion is to reconsider assumptions frequently, and analyze stakeholder preferences and the process consequences of an intervention more thoroughly.

We close with some recommendations for further research and for hospital managers.

\section{Recommendations for further research:}

- Apply our insights in other departments with similar system characteristics, such as outpatient clinics, laboratories, and radiotherapy departments.

- Develop an instrument that makes it possible to quantitatively weigh various $\mathrm{OM}$ performance indicators such as waiting times and access times.

- Examine how the "medical world" and the "OM world" can integrate successfully. We have applied one specifically interesting method that supports this: computer simulation (see Chapters 4 and 6). This method connects both worlds, because it creates a safe environment that allows us to quantitatively and prospectively assess OM interventions and to objectively show the involved stakeholders the results of these interventions in their working processes, without any risk for these processes. In other words, simulation creates evidence of the impact of interventions, without experimenting in real life. We should try to find more of those methods that connect both worlds.

- Education programs for physicians should raise consciousness for the logistical aspects of their actions in healthcare. This will help to further bridge the two "worlds" of OM and medicine. Even if it will only cover a fraction of their courses, it can open eyes of medical students and bring more understanding of the positive effects of OM.

- Focus on ways to successfully come up with, assess, and implement disruptive innovations in hospitals or equivalent organizations.

\section{Recommendations for hospital managers:}

- Calculate the consequences of intended OM interventions prospectively, because leading coalitions in hospitals are sensitive to quantitative data. As stated in the above paragraph, computer simulation is a method that can contribute to this.

- Consider out-of-the-box interventions like walk-in systems, even though they may seem contra-intuitive. Chapters 5-7 have taught us what positive results it can generate in terms of clear performance indicators.

- Introduce incentives to come with OM solutions. For example, this can be done by attracting more OM expertise, start OM projects or issuing it on the agenda of the board.

Examine and challenge assumptions when stakeholders state that an OM intervention is not possible. The high level of variability and complexity are often an excuse to say that OM does not work in hospitals. This is usually expressed by people who do not realize that variability is predominantly caused by our way of managing the complex processes. So, it is in fact par excellence an argument to use OM, so we can work on (for example) smarter imaging management. 


\section{BIBLIOGRAPHY}

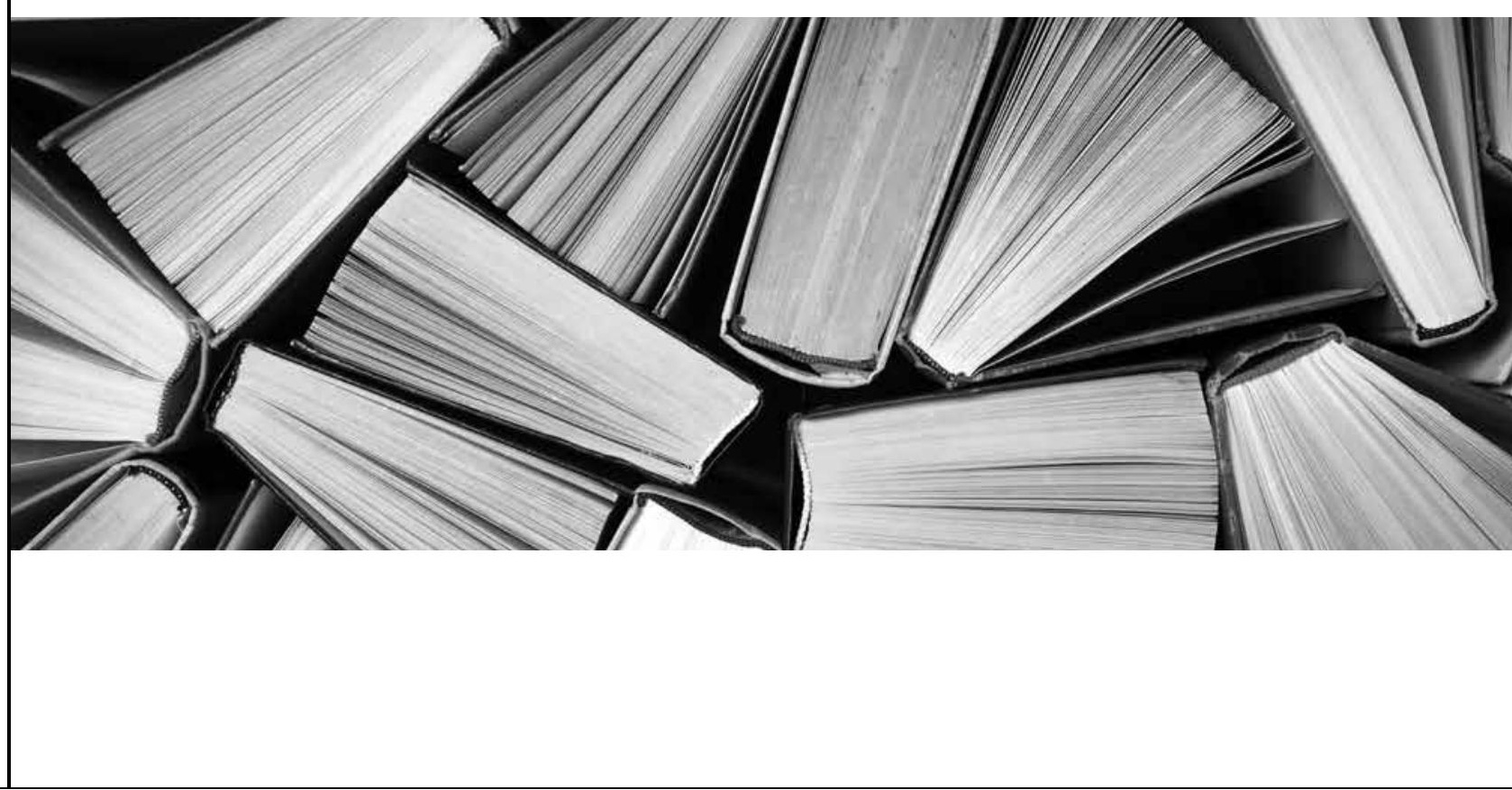


1. van Harten WH, Hans EW, van Lent WAM. Aanpak efficiency te doordacht. https://www.medischcontact.nl/nieuws/laatste-nieuws/artikel/aanpak-efficiencyte-ondoordacht.htm. Updated 2010. Accessed 03/06, 2017.

2. de Weerd P. Zorglogistiek: Zeven werkwijzen van zeven ziekenhuizen. http://www.logistiek.nl/warehousing/artikel/2015/3/zorglogistiek-zeven-werkwijzenvan-zeven-ziekenhuizen-10199044. Updated 2016. Accessed 03/06, 2017.

3. Albada A, Triemstra M. Patients' priorities for ambulatory hospital care centres. A survey and discrete choice experiment among elderly and chronically ill patients of a dutch hospital. Health Expect. 2009;12(1):92-105.

4. Vanberkel PT, Boucherie RJ, Hans EW, Hurink JL, Litvak N. Efficiency evaluation for pooling resources in health care. OR spectrum. 2012;34(2):371-390.

5. Strunk BC, Ginsburg PB, Banker MI. The effect of population aging on future hospital demand. Health Aff (Millwood). 2006;25(3):w141-9.

6. Folland S, Goodman AC, Stano M. The economics of health and health care: Pearson international edition. Routledge; 2016.

7. Grossman M. Demand for health: A theoretical and empirical investigation. Columbia University Press; 2017.

8. Chandra A, Skinner J. Technology growth and expenditure growth in health care. Journal of Economic Literature. 2012;50(3):645-680.

9. Huishoudboekje van nederland 2017. https://www.rijksoverheid.nl/onderwerpen/ prinsjesdag/inhoud/miljoenennota-rijksbegroting-en-troonrede/huishoudboekje. Updated 2017. Accessed 04/03, 2017.

10. Joumard I, Hoeller P, André C, Nicq C. Health care systems: Efficiency and policy settings. 2010th ed. OECD Publishing; 2010. http://dx.doi.org/10.1787/ 9789264094901-en.

11. Chandra A, Skinner J. Technology growth and expenditure growth in health care. Journal of Economic Literature. 2012;50(3):645-680.

12. Westra $D$, Kroese $M$, Ruwaard $D$. Substitutie: Wat weten we, wat moeten we weten en wat moeten we doen? Nederlands Tijdschrift voor Geneeskunde. 2017:1-3:1.

13. Reinhardt UE. Does the aging of the population really drive the demand for health care? Health Aff (Millwood). 2003;22(6):27-39.

14. Zweifel P, Felder S, Meiers M. Ageing of population and health care expenditure: A red herring? Health Econ. 1999;8(6):485-496.

15. Dall TM, Gallo PD, Chakrabarti R, West T, Semilla AP, Storm MV. An aging population and growing disease burden will require a large and specialized health care workforce by 2025. Health Aff (Millwood). 2013;32(11):2013-2020.

16. Rowe JW, Fulmer T, Fried L. Preparing for better health and health care for an aging population. JAMA. 2016;316(16):1643-1644.

17. Vogelsang EM, Raymo JM, Liang J, Kobayashi E, Fukaya T. Population aging and health trajectories at older ages. Journals of Gerontology Series B: Psychological Sciences and Social Sciences. 2017; 72(6):1111-1112.
18. Potter SJ, McKinlay JB. From a relationship to encounter: An examination of longitudinal and lateral dimensions in the doctor-patient relationship. Soc Sci Med. 2005;61(2):465-479.

19. Stacey CL, Henderson S, MacArthur KR, Dohan D. Demanding patient or demanding encounter?: A case study of a cancer clinic. Soc Sci Med. 2009;69(5):729-737.

20. Gröne O, Garcia-Barbero M. Integrated care. International journal of integrated care. $2001 ; 1(2)$.

21. Johnston R, Clark G. Service operations management: Improving service delivery. Pearson Education; 2008.

22. Coffey RJ, Richards JS, Remmert CS, LeRoy SS, Schoville RR, Baldwin PJ. An introduction to critical paths. Quality Management in Healthcare. 2005;14(1):46-55

23. Allen D. From boundary concept to boundary object: The practice and politics of care pathway development. Soc Sci Med. 2009;69(3):354-361.

24. Hunter B, Segrott J. Re-mapping client journeys and professional identities: A review of the literature on clinical pathways. Int J Nurs Stud. 2008:45(4):608-625.

25. Rotter T, Kinsman L, James EL, Machotta A, Gothe H, Willis J, Snow P, Kugler J. Clinical pathways: Effects on professional practice, patient outcomes, length of stay and hospital costs. The Cochrane Library. 2010.

26. Cardoen B, Demeulemeester E. Capacity of clinical pathways-a strategic multilevel evaluation tool. J Med Syst. 2008;32(6):443-452

27. Schrijvers G, van Hoorn A, Huiskes N. The care pathway: Concepts and theories: An introduction. Int J Integr Care. 2012;12(Spec Ed Integrated Care Pathways):e192.

28. Schrijvers G, van Hoorn A, Huiskes N. The care pathway: Concepts and theories: An introduction. Int J Integr Care. 2012;12(Spec Ed Integrated Care Pathways):e192.

29. Smith-Bindman R, Miglioretti DL, Johnson E, Lee C, Feigelson HS, Flynn M, Greenlee RT, Kruger RL, Hornbrook MC, Roblin D, Solberg LI, Vanneman N, Weinmann $S$, Williams AE. Use of diagnostic imaging studies and associated radiation exposure for patients enrolled in large integrated health care systems, 1996-2010. JAMA. 2012;307(22):2400-2409.

30. Volksgezondheid en zorg. https://www.volksgezondheidenzorg.info/node/8386/ tabel. Updated 2017. Accessed 05/20, 2017.

31. Basta YL, Tytgat KM, Klinkenbijl JH, Fockens P, Smets EM. Waiting time at a fast-track diagnostic clinic. Int J Health Care Qual Assur. 2016;29(5):523-535.

32. Catania C, De Pas T, Minchella I, De Braud F, Micheli D, Adamoli L, Spitaleri G, Noberasco C, Milani A, Zampino MG, Toffalorio F, Radice D, Goldhirsch A, Nolè F. "Waiting and the waiting room: How do you experience them?" emotional implications and suggestions from patients with cancer. Journal of Cancer Education. 2011;26(2):388-394.

33. Paul C, Carey M, Anderson A, Mackenzie L, Sanson-Fisher R, Courtney R, ClintonMcHarg T. Cancer patients' concerns regarding access to cancer care: Perceived impact of waiting times along the diagnosis and treatment journey. European journal of cancer care. 2012;21(3):321-329. 
34. Neal RD, Tharmanathan P, France B, Din NU, Cotton S, Fallon-Ferguson J, Hamilton W, Hendry A , Hendry M , Lewis R, Macleod U, Mitchell ED , Pickett M , Rai T, Shaw K, Stuart N, Tørring ML, Wilkinson C, Williams B, Williams N and Emery J. Is increased time to diagnosis and treatment in symptomatic cancer associated with poorer outcomes? systematic review. Br J Cancer. 2015;112 Suppl 1:S92-107.

35. Torring ML, Frydenberg M, Hansen RP, Olesen F, Hamilton W, Vedsted P. Time to diagnosis and mortality in colorectal cancer: A cohort study in primary care. Br J Cancer. 2011;104(6):934-940.

36. Erikson C, Salsberg E, Forte G, Bruinooge S, Goldstein M. Future supply and demand for oncologists: Challenges to assuring access to oncology services. Journal of Oncology Practice. 2007;3(2):79-86.

37. Maister DH. The psychology of waiting lines. Harvard Business School; 1984

38. O'Rourke N, Edwards R. Lung cancer treatment waiting times and tumour growth. Clin Oncol. 2000;12(3):141-144

39. Yu L, Chojniak R, Borba M, Girao D, Lourenço M. Prevalence of anxiety in patients awaiting diagnostic procedures in an oncology center in brazil. Psycho-Oncology. 2011;20(11):1242-1245.

40. Kielar AZ, El-Maraghi RH, Schweitzer ME. Improving equitable access to imaging under universal-access medicine: The ontario wait time information program and its impact on hospital policy and process. Journal of the American College of Radiology. 2010;7(8):573-581.

41. Zorgautoriteit N. Marktscan medisch specialistische zorg: Weergave van de markt 2006-2011 [market scan of medical specialist care: Description of market 2006-2011] 2011.

42. Hofman L. Capacity management at the radiology department of Isala: managing the variability of scheduled and unscheduled arrivals. 2014. MSc thesis report Industrial Engineering \& Management, University of Twente (essay.utwente.nl)

43.Grant L, Appleby J, Griffin N, Adam A, Gishen P. Facing the future: The effects of the impending financial drought on NHS finances and how UK radiology services can contribute to expected efficiency savings. Br J Radiol. 2012;85(1014):784-791.

44. Vanberkel PT. Interacting hospital departments and uncertain patient flows: Theoretical models and applications. Ph.D. thesis, University of Twente; 2011.

45. Mollura DJ, Mayo-Smith WW. Radiology overview: Defining radiology and stakeholders in the radiology enterprise. In: Radiology in global health. Springer; 2014:7-11.

46. Anderson $\mathrm{CL}$, Agarwal R. The digitization of healthcare: Boundary risks, emotion, and consumer willingness to disclose personal health information. Information Systems Research. 2011;22(3):469-490.

47. Henry W, Wyatt JC. Survey of doctors' experience of patients using the internet. Journal of Medical Internet Research. 2002;4(1):e5.

48. Smart JM, Burling D. Radiology and the internet: A systematic review of patient information resources. Clin Radiol. 2001;56(11):867-870.
49. Loozen EM. Public healthcare interests require strict competition enforcement. Health Policy. 2015;119(7):882-888.

50. Andritsos DA, Tang CS. Introducing competition in healthcare services: The role of private care and increased patient mobility. Eur J Oper Res. 2014;234(3):898-909.

51. Ondategui-Parra S, Gill IE, Bhagwat JG, Intrieri LA, Gogate A, Zou KH, Nathanson $\mathrm{E}$, Seltzer SE, Ros PR. Clinical operations management in radiology. Journal of the American College of Radiology. 2004;1(9):632-640.

52. Lodge A, Bamford D. New development: Using lean techniques to reduce radiology waiting times. Public Money and Management. 2008;28(1):49-52.

53. Slack N. Operations strategy. Wiley Online Library; 2015.

54. Vissers J, Beech R. Health operations management: Patient flow logistics in health care. Routledge; 2005

55. Slack N, Chambers S, Johnston R. Operations management. Harlow: Pearson Higher Education; 2003

56. Hulshof PJ, Kortbeek N, Boucherie RJ, Hans EW, Bakker PJ. Taxonomic classification of planning decisions in health care: A structured review of the state of the art in OR/MS. Health systems. 2012;1(2):129-175.

57. Ebell MH, Siwek J, Weiss BD, Woolf SH, Susman J, Ewigman B, Bowman M. Strength of recommendation taxonomy (SORT): A patient-centered approach to grading evidence in the medical literature. J Am Board Fam Pract. 2004;17(1):59-67.

58. Walshe K, Rundall TG. Evidence-based management: From theory to practice in health care. Milbank O. 2001;79(3):429-457.

59. Green J. The role of theory in evidence-based health promotion practice. 2000.

60. Donabedian A. The quality of care: How can it be assessed? JAMA. 1988;260(12):1743-1748.

61. Scott G. The voice of the customer: Is anyone listening? Journal of Healthcare Management. 2001;46(4):221.

62. Delbanco TL. Enriching the doctor-patient relationship by inviting the patient's perspective. Ann Intern Med. 1992;116(5):414-418.

63. Cleary PD. The increasing importance of patient surveys. now that sound methods exist, patient surveys can facilitate improvement. BMJ. 1999;319(7212):720-721.

64. Rogers G, Smith D. Methodology matters. reporting comparative results from hospital patient surveys. International Journal for Quality in Health Care. 1999;11(3):251-259.

65. Cleary PD, Edgman-Levitan S, Roberts M, Moloney TW, McMullen W, Walker JD Delbanco TL. Patients evaluate their hospital care: A national survey. Health Aff (Millwood). 1991;10(4):254-267.

66. Borgman NJ. Managing urgent care in hospitals. Ph.D. thesis. University of Twente. 2017.

67. Brailsford S, Harper PR, Patel B, Pitt M. An analysis of the academic literature on simulation and modelling in health care. Journal of simulation. 2009;3(3):130-140.

68. Cardoen B, Demeulemeester E, Beliën J. Operating room planning and scheduling: A literature review. Eur J Oper Res. 2010:201(3):921-932. 
69. Elder E, Johnston AN, Crilly J. Review article: Systematic review of three key strategies designed to improve patient flow through the emergency department. Emergency Medicine Australasia. 2015;27(5):394-404

70. Günal MM, Pidd M. Discrete event simulation for performance modelling in health care: A review of the literature. Journal of Simulation. 2010;4(1):42-51.

71. Jack EP, Powers TL. A review and synthesis of demand management, capacity management and performance in health-care services. International Journal of Management Reviews. 2009;11(2):149-174.

72. Johnston M, Samaranayake P, Dadich A, Fitzgerald J. Modelling radiology department operation using discrete event simulation. 2009:678-684.

73. Kortbeek N. Quality-driven efficiency in healthcare. Ph.D. thesis. Universiteit Twente; 2012.

74. Marynissen J, Demeulemeester E. Literature review on integrated hospital scheduling problems. Technical report, Faculty of Economics and Business, KU Leuven, 2016.

75. Mielczarek B, Uziałko-Mydlikowska J. Application of computer simulation modeling in the health care sector: A survey. Simulation. 2012;88(2):197-216.

76. Mohiuddin S, Busby J, Savovic J, Richards A, Northstone K, Hollingworth W, Donovan JL, Vasilakis C. Patient flow within UK emergency departments: A systematic review of the use of computer simulation modelling methods. BMJ Open. 2017;7(5):e015007-2016-015007.

77. Oredsson S, Jonsson H, Rognes J, Lind L, Göransson KE, Ehrenberg A, Asplund K, Castrén $\mathrm{M}$, Farrohknia N. A systematic review of triage-related interventions to improve patient flow in emergency departments. Scandinavian journal of trauma, resuscitation and emergency medicine. 2011;19(1):43.

78. Dehghani M, Moftian N, Rezaei-Hachesu P, Samad-Soltani T. A step-by-step framework on discrete events simulation in emergency department; A systematic review. Bulletin of Emergency \& Trauma. 2017;5(2):79.

79. Sobolev BG, Sanchez V, Vasilakis C. Systematic review of the use of computer simulation modeling of patient flow in surgical care. J Med Syst. 2011;35(1):1-16.

80. Thor J, Lundberg J, Ask J, Olsson J, Carli C, Härenstam KP, Brommels M. Application of statistical process control in healthcare improvement: Systematic review. Qual Saf Health Care. 2007;16(5):387-399.

81. Vanberkel PT, Boucherie RJ, Hans EW, Hurink JL, Litvak N. A survey of health care models that encompass multiple departments. 2009. (Memorandum; No. 1903). Enschede: University of Twente, Department of Applied Mathematics.

82. Williams J, Smythe W, Hadjistavropoulos T, Malloy DC, Martin R. A study of thematic content in hospital mission statements: A question of values. Health Care Manage Rev. 2005;30(4):304-314.

83. Spear SJ. Fixing health care from the inside, today. Harv Bus Rev. 2005;83(9):78.

84. Karnon J. Alternative decision modelling techniques for the evaluation of health care technologies: Markov processes versus discrete event simulation. Health Econ. 2003:12(10):837-848.
85. Karnon J, Brown J. Selecting a decision model for economic evaluation: A case study and review. Health Care Manag Sci. 1998;1(2):133-140.

86. Fone D, Hollinghurst S, Temple M, Round A, Lester N, Weightman A, Roberts K, Coyle E, Bevan G, Palmer S. Systematic review of the use and value of computer simulation modelling in population health and health care delivery. $J$ Public Health Med. 2003;25(4):325-335.

87. Lehaney $B$, Hlupic V. Simulation modelling for resource allocation and planning in the health sector. J R Soc Health. 1995;115(6):382-385.

88. Marshall A, Vasilakis C, El-Darzi E. Length of stay-based patient flow models: Recent developments and future directions. Health Care Manag Sci. 2005;8(3): 213-220.

89. Goldratt EM, Cox J. The goal of process of ongoing improvement. Great Barrington, MA: North River Press; 1992.

90. Hans EW, Van Houdenhoven M, Hulshof PJ. A framework for healthcare planning and control. In: Handbook of healthcare system scheduling. Springer; 2012:303320

91. De Leeuw A. Bedrijfskundig management. Uitgeverij Van Gorcum; 2000.

92. Law AM, Kelton WD. Simulation modeling and analysis. Singapore: McGraw-Hill; 2000.

93. EdManagement. Experts: Cut costs of ED observation. ED Management 2001;13(6):64-65 66.

94. Asplin BR, Magid DJ, Rhodes KV, Solberg LI, Lurie N, Camargo CA. A conceptual model of emergency department crowding. Ann Emerg Med. 2003:42(2):173-180.

95. Benneyan JC. An introduction to using computer simulation in healthcare: Patient wait case study. J Soc Health Syst. 1997;5(3):1-15.

96. Browne G, Lam L, Giles H, McCaskill M, Exley B, Fasher B. The effects of a seamless model of management on the quality of care for emergency department patients. J Qual Clin Pract. 2000;20(4):120-126.

97. Chin L, Fleisher $\mathrm{G}$. Planning model of resource utilization in an academic pediatric emergency department. Pediatr Emerg Care. 1998;14(1):4-9.

98. Clague JE, Reed PG, Barlow J, Rada R, Clarke M, Edwards RH. Improving outpatient clinic efficiency using computer simulation. Int J Health Care Qual Assur. 1997;10(5):197-201.

99. Connelly LG, Bair AE. Discrete event simulation of emergency department activity: A platform for system-level operations research. Acad Emerg Med. 2004;11(11):1177-1185.

100. Costa A, Ridley S, Shahani A, Harper PR, De Senna V, Nielsen M. Mathematica modelling and simulation for planning critical care capacity. Anaesthesia. 2003;58(4):320-327.

101. Delaney G, Gebski V, Lunn A, Lunn M, Rus M, Manderson C, Langlands AO. Basic treatment equivalent (BTE): A new measure of linear accelerator workload. Clin Oncol. 1997;9(4):234-239. 
102. Dexter F, Macario A. Decrease in case duration required to complete an additional case during regularly scheduled hours in an operating room suite: A computer simulation study. Anesthesia \& Analgesia. 1999;88(1):72-76.

103. Dexter F, Macario A, Traub RD. Which algorithm for scheduling add-on elective cases maximizes operating room utilization? use of bin packing algorithms and fuzzy constraints in operating room management. The Journal of the American Society of Anesthesiologists. 1999;91(5):1491-1491.

104. Dexter F, Macario A, O'neill L. Scheduling surgical cases into overflow block time - computer simulation of the effects of scheduling strategies on operating room labor costs. Anesthesia \& Analgesia. 2000;90(4):980-988.

105. Dexter F, Traub RD. How to schedule elective surgical cases into specific operating rooms to maximize the efficiency of use of operating room time. Anesthesia \& Analgesia. 2002;94(4):933-942.

106. Edwards RH, Clague JE, Barlow J, Clarke M, Reed PG, Rada R. Operations research survey and computer simulation of waiting times in two medical outpatient clinic structures. Health Care Anal. 1994;2(2):164-165 166167168169.

107. El-Darzi E, Vasilakis C, Chaussalet T, Millard P. A simulation modelling approach to evaluating length of stay, occupancy, emptiness and bed blocking in a hospital geriatric department. Health Care Manag Sci. 1998;1(2):143-149.

108. Fowler DG. Development of a computer simulation for laboratory planning. Clinical Laboratory Science. 1998;11(5):280.

109. Fries BE, Ginsberg AS. The effect of delay rules in controlling unscheduled visits to hospitals. Med Care. 1979;17(9):967-972.

110. Fries BE, Marathe VP. Determination of optimal variable-sized multiple-block appointment systems. Oper Res. 1981;29(2):324-345.

111. George J, Fox D, Canvin R. A hospital throughput model in the context of long waiting lists. J Oper Res Soc. 1983;34(1):27-35.

112. Gorunescu F, McClean SI, Millard PH. Using a queueing model to help plan bed allocation in a department of geriatric medicine. Health Care Manag Sci. 2002;5(4):307-312.

113. Graff LG, Radford MJ. Formula for emergency physician staffing. Am J Emerg Med. 1990;8(3):194-199.

114. Hamilton WF. Systems analysis in emergency care planning. Med Care. 1974;12(2):152-162.

115. Hancock WM, Martin JB, Storer RH. Simulation-based occupancy recommendations for adult medical/surgical units using admissions scheduling systems. Inquiry. 1978;15(1):25-32.

116. Aharonson-Daniel L, Paul RJ, Hedley AJ. Management of queues in out-patient departments: The use of computer simulation. J Manag Med. 1996;10(6):50-58.

117. Huang XM. A planning model for requirement of emergency beds. IMA J Math Appl Med Biol. 1995;12(3-4):345-353.

118. Huang $X$. Decision making support in reshaping hospital medical services. Health Care Manag Sci. 1998;1(2):165-173.
119. Huarng F, Hou Lee M. Using simulation in out-patient queues: A case study. Int J Health Care Qual Assur. 1996:9(6):21-25.

120. Jebali A, Alouane ABH, Ladet P. Operating rooms scheduling. Int J Prod Econ. 2006;99(1):52-62.

121. Jones R. Product line management development and integration. Journal of Nursing Administration. 1993;12(5):21-22 23242526.

122. Jones-Schenk J, Hartley P. Organizing for communication and integration J Nurs Adm. 1993;23(10):30-33.

123. Kuo PC, Schroeder RA, Mahaffey S, Bollinger RR. Optimization of operating room allocation using linear programming techniques. J Am Coll Surg. 2003;197(6):889895

124. Laskowski-Jones L. Starling's curve: A way to conceptualize emergency department overcrowding. Journal of Emergency Nursing. 2005;31(3):229-230.

125. Lebowitz P. Schedule the short procedure first to improve OR efficiency. AORN J. 2003;78(4):651-659.

126. Lehmann CA, Leiken AM. Reengineering the clinical laboratory. transitioning to an open laboratory. MLO Med Lab Obs. 1996;28(11):48, 52-3.

127. Mackay M, Millard PH. Application and comparison of two modelling techniques for hospital bed management. Australian Health Review. 1999;22(3):118-143.

128. Malloch KM, Milton DA, Jobes MO. A model for differentiated nursing practice. J Nurs Adm. 1990;20(2):20-26.

129. Mansdorf BD. Allocation of resources for ambulatory care -a staffing model for outpatient clinics. Public Health Rep. 1975:90(5):393-401.

130. Marcon E, Kharraja S, Smolski N, Luquet B, Viale JP. Determining the number of beds in the postanesthesia care unit: A computer simulation flow approach. Anesthesia \& Analgesia. 2003;96(5):1415-1423.

131. Matukaitis J, Stillman P, Wykpisz E, Ewen E. Appropriate admissions to the appropriate unit: A decision tree approach. Am J Med Qual. 2005;20(2):90-97.

132. McGuire F. Using simulation to reduce length of stay in emergency departments. Journal of the Society for Health Systems. 1997;5(3):81-82 838485868788899091

133. Nguyen J, Six P, Parisot R, Antonioli D, Nicolas F, Lombrail P. A universal method for determining intensive care unit bed requirements. Intensive Care Med. 2003;29(5):849-852.

134. Ogulata SN, Erol R. A hierarchical multiple criteria mathematical programming approach for scheduling general surgery operations in large hospitals. J Med Syst. 2003;27(3):259-270.

135. Reilly TA, Marathe VP, Fries BE. A delay-scheduling model for patients using a walk-in clinic. J Med Syst. 1978;2(4):303-313.

136. Rose MB, Davies DC. Scheduling in the operating theatre. Ann R Coll Surg Engl. 1984;66(5):372-374.

137. Ross MA, Naylor S, Compton S, Gibb KA, Wilson AG. Maximizing use of the emergency department observation unit: A novel hybrid design. Ann Emerg Med. 2001;37(3):267-274. 
138. Rotstein Z, Wilf-Miron R, Lavi B, Seidman DS, Shahaf P, Shahar A, Gabay U, Noy S. Management by constraints: Considering patient volume when adding medical staff to the emergency department. Isr Med Assoc J. 2002;4(3):170-173.

139. Saunders CE, Makens PK, Leblanc LJ. Modeling emergency department operations using advanced computer simulation systems. Ann Emerg Med. 1989;18(2):134140.

140. Kim S, Horowitz I, Young KK, Buckley TA. Analysis of capacity management of the intensive care unit in a hospital. Eur J Oper Res. 1999;115(1):36-46.

141. Shmueli $A$, Sprung $C L$, Kaplan EH. Optimizing admissions to an intensive care unit. Health Care Manag Sci. 2003;6(3):131-136.

142. Shukla RK. Admissions monitoring and scheduling to improve work flow in hospitals. Inquiry. 1985:92-101.

143. Siddharthan $\mathrm{K}$, Jones WJ, Johnson JA. A priority queuing model to reduce waiting times in emergency care. Int J Health Care Qual Assur. 1996;9(5):10-16.

144. Sokal SM, Craft DL, Chang Y, Sandberg WS, Berger DL. Maximizing operating room and recovery room capacity in an era of constrained resources. Archives of Surgery. 2006;141(4):389-395.

145. Sonnenberg A. Waiting lines in the endoscopy unit. Gastrointest Endosc. 2000;52(4):517-524.

146. Stahl JE, Rattner D, Wiklund R, Lester J, Beinfeld M, Gazelle GS. Reorganizing the system of care surrounding laparoscopic surgery: A cost-effectiveness analysis using discrete-event simulation. Medical decision making. 2004;24(5):461-471.

147. Strum DP, Vargas LG, May JH, Bashein G. Surgical suite utilization and capacity planning: A minimal cost analysis model. J Med Syst. 1997;21(5):309-322.

148. Su S, Shih C. Managing a mixed-registration-type appointment system in outpatient clinics. Int J Med Inf. 2003;70(1):31-40.

149. Tyler DC, Pasquariello CA, Chen C. Determining optimum operating room utilization. Anesthesia \& Analgesia. 2003;96(4):1114-1121.

150. Utley M, Gallivan S, Treasure T, Valencia O. Analytical methods for calculating the capacity required to operate an effective booked admissions policy for elective inpatient services. Health Care Manag Sci. 2003;6(2):97-104.

151. Vaisman U, Kamrath F, Foth K. Innovative automation: The competitive/ collaborative human factor. Adm Radiol. 1995;14(3):23-27.

152. Vasilakis $C$, Kuramoto L. Comparing two methods of scheduling outpatient clinic appointments using simulation experiments. Clinical and investigative medicine. 2005;28(6):368

153. Wan TT, Hsu N, Feng R, Ma A, Pan S, Chou M. Technical efficiency of nursing units in a tertiary care hospital in Taiwan. J Med Syst. 2002;26(1):21-27.

154. Worthington D, Brahimi M. Improving out-patient appointment systems. Int J Health Care Qual Assur. 1993;6(1).

155. Zilm F, Hollis RB. An application of simulation modeling to surgical intensive care bed need analysis in a university hospital. Hosp Health Serv Adm. 1983;28(5): $82-101$
156. Brahimi M, Worthington $D$. Queueing models for out-patient appointment systems - A case study. J Oper Res Soc. 1991;42(9):733-746.

157. Coats TJ, Michalis S. Mathematical modelling of patients flow through an accident and emergency department. Emerg Med J. 2001;18(3):190-192.

158. Tucker JB, Barone JE, Cecere J, Blabey RG, Rha C. Using queueing theory to determine operating room staffing needs. Journal of Trauma and Acute Care Surgery. 1999;46(1):71-79.

159. Dexter F, Macario A, O'neill L. Scheduling surgical cases into overflow block time - computer simulation of the effects of scheduling strategies on operating room labor costs. Anesthesia \& Analgesia. 2000;90(4):980-988.

160. Elkhuizen S, Limburg M, Bakker P, Klazinga N. Evidence-based re-engineering Re-engineering the evidence: A systematic review of the literature on business process redesign (BPR) in hospital care. Int J Health Care Qual Assur. 2006;19(6):477-499.

161. Boland GW. Enhancing CT productivity: Strategies for increasing capacity. Am J Roentgenol. 2008:191(1):3-10.

162. Jin PFK, Dijkgraaf M, Alons C, van Kuijk C, Beenen LF, Koole GM, Goslings JC. Improving CT scan capabilities with a new trauma workflow concept: Simulation of hospital logistics using different CT scanner scenarios. Eur J Radiol. 2011;80(2):504-509.

163. Karstoft J, Tarp L. Is lean management implementable in a department of radiology? Insights into imaging. 2011;2(3):267-273.

164. Hu M, Pavlicek W, Liu P, Zhang M, Langer SG, Wang S, Place V, Miranda R, Wu TT. Efficiency metrics for imaging device productivity. revised and resubmitted to RadioGraphics at. 2010;7:16.

165. Boland GW, Duszak R,Jr, Mayo-Smith W. Optimizing modality operations. J Am Coll Radiol. 2014;11(7):654-655.

166. Pérez E, Ntaimo L, Bailey C, McCormack P. Modeling and simulation of nuclear medicine patient service management in DEVS. Simulation. 2010;86(8-9):481-501.

167. Reinus WR, Enyan A, Flanagan P, Pim B, Sallee DS, Segrist J. A proposed scheduling model to improve use of computed tomography facilities. J Med Syst. 2000;24(2):61-76.

168. Tokur S, Lederle K, Terris DD, Jarczok MN, Bender S, Schoenberg SO, Weisser G. Process analysis to reduce MRI access time at a german university hospital. Int J Qual Health Care. 2012;24(1):95-99.

169. Falsini D, Perugia A, Schiraldi MM. An operations management approach for radiology services. Sustainable Development: Industrial Practice, Education \& Research. 2010.

170. Tolga Taner M, Sezen B, Atwat KM. Application of six sigma methodology to a diagnostic imaging process. Int J Health Care Oual Assur. 2012;25(4):274-290.

171. Porter ME, Teisberg EO. Redefining competition in health care. Harv Bus Rev. 2004:64-77 
172. Harper PR. A framework for operational modelling of hospital resources. Health Care Manag Sci. 2002;5(3):165-173.

173. Lagoe RJ, Westert GP, Kendrick K, Morreale G, Mnich S. Managing hospital length of stay reduction: A multihospital approach. Health Care Manage Rev. 2005;30(2):82-92.

174. Rozich JD, Resar RK. Using a unit assessment tool to optimize patient flow and staffing in a community hospital. Jt Comm J Qual Improv. 2002;28(1):31-41.

175. Haraden C, Resar R. Patient flow in hospitals: Understanding and controlling it better. Front Health Serv Manage. 2004;20(4):3.

176. Mahaffey S. Optimizing patient flow in the enterprise. Health Manag Technol. 2004;25(8):34-37.

177. Flanagan S, Kjesbo A. Conquering capacity: By improving its patient flow, one hospital has been able to admit an additional 400 patients since january 2003 and expects to maintain that potential. Healthcare Financial Management. 2004;58(7):92-97.

178. Kirby A, Kjesbo A. Tapping into hidden hospital bed capacity. Healthcare Financial Management. 2003;57(11):38-42.

179. Bowers J, Mould G. Managing uncertainty in orthopaedic trauma theatres Eur J Oper Res. 2004;154(3):599-608.

180. Blake JT, Donald J. Mount sinai hospital uses integer programming to allocate operating room time. Interfaces. 2002;32(2):63-73.

181. Guinet A, Chaabane S. Operating theatre planning. Int J Prod Econ. 2003;85(1): 69-81.

182. Miller BJ. Facility capacity constraints present a strategic planning opportunity. Health Care Strateg Manage. 2001;19(11):12.

183. Manansang $\mathrm{H}$, Heim JA. An online, simulation-based patient scheduling system. 1996:1170-1175

184. Lapierre SD, Batson C, McCaskey S. Improving on-time performance in health care organizations: A case study. Health Care Manag Sci. 1999;2(1):27-34.

185. Begun JW, Kaissi AA. Uncertainty in health care environments: Myth or reality? Health Care Manage Rev. 2004;29(1):31-39.

186. Vissers JM, Van Der Bij J, Kusters RJ. Towards decision support for waiting lists: An operations management view. Health Care Manag Sci. 2001;4(2):133-142.

187. Hopp WJ, Spearman ML, eds. Factory physics, foundations of manufacturing management. second ed. New York: Irwin McGraw-Hill; 2001.

188. Baker LC, Phibbs CS, Guarino C, Supina D, Reynolds JL. Within-year variation in hospital utilization and its implications for hospital costs. J Health Econ. 2004;23(1):191-211.

189. Litvak E, Buerhaus PI, Davidoff F, Long MC, McManus ML, Berwick DM. Managing unnecessary variability in patient demand to reduce nursing stress and improve patient safety. The Joint Commission Journal on Quality and Patient Safety. 2005;31(6):330-338
190. Strum DP, May JH, Sampson AR, Vargas LG, Spangler WE. Estimating times of surgeries with two component ProceduresComparison of the lognormal and normal models. The Journal of the American Society of Anesthesiologists. 2003;98(1):232-240.

191. Hopp WJ, Spearman ML, Woodruff DL. Practical strategies for lead time reduction. Manufacturing Review. 1990;3(2):78-84.

192. Shojania KG, Grimshaw JM. Evidence-based quality improvement: The state of the science. Health Aff (Millwood). 2005;24(1):138-150.

193. Kung P, Tsai W, Yaung C, Liao K. Determinants of computed tomography and magnetic resonance imaging utilization in taiwan. Int J Technol Assess Health Care. 2005;21(01):81-88.

194. Clancy CM, Cronin K. Evidence-based decision making: Global evidence, local decisions. Health Aff (Millwood). 2005;24(1):151-162.

195. Shingo S. Revolution in manufacturing: SMED. Portland, OR: Productivity Press; 1995.

196. Barron WM, Krsek C, Weber D, Cerese J. Critical success factors for performance improvement programs. The Joint Commission Journal on Quality and Patient Safety. 2005;31(4):220-226.

197. Walston SL, Lazes P, Sullivan PG. Improving hospital restructuring: Lessons learned. Health Care Manage Rev. 2004;29(4):309-319.

198. Horton SS. Increasing capacity while improving the bottom line. Front Health Serv Manage. 2004;20(4):17.

199. Bhattacharjee P, Ray PK. Simulation modelling and analysis of appointment system performance for multiple classes of patients in a hospital: A case study. Operations Research for Health Care. 2016;8:71-84.

200. Wessman BV, Moriarity AK, Ametlli V, Kastan DJ. Reducing barriers to timely MR imaging scheduling. Radiographics. 2014;34(7):2064-2070.

201. Huang Y, Marcak J. Radiology scheduling with consideration of patient characteristics to improve patient access to care and medical resource utilization. Health Systems. 2013;2(2):93-102.

202. Zacharias C, Armony M. Joint panel sizing and appointment scheduling in outpatient care. Management Science. 2016;63(11):3978-3997.

203. Liu N, Ziya S. Panel size and overbooking decisions for appointment-based services under patient no-shows. Production and Operations Management. 2014;23(12):2209-2223.

204. van Sambeek JR, Joustra PE, Das SF, Bakker PJ, Maas M. Reducing MRI access times by tackling the appointment-scheduling strategy. BMJ Qual Saf. 2011;20(12):1075-1080

205. Aeenparast A, Tabibi SJ, Shahanaghi K, Aryanejhad MB. Reducing outpatient waiting time: A simulation modeling approach. Iranian Red Crescent Medical Journal. 2013;15(9):865-869.

206. Hall R. Patient flow: Reducing delay in healthcare delivery. Second ed. New York: Springer; 2013. 
207. Karnon J, Afzali HHA. When to use discrete event simulation (DES) for the economic evaluation of health technologies? A review and critique of the costs and benefits of DES. Pharmacoeconomics. 2014;32(6):547-558.

208. Lee S, Min D, Ryu J, Yih Y. A simulation study of appointment scheduling in outpatient clinics: Open access and overbooking. Simulation. 2013;89(12):14591473

209. AMC. Afdeling radiologie: Wanneer ben ik aan de beurt? https://www.amc.nl/web/ Zorg/Patient/Afspraak-op-de-polikliniek/Afdeling-Radiologie/Wanneer-ben-ikaan-de-beurt.htm. Updated 2017. Accessed 03/24, 2017.

210. Teichgräber U, Gillessen C, Neumann F. Methoden des prozessmanagements in der radiologie. 2003;175(12):1627-1633.

211. Ondategui-Parra S, Bhagwat JG, Zou KH, Gogate A, Intriere LA, Kelly P, Seltzer SE, Ros PR. Practice management performance indicators in academic radiology departments 1. Radiology. 2004;233(3):716-722.

212. Reinus WR, Totty WG. Computer-assisted scheduling of radiologists. AJR Am J Roentgenol. 1986:147(1):203-204.

213. Walter SD. A comparison of appointment schedules in a hospital radiology department. Br J Prev Soc Med. 1973;27(3):160-167.

214. Elkhuizen SG, Das SF, Bakker PJ, Hontelez JA. Using computer simulation to reduce access time for outpatient departments. Qual Saf Health Care. 2007;16(5):382-386.

215. Coelli FC, Ferreira RB, Almeida RMV, Pereira WCA. Computer simulation and discrete-event models in the analysis of a mammography clinic patient flow. Comput Methods Programs Biomed. 2007;87(3):201-207.

216. Murad MH, Shah ND, Van Houten HK, Ziegenfuss JY, Deming JR, Beebe TJ, Smith $\mathrm{SA}$, Guyatt $\mathrm{GH}$, Montori VM. Individuals with diabetes preferred that future trials use patient-important outcomes and provide pragmatic inferences. J Clin Epidemiol. 2011;64(7):743-748.

217. Barry MJ, Edgman-Levitan S. Shared decision making - the pinnacle of patientcentered care. N Engl J Med. 2012;366(9):780-781.

218. Barsteiner JH, Disch J, Walton MK. Person and family centered care. Indianapolis, IN: Sigma Theta Tau International; 2014

219. Stacey D, Bennett CL, Barry MJ, Ziegenfuss JY, Deming JR, Beebe TJ, Smith SA Guyatt GH, Montori VM. Decision aids for people facing health treatment or screening decisions. Cochrane Database Syst Rev. 2011;10(10).

220. Gerteis M, Edgman-Levitan S, Daley J, Delbanco T. Through the patient eyes. San Francisco, CA: Jossey-Bass; 1993

221. Rubrech J, Stuyling de Lange G. Kwaliteit verbeteren in de zorg. Amsterdam: Pearson Education Benelux; 2010.

222. Douven R, Boone J. Efficientie, concurrentie en globale budgetten in de zorg. TPEdigitaal 2014, jaargang 8(2), p82-97.

223. NFU. Verbeteren van kwaliteit. http://www.nfukwaliteit.nl/programmas/ verbeteren-van-kwaliteit/.
224. Joosten F, Niekel R, te Loo R, van den Heuvel G. Inloop-CT blijkt success. Medisch Contact. 2011. Available from: https://www.medischcontact.nl/nieuws/laatstenieuws/artikel/inloopct-blijkt-succes.htm\#reacties.

225. Wang W, Gupta D. Adaptive appointment systems with patient preferences. Manufacturing \& Service Operations Management. 2011;13(3):373-389.

226. Wang J, Fung RY. Dynamic appointment scheduling with patient preferences and choices. Industrial Management \& Data Systems. 2015;115(4):700-717.

227. Braaksma A. Timely and efficient planning of treatments through intelligent scheduling. Vol 15. University of Twente; 2015

228. Alting W. Patiëntenpreferenties: Een toegangstijdenonderzoek naar poliklinische patiënten van het NKI-AVL. 2009.

229. Liu N, Finkelstein SR, Kruk ME, Rosenthal D. When waiting to see a doctor is less irritating: Understanding patient preferences and choice behavior in appointment scheduling. Management Science. 2017.

230. Albada A, Triemstra M. Ziekenhuis met servicepunten: Wat willen patiënten van ziekenhuis bernhoven? 2006

231. Liu N, Finkelstein SR, Kruk ME, Rosenthal D. When waiting to see a doctor is less irritating: Understanding patient preferences and choice behavior in appointment scheduling. Management Science. 2017.

232. Saaty TL. Decision making - the analytic hierarchy and network processes (AHP/ANP). Journal of systems science and systems engineering. 2004;13(1):1-35.

233. Dolan JG. Shared decision-making-transferring research into practice: The analytic hierarchy process (AHP). Patient Educ Couns. 2008;73(3):418-425.

234. Danner M, Hummel JM, Volz F, van Manen JG, Wiegard B, Dintsios CM, Bastian H, Gerber A, ljzerman MJ. Integrating patients' views into health technology assessment: Analytic hierarchy process (AHP) as a method to elicit patient preferences. Int J Technol Assess Health Care. 2011;27(04):369-375.

235. Thokala P, Devlin N, Marsh K, Baltussen R, Boysen M, Kalo Z, Longrenn T, Mussen Fi Peacock S, Watkins J, lizerman M. Multiple criteria decision analysis for health care decision making - an introduction: Report 1 of the ISPOR MCDA emerging good practices task force. Value in health. 2016;19(1):1-13.

236. Gartner D, Kolisch R. Scheduling the hospital-wide flow of elective patients. Eur J Oper Res. 2014;233(3):689-699.

237. Gupta D, Denton B. Appointment scheduling in health care: Challenges and opportunities. IIE transactions. 2008;40(9):800-819.

238. Conforti D, Guerriero F, Guido R. Optimization models for radiotherapy patient scheduling. 4OR: A Quarterly Journal of Operations Research. 2008;6(3):263-278.

239. Kok MM, Birgelen C, Lam MK, Löwik MM, van Houwelingen KG, Stoel MG, Louwerenburg JH, de Man FH, Hartmann M, Doggen CJ, van Til JA, IJzerman MJ. Patient preference regarding assessment of clinical follow-up after percutaneous coronary intervention: The PAPAYA study. Eurolntervention. 2016;11(13):14871494. 
240. Sullivan M. The new subjective medicine: Taking the patient's point of view on health care and health. Soc Sci Med. 2003;56(7):1595-1604.

241. Berry LL, Seiders K, Wilder SS. Innovations in access to care: A patient-centered approach. Ann Intern Med. 2003;139(7):568-574.

242. Neuberger J. The educated patient: New challenges for the medical profession. J Intern Med. 2000;247(1):6-10.

243. Chewning B, Bylund CL, Shah B, Arora NK, Gueguen JA, Makoul G. Patient preferences for shared decisions: A systematic review. Patient Educ Couns. 2012;86(1):9-18.

244. Tantau C. Accessing Patient-Centered care using the advanced access model. J Ambulatory Care Manage. 2009;32(1):32-43.

245. Steinbauer JR, Korell K, Erdin J, Spann SJ. Implementing open-access scheduling in an academic practice. Fam Pract Manag. 2006;13(3):59-64.

246. Chapman JL, Zechel A, Carter YH, Abbott S. Systematic review of recent innovations in service provision to improve access to primary care. Br J Gen Pract. 2004;54(502):374-381

247. Griffiths V, Ahmed-Jushuf I. Is triage an appropriate way of dealing with walk-in patients attending genitourinary medicine clinics? Int J STD AIDS. 2005;16(12): 819-821.

248. Salisbury C, Munro J. Walk-in centres in primary care: A review of the international literature. Br J Gen Pract. 2002;53(486):53-59.

249. Pope C, Chalder M, Moore L, Salisbury C. What do other local providers think of NHS walk-in centres? results of a postal survey. Public Health. 2005;119(1):39-44.

250. Grant C, Nicholas R, Moore L, Salisbury C. An observational study comparing quality of care in walk-in centres with general practice and NHS direct using standardised patients. BMJ. 2002;324(7353):1556.

251. Barnsley J, Williams AP, Kaczorowski J, Vayda E, Vingilis E, Campbell A, Atkin K. Who provides walk-in services? survey of primary care practice in ontario. Can Fam Physician. 2002;48:519-526.

252. Rogers A, Kennedy A, Nelson E, Robinson A. Patients' experiences of an open access follow up arrangement in managing inflammatory bowel disease. Qual Saf Health Care. 2004;13(5):374-378.

253. Guthrie B, Wyke S. Personal continuity and access in UK general practice: A qualitative study of general practitioners' and patients' perceptions of when and how they matter. BMC Family Practice. 2006;7(1):11.

254. Bower P, Roland M, Campbell J, Mead N. Setting standards based on patients' views on access and continuity: Secondary analysis of data from the general practice assessment survey. BMJ. 2003;326(7383):258.

255. Allen D, Leavey R, Marks B. Survey of patients' satisfaction with access to general practitioners. J R Coll Gen Pract. 1988;38(309):163-165.

256. Handy P, White J, Sankar KN. Being seen within 48 hours - what do patients think? Int J STD AIDS. 2008;19(7):480-481.
257. Lacy NL, Paulman A, Reuter MD, Lovejoy B. Why we don't come: Patient perceptions on no-shows. Ann Fam Med. 2004;2(6):541-545.

258. Huang X. Patient attitude towards waiting in an outpatient clinic and its applications. Health Services Management Research. 1994;7(1):2-8.

259. Dunnill MG, Pounder RE. Medical outpatients: Changes that can benefit patients. Clin Med (Lond). 2004:4(1):45-49.

260. Moayyedi P, Wardman M, Toner J, Ryan M, Duffett S. Establishing patient preferences for gastroenterology clinic reorganization using conjoint analysis. Eur J Gastroenterol Hepatol. 2002;14(4):429-433

261. Gerard K, Salisbury C, Street D, Pope C, Baxter H. Is fast access to general practice all that should matter? A discrete choice experiment of patients' preferences. $J$ Health Serv Res Policy. 2008;13 Suppl 2:3-10.

262. Rubin G, Bate A, George A, Shackley P, Hall N. Preferences for access to the GP: A discrete choice experiment. Br J Gen Pract. 2006;56(531):743-748.

263. Salisbury C, Goodall S, Montgomery AA, Pickin DM, Edwards S, Sampson F, Simons L, Lattimer V. Does advanced access improve access to primary health care? questionnaire survey of patients. Br J Gen Pract. 2007;57(541):615-621.

264. Sandison AJ, King DH, Padayachee TS, Taylor PR. A one-stop vascular clinic: A practical proposition with non-invasive assessment. Ann R Coll Surg Engl. 1997;79(6):447-450.

265. Patel HR, Luxman CN, Bailey TS, Brunning JDM, Zemmel D, Morrell LK, Nathan MS Miller RA. Outpatient clinic: Where is the delay? J R Soc Med. 2002;95(12):604-605.

266. Miller D, Frost A, Hall A, Barton C, Bhoora I, Kathuria V. A 'one-stop clinic'for the diagnosis and management of rotator cuff pathology: Getting the right diagnosis first time. Int J Clin Pract. 2008;62(5):750-753.

267. Durrande-Moreau A, Usunier J. Time styles and the waiting experience: An exploratory study. Journal of Service Research. 1999;2(2):173-186.

268. Durrande-Moreau A. Waiting for service: Ten years of empirical research. International Journal of Service Industry Management. 1999;10(2):171-194.

269. Saaty TL. Group decision making and the AHP. The analytic hierarchy process. 1989:59-67.

270. Smid K. A simulation model to support implementation of a combined walk-in and appointment system at diagnostic facilities. 2013

271. Kortbeek N, Zonderland ME, Braaksma A, Vliegen IMH, Boucherie, RJ, Litvak N, Hans, EW. Designing cyclic appointment schedules for outpatient clinics with scheduled and unscheduled patient arrivals. Performance Evaluation. 2014;80:5 26.

272. Kortbeek N, Zonderland ME, Braaksma A, Vliegen IMH, Boucherie, RJ, Litvak N, Hans, EW. Designing cyclic appointment schedules for outpatient clinics with scheduled and unscheduled patient arrivals. Performance Evaluation. 2014;80:5-26.

273. Veldwijk J. Do today's work today: Don't send patients away!: An appointment scheduling algorithm that can deal with walk-in. Master thesis. University of Twente; 2012 . 
274. Zhao Z, Zhu X, Li X. Scheduling outpatient appointment when considering the cancellation and no-shows. 2013:3490.

275. Anderson K, Zheng B, Yoon SW, Khasawneh MT. An analysis of overlapping appointment scheduling model in an outpatient clinic. Operations Research for Health Care. 2015;4:5-14

276. Salzarulo PA, Mahar S, Modi S. Beyond patient classification: Using individual patient characteristics in appointment scheduling. Production and Operations Management. 2015.

277. Yan C, Tang J, Jiang B. Sequential appointment scheduling considering walk-in patients. Mathematical Problems in Engineering. 2014;2014.

278. Zacharias C, Pinedo M. Appointment scheduling with No-Shows and overbooking Production and Operations Management. 2014;23(5):788-801.

279. Cao W. An integrated overlapping and overbooking outpatient appointment scheduling system. State University of New York at Binghamton; 2014

280. Wiesche L, Schacht M, Werners B. Strategies for interday appointment scheduling in primary care. Health Care Manag Sci. 2016:1-16.

281. Borgman NJ, Vliegen IM, Boucherie RJ, Hans EW. Appointment scheduling with unscheduled arrivals and reprioritization. Flexible Services and Manufacturing Journal. 2017:1-24.

282. Cayirli T, Yang KK, Quek SA. A universal appointment rule in the presence of No-Shows and Walk-Ins. Production and Operations Management. 2012;21(4): 682-697.

283. Peng Y, Qu X, Shi J. A hybrid simulation and genetic algorithm approach to determine the optimal scheduling templates for open access clinics admitting walk-in patients. Comput Ind Eng. 2014;72:282-296.

284. Robinson LW, Chen RR. A comparison of traditional and open-access policies for appointment scheduling. Manufacturing \& Service Operations Management. 2010;12(2):330-346

285. Elkhuizen SG, van Sambeek JR, Hans EW, Krabbendam KJ, Bakker PJ. Applying the variety reduction principle to management of ancillary services. Health Care Manage Rev. 2007;32(1):37-45.

286. Sambeek JRC, Hummel JM. Patients who require CT-scanning prefer walk-in.

287. Cayirli T, Veral E. Outpatient scheduling in health care: A review of literature. Production and operations management. 2003;12(4):519-549.

288. Tideman R, Pitts M, Fairley C. Effects of a change from an appointment service to a walk-in triage service at a sexual health centre. Int J STD AIDS. 2003;14(12):793-795.

289. Law Averill M, David KW. Simulation modeling and analysis. Mc-Graw Hill. 2000.

290. Van Sambeek J, Cornelissen F, Bakker P, Krabbendam J. Models as instruments for optimizing hospital processes: A systematic review. Int J Health Care Qual Assur. 2010;23(4):356-377.

291. Jun J, Jacobson SH, Swisher J. Application of discrete-event simulation in health care clinics: A survey. J Oper Res Soc. 1999;50(2):109-123.
292. Luigi S, Michael B, Valerie M. OECD health policy studies waiting time policies in the health sector what works?: What works? OECD Publishing; 2013

293. Siciliani L, Hurst J. Tackling excessive waiting times for elective surgery: A comparative analysis of policies in 12 OECD countries. Health Policy. 2005;72(2):201-215.

294. Mulcahy CM, Parry DC, Glover TD. The "patient patient": The trauma of waiting and the power of resistance for people living with cancer. Qual Health Res. 2010;20(8):1062-1075.

295. Wachttijden ziekenhuiszorg radiologie maart 2017. https://www.volksgezondheidenzorg.info/node/8386/tabel. Updated 2017. Accessed 04/28, 2017.

296. Olisemeke B, Chen Y, Hemming K, Girling A. The effectiveness of service delivery initiatives at improving patients' waiting times in clinical radiology departments: A systematic review. J Digital Imaging. 2014;27(6):751-778.

297. Boer MD. Is het wachten zonder een afspraak de moeite waard? Master thesis, Erasmus University; 2009.

298. Scholtens M. Visiting the CT-scan; appointment system or walk in? Patient preferences and possible arrival pattern. Master thesis. University of Twente; 2009.

299. Maraha M. Efficiënter gebruik van CT-scanners: Casus bij medisch spectrum twente. Master thesis. University of Twente; 2011.

300. Postema TRF. The role of intra-organisational stakeholder dynamics in IT-based innovation adoption processes in hospitals. Master thesis. University of Twente; 2012.

301. Yoon P, Steiner I, Reinhardt G. Analysis of factors influencing length of stay in the emergency department. Canadian Journal of Emergency Medicine. 2003;5(3): 155-161.

302. Chau I, Kelleher MT, Cunningham D, Norman AR, Wotherspoon A, Trott P, RhysEvans P, Querci Della Rovere G, Brown G, Allen M, Waters JS, Haque S, Murray T, Bishop L. Rapid access multidisciplinary lymph node diagnostic clinic: Analysis of 550 patients. Br J Cancer. 2003;88(3):354-361.

303. Nitrosi A, Borasi G, Nicoli F, Modigliani G, Botti A, Bertolini M, Notari P. A filmless radiology department in a full digital regional hospital: Quantitative evaluation of the increased quality and efficiency. J Digital Imaging. 2007;20(2):140.

304. Van den Heuvel G, te Loo E. Werken zonder wachtlijst - CT op inloop. Gamma Professional. 2010;60(4):26-27 2829

305. Brailsford S, Vissers J. OR in healthcare: A european perspective. Eur J Oper Res. 2011;212(2):223-234

306. McManus ML, Long MC, Cooper A, Mandell J, Berwick DM, Pagano M, Litvak E. Variability in surgical caseload and access to intensive care services. Anesthesiology: The Journal of the American Society of Anesthesiologists. 2003;98(6):1491-1496.

307. Hopp WJ, Spearman ML. Factory physics. Waveland Press; 2011.

308. Carter M. Diagnosis: Mismanagement of resources. OR MS TODAY. 2002;29(2):26-33. 

- Part I: Differentiation. Health Care Manage Rev. 2001;26(1):56-69.

310. Glouberman S, Mintzberg H. Managing the care of health and the cure of disease - Part II: Integration. Health Care Manage Rev. 2001;26(1):70-84.

311. Tones K, Tilford S. Health promotion: Effectiveness, efficiency and equity. Nelson Thornes; 2001.

312. Laeven AMW. Een gezonde blik naar buiten: Een onderzoek naar oorzaken en gevolgen van marktoriëntatie bij algemene ziekenhuizen. Kluwer Deventer; 2008.

313. Stevenson WB, Pearce JL, Porter LW. The concept of "coalition" in organization theory and research. Academy of Management Review. 1985;10(2):256-268.

314. Thompson DA, Yarnold PR. Relating patient satisfaction to waiting time perceptions and expectations: The disconfirmation paradigm. Acad Emerg Med. 1995:2(12):1057-1062.

315. Robinson LW, Chen RR. Estimating the implied value of the customer's waiting time. Manufacturing \& Service Operations Management. 2011;13(1):53-57.

316. Christensen C. The innovator's dilemma: When new technologies cause great firms to fail. Harvard Business Review Press; 2013.

317. Christensen CM, Bohmer R, Kenagy J. Will disruptive innovations cure health care? Harv Bus Rev. 2000;78(5):102-112.

\section{SAMENVATTING IN HET NEDERLANDS}

Slimmere inzet van radiologie - door middel van Operations Management 
Omdat de druk op efficiëntie toeneemt, ziekenhuizen steeds complexer worden en patiënten en andere stakeholders steeds veeleisender worden, dienen ziekenhuizen stil te staan bij hun waardepropositie richting hun stakeholders. Dit proefschrift richt zich op het tegelijkertijd verhogen van de service en het efficiënt inzetten van de middelen, waarbij wij gereedschappen aanreiken om de bedrijfsprocessen in ziekenhuizen te optimaliseren. We hebben ervoor gekozen om één afdeling aan te pakken, waar een groot deel van de patiënten gebruik van maakt en die een grote bottleneck vormt: de radiologieafdeling. Deze vormt een bottleneck, omdat radiologie voor steeds meer aandoeningen gebruikt wordt en patiënten meestal langer dan gewenst moeten wachten op hun onderzoek. Bovendien is het belangrijk dat deze afdeling efficiënt benut wordt, aangezien radiologie-apparatuur duur is. Daarom zijn ziekenhuizen erg gebaat bij 'slimmere inzet van radiologie'.

Slimmer radiologie inzetten hebben wij aangepakt met de discipline Operations Management (OM): de analyse, het ontwerp, de planning en het beheersen van alle stappen die nodig zijn om radiologie aan te bieden. Hierin hebben wij ons gericht op het tactische planningsniveau, dat onder meer gaat over patiëntpaden, het toegangsbeleid en het bepalen van de planningsstrategie voor afspraken. Onze belangrijkste onderzoeksvraag is hoe we OMoplossingen kunnen vinden, implementeren en evalueren, zodat de operationele prestaties van radiologieprocessen in ziekenhuizen verbeteren, bezien vanuit een multi-stakeholder perspectief.

Wij hebben diverse methoden gebruikt om deze onderzoeksvraag te beantwoorden. Ten eerste hebben wij een literatuuronderzoek in de vorm van een 'systematic review' uitgevoerd. Ten tweede hebben wij verschillende casestudies uitgevoerd, bij de radiologie-modaliteiten die de grootste bottleneck vormen: de CT en de MRI. Daarnaast hebben wij onderzoek uitgevoerd naar de voorkeuren van patiënten, waaruit wij hun mening hebben gedestilleerd over wat zij verbeterd zouden willen zien. Dit gaf voor ons weer aanleiding tot een onderzoek met computersimulatie, waarin we hebben nagebootst wat de gevolgen zijn van de meest veelbelovende OM-oplossing: CT op inloop. Vervolgens hebben wij deze oplossing kunnen evalueren in een praktijksituatie in een ziekenhuis dat al enige jaren heeft gewerkt met CT op inloop.

Doordat wij een combinatie van methoden hebben toegepast, met computersimulatie en implementaties in de praktijk, zijn wij dichter in de buurt gekomen van 'evidence based', dan de meeste OM-onderzoeken. Bovendien hebben wij het succes van de verbeteringen bepaald met inbreng van zowel management, zorgprofessionals als patiënten. Wij hebben onze casestudies en patiëntpreferentie-onderzoeken uitgevoerd in twee Nederlandse ziekenhuizen: het AMC en Rijnstate.

Hoofdstuk 2 heeft als doel om beslissingsondersteunende modellen te vinden, die zijn gericht op het ontwerpen en het besturen van processen met patiëntenstromen. Hierin hebben wij de belangrijkste typen problemen geidentificeerd en onderzocht hoe bruikbaar de modellen zijn voor het nemen van beslissingen door het management. Dit deden wij door middel van een systematic review, vanuit drie databases met wetenschappelijke literatuur. Op basis van onze vooraf vastgestelde criteria selecteerden wij 68 artikelen, die wij verder hebben geanalyseerd. 31 daarvan beschreven simulatiemodellen, 10 beschrijvende modellen en 27 analytische modellen. De review liet zien dat beschrijvende modellen alleen worden gebruikt voor procesontwerpproblemen en dat analytische en computersimulatiemodellen voor alle typen problemen worden gebruikt. Slechts enkele modellen zijn gevalideerd in de praktijk en het lijkt erop dat de meeste modellen niet worden gebruikt voor hun eigenlijke doel: het management ondersteunen in beslissingen nemen. De vergelijkbaarheid van de relevante databases blijkt gering. Daarnaast bleken er onvoldoende passende 'sleutelwoorden' en 'MeSH-headings' te zijn zodat het systematisch doorzoeken van de databases binnen het brede veld van zorgmanagement relatief complex is. Onze bevindingen geven managers inzicht in de eigenschappen van verschillende typen beslissingsondersteunende modellen en in de soorten situaties waarin zij gebruikt worden. Ons literatuuronderzoek uit 2009 was het eerste dat systematisch verschillende soorten beslissingsondersteunende modellen in ziekenhuizen analyseert. Dit proefschrift bevat zowel dit onderzoek als een update die de periode 2009-2017 beslaat.

Hoofdstuk 3: CT-scans blijken een bottleneck in veel processen van patiëntenzorg. Een belangrijke oorzaak van relatief lage bezetting van deze capaciteit is de variabiliteit in de duur van het scanproces. Door deze variabiliteit te verminderen, zijn wij er in het AMC in geslaagd om tegelijkertijd de toegangstijd te verkorten van 21 naar 5 dagen en de bezettingsgraad te verhogen van $44 \%$ naar $51 \%$. Onze strategie is toepasbaar in elke ziekenhuisfaciliteit met een afspraaksysteem, waar de duur van het proces variabiliteit kent. Dit maakt 
het mogelijk om tegelijkertijd kosten te besparen en de service voor de patiënt te verhogen.

Hoofdstuk 4: Hoge toegangstijden voor MRI-faciliteiten hebben negatieve impact op de kwaliteit van zorg en het serviceniveau. Omdat de faciliteiten zowel schaars als duur zijn, is het beter bezetten van de capaciteit de meest economische manier om de toegangstijden te verlagen. In de praktijk blijkt dat afspraken van patiënten vaak niet efficiënt gepland worden. Daarmee lijkt het optimaliseren van de planningsstrategie de meest kansrijke manier om toegangstijden te verlagen. Het doel van deze studie was het reduceren van de MRI toegangstijden door de planningsstrategie te optimaliseren en deze nieuwe strategie te implementeren in de praktijk in het AMC. Wij hebben het planningsproces geanalyseerd om verbeterpotentieel te definiëren en het proces na te bootsen met computersimulatie. Met deze simulatie konden wij theoretisch experimenteren met diverse planningsstrategieën. Wij hebben de meest veelbelovende strategieën gedefinieerd en door het simulatiemodel gehaald. Er bleek dat het reduceren van het aantal bloktypes tot maximaal 93\% lagere toegangstijden kan leiden. Met de resultaten hiervan hebben wij de nieuwe planningsstrategie ontworpen en vervolgens geïmplementeerd. Wij hebben het minimaal aantal bloktypes ingevoerd, dat praktisch haalbaar bleek. Dit leidde tot werkelijke afname in toegangstijden van respectievelijk $36,22,28$, 9, en 9 naar $7,2,10,3$, en 1 kalenderdag(en), afhankelijk van de patiëntgroep. Onze studie heeft bewezen dat modelleren van het planningsproces kan bijdragen aan het optimaliseren van de planningsstrategie, dat kan leiden tot reductie van de toegangstijden voor radiologische faciliteiten zoals de MRI.

Hoofdstuk 5: Hoewel innovaties in het toegangsbeleid tot zorgfaciliteiten bedoeld zijn om de patiëntgerichtheid te verhogen, worden de voorkeuren van patiënten zelden onderzocht. Vrije inloop voor de CT-scan lijkt veelbelovend vanuit het perspectief van de patiënt, maar dit is nooit bij hen getoetst. Deze studie onderzoekt in welke mate CT op inloop aansluit bij de voorkeuren van patiënten. Wij hebben de methode 'Analytic Hierarchy Process' (AHP) toegepast op 106 patiënten die een CT-scan nodig hadden. Hierbij vroegen wij naar hun perspectief over de prestatie-indicatoren 'toegangstijd', 'wachttijd', 'one stop shopping' en 'keuzevrijheid'. We lieten patiënten prioriteren en verschillende combinaties van prestatieniveaus beoordelen. De patiënten prioriteerden de indicatoren met de relatieve waarden van respectievelijk
$0.224,0.188,0.432$ en 0.157 . Zes ontwerpen voor het toegangssysteem bleken acceptabel en relevant, waarvan de meest gewenste de inloopscenario's bleken. Hieruit concluderen wij dat voor de CT-scan vanuit patiëntperspectief inloop een beter toegangsbeleid is dan een afspraaksysteem. Tevens heeft deze studie laten zien dat AHP waardevol kan zijn om patiëntvoorkeuren voor toegang tot ziekenhuisfaciliteiten te onderzoeken.

Hoofdstuk 6: In ziekenhuizen blijkt het bij een inloopsysteem makkelijker te zijn om het aantal ziekenhuisbezoeken te beperken dan bij een afspraaksysteem. Helemaal bij radiologische faciliteiten kan een inloopsysteem flink bijdragen aan zowel de kwaliteit van zorg als het serviceniveau. Hoewel CTfaciliteiten vaak hoge toegangstijden hebben, wordt het inloopsysteem zelden gehanteerd. Het doel van deze studie was het verkennen hoe de introductie van een inloopsysteem de prestaties van de CT-modaliteit zou kunnen beïnvloeden. Hiertoe hebben wij een casestudie uitgevoerd in het AMC. Wij hebben een uitgebreide set van gegevens verzameld en geanalyseerd. Vervolgens hebben we prestatie-indicatoren gedefinieerd en gemeten. Wij hebben computersimulatie gebruikt om prospectief inloopinterventies te evalueren. Het model is gevalideerd en er is een gevoeligheidsanalyse op uitgevoerd. We hebben scenario's gedefinieerd en door het simulatiemodel gehaald. Bezoek op inloop is niet voor alle patiënten mogelijk, bijvoorbeeld omdat er soms professionals uit andere ziekenhuisafdelingen nodig zijn en dit ingepland moet worden. Daarom hebben wij een optimale balans gezocht tussen inloop en afspraken. Bij die betreffende inloopinterventie kan een groot aantal patiënten het aantal ziekenhuisbezoeken beperken en zelf kiezen wanneer zij gescand worden. Uit de simulatie bleek dat de gemiddelde toegangstijd dan vermindert van 3 dagen naar 1 dag en dat de gemiddelde wachttijd in de wachtkamer toeneemt van 12 naar 20 minuten voor de patiënten die gebruik maken van inloop. De gemiddelde uitloop aan het einde van de dag neemt bij inloop 15 minuten toe. Daarnaast bleek het bij inloop mogelijk om 10\% meer patiënten te scannen en werd ook bespaard op administratief werk, omdat er minder gepland hoefde te worden. Onze studie toont aan dat een inloopsysteem voor de CT-scan kan bijdragen aan zowel het serviceniveau als de efficiëntie. Een combinatie van inloop en afspraken biedt de beste oplossing. Wij lieten zien dat dit het aantal ziekenhuisbezoeken vermindert, toegangstijden wegneemt, je hiermee meer patiënten kan helpen, dit minder planningsinspanning kost en patiënten keuzevrijheid geeft in het moment dat zij willen komen. 
Hoofdstuk 7: Hoge toegangstijden voor de CT-scan worden gezien als een groot probleem in veel ziekenhuizen. Een inloopsysteem is een interventie die toegangstijden wegneemt, omdat patiënten dan direct binnen kunnen lopen zonder afspraak. Ziekenhuis Rijnstate implementeerde CT op inloop in 2010, wat ons gelegenheid gaf om de positieve en negatieve effecten ervan in de praktijk te bestuderen. Onze methoden waren interviews met medewerkers $(n=10)$, patiëntpreferentie-onderzoek $(n=535)$ en data-analyse uit het elektronisch patiëntendossier van 129.148 patiënten tussen oktober 2008 en maart 2017. Alle stakeholders gaven aan dat de introductie van het inloopsysteem een verbetering opleverde. De interviews resulteerden in de volgende prestatie-indicatoren: toegangstijd, wachttijd in de wachtkamer, one stop shop, keuzevrijheid, productiviteit en medewerkerstevredenheid. Uit het patiëntpreferentie-onderzoek bleek dat $79 \%$ van de patiënten een maximale wachttijd van 15-30 minuten accepteert. Op de vraag welke prestatie-indicator zij het belangrijkst vinden, antwoordden 134 patiënten one stop shop, boven toegangstijd, wachttijd en keuzevrijheid (die zaten tussen de 79 en 88 antwoorden). De data-analyse toonde een verdubbeling van de jaarlijkse productie over de gemeten periode, terwijl de capaciteit nauwelijks was toegenomen. Het percentage poliklinische patiënten dat 30 minuten of minder moest wachten verminderde van $85,2 \%$ in 2009 tot $59,5 \%$ in 2016 , maar het absolute aantal poliklinische patiënten met deze 'acceptabele' wachttijd nam toe van 5.146 naar 7.681. Uitloop aan het einde van de dag voor poliklinische patiënten is afgenomen door de jaren heen. CT op inloop scoort beter op de belangrijke prestatie-indicatoren dan een volledig afspraaksysteem. Dit komt doordat de toegangstijd afneemt, het one stop shop mogelijk maakt en meer tevredenheid geeft voor zowel patiënten, verwijzende specialisten als alle type medewerkers van de radiologie-afdeling. Bovendien wijzen alle resultaten erop dat de invoering van inloop de productiviteit kan verhogen.

Hoofdstuk 8 belicht achtereenvolgens de geleerde lessen over OM in ziekenhuizen en het inloopsysteem, onze conclusies, de relevantie van onze onderzoeken en onze aanbevelingen. Naast volume, variatie en zichtbaarheid, is met name variabiliteit een belangrijke factor bij het inzetten van OM in het ziekenhuis. Er komen diverse soorten variabiliteit voor, zoals in aankomstpatroon, in patiëntpaden, in de hoeveelheid capaciteit, in de duur van processen en in patiënttypes. Wanneer variabiliteit voorkomt zijn buffers - zoals extra capaciteit of tijd - nodig of ze ontstaan vanzelf. Maar te veel buffers is onwenselijk, omdat ze inefficiënt zijn of slechtere service betekenen. Daarom is het wenselijk om variabiliteit te verminderen, zodat de buffers minder aanwezig zullen zijn. De hoge mate van variabiliteit in ziekenhuisprocessen wordt deels veroorzaakt door de eigen complexiteit van deze processen, maar het deel variabiliteit dat door onszelf wordt veroorzaakt - 'kunstmatige variabiliteit' wordt erg onderschat. Vooral deze kunstmatige variabiliteit brengt kansen met zich mee voor procesverbeteringen. Onze belangrijkste OM-les voor ziekenhuismanagers is om handig om te gaan met variabiliteit. Dit betekent vaker en diepgaandere analyse van procesdata, beter voorspellen, proberen variabiliteit te verminderen (bijvoorbeeld door standaardisatie) en efficiënte inzet van flexibiliteit of buffers zodat je slim omgaat met de overgebleven variabiliteit.

Onze volgende les betreft de toepasbaarheid van OM in ziekenhuizen. Aangezien OM uit de industriële sector vandaan komt, loont het om de verschillen tussen ziekenhuizen en de industriële sector beter te doorgronden. Wij identificeerden als belangrijkste verschillen tussen deze sectoren die het gebruik van OM beïnvloeden: 1) zorgprocessen kennen meer variabiliteit, 2) in ziekenhuizen zijn klanten veel afhankelijker, 3) ziekenhuizen hebben te maken met meer stakeholders, 4) iemand die zorg ontvangt is meestal niet de directe betaler, 5) processen zijn in de zorg vaak lastiger te plannen (gezien de onvoorspelbaarheid), 6) ziekenhuizen hebben meer maatschappelijke verantwoordelijkheid, 7) de zorg kent meer afhankelijkheid van overheidsbeleid en 8) in de zorg zijn de begrippen kwaliteit en kosten moeilijker te definiëren. Naast deze verschillen in systeemeigenschappen, is de toepasbaarheid van OM ook afhankelijk van de manier waarop mensen binnen het betreffende systeem denken. Dit gegeven hebben wij aangeduid als de verschillen tussen de medische wereld en de OM-wereld. Uit onze beschouwing kwamen als belangrijkste verschillen tussen deze twee werelden naar voren: 1) onderzoeksmethodiek, 2) focus, 3) wijze van veranderen, 4) de bereidheid om risico's te nemen en 5) de leidende coalitie. Wanneer je de verschillen tussen deze twee werelden goed weet te doorgronden en in staat bent om ze dichter bij elkaar te brengen, kun je met $\mathrm{OM}$ in ziekenhuizen meer impact maken.

Uit onze onderzoeken leerden wij dat het succes van inloop of juist een afspraaksysteem afhankelijk is van de kenmerken van het systeem en de wijze waarop dit systeem wordt aangepast en bestuurd. Inloop levert meer op naarmate: 1) patiënten in een constantere stroom binnen komen, 2) deze instroom ook nog voorspelbaarder is, 3) er meer scans op een dag gedaan kunnen wor- 
den, 4) er meer verscheidenheid is in scantijden, 5) deze scantijden onvoorspelbaarder zijn, 6) de tijd voor nabewerkingen korter is, 7) de capaciteit flexibeler is, 8) patiënten minder precies op tijd komen, 9) patiënten minder specifieke voorbereiding nodig hebben en 10) patiënten zich minder ergeren aan wachttijd in de wachtkamer.

Onze belangrijkste boodschap is dat slimmere radiologieprocessen gewenst zijn en dat OM hier in belangrijke mate aan kan bijdragen. Disruptieve OM-veranderingen zoals een inloopsysteem zijn nauwelijks bestudeerd, maar blijken de prestaties van het systeem sterk te kunnen verbeteren. Om succesvol nieuwe OM-concepten voor de radiologie te ontwerpen en implementeren is het nodig om 1) je te richten op hoe om te gaan met variabiliteit, 2) zowel de OM-wereld als de medische wereld te doorgronden en 3 ) bereid en in staat te zijn om disruptieve veranderingen door te voeren. Wiskundig modelleren en computersimulatie zijn effectieve gereedschappen om prospectief maatregelen te analyseren, waarbij een vorm van bewijs voor succes wordt geleverd, wat helpt om de betrokkenen mee te krijgen.

\section{ABOUT THE AUTHOR}

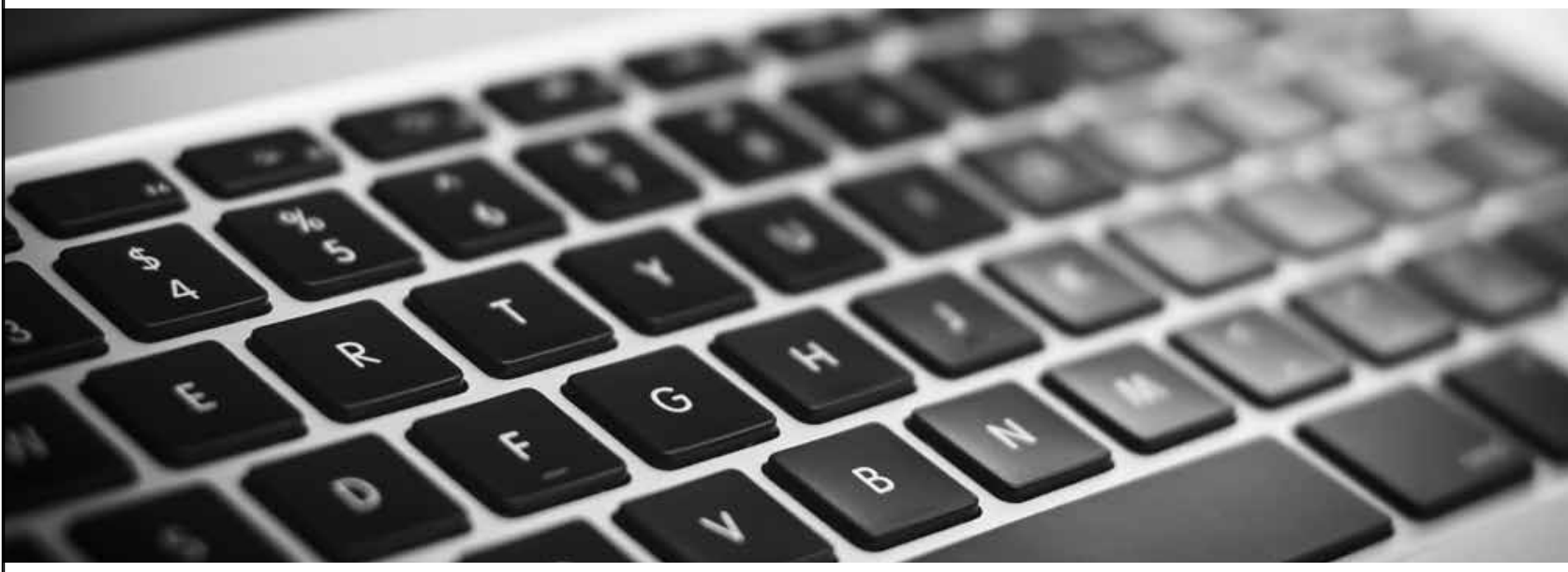




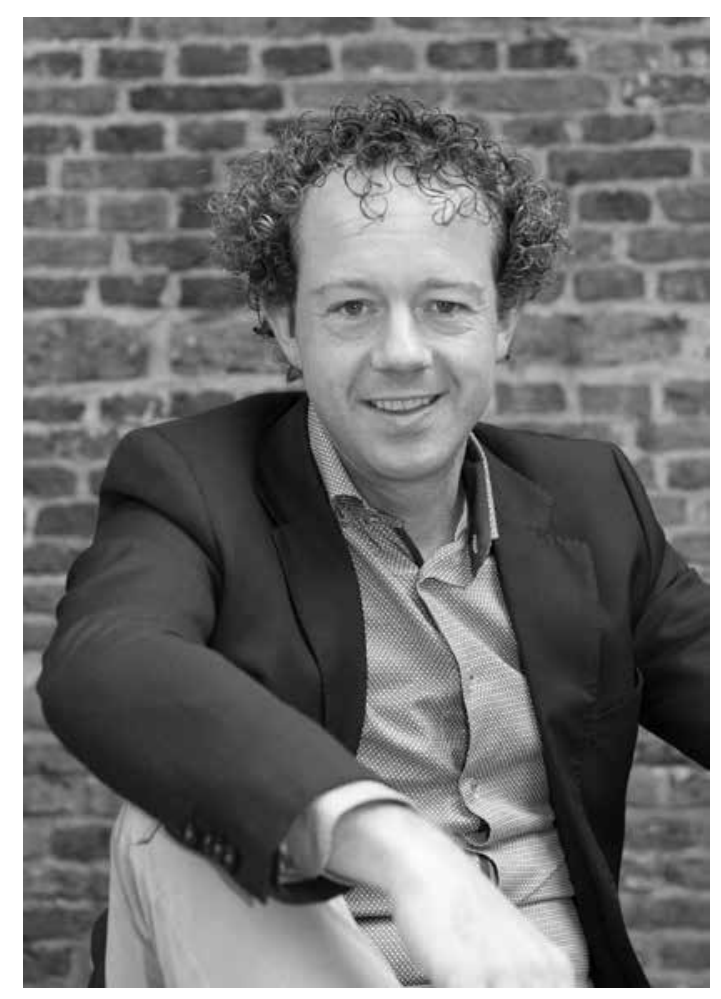

Jasper van Sambeek was born in Eindhoven, the Netherlands, on June 26, 1980. In 1998, he obtained his diploma for preparatory university education (in Dutch: VWO) at Augustinianum in Eindhoven, after which he started studying Industrial Engineering and Management at the University of Twente in Enschede. He specialized in Medicine and Management and graduated in 2005 after an internship in a hospital in Bandung, Indonesia and a graduation internship in Haga Hospital in The Hague. He started his career as a management consultant health care at Berenschot and began his Ph.D. research at the department of Quality and Process Innovation (in Dutch: Kwaliteit en Proces Innovatie; KPI) of the AMC. His Ph.D. program was a joint program between the KPI department and the department Industrial Engineering \& Business Information Systems at the University of Twente. For Berenschot Jasper managed many projects for health care organizations, such as hospitals, mental health care institutions, nursing homes, disabled care institutions and health care insurers. The consultancy concerned mostly Operations Management, business operations, financial operations and strategy

In 2011, Jasper was employed as a program leader for Sleutelnet and in 2012 he was appointed as the director. Sleutelnet is a strategic alliance of the health care organizations in the region South-Holland North. Is was founded by five health care providers to establish and manage data exchange between health professionals and scale up e-health in the region. Since 2011, the number of members of Sleutelnet increased to 28 institutions and over 1000 primary care practices, and the number of services increased from one to seven. In 2017, Jasper graduated for his MBA at the Erasmus School of Health Policy \& Management at the Erasmus University. He lives in Amsterdam with his wife Hanka and his daughters Roos (5) and Saar (4). Jaspers main drives are to innovate and improve the health care delivery chain and to have fun. 



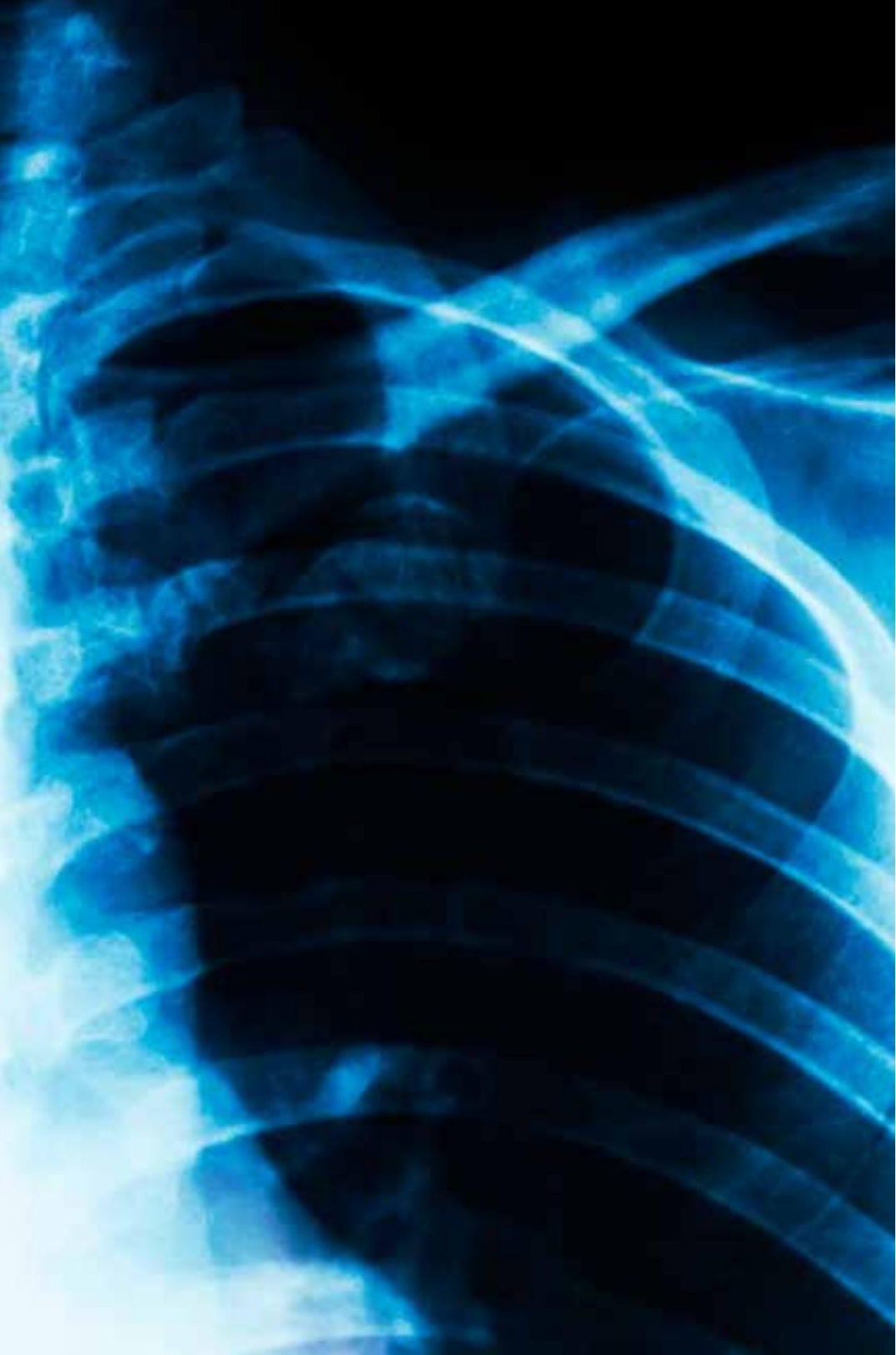

Patients who require imaging in hospitals often have to wait for weeks for their scan. The studies described in this dissertation focus on improving the imaging service levels, together with efficient deployment of resources. We accomplished this by applying Operations Management (OM) techniques and combining theory with implementations in practice. We determined the success of the improvements by involving both management, professionals, and patients. Herewith, we provide tools to optimize hospital processes. We found that there is need for smarter imaging processes and $\mathrm{OM}$ can greatly contribute to this. 


\section{STELLINGEN}

behorende bij het proefschrift van Jasper van Sambeek

Smarter Imaging Management - Operations Management for Radiology

1. Visualisatie van procesuitkomsten leidt tot begrip, begrip leidt tot commitment, commitment leidt tot implementatie.

2. Variabiliteit in processen wordt voornamelijk door ziekenhuizen zelf veroorzaakt.

3. Lange toegangstijden zijn onwenselijker dan lange wachttijden.

4. In de medische wereld bestaat er veel weerstand om rigoureus processen te veranderen.

5. OM is waardevol, OM-oplossingen bedenken voor een praktijksituatie is waardevoller, OM-oplossingen implementeren in de praktijk is het meest waardevol.

6. Eén van de belangrijkste succesfactoren voor 'smarter imaging management' is het dichter bij elkaar brengen van de medische wereld en de OM wereld.

7. Men gaat met $O M$ om alsof het een commodity is: als het werkt ziet niemand het en als het niet werkt klaagt iedereen.

8. In ziekenhuizen denkt men dat patiënten goede zorg willen, maar ze willen goede gezondheid.

9. Als er ergens knappe en mooie prestaties worden geleverd is het wel in ziekenhuizen. 